Portland State University

PDXScholar

1989

\title{
Factors Affecting persistence of Non-Traditional Students in a Non-Traditional Baccalaureate Degree Program
}

Dixie Lee Lund

Portland State University

Follow this and additional works at: https://pdxscholar.library.pdx.edu/open_access_etds Let us know how access to this document benefits you.

Recommended Citation

Lund, Dixie Lee, "Factors Affecting persistence of Non-Traditional Students in a Non-Traditional Baccalaureate Degree Program" (1989). Dissertations and Theses. Paper 1195.

https://doi.org/10.15760/etd.1194

This Dissertation is brought to you for free and open access. It has been accepted for inclusion in Dissertations and Theses by an authorized administrator of PDXScholar. Please contact us if we can make this document more accessible: pdxscholar@pdx.edu. 


\title{
FACTORS AFFECTING PERSISTENCE OF NON-TRADITIONAL STUDENTS IN A NON-TRADITIONAL BACCALAUREATE DEGREE PROGRAM
}

by

DIXIE LEE LUND

A dissertation submitted in partial fulfillment of the requirements for the degree of

\author{
DOCTOR OF EDUCATION \\ in \\ EDUCATIONAL LEADERSHIP
}

Portland State University

1989 


\section{TO THE OFFICE OF GRADUATE STUDIES;}

The members of the Committee approve the dissertation

of Dixle Lee Lund presented June 29, 1989.

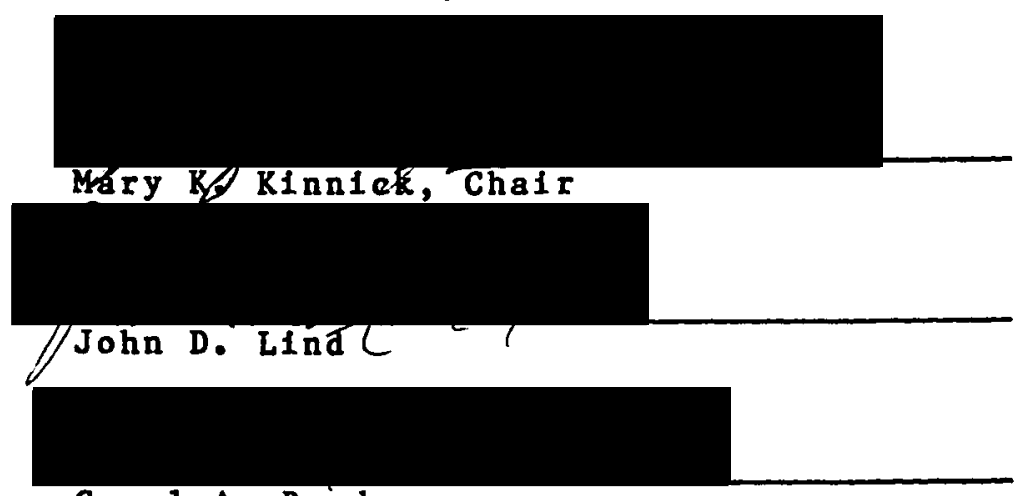

Carol A. Burden

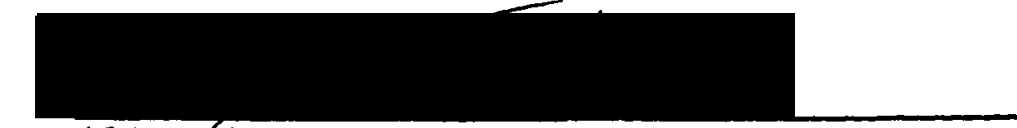

Alice/Jacobsan

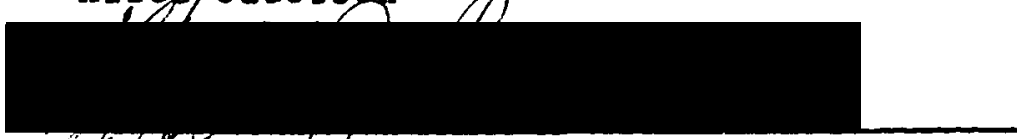

Mílqn J. Bénnett

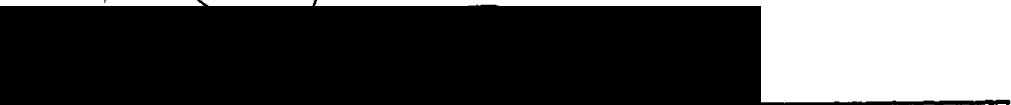

Jeps J. Robinson

APPROVED:

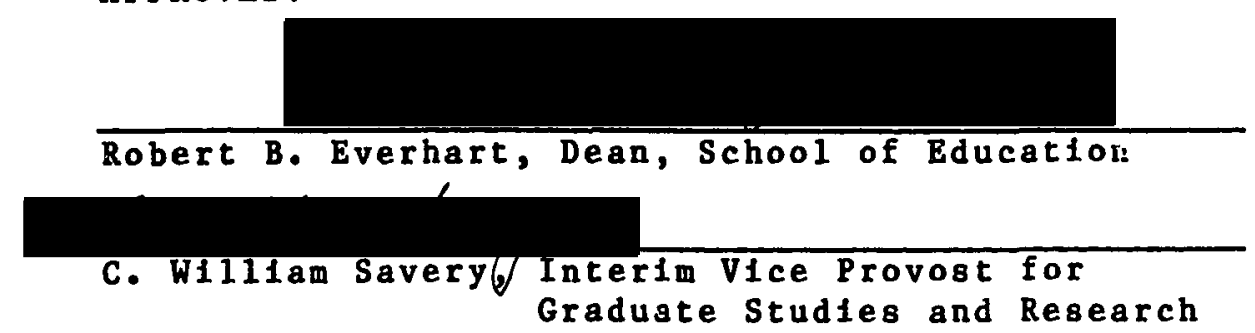




\section{ACKNOWLEDGMENTS}

This study is the result of contributions and support provided to me from a great number of people. I first of all wish to thank the 316 External Degree participants who took the time to answer the survey on which the findings and recommendations of this effort are based.

I also thank my employer, Eastern Oregon State College and many of my colleagues there, for having the vision which created the External Degree in response to the unmet educational needs of so many adult learners throughout oregon and beyond. Thanks especially to my supervisor, Dr. Lee Insko, and the entire staff of the Eastern Oregon state College Division of Continuing Education for their support of my own "continuing education" and especially of this project which required that they assume an additional workload during my absence.

I thank the members of my dissertation committee, Drs. Jack Lind, Carol Burden, Alice Jacobson, Milton Bennett all of Portland State University, and Dr. Jens Robinson of Eastern Oregon State College, and especially the Chair of the committee from Portland State, Dr. Mary Kinnick, for her steadfast support during my entire doctoral program. 
As the participants in this study demonstrated, one usually does not persist and succed in accomplishing a goal without the emotional support of those closest to us. Thank you, Ed, Amy, and Brian, for helping me, for putting up with my preoccupations and moodiness, and especially for believing in me and being my cheerleading section when I needed it most. 


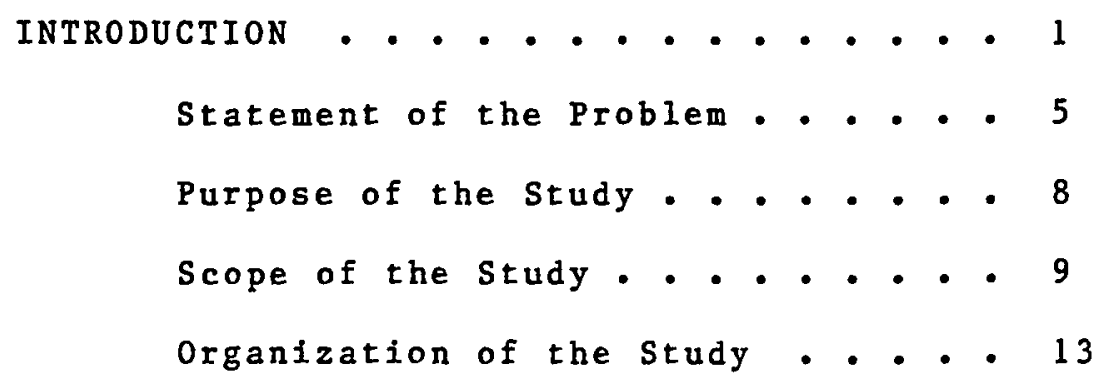


Data-Gathering Procedures

and Instruments ...... 101

Identification of Population

to Study....... 101

Distribution of Survey . . . 101

Receipt of Completed Surveys - 103

Instrument ......... 107

Statistical Methods Used

For Analysis......... 107

Nul1 Hypotheses . . . . . . 109

IV STUDY FINDINGS • . • . . . . . . . • 115

Representativeness of Respondents • 115

Comparison of Leavers

with Finishers....... 117

Comparison of Rural with

Urban Respondents . . . . 164

Comparison of Leavers/Finishers by

Gender \& Family Status . . . 167

Prediction of Leaving Using Stepwise

Multiple Regression . . . . 172

$\mathrm{V}$

CONCLUSIONS AND RECOMMENDATIONS • • • • 175

Summary • • • • • • • • • 175

Conclusions . . . . . . . . 183

Recommendations . . . . . . 187

SOURCES CONSULTED . . . . . . . . . . . . . . 198 APPENDICES

A SURVEY-RELAted Materials . . . . . . 209

B OFFICIAL STATISTICAL TABLES RELATED TO

SIGNIFICANTLY DIFFERENT COMPARISONS

$(P<.05)$ DESCRIBED IN CHAPTERS IV-V 228

C OFFICIAL STATISTICAL TABLES OF ALL NONSIGNIFICANTLY DIFFERENT COMPARISONS 285

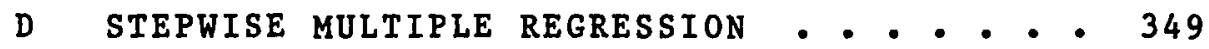




\section{LIST OF TABLES}

TABLE

PAGE

I

II

I I I

I.V

V

VI

VII

VIII

IX

$x$

$X I$
Summary Evaluation of Three Designs

for Studying Attrition .... . 24

Typology of Differential Character-

istics of Older and Younger

Undergraduate Students . . . . 42

Results of Survey Using Bean/

Metzner Variables . . . . . 117

Grade Level Upon Admission to

The External Degree . . . . 119

Barriers to Participating in the

External Degree Program . . . 121

Highest Degree Expected to Obtain . . 123

Do You Generally Complete Assignments

on Time? . . . . . . . . . 126

Do You Procrastinate with Doing

Your Work? . . . . . . . 126

Degree of Confidence with Study Skills 127

Degree of Confidence with Ability to

Cope with Stress........ 128

Degree of Confidence with Coping

with Academics........ 128 
XII

XII I

XIV

$\mathrm{XV}$

XVI

XVII

XVIII

$\mathrm{XIX}$

$\mathrm{XX}$

$\mathrm{XXI}$

$X X I I$

XXIII

XXIV
Able to Find Time to do Assignments? . 129

Degree of Confidence with

Reading Ability . . . . . 130

Degree of Confidence with

Verbal Expression . . . . . 130

Degree Requirements Made Clear

to You by Your Advisor? ....

Should La Grande Campus Meetings w/Your

Advisor be Required?......

Satisfaction with Quality of

Academic Advising Received...

132

Satisfaction with Quantity of

Academic Advising Received...

Frequency of Desired Courses

Being Offered . . . . . . .

Convenience of Time When Courses

Were Offered For You ......

Did you Focus in a Subject Area While

Pursuing Degree? . . . . . .

Did you Receive Credit Through

Portfolio Essays? ...... 137

Did you Receive Credit by

Correspondence Courses? ... .

Did you Take Weekend College in

Non-La Grande Sites? . . . . 
XXV

XXVI

XXVII

$X X V I I I$

XIX

$\mathrm{XXX}$

XXXI

XXXII

XXXI I I

$\mathrm{XXXIV}$

XXXV

XXXVI

XXXVII

XXXIX
Did you Take Weekend College Classes

in La Grande? • • • • . . . 138

Did you Receive Credit Through Transfer

Courses at other Institutions? 139

Hours Per Week Employed Outside

the Home... . . . . . . 141

Extent of Encouragement from

Spouse/Significant other . . . 142

Extent of Encouragement from Parents - 142

Extent of Encouragement from Children. 143

Extent of Encouragement from Friends • 143

Extent of Encouragement Erom Employer. 143

No. Children at Home While in

External Degree Program . . . 145

Awareness of Other External

Degree Programs . . . . . . 146

Did you Consider Transferring

to Another Institution? . . . 146

Reason Enrolled in External Degree • - 148

External Degree's Impact on

Knowing Myself . . . . . . . 149

XXXVII External Degree's Impact on

Using Interpersonal Skills . . 149

External Degree's Impact on Seeing

Alternate Points of View . . . 150 
XL

XLI

XLII

XLIII

$X L I V$

$X \amalg V$

XLVI

XLVII

XLVIII

XLIX

L

L I

L I I

LIII

LIV
Academic Expectations More Difficult

Than you Liked? . . . . . . 150

Should Standardized Testing be Required

in the Program? ........ 151

Instructor Feedback on Courses Timely? 151

Difficulty with Asking

Advisor for Help . . . . . 152

Difficulty with Asking

Instructors for Help. . . . 152

Did Rules/Procedures of Program

Inhibit Your Progress? . . . 153

Degree Required for Career

Continuation? . . . . . . . 153

Cut Back on Social Activities

with Friends? . . . . . . . 154

Cut Back on Alone Time with Spouse/

Significant other? . . . . 155

Cut Back on Housework/Home Maintenance? 155

Cut Back on Civic Responsibilities? • 156

Amount of Time Required for Program. . 156

Any Discussion with Non-EOSC

Personnel About Leaving? • • - 159

Quality of EOSC Education Received • 159

How High is the Quality of Eastern

Oregon State? .......... 160 
LV

LV I

LVII

LVIII

LIX

LX

LXI

LXII

LXIII

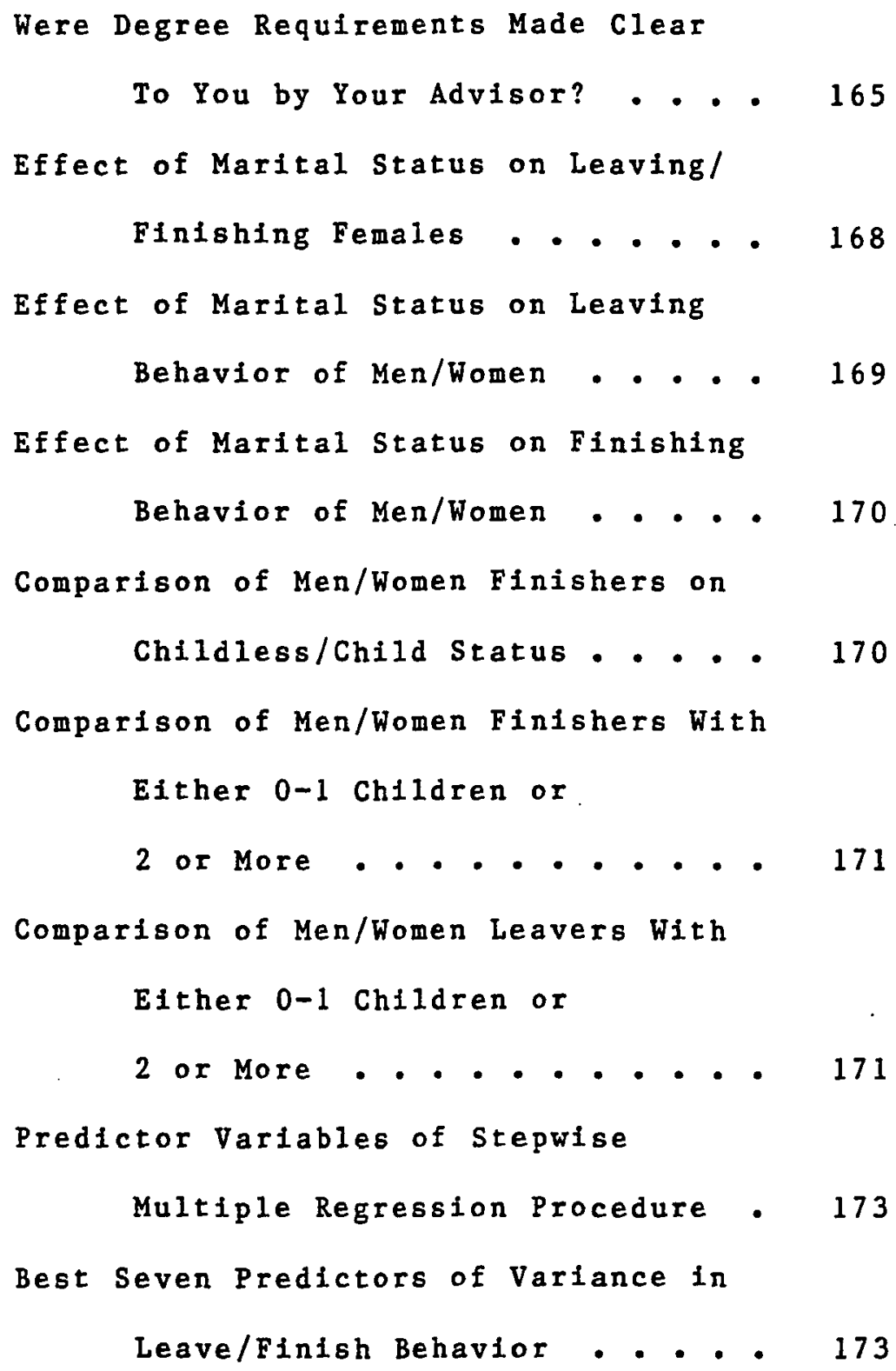




\section{LIST OF FIGURES}

FIGURE

PAGE

1. Geographic Distribution of 469

Study Subjects . . . . . . . 10

2. Geographic Distribution of 228 Leavers . . 11

3. Geographic Distribution of 241 Finishers - 12

4. Non-Traditional Student Attrition . . . 73

5. Geographic Distribution of

316 Respondents . . . . . . . 104

6. Geographic Distribution of 112

Responding Leavers . . . . . . 105

7. Geographic Distribution of 204

Responding Finishers........ 106 
AN ABSTRACT OF THE DISSERTATION OF Dixie lee Lund for the Doctor of Education in Educational Leadership presented June $29,1989$.

Title: Factors Affecting Persistence of Non-Traditional

Students in a Non-Traditional Baccalaureate

Degree Program

APPROVED BY THE MEMBERS OP THE DISSERTATION COMMITTEE:

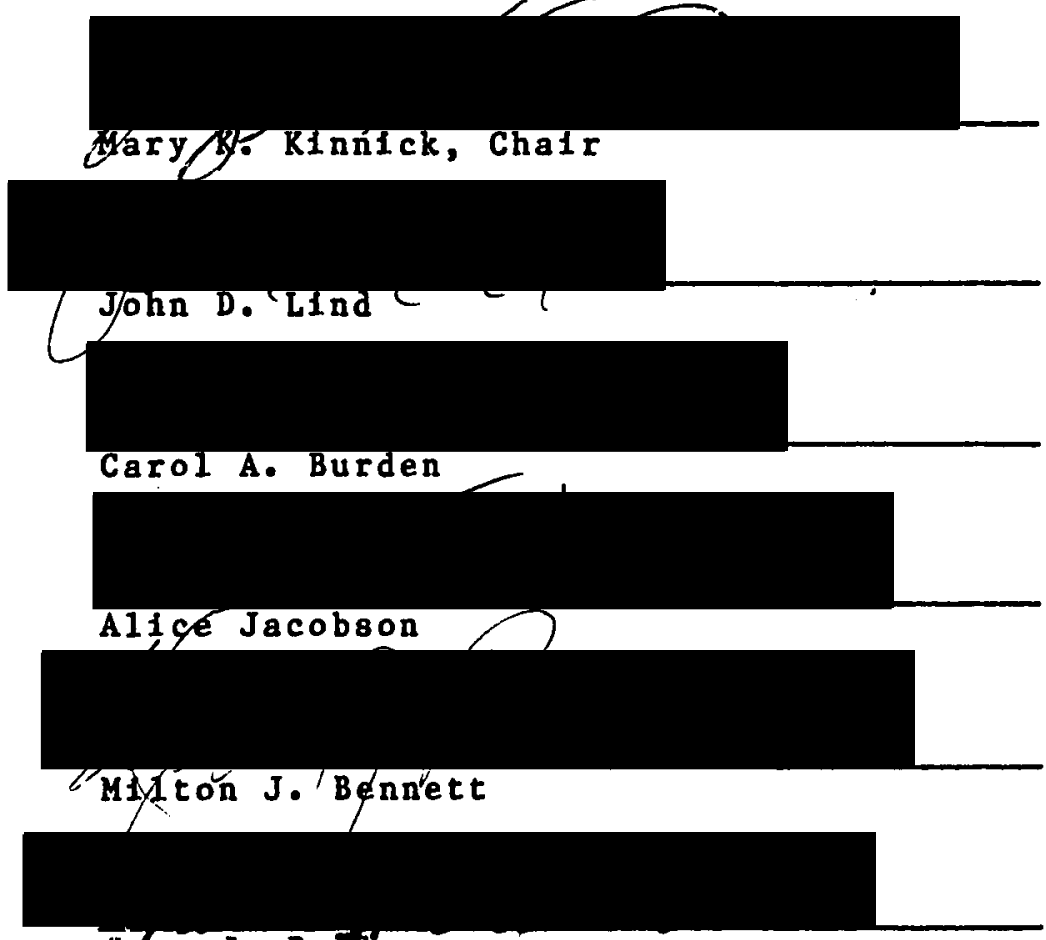

Jgns J. Rolinson

Limfed theoretical research exists regarding attri-

tion of nontraditional (older, part-time, commuter) students on American college and university campuses today. Thus, 
when colleges or universities seek to improve programs specifically designed for such students, there is no broad research base on which to rely. The present study sought to determine if there were differences, especially onas the institution could do something about, between non-traditional students who left such a program and those who completed it. A conceptual model of non-traditional student attrition, developed by adult educators/researchers, Drs. John Bean and Barbara Metzner, provided the theoretical base for the study. Data were obtained from 80 questions on a survey mailed to 469 leavers and finishers in the Eastern oregon State College External Degree Program. The questions represented four variable categories of the Bean/Metzner model: (1) background, (2) defining, (3) academic, and (4) environmental, and psychological (satisfaction) and academic outcomes. Of the 402 deliverable surveys, $82 \%$ were returned. from 112 leavers and 204 finishers.

Chi-square and t-tests of significance provided little differentiation between leavers and finishers on background and defining variables. For example, leavers and finishers were similar in age (most were 44-46 years); the majority were Caucasian, married, and had children; lived in oregon communities of less than 50,000 population within 60 miles of a post-secondary institution (not necessarily Eastern Oregon State College); had performed well (3.00-3.49 GPA) in 
high school; and were employed outside the home at least 30 hours a week.

Differences in the leavers and finishers' educational goals (a background variable) and the grade level at which they entered the Program (a defining variable) were statistically significant at $p<.05$. A significant number of leavers had either no degree aspirations or sought only an associate, rather than the baccalaureate provided by the External Degree Program. And, though a majority of leavers and finishers entered the Program as juniors, a significant number of leavers began as either freshmen or sophomores. Gender alone did not account for differences in attrition. However, female participants, whether leavers or finishers, had significantly fewer (if any) children than did either leaving or finishing male participants. And, married women. finished the Program significantly more often than did single women.

Numerous academic and environmental variables accounted for significant differences between leavers and finishers. For example, the majority of leavers left early; over half indicated they left "before they ever really got started." Conversely, most finishers indicated that by using several non-traditional credit options (especially assessment-of-prior-learning, correspondence, and weekend college), they were able to average at least 12 credits each term of their participation. Though most of the leavers and 
finishers participated in the Program's prior learning workshop, only a majority of finishers received credit for essays developed after workshop instruction.

The greatest barrier confronting leavers and finishers was lack of time. Finishers cited, however, more often than did leavers, a reduction in the amount of time they normally spent with spouses, friends, and in civic responsibilities while participating in the Program. Neither finances nor distance posed significant problems for leavers or finishers, whether rural or urban. Personal motivation, rather than career expectation, was the primary reason for participating in the Program for leavers and finishers. And, other than the emotionally supportive spouses of leavers and finishers, an encouraging environment of significant others (friends, employer, parents, children) was either absent or significantly less evident in the lives of the leavers than in the finishers.

Study findings indicated areas within the External Degree that were perceived andor interacted with differently by leavers than by finishers. There is, therefore, an opportunity for Eastern Oregon State College to intervene with changes that should improve the retention of the nontraditional students who participate. Recommendations included revising the assessment-of-prior-learning workshop and developing a peer mentoring system and a two-year degree Program. 


\section{CHAPTER I}

\section{INTRODUCTION}

More adults are attending American colleges and universities today than ever before. According to the Carnegie Council and the U.S. Department of Education (cited in Bean \& Metzner, 1985), this trend is expected to continue. Coupled with a decrease in the number of traditional-age college students (18-22 years), this nontraditional student population is composing an increasingly larger proportion of the undergraduate college student body. As Flaherty (1978) recognizes:

$$
\begin{aligned}
& \text { Faced with the prospect of steadily declining } \\
& \text { numbers of students in the } 18-22 \text { year-old age } \\
& \text { group, administrators of institutions of higher } \\
& \text { education recognized the necessity of finding a } \\
& \text { new source of students. Not only have adult } \\
& \text { part-time learners been encouraged to attend } \\
& \text { college classes, they have been actively } \\
& \text { recruited by admissions officers. (p. } 375 \text { ) } \\
& \text { of the } 12 \text { million college students enrolled today, }
\end{aligned}
$$
over half of the undergraduates are women, two of five are over 25 years old, and more than $40 \%$ attend college parttime (National Institute of Education, cited in Bean and Metzner, 1985).

What has caused this influx of adult students? The following summary, extracted from Bean and Metzner (1985, p. 486-487), may explain some of the causes. 
1. Institutional: The birth of the community college movement in the 1960 s drew many adult, part-time students not only to twoyear institutions, but also into the fouryear colleges and universities.

2. Curricular: Faced with dwinding numbers of traditional-age college students, institutions revamped their curricula and scheduling to recruit adult students and respond to their particular demands. The result? Even more adults entered the college environment in response to expanded course offerings and availability.

3. Political: The Allied victory in World War II and the resulting support for "democratic" institutions enhanced by former President Truman's 1947 report, Higher Education for American Democracy, popularized the college movement. Coupled with financial incentives from the federal government (the GI Bill, Basic Educational opportunity and Pell Grants, for example), and a U.S. sense of threatening competition from the Soviet Union's successful launch of Sputnik, the political atmosphere fostered a belief in the value of higher education.

4. Economic: A decrease in the number of bluecollar jobs and a corresponding increase in the number of higher-paying positions requiring specialized training have sent large numbers of non-traditional students to educational institutions for vocational purposes.

5. Social: The changing perception of women's roles into expanded job positions; the perception/reality of the need for a twoincome family; the decrease in the number of children that couples are choosing to have; and general sociological support for lifelong learning, have all had the effect of sending more adults into college and university settings.

Even though the number of adult students continues to rise, such a rise:

Has not been enough to counter the decline in the size of the high school graduates. In 1984, 
total enrollment in higher education shrank from a 1981 high of 12.37 million students to 12.2 million. It is predicted to further decline to an estimated low of 10.5 million in 1995 before Increasing again in the latter part of the decade. (Tinto, 1987, p. 2)

Declining enrollments and the prospects of a continued shrinkage of the pool of traditional-age potential college students have resulted in attention to two goals:

(1) retaining a higher percentage of students who enroll, and

(2) attracting a large number of older students. (Greer, 1980 , p. 1)

Retaining students through completion of the baccalaureate is a challenge for many colleges and universities. As Tinto (1987) notes, "more students leave their college or university prior to degree completion than stay" (p. 1). To illustrate the breadth of the attrition issue, he states:

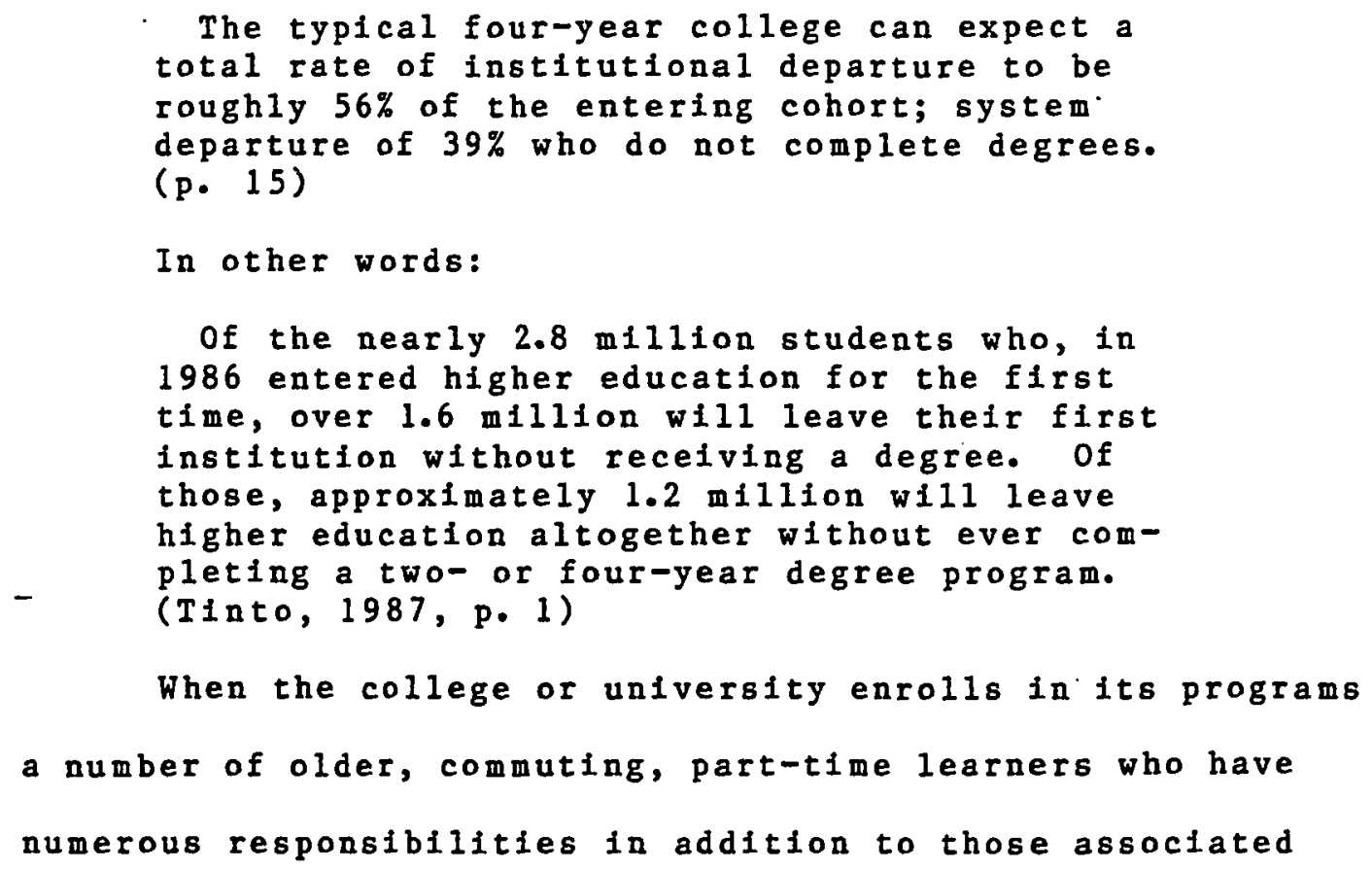

When the college or university enrolls in its programs a number of older, commuting, part-time learners who have numerous responsibilities in addition to those associated 
with being a student, the retention challenge increases. Nevertheless, a number of colleges and universities across the nation and throughout the world have established baccalaureate degree programs that provide access to and flexibility for adult learners (Moore, 1987).

As numerous comparative studies have pointed out (Astin, 1975; Fetters, 1977; and Tinto, 1988), nontraditional students show a higher rate of attrition from college than their traditional peers. "Part-time students," says Tinto (1987, p. 10), "are less likely than other students to complete degree programs." An even greater challenge may be added when the format of the college/ university degree program requires, by its non-traditional nature, (i.e., correspondence, weekend/evening classes), that students participate and progress on a relatively independent basis without the traditional support obtained from frequent, regular, face-to-face student-faculty and/or student-student interaction. But as Terenzini (1982) writes:

\footnotetext{
The issue before administrators is not really how to retain students but, rather, how to retain those who can meet the academic requirements, would like to continue, and would benefit from an education at the institution. What aspects of students' experiences over which the institution has some control tend to promote retention or attrition? (p. 55)
}

In light of research which finds that non-traditional students have higher attrition rates, college and university administrators must ask if the two goals of retaining a higher percentage of students who enroll and attracting a 
larger number of older students are compatible (Greer, 1980). Consequently, it is important for all institutions (and for the present study, especially for a small, public, rurally-isolated, four-year liberal arts college in Eastern oregon), to decide on the specific nature of their educational missions. For what purpose and by what means, for example, are students being admitted; their needs responded to; and their numbers retained within the institution? The findings from this study will shed light on one group of students that Eastern Oregon State College in La Grande, Oregon, serves--the non-traditional, geographically dispersed student body within. the External Degree Program.

\section{STATEMENT OF THE PROBLEM}

In his recent publication, Leaving College, Tinto (1987) warns educational administrators and researchers of attrition against "underestimating the tenacity of some individuals" (p. 23) when it comes to completing a college program. He emphasizes that "decisions to withdraw are more a function of what occurs after entry than of what precedes it" (p. 6). He concludes:

Educators should not unnecessarily limit the options individuals have in completing their degrees. If anything, these should be increased. ( $p .23$ )

Many options for completing a degree are found in the Eastern Oregon State College External Degree Program. Created in 1979, this Program leads to a baccalaureate in 
General Studies and provides access to and accommodation for the variety of schedules and interests of the adults who enter. Speaking of such a degree, Tinto (1987) writes:

General Studies degree programs are likely to attract students who place more value on the intrinsic rewards of college than on the extrinsic. Extrinsic seekers are more likely to transfer to other institutions. (p. 111)

With no La Grande campus residency requirement and numerous at-home or weekend-only course options, the External Degree Program has admitted over 1,000 adult learners in its 10-year history. Tinto (1987) reminds planners of nontraditional educational programs, however, that "intentions are linked to the likelihood of degree completion" (p. 40), and :

(Only) highly motivated and committed persons who commit themselves to the attainment of their goals within a specific instructional context are likely to complete their degrees within that school. (p. 110)

Accurate External Degree Program admissions records began in 1982. In a six-year recordkeeping history through Summer 1988, 241 students had graduated; other "persisters," numbering 500+, were still progressing toward the degree; and the remainder, 228 , had either temporarily or permanentiy dropped out.

The costs involved in interviewing, admitting, advising, and mentoring non-traditional students through the External Degree Program, only to result in an extremely long completion period or, even worse, a high dropout rate, are substantial. Since this program continues to be funded on a 
self-support basis (i.e., student tuition only), the mutual goal for participants and program administrators to achieve a cost-effective model, while increasing the completion rate of students, is of paramount importance.

Though high attrition rates are recognized in programs that attract non-traditional learners, the reasons why these students drop out of school are not well understood (Bean \& Metzner, 1985). Rather than clearly identifying variables that could predict attrition of non-traditional students, many studies have merely described the statistically different tabulations regarding attrition of residential vs. commuting students (Astin, Iffert, \& Newcombe, cited in Bean \& Metzner, 1985), younger vs. older students (Von der Embse \& Childs, 1979; Greer, 1980), and full-time vs, part-time learners (Lenning, as cited in Bean \& Metzner, 1985). Little information is available that discusses differences in persistence among non-traditional students themselves. Bean and Metzner credit the works of Spady (1970), Tinto (1975), and Pascarella (1980) with producing the most influential theoretical contributions to understanding the student attrition process. Their studies, however, rely heavily on the effect of traditional college socialization experiences to explain attrition. Since non-traditional students, say Bean and Metzner, already lack or are disinterested in such social integration into the institution, a different theory explaining their attrition pattern must be used in order to link the variables studied. 
Thus, the problem which prompted this study was twofold:

1. The high cost, in time and dollars, for both participants and Program administrators associated with a correspondingly high incompletion rate in the Eastern Oregon State College External Degree Program.

2. The lack of any extensive research base regarding non-traditional student attrition that External Degree Program administrators could draw upon when implementing changes designed to improve retention.

PURPOSE OF THE STUDY

Approval was recently given to Eastern Oregon State College to go statewide with its External Degree Program via consortial arrangements with community colleges and other four-year colleges and universities in oregon. Prior to developing more consortia, however, the college needed to identify and remedy, where possible, those parts of the screening process and degree-delivery system that were weak. In uncovering a profile of External Degree students who finished the program by obtaining their baccalaureate and comparing this profile with those who did not, this study provided information that could significantly improve the educational practices already in place. Appropriate modifications in the program should result, therefore, in a higher completion rate for students who are admitted and a more cost-effective model for serving non-traditional learners. 
The purpose of this study, then, was to determine

if there were themes around which finishers gravitated. In other words, "Who was 'making it' and how?" Specifically, the following questions, adopted from Bean and Metzner's (1985) Conceptual Model of Non-Traditional Student Attrition, provided the theoretical framework for studying the differences between the finishers and the leavers:

1. Were there significant differences in baskground and other defining variables between the two groups of students?

2. Were there significant differences in academic variables between the two groups of students?

3. Were there significant differences in environmental variables between the two groups of students?

SCOPE OF THE STUDY

of the $1000+$ students admitted to the External Degree Program between 1982 and Spring 1988, three groups were identified: (1) finishers, (2) leavers, and (3) actives. Two of these groups, the finishers, numbering 241 , and the leavers, numbering 228 , constituted the 469 subjects targeted for this study. A geographic breakdown of these students follows on the next three pages. 


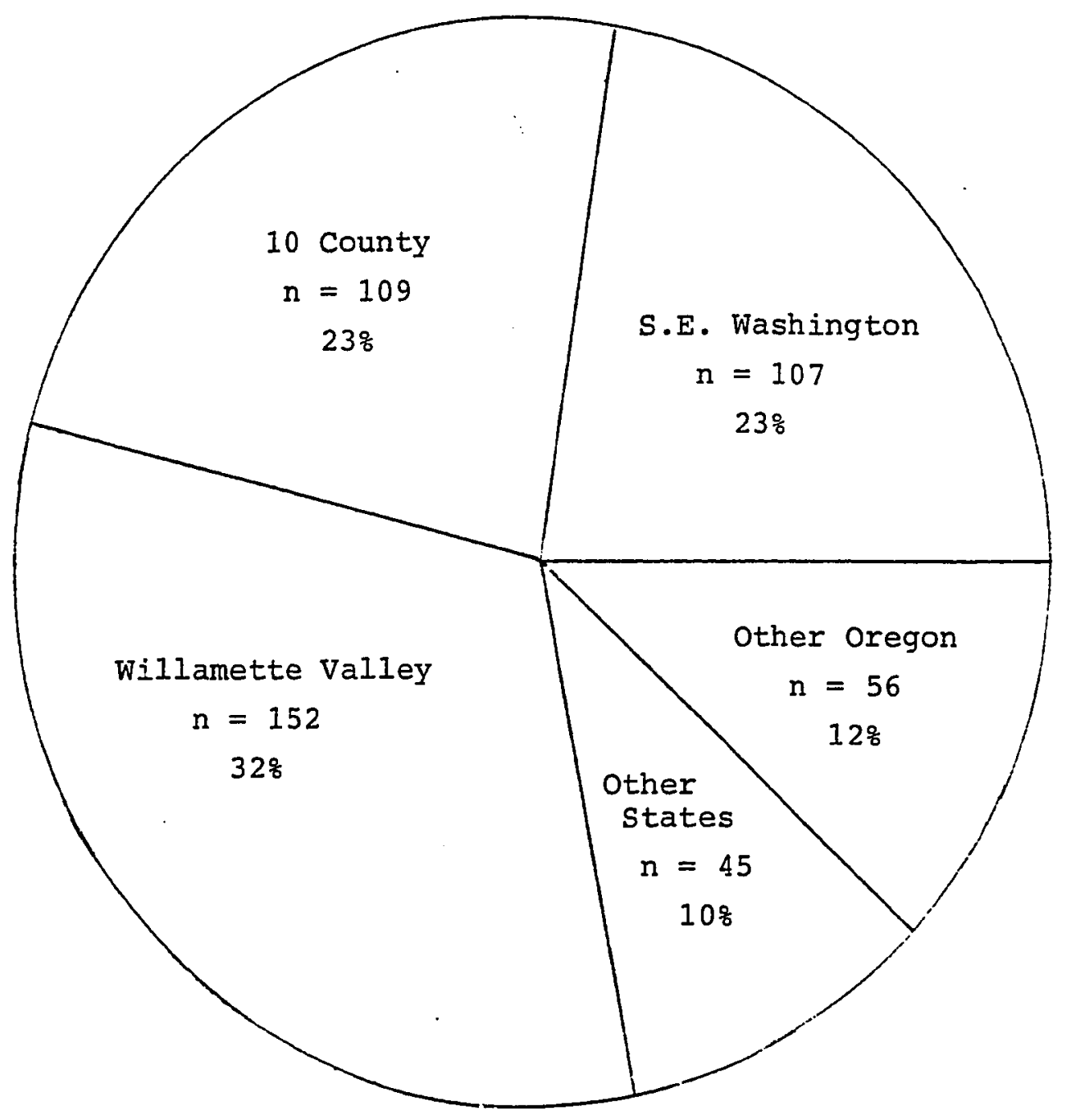

Figure 1. Geographic Distribution of 469 study Subjects

Definition of Categories

10 County: Eastern $40 \%$ of Oregon, including Baker, Gilliam, Grant, Harmey, Malheur, Morrow, Umatilla, Union, Wallowa, and Wheeler counties. Designated by Oregon Iegislature as "EOSC Service Region"

S.E. Washington: Close geographic proximity to La Grande, Oregon, including Tri-Cities area (Kennewick/Pasco/Kichland), Prosser and Walla-Walla, Washington

Willamette Valley: Western Oregon/Southwestern Washington "corridor," including area bordered on south by Eugene, Oregon, and on north by Vancouver, Washington

Other Oregon: other Oregon points not included in above categories Other States: other points not included in above categories 


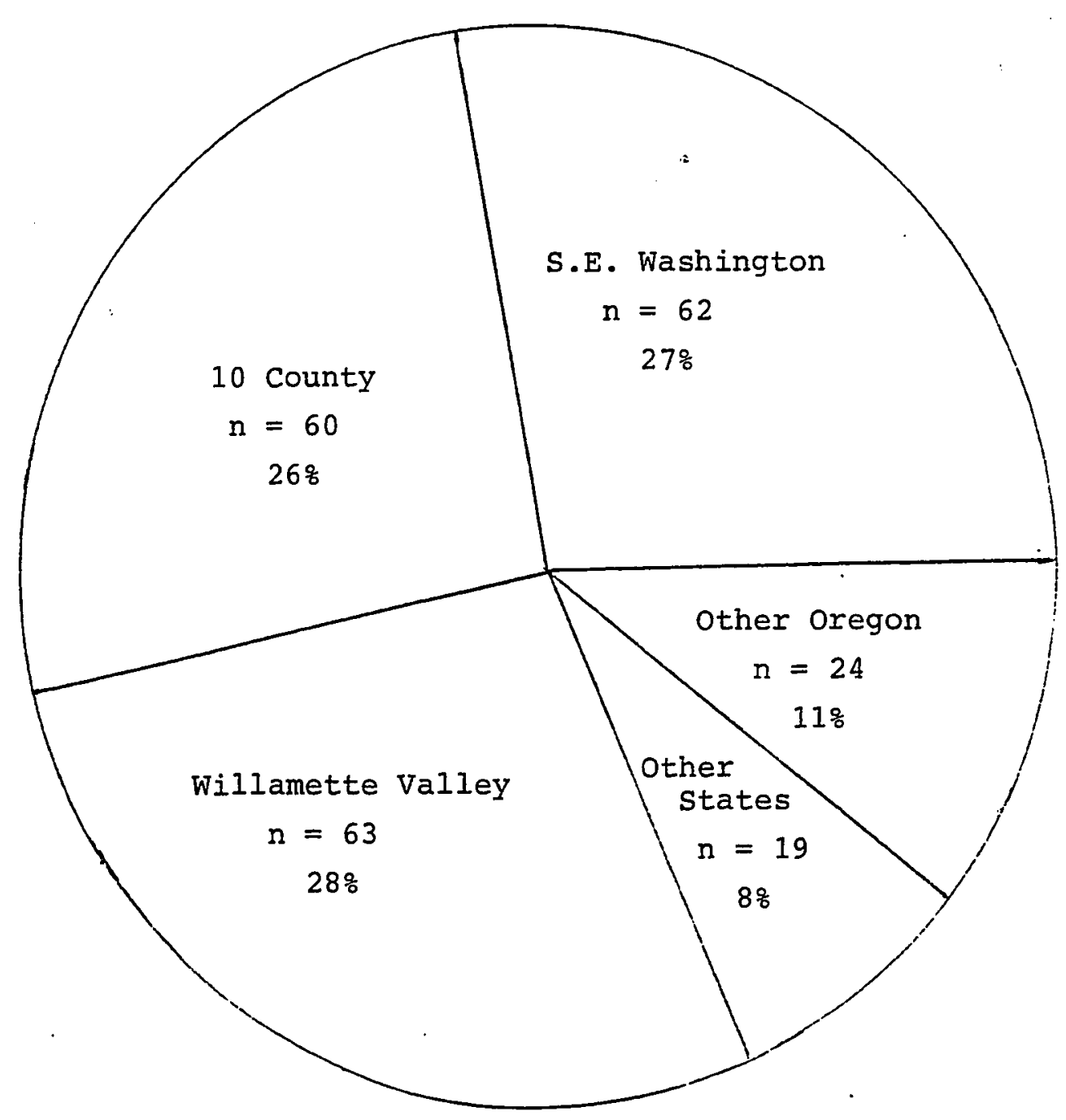

Figure 2. Geographic Distribution of 228 Leavers

\section{Definition of Categories}

10 County: $\quad$ Eastern $40 \%$ of Oregon, including Baker, Gilliam, Grant, Harney, Malheur, Morrow, Umatilla, Union, Wallowa, and Wheeler counties. Designated by Oregon Iegislature as "EOSC Service Region"

S.E. Washington: Close geographic proximity to Ia Grande, Oregon, including Tri-Cities area (Kennewick/Pasco/Richland), Prosser and Walla-Walla, Washington

Willamette Valley: Western Oregon/Southwestern Washington "comidor," including area bordered on south by Eugene, Oregon, and on north by Vancouver, Washington

Other Oregon: Other Oregon points not included in above categories Other States: Other points not included in above categories 


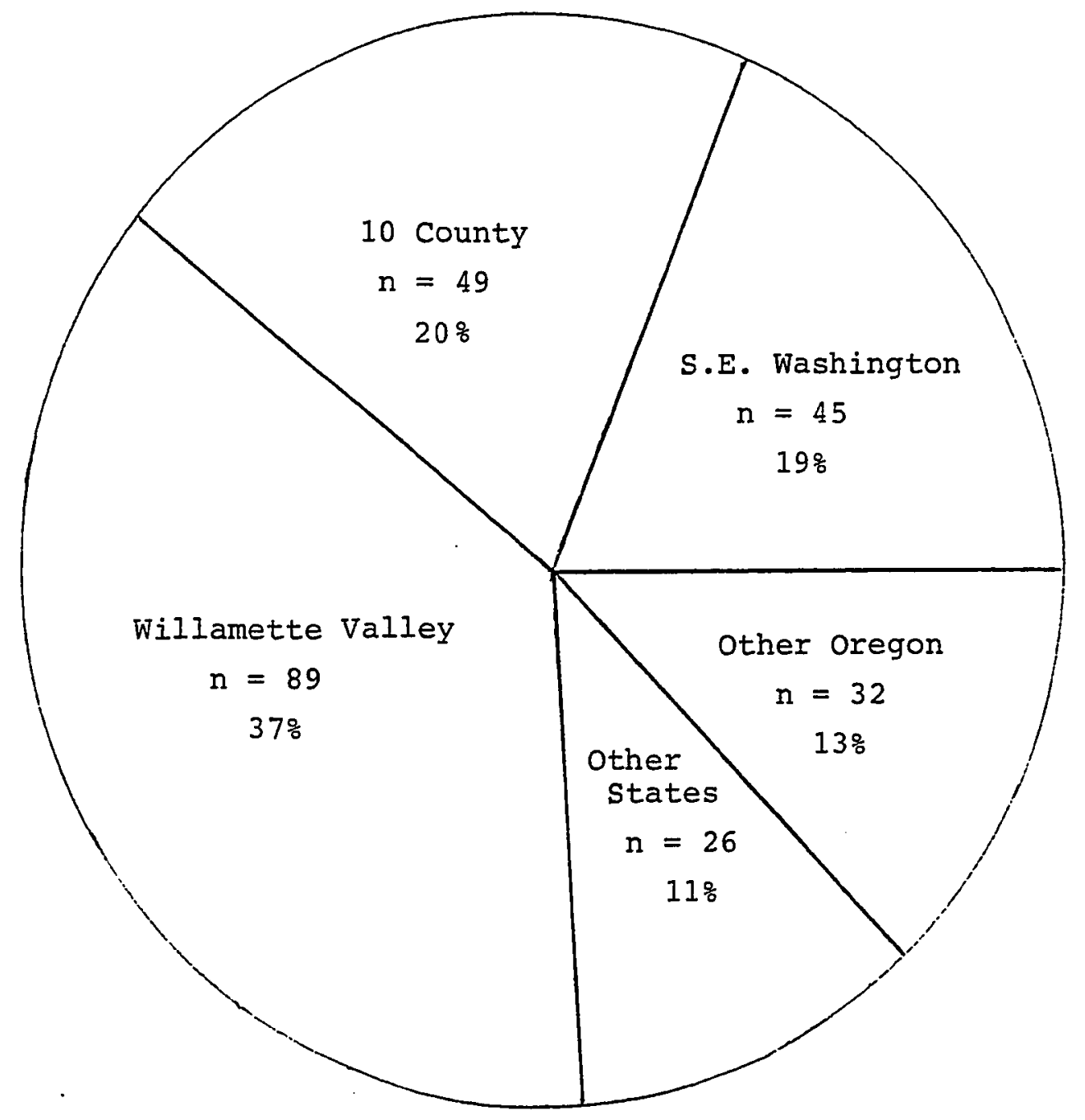

Figure 3. Geographic Distribution of 241 Finishers

Definition of Categories

10 County: $\quad$ Eastern $40 \%$ of Oregon, including Baker, Gilliam, Grant, Harney, Malheur, Morrow, Umatilla, Union, Wallowa, and Wheeler counties. Designated by Oregon Legislature as "EOSC Service Region"

S.E. Washington: Close geographic proximity to La Grande, Oregon, including Tri-Cities area (Kennewick/Pasco/Richland), Prosser and Walla-Walla, Washington

Willamette Valley: Western Oregon/Southwestern Washington "corridor," including area bordered on south by Eugene, Oregon, and on north by Vancouver, Washington

Other Oregon: Other Oregon points not included in above categories Other States: Other points not included in above categories 
ORGANIZATION OF THE STUDY

The present study is organized into five chapters:

CHAPTER I, the introduction, describes the (1) statement of the problem; (2) the purpose of the study; and (3) the scope of the study; and (4) the organization of the study.

CHAPTER II reviews the related literature and is divided into five components: (1) attrition studies: theory, design, and applications; (2) the adult as learner;

(3) telecommunications delivery of distance education;

(4) differences between rural and urban adult learners; and (5) adult development.

CHAPTER III, methods and procedures, (1) summarizes the study; (2) explains the design; (3) identifies the limitations; (4) operationalizes the variables; and (5) describes the methods/procedures used to gather and analyze the data.

CHAPTER IV reports the study findings and provides simplified tables showing statistically significant differences at $p<05$. (Official tables for the significanty different comparisons are found in Appendix B; tables for comparisons which resulted in no significant differences are found in Appendix C.)

CHAPTER $V$ discusses and summarizes the findings and provides recommendations. 
CHAPTER II

REVIEW OF THE LITERATURE

The literature reviewed for the present study is divided into four sections:

1. Attrition Studies: Theory, Design, Applications

2. The Adult as Learner

3. Differences between Rural and Urban Adult Learners

4. Adult Development

Each area was researched because of its contribution to the design, findings, and analysis of the present study. For example, the literature on attrition studies helped to determine which existing theories about retention already addressed the environment in which the External Degree student functioned. Specifically, the External Degree students are, for the most part, older ( $>24$ years), part-time (take <12 credits per quarter), commuters (reside off campus and/or in communities beyond La Grande). The attrition literature about traditional students was compared with the minimal amount that existed about non-traditional students in order to select the most appropriate variables to study. Part two of the Iiterature review, The Adult as Learner, was conducted in order to grasp a broader understanding of differences in learning behavior between non-traditional students and their traditional counterparts. 
This reading helped to formulate the definition of subjects in the present study as non-traditional, or:

\footnotetext{
...older than 24 , or does not live in a

campus residence (e.g., is a commuter), or is a part-time student, or some combination of these three factors; is not greatly influenced by the social environment of the institution; and is chiefly concerned with the institution's academic offerings especially courses, certification, and degrees. (Bean and Metzner, 1985, p. 489 )
}

Part three, Differences between Rural and Urban Adult Learners, was included because students in the External Degree Program come from both environments. Much of the literature about rural adult learners describes more, or at least different, barriers they perceive to continuing their educations than do their urban counterparts (McCannon, 1977 \& 1985). Because program options in the External Degree attempt to overcome such barriers, this review contributed to the inclusion of variables in the study that might otherwise not have been present. For example, subjects were asked about the type of barriers they experienced to participating in the External Degree Program, and their responses were analyzed along a geographic dimension of rural to urban. More importantly, however, this part of the literature review renewed this author's commitment to Improve the educational outreach efforts to the rural residents of Eastern Oregon that Eastern Oregon State College is legislatively mandated to serve.

Finally, part four of the literature review, Adult Development, helped provide a framework into which the 
subjects' narrative comments could fit. For example, that stage in life popularly referred to as the midife crisis occurs at about 42-45 years. As many External Degree students were also in this age range, the literature review helped to extract from their narrative comments the main issues the respondents struggled with while participating in the External Degree.

ATTRITION STUDIES: THEORY, DESIGN, APPLICATIONS

Theory

According to Bean (1982), theories are important to educational research about student attrition because they do two things:

1. They explain why dropout occurs.

2. They identify which students are most likely to drop out. (p. 17)

The theory guides the research and identifies which variables to use or not to use. Then, working from a theory, a model is created which hypothesizes the relationship between a set of variables in an attempt to explain or account for some phenomenon.

Atheoretical models are strictly descriptive and do not attempt to match theory to the study and/or to link together the reasons behind an association of variables (Bean, 1982, p. 17). Models based on a student's background characteristics (age, residency, high school performance, gender, ethnicity, educational goals, and family educational 
levels) are, says Bean (1982, p. 17), "still just descriptive and focus on strategies for admission, not on strategies for retention." And, according to Bean, the person-role fit models, again basically descriptive, are highly complex and involve profiling either before or upon college admission and again later in the students' programs. Types of attrition models which are based on theory are the longitudinal ones of Spady (1970), Tinto (1975), Pascarella (1980), and Bean (1982). Because the theoretical model underlying the present study borrows much from these wellestablished theories, a brief review of the literature related to them is included here.

Spady's (1970) sociological model of the dropout process was based on Durkheim's (1951) theory of suicide. Spady viewed the college/university setting as both academic and social. In this environment, the presence/absence of integration through interactions the student has with faculty, friends, or rules and regulations contributed to the student's decision to remain in school (the society) rather than to drop out (as the suicide victim did). Shared group values, grade performance, normative congruence, and friendship support were all expected to lead to increased social integration. Positive social integration led to increased student satisfaction, which led to increased institutional commitment and, thus, a decrease in the likelihood of dropping out. Spady's model cited several important factors related to the dropout process--family 
background, academic potential, ability, and socio-economic status. Most important in this model, however, was the effect of interaction between the student and the academic and social system on the student's persist or dropout decision. To the extent that the rewards available with either (the academic or social) system appeared insufficient, however, the student may have decided to withdraw (spady, 1970, p. 77).

Tinto (1975), also relying on Durkheim's theory of suicide, expanded on Spady's model. According to Bean (1982), Tinto emphasizes the interaction of background characteristics on goal and institutional commitment. "Goal commitment," says Tinto, "Is the level of expectation and the intensity with which the expectation is held" (p. 93). He further states:

\footnotetext{
An individual's educational goal commitment is an important input variable in the model of dropout because it helps specify the psychological orientations the individual brings with him into the college setting--orientations that are important predictors of the manner in which individuals interact in the college environment. ( $p .93$ )
}

Institutional commitment, on the other hand, refers to the extent with which an individual is committed to remaining at one Institution until graduation. Working in a circular fashion, Tinto saw goal commitment leading to higher grade performance and intellectual development, which, ultimately, led to academic integration and, thus, a decrease in the likelihood of dropping out. Such academic 
integration would, in turn, restart the circle, by further enhancing the goal commitment. Institutional commitment, on the other hand, created interactions with others (faculty and peers) which led to social integration, and, thus, a decrease in the likelihood of dropping out. Likewise, the circle is rekindled as such social integration contributes to institutional commitment.

$$
\text { Tinto's later research ( } 1982 a \text { for example) continued }
$$
to emphasize the effect that commitment, or lack thereof, had on dropout decisions: "Dropping out may be more a result of not caring than it is of not being able to meet the demands of college work" (p. 6). Tinto also further reinforced Spady's emphasis on social integration, stating:

Evidence abounds that social skills are equally important to persistence in college. These skilis enable the person to locate, interact with, and use the resources for attainment. (1982a, p. 6)

This emphasis on social integration and interaction as a means of increasing persistence in the academic environment is again mentioned in Tinto (1982b):

Evidence continues to mount that students' decisions to withdraw are significantly affected by the degree of their intellectual and social integration into the life of the institution. (p. 697)

Tinto's recent literature (1987) more thoroughly incorporates the time dimension in researching student attrition. In this respect, Tinto expands on both Spady's and his own earlier research by describing the: 


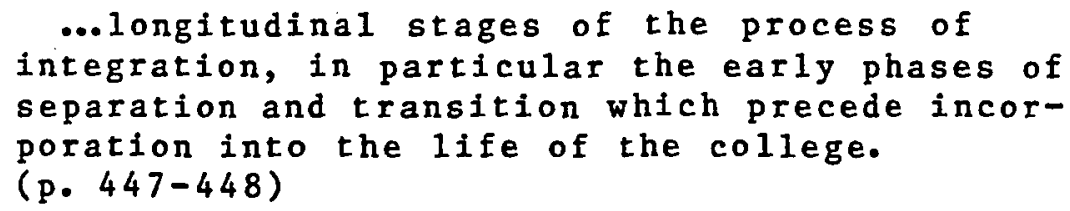

His expanded model includes the need for "all individuals, regardless of institution, to make some form of intellectual transition to the academic demands of college Iife" (p. 449). To assist with this transition, Tinto encourages the inclusion of orientation programs geared to the needs of adult learners who are entering college for the first time or returning after a lengthy absence (p. 449-452). The importance of informal contact between students and faculty in promoting persistence in higher education is the theme of Pascarella's (1980) conceptual model. Such student-faculty contact impacts both the academic and social integration process. As seen by Pascarella, this contact promotes intellectual and interpersonal self-concept, resulting in, among other things, persistence in college. As a student's background characteristics interact with institutional factors in Pascarella's model (i.e., institutional size or faculty culture), opportunities for informal contact with faculty are elther increased or extinguished. Such student-faculty contact, and other college experiences with peers both inside and outside the classroom, impact the student's academic and social outcomes (GPA, satisfaction, self-concept), and from there, withdrawal/persist decisions are made. 
Bean's (1980) review of the Spady, Tinto, and Pascarella models cites three characteristics they all have in common:

1. They describe attrition as a longitudinal process.

2. They all rely on Durkheim and have a theoretical base in the social and academic integration of students.

3. They are all very complex in order to enhance accuracy and promote generalizability.

In addition, says Bean (1980), they require an answer to two critical attrition questions:

1. Which is more important in dropout decisions?

a. entry-level characteristics

b. institutional characteristics

2. Which is more important for the institution to promote?

a. academic factors

b. social factors

Bean indicates that the answer to the first question sets up a choice of two directions: (1) Do institutions recruit more of those more likely to persist, or (2) Do institutions spend more on programs that respond to factors that keep people in school?

The answer to the second question, says Bean, w111 determine where institutional resources should be allocated. Bean's (1982) earlier model of student retention was developed from his study of an industrial model by Price and Mueller. Although incorporating much of the Spady and Tinto 
models and recognizing the importance of both academic and social integration, he further identified with and included the impact of "environmental press"--for example, finances, family, and other non-student responsibilities (Murray, c1ted In Bean \& Metzner, 1985, p. 489). Such external forces can significantly impact a student's withdrawal decision. In Bean's model, another variable, "intent to leave," which was based on the work of Fishbein and Ajzen (1975), is Inserted Immediately prior to when the continue/withdraw decision is made (p. 25). Bean also included Bentler and Speckart's (1979) theme of the influence of past behavior on current decisions.

Bean's (1982) earlier conceptual model was, like Spady's and Tinto's, longitudinal, complex, and drew on social and academic integration of students as influencing declsions to withdraw. The model had four classes of variables: (1) background; (2) organizational; (3) environmental; and (4) attitudinal outcomes. All four variables affected a student's intent to leave, "the immediate precursor to dropping out" (Bean, 1982, p. 25).

The current model of non-traditional student attrition (Bean and Metzner, 1985) and the one being used for this study, reflects the direct effect on attrition of the significantly different environment of the non-traditional student, defined as older, part-time, and/or commuter. 


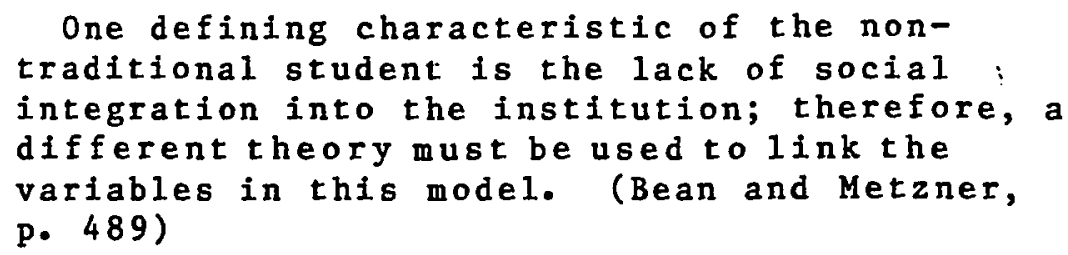

This model thus includes the influence of the nontraditional student's external environment. Likewise, social integration variables are eliminated from the current model because Bean and Metzner's 1985 review of the literature comparing non-traditional with traditional students:

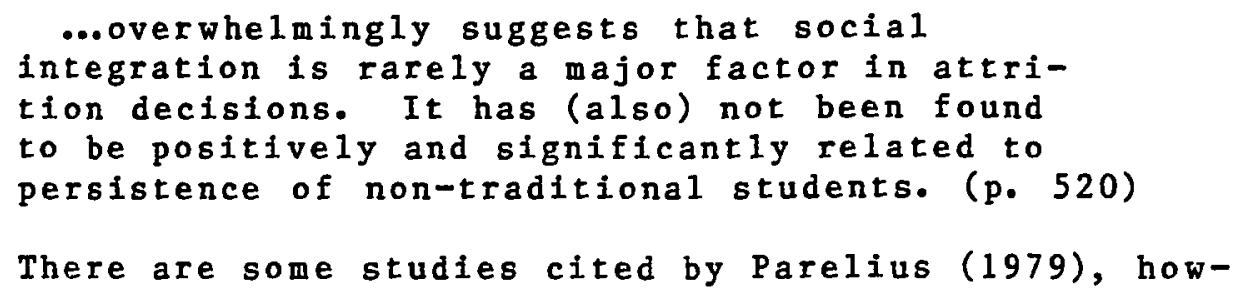


Des1gn

Terenzini (1982) provides a summary of the various research designs avaliable to the educational researcher studying the student attrition problem. The autopsydesign, occurs when information is collected from dropouts, usually after the fact and usually with a survey, to see why they withdrew. In cross-sectional designs, information is collected from currently enrolled students and, at a later time, compared for those who have dropped and those who remain. The longitudinal design collects the same informationat two or more pointsintime from the samegroup of students and then, as the group distributes itself over time into persisters or dropouts, the collected data is analyzed. Following is a summary of the three designs he discusses:

TABLE I

SUMMARY EVALUATION OF THREE DESIGNS FOR STUDYING ATTRITION

\begin{tabular}{|c|c|c|c|}
\hline Covidnation & Amerag sondise & $\begin{array}{l}\text { Coussistionel } \\
\text { Suntios }\end{array}$ & $\begin{array}{l}\text { Lonpundied } \\
\text { Sinfors }\end{array}$ \\
\hline \multicolumn{4}{|l|}{ Renerenth Conviderations } \\
\hline 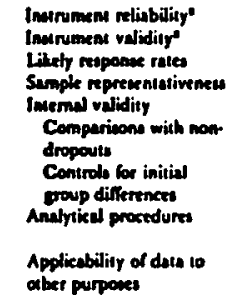 & 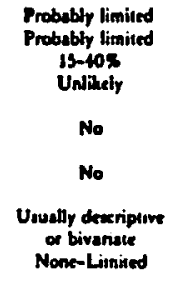 & 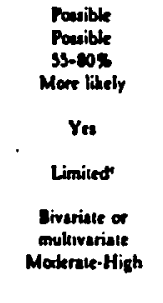 & 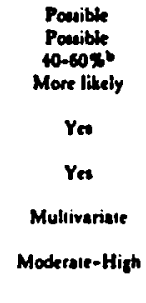 \\
\hline \multicolumn{4}{|l|}{ Thangine considerations } \\
\hline 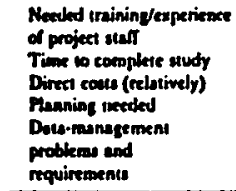 & $\begin{array}{l}\text { Mlintinel } \\
\text { 3-5 monahs } \\
\text { Limiled } \\
\text { Few. }\end{array}$ & $\begin{array}{l}\text { Moderute to } \\
\text { edvanced } \\
\text { G-9 monshs } \\
\text { Low-Moderale } \\
\text { Limined-Moderate } \\
\text { Few-Modente. }\end{array}$ & $\begin{array}{l}\text { Advanced } \\
\text { is monthe } \\
\text { Hith } \\
\text { Considerable } \\
\text { Meny }\end{array}$ \\
\hline 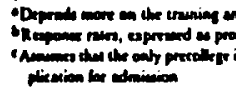 & 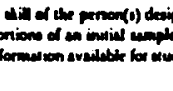 & 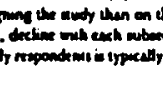 & 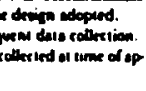 \\
\hline
\end{tabular}

Source: Terenzini, 1982 . 
As shown in the table, questionnaires received only from non-persisters are insufficient to ensure internal validity of an attrition study. Terenzini (1982) defines internal validity as:

The design's capability of ensuring that an observed relation between an independent and a dependent variable is not spurious and that alternative explanations for the observed relation have been controlled and can be ruled out. Basically, internal validity can be enhanced in either of two ways: (1) through the random assignment of persons to experimental and control groups (probably impossible in attrition studies) or (2) through the use of a nonequivalent comparison group with statistical controls to take initial group differences into account. (p. 57 )

Therefore, to increase internal validity of an attri-

tion research study, data should be gathered from persisters at the same time and under the same conditions as it is from non-persisters.

Application: Traditiona1 students

Because the non-traditional model of Bean and Metzner is founded, in part, on traditional student research, a brief description of several attrition studies involving traditional students in included here. First, traditional students are defined as generally unmarried, <23 years in age, and registered for fulltime academic loads.

A number of attrition-related studies have been conducted with traditional students. For example, at the University of Texas (Austin), Krebs and Liberty (1971) wrote of the analysis they did on data collected during exit 
interviews with three groups of traditional withdrawing students. Group l, those performing satisfactorily and with no prior history of probation or enforced withdrawal, appeared upon withdrawal to be a "relatively able and materially secure group of students whose chief problem was immaturity" (p. 9). Group 2 students were currently on scholastic probation but had no prior record of enforced withdrawal. Findings from their exit interviews revealed that low academic skills figured most significantly into their withdrawal decisions. They shared, however, the same problems as were prominent in Group 3; that is, finances and relationships with spouses and fiancees. The records of Group 3 students indicated both scholastic probation and a previous history of enforced withdrawal. Depending on the academic history of the individual, therefore, three. different variables (social, academic, environmental) had the greatest effect on withdrawal decisions for three different groups of students. As Krebs and Liberty note, "in voluntary withdrawals, it appears that we are in fact dealing with a complex self- and social problem" (p. 8). Another attrition study done by Herndon (1984) determined among a group of 226 financial aid recipients (mostly traditional students) that persisters were more likely than withdrawals to (1) have good high school grades, (2) have good standardized aptitude test scores, (3) reside in college residence halls, and (4) receive college work study grants. 
Bean (1985) conducted another traditional-student attrition study that used the socialization/selection issue as the theoretical base. Factors within the socialization/ selection issue included one academic, college grades; one social, institutional fit; and one personal, institutional commitment. Independent variables influencing the three factors in Bean's model included (a) academics; (b) social or psychosocial issues; and (c) environmental support/ constraints. The actual criterion that Bean measured was dropout syndrome; "that is, a conscious, openly discussed intention to leave an institution coupled with actual attrition" (p. 36). This definition eliminated from the dropout numbers those students who, because of unpredicted health or family crises, had to leave without intending to. Differences in dropout syndrome across class levels were also measured. Bean found a set of 13 independent variables that accurately accounted for $47 \%$ of the variance in dropout syndrome for freshmen, $35 \%$ for sophomores, $27 \%$ for juniors, and $35 \%$ overall. For Bean's group of traditional students, there were only 2 cases out of 43 tested where significant differences based on class level were found. First, the influence of institutional fit on dropout syndrome decreased signaticantly over time; i.e., "If students are not selected or socialized to the values of the institution early, they are likely to drop out" (p. 53). Secondly, students increase their level of institutional 
commitment significantly over time, but the influence of

such commitment on dropout syndrome decreases.

As has been found in other attrition studies with

traditional students, socialization has a large, significant effect on institutional fit. Where the institutional fit is good, or as Rootman (1972) states, "there is a good personrole or interpersonal fit" (p. 258), the likelihood of continuation at the institution is increased. Another attrition-related study with traditional students based its work on the analogy that students in a college environment are like employees in a work setting. Using research on job satisfaction and employee performance, Bean and Bradley's (1986) study developed a model in which academic performance (GPA) and satisfaction were the dependent variables with reciprocal effects on each other. Bean and Bradley's findings consistently indicate that:

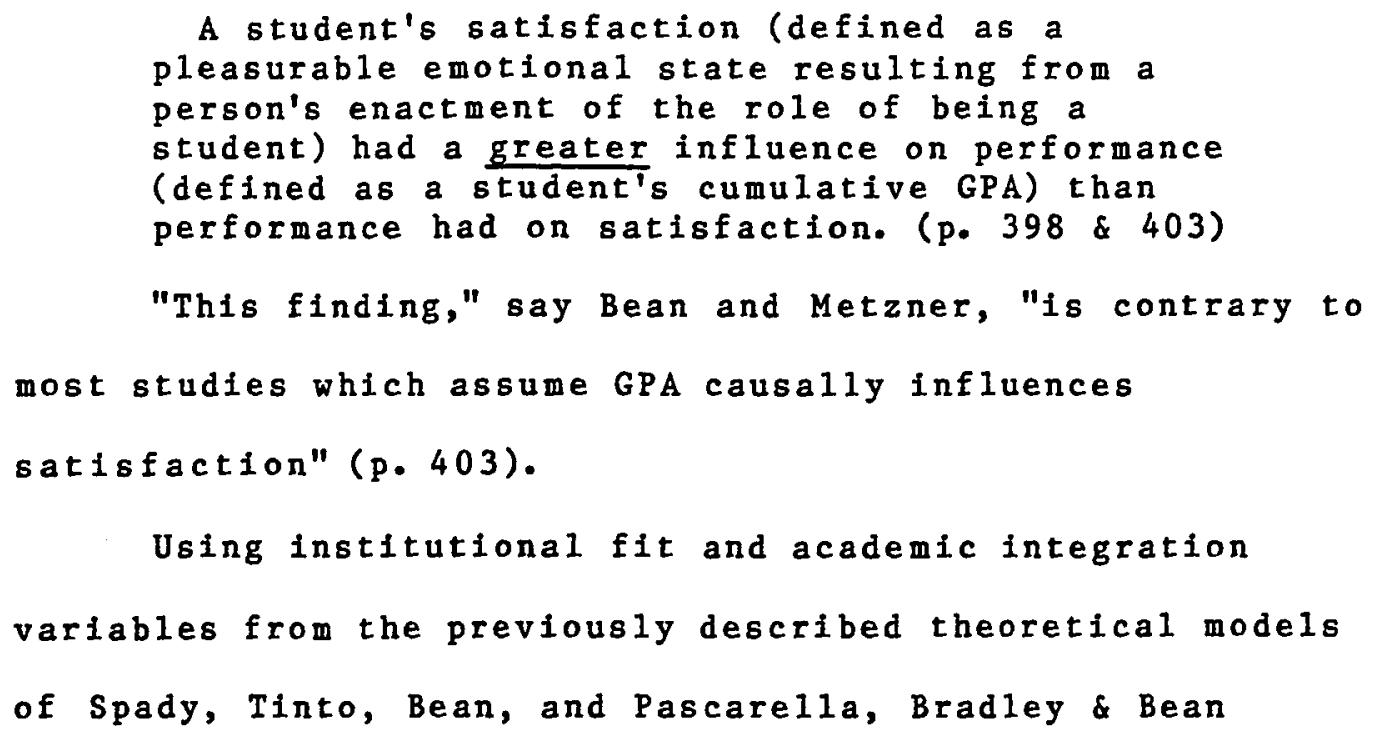


(1986) found that academic integration had a larger effect on satisfaction for men than for women. They also found that institutional fit (similar to social integration) had a larger effect on satisfaction for women than for men (p. 406). Institutional fit was defined as the extent to which a student felt that he/she belonged at the institution. Academic integration was defined as the interest, motivation, and confidence one felt as a student and the perception that one "thought like faculty" (p. 395). Basically, their findings indicated that (a) the causes of satisfaction differ for men and women; (b) only for women is the relationship between GPA and satisfaction statistically significant; and (3) where the relationship exists, the effects of satisfaction on GPA are greater than the effects of GPA on satisfaction.

Application: Non-Traditional Students Smith's (1980) study of persisters and non-persisters included both traditional and non-traditional students. He found an inconsistent link between age and dropout. This finding is in line, however, with conflicting results obtained in a review by Pantages and Creedon (cited In Bean \& Metzner, 1985) of attrition literature which concluded that age was not a primary factorincausing attrition, but in Astin (1975) and Newman's (cited in Greer, 1980) studies which indicated it was. Smith further found that female subjects in his study were more likely to complete their 
programs on time, but men were more likely to return (after stopping out) to complete in general. Marriage decreased the likelihood of completion; ethnicity had no effect. The higher one's socioeconomic status, the greater the like11hood of persisting in Smith's study. He also found that high school grades were positively linked to college academic performance, but satisfactory college integration was not always linked to persistence.

other attrition studies conducted with a variety of non-traditional students, as either the entire sample population or as a comparative group to traditional students, were also reviewed. For example, a study by Irving Rootman (1972) looked at voluntary withdrawal from the U.S. Coast Guard Academy. Using stepwise multiple regression, Rootman eventually developed a six-key variable theoretical model wherein "person-role fit" and "Interpersonal fit" emerged as the mafor determinants of voluntary withdrawal (p. 258-262). Like the theoretical attrition models of Spady and Tinto, Rootman's theory also emphasized the need for social integration in promoting retention efforts. Berkove (1976) examined environmental factors that differentiated dropouts from persisters in a non-traditional population consisting of 361 married females over the age of 25. She found a clear distinction between dropouts and persisters on one environmental factor, self-perception of stres8. She had mixed findings on the other two factors, husband's support and attitude toward marriage. In fact: 
While at least half of the women found specific areas to be problematic to some extent (e.g., time for myself, time for children, taking on too many responsibilities, neglecting housework, integrating my responsibilities as student, wife, and mother), dropouts indicated that those areas created significantly greater problems for them than they did for the "successful" (persisting) student. (p. 3-4)

The students' perceptions of their husbands' support was less clearly differentiated between dropouts and persisters. Emotional support was not perceived as significantly different between the two groups, but functional support was. Such functional support as helping with the housework was reported to be offered on a lesser scale todropouts than to persisters.

The report of the women's attitudes toward their marriages was also mixed. For dropouts, the women's attitudes toward their marriages improved. However, those dropouts who had satisfactory opinions about their marriages before re-entering college, reported significantly lower opinions after dropout. The opinions of the persisters who were initially happy with their marriages rose significantly as they continued their college studies.

Malin, Bray, Dougherty, and Skinner (1980) conducted a study with non-traditional students to determine differences between men and women regarding (a) their college performance as measured by GPA, and (b) their level of satisfaction with college in general. Though not an attrition study, per se, this research, nevertheless, has implications for persistence-withdrawal decisions because of 
its connection to the findings of Bean \& Bradley (1986) regarding satisfaction/performance. Malin's students were "over the age of 24 and were enrolled either part-time or full-time in undergraduate or post-baccalaureate (but not formal degree-granting graduate) programs" (p. 117). Demographics from their 343 respondents showed that $56 \%$ were men and $44 \%$ women. They were primarily upper-level undergraduates attending college part-time, and most had been away from school for at least three years.

The results of this research did not support the general contention that adult women, (rather than men), face special problems in coping with the college experience. (p. 126)

Men in this study had lower GPAs, were less satisfied with college, and reported less positive intellectual and personal achievement. They also reported more suffering than did women from family complaints about time and money spent on college and, in general, experienced more serious conflicts about their multiple roles as spouse, parent, employee, and student. Because of lower academic integration and a higher environmental press, the findings of Malin and others suggest a higher withdrawal rate for the male non-traditional student.

Another attrition study with non-traditional commuting students over the age of 25 years at a junior college was conducted by Greer (1980). Using Tinto's (1975) model, Greer sought to determine if age was a discriminating factor of withdrawals and persisters in two college environments: 
(1) the regular academic program, and (2) a developmental program. Overall, Greer found that age was negatively related to persistence in the regular academic program, but positively related in the developmental one (p. 7-8). Greer's (1980) research further supports the later theory of Bean and Metzner (1985, p. 16) in that:

The older students attached little importance to such things as meeting new people, making friends, and participating in campus activities.

Social integration, in other words, was not a primary factor in either withdrawal or persistence decisions.

Another finding of Greer's was that in the regular academic program, older students were more academically successful than younger students, but had higher attrition rates. The older students also were more certain of their goals and had a more positive image of the college. However, this apparent successful academic integration did not contribute to increased retention.

In 1972, Reehling (1980) began a longttudinal study of 323 adult women, 30 years or age or older, attending a community college program cooperatively sponsored by a major midwestern university. The follow-up study of these women in 1978 revealed that the $75 \%$ who had continued their education did so more because of high internal motivation for self-improvement and intellectual stimulation than for any other reason(s). Reehling's attempts at predicting persistence/withdrawal through a series of stepwise discriminant analyses were partiy successful. The 
discriminant function was able to accurately predict $96 \%$ of those who continued, but on 1 y $10 \%$ of those who did not (p. 494). One interesting finding from Reehling's study was that "encouragement from others had definitely not been a main reason for these women to pursue their educational goals" (p. 493). The lack of encouragement may be a less severe deterrent to continuation than is the presence of disharmony or college-induced stress in the personal environment of the adult learners. What Reehling found was that dropouts indicated environmental pressures as main reasons for leaving, but persisters did not. What persisters did show was a very high degree of internal motivation which, "when one views 1972, was probably a required trait in the women who 'pioneered'the first large wave of female re-entries into higher education" (p. 496).

Another longitudinal study with students who met the definition of "non-traditional" was conducted by Pascarella, Duby, Miller, and Rasher (1981). They sought to determine if pre-enrollment variables and academic achievement variables were reliable predictors of withdrawal-persistence behavior for non-residential students. Though some preenrollment traits (secondary school performance for example) did significantly differentiate among students, such characteristics were more effective in distinguishing stopouts from either persisters or withdrawals. It was only after the first quarter's academic performance was added 
that a clear distinction between persisters and withdrawals was evident.

What Pascarella and the others surmised was that some students, upon receiving their first quarter GPAs, quickly saw they did not have the background or shared norms that were needed to succeed and, therefore, withdrew (p. 34). Satisfactory first quarter academic performance, on the other hand, began the academic and institutional integration that is correlated with persistence. In summary, what Pascarella and others concluded about their non-traditional student population is consistent with other traditional student research, which suggests that "voluntary withdrawal is less a function of pre-enrollment traits than of postenrollment experiences" (p. 347).

Pascarella conducted another attrition study with Duby and Iverson (1983) at a non-residential setting. They found that the academic integration results were consistent with studies done at residential universities, but that social integration showed a negative influence on persistence. This latter finding is inconsistent with the Spady (1970), Tinto (1975), and Pascarella and Terenzini $(1977,79,80)$ theories that stressed the positive influence played by social integration on retention. Thus, the Pascarella et al. (1983) findings give even more credence to looking at some other variable, i.e., environmental factors, as the critical link in non-traditional student retention studies. 
Pascarella (1985) also conducted a longitudinal, multi-institutional study of over 4,000 students to compare differences between on-campus students and commuters on intellectual and interpersonal self-concept. Previous research on student educational outcomes associated with living on campus versus commuting to college (Astin, Chickering, and Iffert, cited in Pascarella, 1985, p. 292) showed that commuters were less likely to persist and had the following characteristics:

1. Commuters were less disposed than residential students to engage in various educationally and developmentally influential activities.

2. Commuters were less likely to participate in non-required offerings, resulting in less interaction with students and faculty.

3. Commuters were less likely to be influenced developmentally by their college experience (measured by various dimensions of change; i.e., increase in aspirations, perceived competence and ability, and commitment to long-range goa16.)

The 1985 study by Pascarella sought to determine what impact on student development could be explained by resident living. His findings indicated that:

Living on campus had a significant, direct effect on two causally subsequent variables in the model: social integration with peers and with faculty. Residential status, however, was not significantly associated with academic integration or with either academic or interpersonal self-concept. (p. 298)

Though his findings might imply support for the social- and academic-integration models of Spady and Tinto, Pascarella's data was collected during 1975-77, and he 
cautions about generalizing the findings now, "particularly with increased numbers of older and non-traditional students in American higher education" (p. 299).

In another attrition study, Voorhees (1987) found that academic integration variables (GPA, hours spent studying, informal contact with faculty) did not meet statistical criteria to be considered for persistence. He surmised that community college students (usually older, part-time commuters; i.e., non-traditionals) did not have as much time to spend on academic matters because of other (external environmental) commitments.

In conclusion, the literature reviewed on Attrition Studies points to a need: (1) to base institution-specific studies on a theoretical model; (2) to clearly specify the population being studied and select the appropriate variables thereof; and (3) to determine, as closely as possible, the causes of student persist-withdraw decisions in addition to just reporting descriptive data. In addition, this review guided the design of the present study. As a result, improvements, as recommended by Terenzini (1982), were built into the autopsy design to lessen the weaknesses that are characteristic in expost facto research. For example, rather than just obtaining descriptive data from External Degree leavers and then making some generalizations about who they are and why they are dropping out, a comparative group of finishers from the same degree program was included. As a result, assessment 
of any statistically significant differences between these two groups of students was possible.

likewise, the literature regarding attrition of traditional students as compared to that of non-traditional students points out differences in the contribution of the variables studied. For example, most of the attrition studies of traditional students focuses on the contribution of three major sets of variables: (1) background, (2) social integration of institutional fit, and (3) academic integration. Any influences from the environment of the traditional student were more a part of that student's social/academic integration and, therefore, did not establish themselves as a distinct category. For non-traditional students, however, the attrition studies reviewed indicated the importance of environmental factors as distinctly contributing to persist/withdrawal behavior. Academic integration variables were still noticeable discriminators in the non-traditional student studies, but socialization variables were frequently ruled out as not contributing to persist/withdrawal decisions.

\section{THE ADULT AS LEARNER}

A concise summary of the review of the literature regarding the adult learner is found in Hughes (1983). His synthesis of the diverse Iiterature on non-traditional students was guided by three questions: 
1. Who is the non-traditional student?

2. What do they want from higher education?

3. How can educators respond? ( $p .51$ )

Hughes' summary of the literature revealed three characteristics (in addition to being 23 years or older which is somewhat generally accepted as the age divider) that distinguish the non-traditional college student from the traditional student. First, non-traditional students have multiple commitments. They are most frequentiy carrying several roles as student, spouse, parent, employee, taxpayer, voter, and concerned community citizen. In contrast, traditional students most frequently have limited commitments.

Secondly, non-traditional students are not campus focused. "The family or work environments often take precedence over the educational environment" (Hughes, 1983, p. 53). In contrast, tradtional students, because of their on-campus orlentation and/or residency, are very "campus focused."

Thirdly, non-traditional students prefer learning that is centered more on problem-solving, even:

... when the learning has no more lmmediate application than a better understanding or appreciation of some remote aspect of $11 \mathrm{fe}$. (White, c1ted in Hughes, 1983, p. 56)

This style of learning Hughes calls "informal," as contrasted to the formal, subject-matter focus of traditional students. More succinctly stated, non-traditional 
students prefer a hands-on approach to learning; traditional, a more distance approach because of their sense of "storing up the knowledge for later use since 'living begins after learning is completed"' (White, cited in Hughes, 1983, p. 56).

As Rauch (1981) noted:

Adults learn best when they are participants in the learning system (and) they are very "now" oriented. One does not start an adult class with an orientation, with theory, or with a chronological history. You start with a bang. (p. 12)

In addition to these three broadly stated characteristics that Hughes reports as consistently appearing in the literature, there are other characteristics of adult learners that are frequently cited. For example, some adult learner studies report a trend away from education and liberal arts and toward business, accounting, and urban studies (Solomon and Gordon, cited in Hughes, 1983, p. 54): Even though preparation for work remains a major motivator for beginning or returning to college, Flaherty (1978), however, is one researcher who noted that:

Reasons for the influx of older students are more varied, with personal satisfaction, fulfillment, and interest in civic responsibilities becoming stronger motivators. (p. 375376)

Lance, Lourie, and Mayo (cited in Hughes, 1983, p. 54), found that the subjects of their study, 583 returnIng students over the age of 24 who had been out of school two years or more, had low self-confidence about their 
ability to succeed. Part of the reason for a lower selfconfidence may be traced to the adult's previous educational performance. For example, Kuh and Ardailo's (1979) study comparing adult learners with traditional students substantiated the findings of other researchers that "older students did not achieve as well in high school as their younger counterparts" (p. 212). Flaherty (1978, p. 376), however, notes that "non-traditional students are generaliy more receptive to remedial instruction and/or some type of self-instructional program designed to build selfconfidence."

In addition, Kasworm's (1980) review of prior research on academic achievement of older undergraduates in a variety of institutional settings and special population categories reveals that:

0lder undergraduates do perform adequately and effectively, as assessed by GPAs, in competitive undergraduate environments. (p. 37)

Using this research background, Kasworm evaluated differences between younger and older undergraduates regarding academic capabilities. Her 1980 article reported on a study of their intellectual and soclo-emotional orientations, as measured by the Omnibus Personality Inventory Form $F$, an instrument developed by the Center for the Study of Higher Education at the University of California (Berkeley). She found that older undergraduates, as compared to their younger classmates, displayed significantly higher scores in the areas of personal integration, lack of 
anxiety, theoretical orientation, and analytical problem

solving (p. 30, 39). Kasworm's summary of the different

characteristics of older and younger undergraduate students

\section{follows.}

\section{TABLE II}

TYPOLOGY OF DIFFERENTIAL CHARACTERISTICS OF OLDER AND YOUNGER UNDERGRADUATE STUDENTS

\section{Younger Undergraduales}

1. Quasi-dependent being

2. Limited emotional/financial support for significant others

3. Major lime focus on academic and related extracurricular activities

4. High identification with student role

5. Secking out a ulf-identity

6. Limited awareness of own capabilities

7. Minimal exposure to life/career vole models

8. Minimal self-confidence and developing sense of maturity

9. Introspective orientation

10 Impulse (short-term) decision-making

11. Limited exposure to strategies for learning

12. Passive learner role (unknown readiness to leasn)

13. Limited history of self-directed learning

14. Minimal analynical/critical problem colving skills

15. Limited prior life experiences

\section{Older Undetgraduates}

1. Independent being

2. Major emotional/financial support for significant others

3. Compering time focus on job, family, community, personal responsibilities in relation to academic activities

4. Composite identification with many roles

5. Renewing self.identity

6. Continuing growth of awareness of own capabilities

7. Significant exposure to life/career role models

8. Developed and diversified self.confidence and maturity

9. Varied self/others orientation

10. Capacity for delayed gratification (longterm) decision-making

11. Varied strategies to learning

12. Active learner role (active readiness to (earin)

13. Diversilied opportunities for prior development of self-disected learning

14. Developed analytical/critical problem. wolving skills

15. Varied rich life opporeunities and experiences

Source: Kasworm, 1980.

A comprehensive study conducted at the State University of New York at Albany (Mangano, Conado, and Frank, In Hughes, 1983), showed that returning non-traditional 
students rated several aspects of college life significantly more important than did traditional students. These higher ratings included more flextble scheduling of courses, including evening and weekends; credit for out-of-college experiences; and independent study course expansion. However, no significant differences between non-traditional and traditional students were reported on preferences for concentration, study-skili and memory improvement; for a broad educational background with a number of courses providing specific job skills; and for relaxed, informal, encouraging instructors who have a realistic view of a student's responsibilities outside class and who use many examples in their lectures.

Kimbal1 and Sedlacek (1971) also found in their study of two groups of full-time undergraduates (one less than 36 years old and the other, over 36 ), that the older group was significantly different on two issues. First, the older group felt teachers and administrators cared about students; and secondly, the older group was less critical than the younger group about the college environment in general. One adult-as-learner study, carried out by Wolfgang and Dowling (1981), assessed differences in motivation for participating in college between adults 24 years of age or older and younger undergraduates. Responses were categorized into motivational factors as follows: 
(1) social relationships, "to make new friends"

(2) external expectations, "to carry out the recommendation of some authority"

(3) social welfare, "to improve my ability to serve mankind"

(4) professional advancement, "to secure professional advancements"

(5) escape/stimulation, "to get relief from boredom"

(6) cognitive interest, "just for the sake of learning." ( $p \cdot 642)$

Using a two-way ANOVA, Wolfgang and Dowling found that older students scored significantly higher at the .01 level of significance than younger students on the motivational factor of cognitive interest. older students scored significantly lower than younger students on the motivational factor of social relationships and external expectations. No significant differences between the age groups were found on the other three motivational factors: (1) social welfare and (2) professional advancement were ranked moderately high by both age groups; (3) escape/ stimulation was marked low by both. One implication of the Wolfgang and Dowling study is particularly pertinent to the environment of distancelearning students. The older students scored significantly higher on the cognitive interest factor, and thus, according to Wolfgang and Dowling:

indicated a stronger internal drive for learning, (and) are better candidates for individualized programs that often require a great deal of self-direction and dedication. (p. 646)

In keeping with the cognitive interest theme, Brookfield (1986), too, identifies six principles that promote achievement in the curriculum developed for adult learners: 
1. voluntary participation on the part of the learner

2. mutual respect between/among instructors and learners

3. a collaborative spirit within the learning environment

4. a sense of praxis or alteration between activity and reflection

5. critical reflection opportunities for learners

6. self-direction; empowerment of learners (p. 9-11)

Another study with chronological age and marital status as factors of academic performance was reported by Von der Embse and Childs (1979). Their population of 517 senior-status students at a Midwest state university's college of business administration, was divided into groups by age: those older than 27; the others, 27 or younger. They found that older students. achieved significantly higher GPAs than did the younger students. Although marital status yielded no significant differences between the two age groups, married women achieved significantly higher GPAs than did unmarried women. Marital status was not a significant factor in academic performance among the men. Von der Embse and Childs hypothesize in their concluding remarks that:

The older student's academic performance is influenced by a more self-directed commitment to educational goals; (and) using outside experience as a resource for learning, the older student is more likely than the younger student to be a high achiever. (p. 478) 
In summary, this section of the literature review confirms that the motives, backgrounds, and environments that adult learners bring to the classroom are diverse. As Flaherty (1978) remarks:

Educators will find a great sense of satisfaction from working with adults. The adults' interest is infectious; their motivations stimulating; (and), for the most part, they are indepenoent learners. (p. 37)

Adult learners bring to the academic environment "a different set of attitudes, values, and expectations" (Von der Embse \& Childs, 1979, p. 476). And, as Kasworm's (1980) study suggests:

01der undergraduates have stronger capabilities for conducting analytic inquiry, for assuming self-discipline and responsibilities for learning activities; for involvement in self-directed tutorial and independent study activities, and for integration and synthesizing of theoretical materials. (p. 44)

Demographics in higher education enrollments are changing. And, a summary of the adult-as-learner literature implies one main theme: Institutions which are alert to this change and respond accordingly, by providing the kinds of academic programs and support services that address the needs of adult learners, should reap the benefits of attracting this exciting, challenging group of students. More importantly, such institutions have a better chance of retaining them once they are there. 


\section{DIFFERENCES BETWEEN RURAL AND URBAN ADULT LEARNERS}

The third area of literature reviewed for this study was in the area of rural versus urban adult learners. "Participation rates in education," say Darkenwald \& Larson (1980), "are notably lower in small towns and rural areas than in cities and suburbs" (p. 4). Even so, rural adults comprise nearly $27 \%$ of the nation's adult learners (McCannon, 1985). When McCannon compared them with urban learners, rural adult learners proved remarkably similar on all variables examined--age, sex, reason for participation in adult education, subjects enrolled in, type of provider, number of courses taken, and source of payment. However, McCannon's 1977 and 1985 studies of the differences between rural and urban adult learners pointed to three distinct barriers faced by rural adults more frequently than by their urban counterparts:

(1) access to educational programs, because of distances

(2) lack of adequate finances with which to participate

(3) lack of adequate advising and counseling (. . 13)

Barker (1985) reiterates these differences by expanding on each of the three, citing the most notable as distance or residency location:

Rural learners who live in areas of low population density and/or geographical isolation will most definitely be provided fewer educational services and opportunities. (p. 5) 
Even though telecommunications has the ability to provide access to educational programs and, according to Spears (1985), "serves as a valuable ally in serving rural professionals, its abilities to reach the less-educated in rural areas is seriously questioned" ( $p .15)$. Barriers two and three (lack of finances and lack of advising/counseling) help to explain the justifications behind spear's statement. Financial support for participation is also confounded in rural areas where it is generally more expensive to provide outreach programs with mileage for teachers and/or telecommunications increasing the costs to the consumer. Generally lower income levels of many rural adults further limit accessibility to programs delivered on a selfsupport basis to distant areas (McCannon, 1977 \& 1985; Treadway, 1984; and Zucker, 1986). According to Treadway (1984), current federal criteria for allocating resources ignores the higher costs of delivering instruction to rural areas and overestimates the local resources available to support such services. Such was certainly the case, as reported by Hershfield (1986), in the Learn Alaska Network $\$ 30$ million telecommunications system. This rural-outreach system was terminated after developers failed to recognize that $\$ 200,000$ annually for the entire programing effort was insufficient to meet the educational needs and distance expenses involved in serving native Alaskans in rural areas who were unable to supplement the expense themselves. "Therefore," says Spears (1985), 
"states should not look to technology as the solution to all rural needs" (p. 15).

Perhaps all too frequently, rural adult learners are presented with a smorgasbord of courses--an attempt to meet most of the needs of most of the learners. What is reality, says Treadway (1984) in quoting Margery Walker of the Rural Education Program at the University of Alaska in 1981, is that "rural residents seek coherent programs, sanctioned for field delivery, by campus departments--not just occasional courses" (p. 14). Treadway continues:

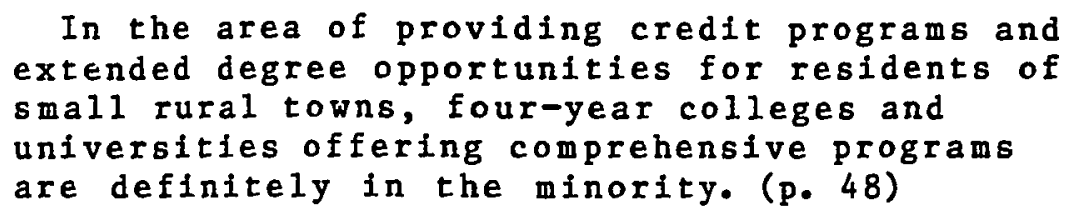

A study reported in 1986 by McDaniel confirmed a distinction between perceptions of barriers to rural adult learners as compared with their urban counterparts. Overwhelmingly, both rural providers and learners felt that they did not have equal choice in selecting educational options. Added to the choice issue are problems of (a) distance and transportation; (b) increased costs; (c) declining incomes; (d) limited access to instructors and advisors; (e) limited support services; and (f) lack of access to materials and resources. Barriers listed by providers and learners across seven Northwest states in the McDaniel study were highly simflar.

Numerous systems and programs designed to serve rural learners are reported in the literature. Many appear to be 
reasonably successful. For example, Benson and Hirschen (1987) cite the Interactive Telecommunications Cable Project in rural downstate New York (Westchester County); the Educational Telecommuncations in Small Rural Schools operation in Norwich, New York; audio-teleconferencing of the University of Nebraska, Eastern Montana State University, and the University of Wyoming; linkages between microcomputers and electronic chalkboards successfully operating in the Mansfield, Pennsylvania, Teleteaching Project and in the Delaware-Chenango Schools network; the interactive TV via satellite with one-way video and two-way audio systems which include programs from oklahoma State, Texas, Utah, and Spokane; Washington; and the Appalachian Educational Satelite program.

The literature reviewed about rural/urban adult learners cited only the differences in terms of access, affordability, and acceptance of the types of educational programs available. No literature was found which compared rural and urban adult learners on their persist/withdrawal behavior in college programs.

\section{ADULT DEVELOPMENT}

Much of the literature reviewed in the area of Adult Development is written by theorists who, according to Schlossberg (1984, p. 4-19), describe adults from an age and stage perspective. Age-related stages are described by Levinson (1978); the new-development stages by Erikson 
(1978, 1980); Fowler (1981); Gould (1978); Havighurst (1972); and Vaillant (1977); ethical/moral development stages by Gilligan (1982) and Kohlberg (1983); cognitive development stages by Perry (1970) and Piaget (1969); and ego-development stages by Kegan (1982) and Loevinger (1976). Non age-related concepts regarding adult development are described by Belenky (1986), and women's "different ways of knowing"; Bridges (1980) and Schlossberg (1984), the importance of understanding and patience in coping with transitions and of weaving play into work and love; Lowenthal's (1975) significant life events; and Neugarten's (1968) individual variability/times.

Although the specific age ranges may differ, most of the age/stage theorists noted above refer to 4-5 stages of adulthood. These stages can be broadly categorized as: (1) Early Adulthood (18-30); (2) Mid Adulthood I (30-45); (3) Midlife Crisis (42-45); (4) Mid Adulthood II (45-60), and (5) Later Adulthood (60+). According to Levinson (1978), individuals in the Early Adulthood stage (18-30 years) are either already involved in full-time, traditional studies or have not yet felt the urge to return to school on a part-time basis--other issues are occupying their time (p. 72-78). For example, in his allmale study, Levinson identified the focus of this "season" of life with a work-related, goal-directed theme. Actively pursuing a fullime college education might be the goal in Levinson's 17-22 year-old category, described as moving out 
of the pre-adult world and experimenting and choosing adult rules (p. 56). But, by age 22-28 when entering the adult world, Levinson's subjects are busy exploring options and developing a stable life structure (p. 58). However, at about age 28-33, Levinson's age 30 transition occurs. "Transitions," according to Bridges (1980), "are natural processes of disorientation and reorientation that mark the turning points of our path of g=owth" (p. 5). Common to all transitions, says Bridges, is (1) an ending; (2) a middle, confusing time, and (3) a new beginning. One's attitude towards the transition, notes Bridges, is dependent on whether the change being experienced is chosen or externally forced. At this stage, Levinson's adult is making efforts to improve or correct his life structure which may result, in a return to college studies. However, other issues begin arising for individuals in this age, namely marital problems and occupational shifts. Bridges speaks to this critical transition period when he references "the riddle of the sphinx," in that the individual now "walks on two feet at noon" (the independent adult), following a period of childhood or "walking on four feet in the morning" (p. 28). Bridges sees the speed with which individuals are able to establish themselves as an independent adult affecting their ability to commit to a goal at the age of 30 (p. 37). For example, as Piaget (1969) asks, did the Individual accommodate or assimilate the situation in life to his/her own 
needs while arriving at the age 30 transition? $0 \mathrm{r}$, rather, did he/she merely power his/her way through to age 30 without much change or self-reflection?

Assimilation would have the individual interpreting new experiences by existing rules, concepts, or schema. It is deemed easier than accommodation which demands that the individual modify his/her existing concept (or expectation) in order to "fit in" the new experience. Piaget, a cognitive theorist, describes these processes as periods of equilibrium/disequilibrium as individuals move through several life stages. Fowler (1981) describes Piaget's theory as being focused on structural changes that constitute one's thought processes at a given time. When enough accommodation occurs to warrant a change, according to Fowler, a new stage emerges.

Piaget's research serves as a backdrop for Kegan's (1982) theories on the evolving self. "Meaning making" is the descriptive phrase Kegan uses to refer to his studies on the evolving self. According to Kegan, the making of one's understanding is a balancing throughout the lifespan of subject and object relations (p. 12, 46-110).

Kegan's three adulthood stages are (1) the interpersonal balance, (2) the institutional balance, and ( 3 ) the interindividual balance. The individuals at the interpersonal balance stage are so dependent on what others think of them (i.e., faculty, advisors, fellow students), that they have no real sense of self that is separate. They are, 
according to Kegan, incapable of establishing true intimacy because their "self" is brought into being by others--"you are the other by which I complete myself" (p. 100).

Other early adulthood college participants fit Kegan's second adulthood stage, the institutional balance. Here, adults are seen as capable of holding conflicting feelings simultaneously. Self-dependence and self-ownership create a personal self-system that can separate, for example, the belief that "I have relationships" from earlier stages of "I am my relationships" (p. 100). Kegan cautions individuals here of exhaustion, resulting from being too selfsufficient.

Individuals at the interindividual balance level are able to separate themselves from their work/performance life and survive, therefore, failing on some task or at least hearing some negative report about their performance. They see themselves as "running" their system, but not being the system itself" (p. 103). Because their sense of self is no longer brought into meaning by others, they are capable of becoming intimate or interpersonal.

All individuals, says Kegan, evolve through a duality of human experience between yearning for inclusion and yearning for independence. The flow between holding on and letting go marks transitions in individuals' lives that need to be understood and supported as much as possible in an academic program. 
Levinson's next three categories are: (1) Settling Down, about ages $33-40$; (2) Midlife Transition, about ages 40-45; and (3) Entering Middle Adulthood, about ages 45-50. The "settling down" students, as Levinson describes them, are the younger "settlers" who are becoming junior members of society by establishing their niche, making it, and identifying the steps on the ladder of success that are needed to move up (p. 59-60). The older settlers in this group are busy "becoming one's own man" (p. 60) by striving to achieve, says Levinson, athority or independence and reappraising their goals and achievements.

Though Levinson's research was done, with males, Bridges claims the "tasks" of completing the midlife transition for women and men are about the same: (1) to terminate the era of early childhood; (2) to initiate middle adulthood; and ( 3 ) to deal with conflicting feelings and values brought about by middle age.

The last age-related category described by Levinson is the 45-50 year-olds "entering middle adulthood" (p. 61). Levinson's men are described here as responding to the task of bringing stability and meaning to one's commitments and values. The dream of achievement, involving a mentor and/or a "special woman" (p. 109) is no longer predominant. Lowenthal and Thurner (1975) see a continual process through a man's lifespan of analysis and reorganization. Relationships play a relatively subordinate role in the tasks associated with the male's adult development: (1) bullding 
and modifying the life structure; (2) working on a single component of the life structure; and ( 3 ) becoming more individuated.

Another way to profile adults is with new-development stage theory. Erikson's (1978) crisis resolution theory is, according to Fowler (1981), built on Freud's psychosexual stages by expanding the circle of influence to include the cultural symbols of the larger society, i.e., the psychosocial environment. Erikson's belief is that one's life consists of a series of events that lead to choices at certain periods in life. The choice is described by Erikson as a "crisis," and the individual is in a period of disequilibrium until the crisis (choice) is resolved. As crises are met and dealt with, the individual's personality is defined and redefined.

Although not discretely age-related, the crisis stages nevertheless represent critical periods during which certain issues become predominant. In the early adulthood category (18-30 years), for example, Erikson describes two periods: 18-22 year-olds dealing with the crisis between achieving an identity or remaining role diffused; and 23-30 year-olds struggling with the issues of intimacy and isolation. Adults of ages 31-50 are in conflict between generativity and stagnation, and those over 50 are attempting to achieve integrity rather than despair. As the adult integrates and differentiates between the choices at each stage, his/her identity is achieved and serves as the basis for commitments 
to values that help resolve later stages of conflict. Erikson suggests that each event in an adult's life may be perceived as either a crisis or a non-crisis event. If perceived as a crisis, individuals usually experience a brief state of "moratorium" as they decide whether or not they are capable of solving the specific crisis. If the perceived crisis is solved, the "identity-achieving" status results; if the crisis is not solved, the individual may either be foreclosed on the subject while seeking an easy solution; identity-diffused or unconcerned; or continue to exist in a moratorium. If the individual does not perceive the event as a crisis in the first place, it is either because (1) the problem has already been solved (identityachieved); (2) the event is denied (identity-foreclosed); or (3) the individual is unconcerned (identity-diffused). At Erikson's 7 th stage, individuals are.either concerned about future generations or have turned inward with a lack of interest or rejection of the younger generation. Building on Erikson's "stage notion of crisis resolution," Gould (1978) characterizes adulthood with descriptions of five age-related levels: (1) 16-22 year-olds growing independent from one's birth family, including an openness to new ideas; (2) 22-28 year-olds stabilizing of concerns, engaging in work, and becoming confident with one's self and autonomy; (3) $28-34$ year-olds showing an increasing dissatisfaction with their marriage but increasing investment with their children. This is a time, 
says Gould, of self-reflection (p. 153). (4) At ages 35-45, Gould sees adults in "quiet desperation," where time becomes finite and concerns mount regarding health and aging parents. (5) Then at age 44-50, the adult stabilizes his/ her personality, increases the involvement with the spouse, kids, and friends, and generally begins to accept things the way they are.

Gould's theory of adult development revolves arcund the changes in self-insight and personal philosophy that arise as the adult grows and continues to integrate his/her "childhood consciousness" into an adult reality. Gould (1978) also incorporates the developmental task theory of Havighurst (1972). This theory emphasizes where, at certain ages, society expects involvement in and/or achievement of certain tasks. These tasks are (1) achieving civic and social responsiblity; (2) establishing/maintaining an economic standard of living; ( 3 ) assisting one's teenage children to become responsible and happy adults; (4) developing adult leisure time activities; (5) relating oneself to one's spouse as a person; (6) accepting and adjusting to the physiological changes of middle age; and (7) adjusting to aging parents.

Vaillant's (1977) longitudinal study is also founded on Erikson's (1978\& 1980) work, although done strictly with 268 men at Harvard. He fills in the gap in Erikson's stages between intimacy (20's) and generativity (40's) and calls it "career consolidation," or a period when adults translate 
their hobbies and ambitions into occupational terms

(Schlossberg, 1984, p. 27). He found that those individuals who were able to achieve intimacy in resolving the 23-30 year-old intimacy vs. Isolation crisis, were then able to deal effectively with their careers. The theme of Vaillant's research effort seems to be on adaptation to life and to the development of coping skills. Inner adaptation factors for Vaillant include (1) biological injury; (2) intellectual growth, and (3) capacity for intimacy. External factors include (1) early loving relationships, (2) the array of targets for identification, and (3) stresses and opportunities. "Psychosexual maturation occurs," says Vaillant, "through the success or failure of negotiating the Eriksonian life crises" (p. 349-50). Fowler (1981) uses several adult development theoretical models to help describe the stages of faith development. For example, Piaget's (1969) and Kohlberg's (1969\& 1973) studies helped Fowler focus on the structuring activity of faith; Erikson, on the functional aspect of faith. Fowler believes that:

The level in one's faith stage will help determine how the Erikson crisis is resolved because the quality of response to the crisis is dependent on one's stage of faith. (p. 107)

"Faith," says Fowler (p. 25), "is the way we commit ourselves to centers of values and power that exert an ordering force in our lives." 
Another way to describe categories of adults is with Kohlberg's (1983) six moral development stages. The first two, (1) Punishment/Obedience and (2) Naive Instrumental Hedonism, are grouped under the broad title "Premoral," and are associated with the preadolescent period of life. Stage 1 individuals see people of high authority unbound by rules; authority for such individuals is associated with age, size, and power. The value of life for a moral Stage 1 individual may get confused with the value of physical possessions. Stage 2 individuals follow rules to get rewards/favors. They believe, according to Loevinger's (1976) interpretation of Kohlberg, that it's OK to take advantage of another's mistakes and that rights have power, even if the exercise of them causes another to suffer ( $p .120)$.

Another category described by Kohlberg is the "Conventional Role-Conforming" morality. Two stages make up this category, roughly associated with ages 13-35. Stage 3 (1321 years) is called Good Relations/Approval, and is characterized by gratitude and the drive to maintain loyalty. In Kohlberg's hierarchy, Stage 4 is called Law and order. At this stage, individuals interpret law as basic for the social order. Individuals at stage 4, for the most part, do not feel responsible for the effects of their behavior beyond one's own defined role responsibilities. The last broad category in the Moral Development theory of Kohlberg is titled "Self-Accepted Moral Principles." The 5th and 6th stages are included here. Number 5 is called Democratic 
Contract, where one conforms in order to maintain the respect of an external spectator who judges in terms of a whole community's welfare. Kohlberg believes that individuals at this stage feel laws should be obeyed because they were developed by the democratic process; punishment serves rehabilitation and it is the contractual obligation of the judge to administer punishment. (p. 99)

Kohlberg's 6th stage is called Individual Principles of Conscience. At this level, one conforms to avoid selfcondemnation; assumes self-responsibility for acts done and not done; believes in the importance of personal trust; and feels that moral principles determine the appropriateness of rules. Though this 6 th stage completes Kohlberg's theory at the present time, he hints (p. 6, 41) at the possibility of a 7 th soft stage of ethical and religious orientation. Gilligan's (1982) criticism of Kohlberg focuses on the differences she perceives between men and women, especially at the $4 \mathrm{th}, 5 \mathrm{th}$, and $6 \mathrm{th}$ stages of moral development. According to Gilligan, female participants are more likely to be responding throughout their lifetimes to "a different voice" that speaks more to relationships than to rights; more to caring for others than to responsibility for self (p. 21, 24-38).

Much adult development theory, according to Gilligan, is based on research done with men. In the case of moral development, the very factors that are seen as strengths for women come through in Kohlberg's hypothetical situations as 
evidencing weakness in. the female's moral judgment. For example, "achievement of Kohlberg's 6th stage," says Gilligan, "is based on a male model of adherence/belief in rules (stage 4) and justice (stages 5 and 6)" (p. 18). The caring and sensitivity of women makes it less natural to fit into these stages, but not, as Gilligan refutes, deficient in moral development. "Judgment," says Gilligan (p. 69), "comes in two modes: (1) masculine, or the public world of social power; and (2) feminine, or the privacy of domestic interchange." The usual expectation in our society, according to Gilligan, is that the masculine mode is "better" and moves toward maturity. The constant tension that is, therefore, created for females is between a more natural inclination to be sensitive and responsible for others versus the "more mature expectation" of developing the self through the appropriate exercise of rights and responsibilities. This conflict between achievement and care leaves women divided in their moral judgments and/or feeling betrayed (Gilligan, p. 159). As Gilligan (p. 135) states, "Women are always in the dilemma of either caring for and worrying about not hurting another or doing what is right for themselves;" i.e., saying no to family/Eriend obligations or expectations in order to study. "The tension between attachment on the one hand, and separation on the other, characterizes and anchors the cycle of human life" (p. 149$)$. 
In the early adulthood period of life, positive resolutions of Erikson's crises result in a dichotomy of identity (self) and intimacy (other). As Gilligan states:

Females will most likely struggle more than men to maintain both these resolutions because of the different voice that speaks to them saying, "We know ourselves as separate only insofar as we live in connection with others, and we experience relationship only insofar as we differentiate other from self." (p. 63)

"The conflict between self and other constitutes," says Gilligan (p. 69), "the central moral problem for women: i.e., birth control vs, abortion, compassion vs, autonomy, virtue vs, power."

Stages of thinking may also be used to describe adults. Perry's (1970) work provides, perhaps, the best description of the development of thinking. Belenky (1986) describes Perry's scheme as:

\footnotetext{
how students' conceptions of the nature and origins of knowledge evolve and how their understanding of themselves as 'knowers' changes over time and how they interpret educational experiences. (p. 4)

As with most, if not all developmental stage theories, Perry also recognizes the irregularities of growth. He describes three alternatives to ethical/intellectual growth
} as (1) temporizing, or pausing for more than a year in any one position, typically with awareness of the next step; (2) retreating after glimpsing multiplicity and then actively denying the legitimacy of another's opinion; and (3) escaping, usually to one of the middle positions where the individual may alienate oneself and become cynical. 
Yet another way to describe adults is with Loevinger's (1982) structural stage theory regarding ego development. Her framework provides 10 sequential stages with only the first two, presocial and symbiotic, reserved for infancy and, therefore, not descriptive of adulthood. In order, stages $3-10$ are:

(3) Impulsive, seeking immediate gratification without regard for negative consequences "as long as I can get away with it."

(4) Self-Protective, where, as an adult, the individual becomes opportunistic, deceptive, and pre-occupied with the control of others.

(5) The Conformist, where the individual is beginning to trust within the family or group but generaliy just obeys rules because they are rules and makes no distinction between rules and norms.

(6) The Conscientious-Conformist, where the individual sees multiple options, is able to differentiate norms from goals, and sees him/herself falling short of. the "ideal."

(7) Conscientious, where the individual has self-evaluated standards, is self-critical, assumes guilt or achievement for consequences of behavior, and internalizes rules.

(8) Individualistic, which carries forward features of the previous stage but adds the dimension of respect for individuality.

(9) Autonomous, previous stage characteristics and adds coping and toleration skills in dealing with conflicting inner needs.

(10) The Integrated Ego, with previous stage characteristics plus the added dimension of being able to reconcile inner conflicts and renunciate the unattainable. 
Belenky (1986) provides a different view of women by describing, not a developmental approach, but rather five "epistemological" viewpoints. She views Piaget's theory as a morality of rights; Kohlberg's as an evolution of moral reasoning for males; and Gilligan's as a morality organized around responsibility and care. Belenky feels, though, that women have a "different way of knowing" that can take shape in five different dimensions:

(1) Silence, where the woman essentially "maintains her place" and is seen but never heard. Such women are subject to the whims of authority and are virtually unable to conceive of their own sense of self.

(2) Received Knowledge, where the woman is capable of getting and passing on knowledge but feels incapable of generating it herself. She listens to the voices of others to determine the right or wrong answers and is, therefore, intolerant of ambiguities. She thinks literally and, without really understanding the ideas, is unable to read between the lines. She believes selfadvancement is $O K$, but only if it is to help others in the process; otherwise, she sees it as selfish and destructive. Her self-concept is formed from other's opinions and expectations of her.

(3) Subjective Knowledge, where the woman senses and listens to "the still small volce" that is emerging "in her gut." Belenky speculates (p. 58) that many women function or come to this level as a result of a crisis of trust with a male authority figure. If such crisis is followed by some confirmatory experience showing the woman that she is capable of learning, she is probably able to walk away from the past. Frequently, the walk leads to more education and/or a turn to a maternal-type authority. Though the future may seem foggy for such women, they are strongly 
self-determined. The caution, here, is that what may become a stubborn independence will thwart further growth.

(4) Procedural Knowledge, is a humbler, but more powerful volce of reason. Women with this perspective are learning and applying objective procedures for obtalning and communicating information. The inner volce is changing to point out and push for acceptance of the fallibility of the gut instinct of perspective three. There is more perspective taking here and more objectivity as the woman becomes a more pragmatic problem solver. For example, the woman is able to organize her educational pursuits so that the goal becomes reality.

(5) Constructed Knowledge, is able to "integrate the different volces" (p. 137). Women here do not avoid conflict and stress, but recognize it as a fact of $11 \mathrm{fe}$. They feel the process of learning is what's important.

A final way to look at adults is through the life events theory of Neugarten (1968). "Her work," says Schlossberg (p. 11), "emphasizes variability or individual 'fanning out." As our lives grow longer and successive choices and commitments accumulate, our lives grow more different from each other than the same. Generational differences, in Neugarten's theory, account for variability among individuals along four dimensions:

(1) one's chronological age (1ifespan)

(2) age-related expectations (social time)

(3) the perfod of history during which one is an adult (historical time)

(4) one's perception of his/her place in the course of life (psychological time). 
$\underline{\text { Summary }}$

Returning to college is a transition, and as Bridges

(1980) notes:

Most of us did only a passable job of resolving identity issues as youth; consequently, whenever we enter a new transition, some of these old identity issues are going to re-emerge. (p. 35 )

The broad concept of transition in terms of reentering college remains a challenge for adult learners who struggle with the added identity of student. According to Bridges, the process of reaching a goal (i.e., completing the baccalaureate), is as important as the goal itself. At 18-30, adult learners may still be so focused on the goal that the rigor of the process becomes an obstacle. Thus, this period of time Bridges calls searching for a place (p. 37) may be a frustrating one for the younger adults in the External Degree Program. Because they are also coping with tensions associated with moving from a dependent role to independency, they may not be ready to commit to the independent nature of study characteristic of the Program. And, some External Degree students in Kegan's institutionalbalance description may burn out before completing the Program because of their inability to back off somewhat from their self-imposed independency. True, the Program expects students to be self-starters, but also provides numerous connections to a helping network of faculty, advisors, and peers in recognition of the support such non-traditional students may need. Avoiding, denying, or ignoring the 
support systems because of too high a reliance on a personal self-system may result in frustration and/or dropout. Individuals at this stage may not be able to receive and integrate the constructive criticism from the support system because of their perceptions of being personally demeaned. This review of the literature in Adult Development helped provide a more comprehensive look at the challenges non-traditional students face when enrolled in a college degree program. Reviewing how different theorists describe the patterns of life through which one becomes an adult provided helpful insights into both age- and stage-related theories regarding adult development. Particular attention was focused on the transition experienced in a midlife crisis, where adults may turn to college as a somewhat temporary respite from what they believe their unfulfilled life to be. For some, the stimulation of learning catches. on, and a commitment to stay results; for others, though, the exposure is temporary and may/may not be productive in moving the adult forward to whatever else beckons. This broader understanding of the phenomena called adult development provided the necessary checks and balances that prevented quick assumptions or generalizations from being made about External Degree students' dropout decisions. The review also faclitated the organization of a summary of the respondents' narrative comments regarding "What would I do differently a second time around when returning to college." 


\section{CHAPTER III}

\section{METHODOLOGY}

The purpose of this study was to identify finishers and leavers in the External Degree Program at Eastern oregon State College, and then to answer these basic questions:

1. Who's "making" it? Who's not?

2. What's the difference between the two groups?

3. Do certain variables predict dropping out?

This chapter presents the methodology used to answer these questions. Separate sections of this chapter will address (a) the setting, (b) the sample population, (c) the research design, (d) the variables of the study, (e) datagathering procedures and instruments, and ( $f$ ) the statistical methods used to analyze the data.

\section{SETTING}

This study was conducted with students admitted to the External Degree Program at Eastern Oregon State College in La Grande, Oregon. The College is located in the northeastern corner of the state. Established in 1929 as Eastern Oregon Normal School, its original mission was as an educational training college for teachers. Over its 60-year 
history, the College evolved into what it is now, a regional state college within the oregon State System of Higher Education. It is one of the seven publicly supported post-secondary institutions in oregon, but the only one east of the Cascade Mountain Range. Thus, the College has been attempting in the 10 years that have passed since the oregon Legislature deemed it a "regional" institution, to serve the educational and cultural needs of the residents of a 10county, sparsely-populated, geographically-isolated, yet immense $(42,000$ square mile) service region. One of the main projects undertaken by the College following the creation of the Division of Continuing Education in 1979 was the External Degree. This program was created to provide an opportunity for adults, who had either never gone to college or whose college studies had been interrupted, to complete a baccalaureate.

In responding to the diverse schedules and interests of such adult students, the External Degree Program offers either a bachelor of science (BS) or a bachelor or arts (BA) in General Studies. Though no campus residency in La Grande is required for the degree, participants must have at least 45 of the 186 minimum quarter hours required for graduation awarded under the supervision of Eastern Oregon State College faculty. This definition of residency fostered the creation of multiple options that External Degree students have available to them in order to meet the 45-hour requirement and to complete the degree itself. (These options will 
be described later in the Defintion of Variables section of this chapter). Other requirements of the degree parallel the on-campus General Studies degree and/or institutional requirements for graduation. Specifically, of the 186 quarter hours required for graduation:

1. 70 hours must be at the upper-division level;

2. 50 must satisfy Eastern's general education (liberal arts) requirements with a minimum of 15 hours in each of 3 disciplines:

(a) humanities, (b) social science, and

(c) natural science;

3. a minimum cumulative grade point average (GPA) of a 2.0 must be achieved on all Eastern 0regon state College credits and on all credits, including transfer credits, appearing on the student's transcript;

4. up to 45 vocational-type credits that do not meet the normal mix of theory and application, including cooperative education (work placement credits) may be applied toward the degree;

5. up to 108 community college credits may apply toward the degree; this limit may be exceeded with approval of the Assistant Academic Dean if the excess credits fit into a planned degree program.

In addition, External Degree graduates, just like graduates in any other Eastern Oregon State College degree program, must pass the College's exit writing test, the Writing Proficiency Exam (WPE). No limitations are imposed on the number or type of credits that can be earned through different options made avaliable to students (e.g., Assessment of Prior Learning portfolio, Weekend College courses, Individualized Studies courses). To preserve the 
intent of a general studies degree, however, no more than 90 of the 186 credits required for graduation can be in the same discipline; and within these 90 hours, no more than 35 can be at the upper-division level.

\section{SAMPLE POPULATION}

Over 1,000 adults have been admitted to the Eastern Oregon State College External Degree Program since accurate program admissions records began in 1982. Using the Program's admissions list, students were identified as either (a) finishers, (known to have graduated through the External Degree Program by Fall Quarter 1988); (b) actives, those individuals whose Program advisors or transcripts reported either portfolio or course activity during 1988); or (c) leavers, those admitted prior to 1988 whose Program advisors and/or transcripts reported no progress made toward the degree for at least one calendar year. Once identified, actives were omitted and the remaining 241 finishers and 228 leavers constituted the sample population of this study.

\section{RESEARCH DESIGN}

The theoretical model on which the study was based came from a published researcher in the field of postsecondary attrition, Dr. John Bean, of the Department of Higher Education and Student Affairs at Indiana University in Bloomington. In collaboration with Barbara Metzner from Indiana University-Purdue University in Indianapolis, Dr. 
Bean developed the Conceptual Model of Non-Traditional

Student Attrition. The model, as shown below, was based on Bean and Metzner's review and interpretation of codifications, or "reviews of research that synthesize the findings of many empirical studies" (p. 493) from the fleld of postsecondary student attrition.

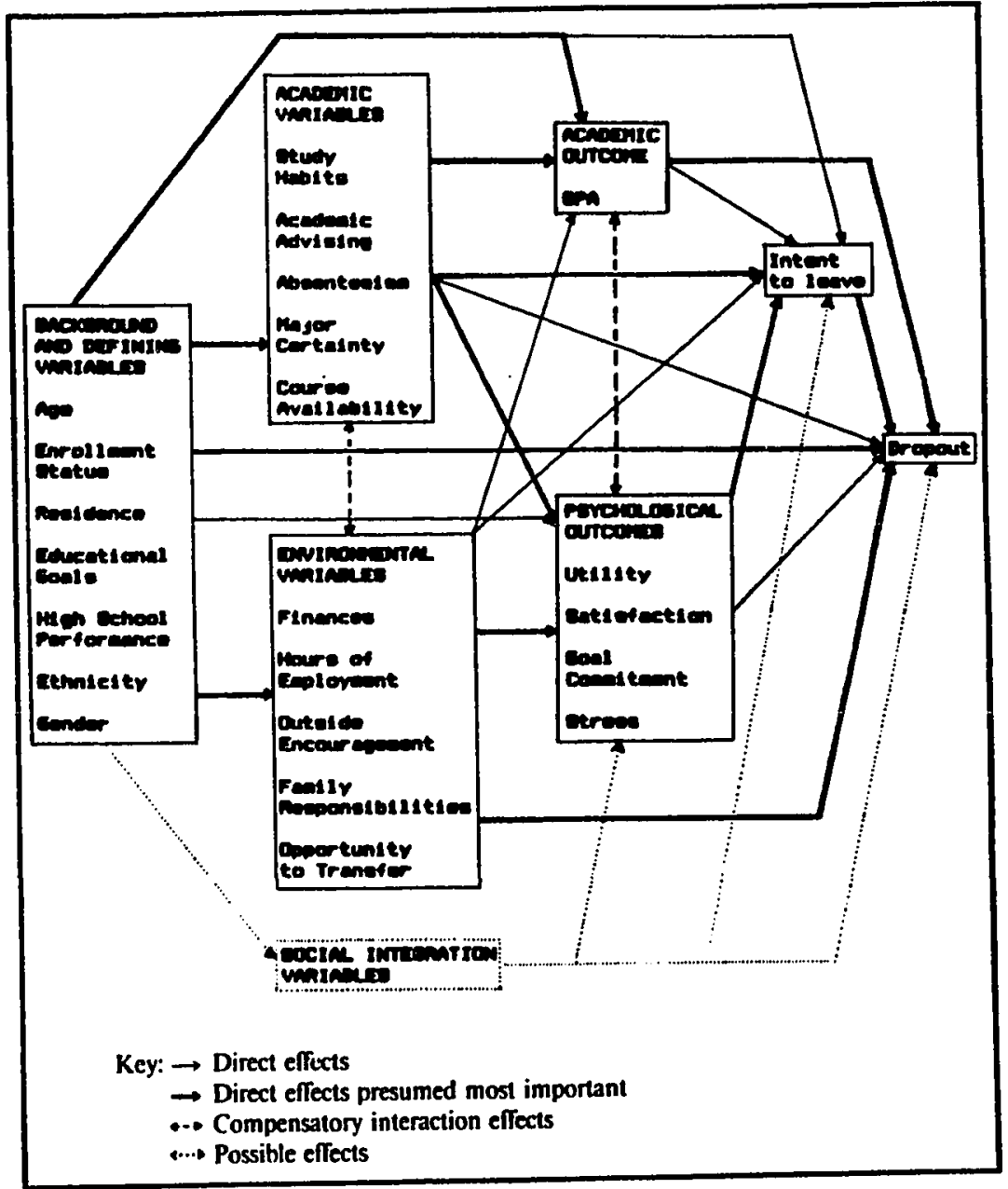

Figure 4. Non-Traditional Student Attrition

Source: Bean and Metzner, 1985 
To overcome or at least reduce several of the weaknesses that Terenzini (1980) identifies as characteristic of the autopsy/post hoc design (p. 56-58), several procedures or features were built in. As already mentioned, the research design was established from a theoretical base about non-traditional student attrition. In addition, the instrument used to collect the data was patterned after one made available by Dr. Bean which he had used in similar research. Some modifications were required in the instrument to reflect the particular situation in the Eastern Oregon State College External Degree Program.

Also, in order to improve the response rate of $15 \%-40 \%$ predicted by Terenzini (p. 63) for mailout surveys, Total Design Method procedures described by Dillman (1978, p. 160199) were followed.

$$
\text { As Terenzini (1982) notes: }
$$

The longitudinal design provides the most extensive planned control of the many variables thought to be potential influences on the persistence behavior of students. (p. 61) However, as Terenzini also comments (p. 61-62) a project staff, with advanced training and time, and sizable financial support are needrt to conduct longitudinal studies. Neither was present to assist with conducting the current study.

The cross-sectional design was considered for the present study. In such a design, data are obtained from a group of students at the same time and reviewed a 
relatively short time later when dropout or persistence can be determined. However, this type of design, notes Terenzini ( 1980 , p. 58-60), also needs a project staff with adequate time and money. In addition, the cross-sectional design did not seem as applicable to a non-traditional program like the External Degree. The nature of the External Degree Program options, especially the assessment of portfolio, creates instances where a 3-9 month period of no transcripting of credits may occur. It may be incorrect, therefore, as well as inappropriate, to identify students as leavers after only one or two quarters following admission to the Program just because no new credits had appeared on their transcripts. Many cross-sectional studies would assume that the no transcripting indicated leaving. However, in the External Degree Program, it may only mean that the student is working on portfolio essays, or weekend college and/or individualized studies assignments. Therefore, after considering all the advantages and disadvantages of the three types of designs, (autopsy, longitudinal, and cross-sectional), the autopsy design, with the previously described strengthening features built in, was selected for the present study.

To determine sample representativeness, the nonrespondents were compared on known defining and background variables (age, sex, GPA, and ethnicity) with the respondents. Similar comparisons between non-responding and responding finishers and leavers were also conducted. The 
results of these comparisons, as described in Chapter IV, affirmed representativeness of the respondents.

\section{LIMITATIONS}

Initial group differences in career and college aspirations or motives for participating in the External Degree Program could not be controlled in this autopsy design, and this aspect of the study is a recognized limitation.

Although generalizability to other populations and/or institutions may be limited, the findings of the present study still contribute to the larger body of knowledge about non-traditional students in general, a body of literature which is recognized as minimal (Knoell, cited in Bean and Metzner, 1985; Lenning, Beal, \& Sauer, 1980; Tinto, 1975, $1982 \mathrm{~b}$; and Zaccaria \& Creaser, cited in Bean and Metzner, 1985).

The wording of several survey questions may have limited the interpretation of their response categories. For example, questions 27-34 and 70-77 provided for an " $n / a$ " response. When comparisons between leavers and finishers were calculated, the " $n / a "$ responses were included. Therefore, the individuals for whom the questions applied were compared against those for whom they did not. The significance of differences which resulted may have been affected more by the number of " $n / a "$ responses (individuals for whom the questions did not apply) rather than by actual differences between/among students for whom they did. 
Differences in responses to a numbr of questions may have been affected by the amount of time the participants spent in the External Degree Program. For example, if leavers left before involving themselves in numerous options available for earning credits toward their degrees, then a larger number of "no" responses to questions asking whether or not they earned credits through certain types of options (questions 3-17), may be more an indication of shortness of time in the program rather than of failure to academically integrate. If finishers more frequently responded "yes" to such questions, then the interpretation of any significant difference between leavers and finishers is limited because the study did not control for length of time in the Program. VARIABLES FOR THE STUDY

Dependent Variables

There was one behavior, persistence, which was measured in this study. The behavior, however, could result in two choices: (1) leaving the Program or (2) finishing the Program.

A leaving student was defined as one who:

(1) had been admitted (beginning with 1982 records) to the Eastern Oregon State College External Degree Program, but

(2) had not shown any activity indicating progress toward finishing the Program for at least one year as verified by: 
(a) no activity on his/her transcript in the Eastern Oregon State College Registrar's office for at least one year (i.e., all of 1988 or more), or

(b) the student's faculty advisor verification that no portfolio essays were in progress.

A completing student was defined as one who:

(1) had been admitted (beginning with 1982 records) to the Eastern Oregon State College External Degree Program, and

(2) who had graduated within this Program with a General Studies Degree.

\section{Independent Variables}

The independent variables included in the present study were adopted from the Bean and Metzner model. As their model on page 73 shows, four variable categories were identified: (1) Defining; (2) Background; (3) Academic; and (4) Enviromental. Also, two outcome categories were included: (1) Psychological Outcomes and (2) Academic Outcomes. Although social integration variables are usually included in traditional student attrition research, Bean and Metzner's review of the literature regarding student attrition (p. 490) determined that while socialization was relatively unimportant for non-traditional students, the noncolleglate environment was. The importance of environmental variables is unique to this model:

Whereas most research has concentrated on what could push a student out of an institution, environmental variables indicate ways in which the student might be pulled from the institution. (Bean, 1982 , p. 28). 
Therefore, the underlying process of attrition on which the present study was based differs from what is frequently seen in attrition studies. For example, Bean and Metzner presume environmental variables to be more important for non-traditional students than academic variables, which lead them to the following hypotheses:

1. When academic and environmental variables are both good (i.e., favorable for persistence), students should remain in school.

2. When both are poor, students should stop/ dropout.

3. When academic variables are good, but environmental variabies are poor, the student should leave school because of the stronger influence of a distracting or unsupportive noncollegiate environment on stop/dropout decisions.

4. When environmental support is good, but academic support poor, students. would be expected to remain enrolled--the environmental support compensates for low scores on academic variables. (p. 491-492)

Defining Variables. Age, enrollment status, and residency were the three aspects of defining variables compared in the current study. These variables are included as reminders that they must be controlled or they would interact with other variables. For example, since the present study focuses only on non-traditional students, any significant impact on attrition of age within this group would need to be assessed. Attrition studies that attempted to link age with persist-withdrawal decisions have produced conflicting 
results. The effect of age on withdrawal appears, say Bean and Metzner, to be indirectly applied through jobs, family responsibilities, and absenteeism associated with work and family expectations. Likewise, Lenning (1982) reported conflicting results when attempting to link age with dropout decisions because "older students are rusty on academics, but are more highly motivated" ( $p .35$ ). To determine any age-related differences of External Degree leavers and finishers, students were asked:

"What age interval best describes you while you were participating in the External Degree Program?"

Response options included: under $23 ; 24-35 ; 36-$ $44 ; 45-54 ; 55-64$; over 64 years.

(The current age of each respondent was also obtained from the Eastern Oregon State College student data base.)

The codifications Bean and Metzrer found regarding enrollment status of full-time vs. part-time students consistently agreed that attrition rates for part-time students were higher than for full-time students. In the Bean and Metzner model, this variable referred to the number of academic credits for which a student was enrolled during the term when the initial assessment occurred. However, because most External Degree students attend a four-credit-hour portfolio development workshop and then spend a minimum of two terms developing a portfolio of prior learning, their transcripts frequently show two or three quarters when no additional credit is recorded. The enrollment status 
variable was modified in the present study, therefore, to refer to (1) the subject's grade level upon entrance to the External Degree; and (2) for leavers, their progress level prior to leaving the Program; and for finishers, the average number of credits per term they completed as they progressed toward graduation. Respondents were asked two questions:

(1) Which term best describes the grade level at which you entered the External Degree Program?

Response options included: Freshman, $0-44$ crs.; Sophomore, 45-89 crs.; Junior, 90-134 crs.; or Senior, 135 crs. or more.

(2) Leavers: Which statement best describes your progress in the External Degree Program up until the time you stopped progressing toward graduation?

Response options included: basically 0 , I never realiy got started; up to about 25 credits; between $25-75$ credits; between 76125 credits; over 125 credits, or:

Finishers: Which statement best describes your progress toward graduation in the External Degree Program?

Response options included: less than 6 crs. per term; between 6-8 credits per term; between 9-11 credits per term; or at least 12 credits per term.

In the Bean and Metzner model, residence was defined as the difference between commuting to campus and residing on/near campus. Since the External Degree Program is designed for commuter students who, for the most part, live with other family members away from the campus grounds, this variable was modified in the present study to differentiate between living in or out of oregon, near or away froma 
college facility, and living in a rural or an urban area. A question about differences in perception of barriers between rural and urban External Degree participants was also included in this variable. The effect of residence on leavers/finishers was assessed by asking the following questions:

While you were participating in the External Degree Program, were you a resident of Oregon all or most of the time?

Yes/No

Was there, while you were participating in the Eastern Oregon State College External Degree Program, a regional outreach-type center provided by Eastern or another community or fouryear college/university near (within 10 miles) of your home?

Yes/No

For the most part, what kind of community did you live in while participating in the External Degree Program?

Response options included: Rural area or farm, 15t miles from city; Town or small city under 50,000; Medium-sized city (50,000-250,000); Suburban area near large city; Large city over 250,000

How many miles away is the home you lived in while participating in the External Degree Program from the La Grande campus of Eastern oregon State College?

Response options included: $0-49$ miles (considered within one hour's drive and includes two counties, Union and Baker, within the Eastern regional service region); 50-149 miles (includes all or parts of seven other regional counties, Wallowa, Malheur, Umatilla, Grant, Morrow, Gilliam and Wheeler as well as S.E. Washington); 150-249 miles (includes more remote regional service area (Harney County) where regular commuting is less likely); 250499 miles (inciudes Willamette Valley ares and beyond); 500 miles or more (would include most out-of-state participants) 
How many miles away is the home you lived in while participating in the External Degree Program from any community college or four-year institution?

Response options included: $0-49$ miles; 50149 miles; $150-249$ miles; $250-499$ miles; 500 miles or more

What was the most difficult barrier you faced to participating in the External Degree?

Response options included: lack of adequate finances; too great a distance from college(s); not enough time to commit to school assignments; lack of encouragement from people in my life; unexpected personal/family crisis; other $(\exp 1 \mathrm{ain})$.

Background Variables. Just as in attrition studies of traditional students (Bean, 1982; Pascarella, 1980; Spady, 1970; and Tinto, 1975), background variables (educational goals, high school performance, ethnictty, family educational levels, and gender) were included in the present study because "past behavior is expected to predict future behavior" (Bentler \& Speckart, cited in Bean and Metzner, p. 492 ).

Background variables are expected to affect how non-traditional students interact with the institution and thus must be taken into account in modeling the attrition process. (Bean \& Metzner, p. 493)

The link between educational goals and persist/dropout decisions produced conflicting findings in the codifications reviewed by Bean \& Metzner, although no research findings regarding dropout were based on educational goals of parttime students. Any impact of educational goals on 
differences between leavers and finishers in the present

study was assessed by asking the following question:

What is the highest degree you expected to eventually receive when you returned to college in the External Degree Program?

Response options included: did not expect to receive a degree; associate degree; baccalaureate degree; graduate degree.

Within background variables, only high school

performance was consistently linked with persist/dropout decisions in the codifications studied by Bean and Metzner. Lenning (1982) reported that even though high school achievement was the highest predictor of college success, it still only accounted for $10 \%$ of the variance in persistence/ withdrawal decisions. To assess the difference that high school performance may have had on leave/finish behavior of External Degree students, the following questions were asked :

What was your high school grade point average (on a 4-point scale where $A=4, B=3, C=2, D-1$ )?

Response options included: $3.76-4.00$; 3.50$3.75 ; 3.00-3.49 ; 2.50-2.99 ; 2.00-2.49 ; 1.50-$ $1.99 ; 1.00-1.49 ; 0.00-0.99 ; N / A$, received a General Education Diploma, (GED).

What ranking in your high school graduating class best describes you?

Response options included: upper $20 \%$; lower $20 \%$; in the middle; $n / a$, received a General Education Diploma (GED).

Although Bean and Metzner also recommend determining differences due to standardized test scores, the External Degree admission procedures do not require such tests. Such 
data, even if it were available from the high school records of the External Degree students, would be difficult to obtain because of the time that has elapsed for most External Degree participants between high school graduation and the present. Therefore, although the standardized test data were not obtained from the participants, they were asked:

Do you think taking any standardized tests should have been required of you while participating in the External Degree? Yes / No

No differences in the codifications reviewed by Bean \& Metzner between persisters and dropouts were attributed strictly to ethnicity. However, because such data were available on the Eastern Oregon State College student data base, the respondents' race was included in the comparisons. specifically, respondents were coded as:

1=Black, non-Hispanic; 2=Indian/Alaskan; $3=$ Asian/Pacific Islander; 4=Hispanic; 5=White, non-Hispanic; $6=$ International; $7=$ No Response

The codifications reviewed by Bean \& Metzner showed that at commuter-oriented, four-year institutions, parents' education did not significantly affect persist/dropout decisions. However, because the present study was conducted with older students, many of whom were expected to be married, External Degree participants were asked about the educational levels of their spouses, as well as their mothers and fathers.

Indicate the number that corresponds to the highest educational level of (1) your mother;

(2) your father; (3) your spouse. 
Response options included: less than high school; high school/GED; post high school, non-college vocational school training; some college; college degree.

Although gender was not shown to directly affect persist/dropout behaviors in the Bean and Metzner codifications, gender differences were included in the present study to determine if the indirect effect on dropout that Bean and Metzner noted between gender and family responsibilities was also evident in the External Degree student population studied. For example, Lenning (1982) reported that married men had higher completion rates than did unmarried men, but married women had lower than unmarried women. Therefore, students were asked if they weremale or female, and in the environmental variable section, if they were/were not married.

Academic Variables. "Academic variables represent the primary way in which non-traditional students interact with the institution" (Bean \& Metzner, p. 492). According to Tinto's (1975) model, the more a student interacts with the institution, the more likely the student will be committed to persisting there. Academic variables, say Bean and Metzner, are expected to have an indirect effect on the dropout/persist behavior of non-traditional students. Five academic variables were included in this category: study skills/habits, academic advising; major certainty; course avallability; and program involvement. Although the Bean and Metzner model also includes absenteeism as an academic 
variable, this factor was eliminated from the present study. No codifications were found in the Bean and Metzner literature review that assessed the effect of absenteeism on non-traditional student attrition. And, since the External Degree Program does not require on-campus residency and students in the Program do not all participate in traditional-type courses where daily/bi-weekly attendance is the norm, absenteeism was not an appropriate variable to include in the present study. The codifications that Bean and Metzner studied regarding the effect of study skills/habits on the dropout/ persist behavior of non-traditional students did not provide any findings from studies done with older students. To attempt to assess the impact of External Degree students' perceptions of their study skills/habits on their complete/ dropout behavior, students were asked the following questions:

While participating in the EOSC External Degree Program,

...did you usually complete your assignments on time?

$$
\text { Yes/No }
$$

To what extent:

Were you able to find time to do assignments?

Did you procrastinate with doing your work?

Were you confident with your study skills?

With your reading ability? Your writing ability? Your verbal expression ability? Your ability to cope with stress? With challenging academics? 
Response options included: not at all; to a small extent; to some extent; to a great extent; to a very great extent.

The amount of time spent in academic advising and the student's satisfaction with the quality of advising service did not show significant differences for non-traditional students at commuter-oriented four-year institutions in the codifications reviewed by Bean and Metzner. Because of Eastern Oregon State College's emphasis on good, dependable, and regular academic advising, however, the following questions related to this variable were included in the present study •

Were degree requirements made clear to you by your advisor? Options: Yes/No

Should La Grande campus meetings between you and your advisor have been required?

Options: Yes/No

To what extent were you satisfied with the amount of academic advising you received? Options: not at all; small; some; great; very great extent

To what extent were you satisfied with the quality of academic advising you received? Options: not at al1; sma11; some; great; very great extent

The codifications reviewed by Bean and Metzner showed a strong positive correlation at commuter-oriented four-year institutions of ajor certainty and persistence. Even though the External Degree, a BS/BA In General Studies, does not require a major, participants are allowed to have a focus to theirdegree with 90 of the 186 credits in the same discipline. For this study, therefore, subjects were asked: 
Did you focus on any particular subject area while accumulating credits toward your degree? Options: Yes/No

Another variable in the academic category is course avalability. Although the codifications studied by Bean and Metzner showed this to be an important variable:

It was nevertheless, not significantly related to differences between dropouts and persisters at commuter-oriented four-year schools. (p. 502)

However, because one hypothesis of the present study was that students who live in areas where more options for completing their college degrees are available to them will be more likely to graduate than will those who live where such options are not so available, this variable was included in the present study. For example, two questions related to this variable were asked:

How often were courses that you desired to take in order to complete your degree offered to you?

Were the courses you wanted to take offered at convenient times for you?

Response options included: does not apply; not at al1; some of the time; most of the time; all of the time.

A final academic variable of interest and possible difference between finishers and leavers in the External Degree Program was the number and type of program options in which the students participated. One hypothesis of this study was that students who spent some time on the La Grande campus taking classes were more likely to complete the External Degree than were those who attempted to satisfy all 
degree requirements by correspondence formats or through other at-home opportunities. Therefore, for this study, students were asked to respond "yes" or "no" about their participation in a number of program options in which they may have participated while enrolled in the External Degree:

I. Correspondence/Regional Options

A. Assessment of Prior Learning Portfolio Workshop: a credit-bearing, upperdivision hour class in which External Degree students who show potential for earning at least 15 credits through documented knowledge obtained outside the traditional classroom, learn how to develop the portfolio in which such learning is displayed. Workshops are held in various locations throughout the State. In the early years of the program, class could also be taken by correspondence.

B. Portfolio Credit: a collection of student-written essays and supporting documentation that attempts to translate experiential learning into academic subject modules that campus faculty then evaluate for college credit.

C. Individualized Studies Program: a collection of courses developed by Eastern Oregon State College faculty that may be done through the mail, using a combination of print, audio, and/or video components.

D. Cooperative Education Program: a mechanism whereby students earn college credit for current, on-the-job work experience where opportunities for new learning can be verified through jointly developed learning objectives by the student, the employer, and the academic advisor. The work placement may be in the student's home community or elsewhere. Faculty visits to verify progress on the learning objectives occur during the 10-week placement. 
E. Course Challenge Options

1. College Level Examination Program (CLEP): an opportunity for students to receive college credit for obtaining satisfactory scores on a variety of general and specific subject area standardized exams developed by the American College Testing Program in Princeton, New Jersey. Paperwork may be filed through the mall and exams proctored in the student's home community.

2. Eastern Oregon State College: any course in the curriculum at EOSC may be challenged for credit by an External Degree student following consultation with the appropriate course instructor. Paperwork may be filed through the mail and exams proctored in the student's home community.

F. Military Evaluation: training obtained while in any branch of the J.S. Armed Forces that is documented in the American Council on Education credit equivalencies handbook may be petitioned for transfer credit at Eastern Oregon State College. The paperwork may be completed at one's home and mailed to the EOSC Registrat's office for processing.

G. Regional Weekend College Program: a collection of modularized ( $1-2$ credit) liberal arts courses offered on a oneweekend format with substantial postweekend assignments that students then complete at home and mail in to instructors. Between 1982-1985, several of these courses were offered in locations other than La Grande where clusters of External Degree students lived; currently, all are offered in just La Grande or Portland. Credit may be applied toward Eastern's general education requirements in humanities, social sciences, or natural sciences. 
H. Regional Center outreach classes: courses offered at any one of six locations (Burns, Baker, Enterprise, John Day, Ontario, or Pendleton) where Eastern has a designated site for delivery of courses.

I. Transfer Courses: credits completed at another institution and then transferred to Eastern for application toward External Degree requirements.

J. Other: some we11-known agencies (American Institute of Banking, National Management Association, Board of Police Standards and Training for example) have credit equivalencies recommended by the American Council of Education in a handbook similar to the one used for military evaluations. Though usually included in a portfollo of prior learning, some External Degree students have recelved direct transfer credit from an evaluation in the EOSC Registrar's office for such training.

II. La Grande Campus Residency Options

A. Weekend College Program: same description as above, but students come to the La Grande campus to attend class.

B. Regular courses/daytime or eventing

c. Portfolio Workshop: same description as above, but students come to the La Grande campus to attend workshop.

Environmental variables. The Bean and Metzner (1985)

model of non-traditional student attrition predicts that environmental variables will have a direct effect on dropout decisions. Finances, hours of employment, outside encouragement, family responsibilities, and opportunities to transfer are the variables categorized as environmental.

The codiffcations Bean and Metzner reviewed Involving finances and dropout indicated a positive relationship; that 


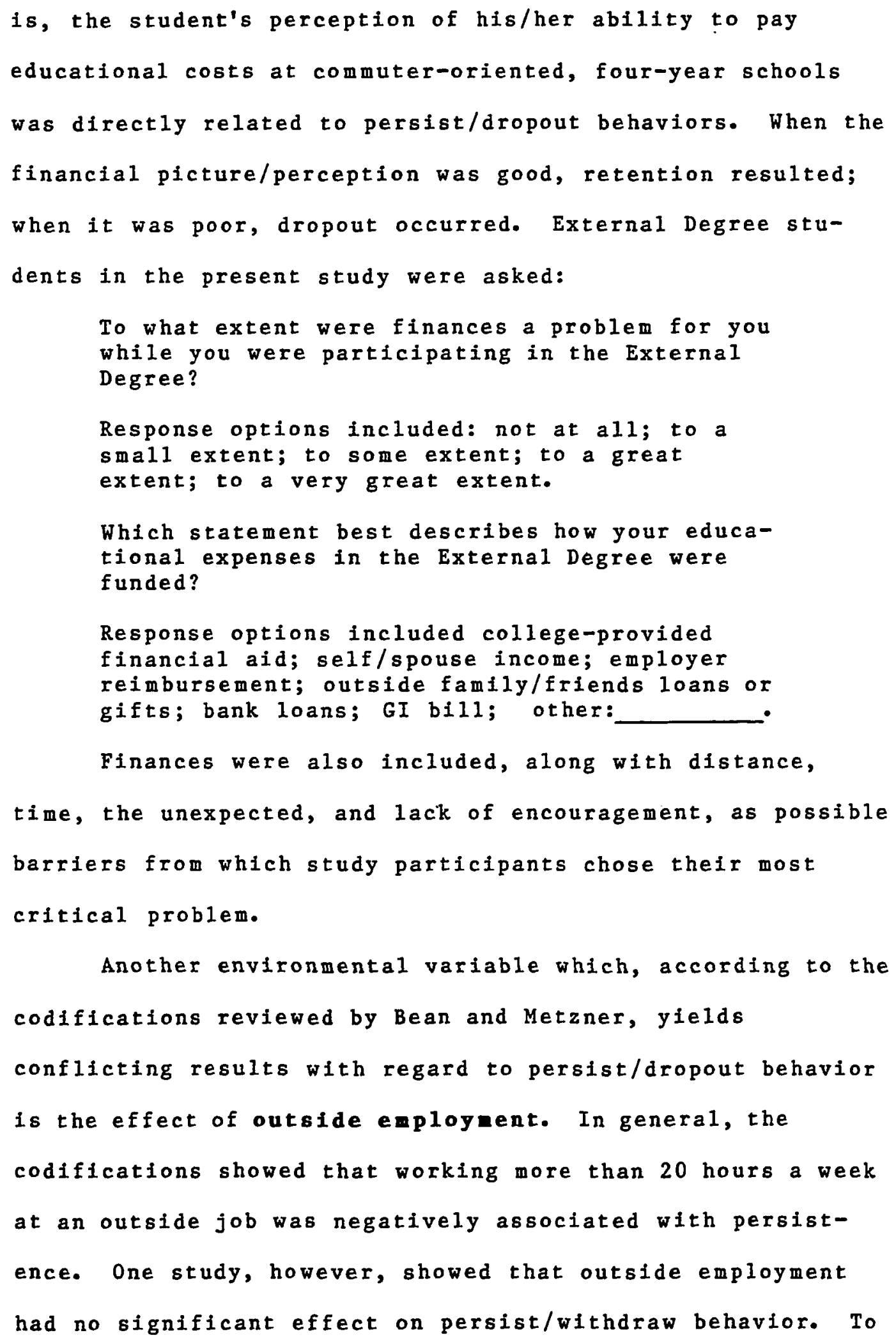


assess any impact on the leaving/finishing behavior of

External Degree students, they were asked:

How many hours per week were you employed outside your home while participating in the

External Degree Program?

Response options included $0,1-10,11-20$, $21-30 ; 31-40$; over 40 .

The presence/effect of outside encouragenent on a student's dropout/completion behavior has not, according to Bean and Metzner, resulted in any codifications for nontraditional students attending commuter-oriented, four-year schools. Outside encouragement is defined as the extent of encouragement to remain at a college that the student recelves from significant others, not employed by the college. External Degree students were asked:

To what extent, did your spouse/significant other encourage the completion of your degree? Your parents? Your friends? Your employer? Your children? Your siblings?

Response options included: not applicable, not at all, to a small extent, to some extent, to a great extent, to a very great extent.

The extent to which fantiy responsibilities significantly affect a non-traditional student's dropout/complete behavior was not represented in the codifications reviewed by Bean and Metzner. However, since their conceptual model of non-traditional student attrition shows a direct effect on dropout of all environmental variables, the extent to which family responsibilities may have affected leaving/ finfshing behavior in the present study was included. For example, External Degree students were asked: 
What was your marital status while participating in the External Degree?

Response options included:

Single; Married; Separated; Divorced; Widowed

How many children did you have living at home while participating in the Program?

Response options included: $0,1,2,3,4+$

A student's perception of his/her ability to transfer to another degree program has produced conflicting findings with regard to dropout/persist behaviors in the codifications reviewed by Bean and Metzner. Whereas some studies show opportunities to transfer positively linked to persistence, others show such perception positively linked to dropout behaviors. Since the Eastern Oregon State College External Degree Program does not require any La Grande campus residency, the need to transfer when a student moves to another community is unnecessary. However, because the Eastern Oregon External Degree Program isn't the only one of its kind (two private institutions, Marylhurst and Linfield in the Willamette Valley of Oregon, for example, provide somewhat similar programs), dropout/complete behavior of the Eastern External Degree student might have been linked to the student's perception of the likelihood of transfer.

Therefore, External Degree students were asked:

While participating in the Eastern oregon State College External Degree, were you aware of any other External Degree type programs that you could have enrolled in? Options: Yes/No

Did you consider transferring to another institution prior to completing/withdrawing from the Eastern External Degree? Yes/No 
The last variable in the Bean and Metzner (1985) model is social integration. This variable was not included in the present study because (1) social integration has not been found to be significantly related to dropout of nontraditional students (Bean \& Metzner, p. 520), and (2) the nature of the External Degree Program does not provide structured opportunities for students to become socially integrated.

Academic outcomes, as measured in this study by the External Degree students' college GPA, have been shown to be consistent and powerful predictors of persistence in numerous studies at various institutions. But, as Bean \& Metzner (1985, p. 521) point out, "College grade average may be relatively less predictive of persistence for part-time, older commuters than for their more traditional peers." With the Eastern Oregon State College student data base as a source, GPAs were obtained on 207 of the 316 respondents. Prior to 1982 , however, transfer GPAs were merged into an EOSC GPA to determine the cumulative GPA reported on the student data base. After 1982, only the GPA earned on EOSC courses was reported for transfer students on the student data base. Therefore, for non-traditional students who did poorly in their younger years and transferred into Eastern's External Degree prior to 1982 , the reported GPA is especially low; transfers after 1982 with the same background started over on a GPA and theirs, therefore, may be much higher relative to their pre-1982 classmates. 
Psychological outcomes, defined as utility, satisfaction, goal commitment, and stress, are located in the Bean and Metzner Conceptual Model of Non-Traditional Student Attrition where they are primarily affected by the academic and environmental variables. Their effect on persist/ dropout decisions of non-traditional students is indirect, acting through "intent to leave" intentions (p. 522).

Utility is defined as the student's perception of the usefulness of the college degree in obtaining/maintaining employment and of developing as a person. Research on the practical job application of persisting in college shows a positive link with completing behavior. No research on growth in personal development of non-traditionals was reported in the codifications studied by Bean and Metzner. External Degree students were asked:

Which factor below best describes the reason you enrolled in the External Degree?

Response options included: Required in my career; to improve myself; to get a job; to get a better job; for the personal challenge; other -

How much impact did participating in the External Degree have on knowing yourself; using interpersonal skills; seeing alternative points of view?

Response options included: little/none; some; quite a bit; a great deal; a very great deal

Another psychological outcome, satisfaction, was defined as the degree to which a student enjoyed the role of being a student and reported a lack of boredom with college courses. For commuter-oriented, four-year institutions, the 
codifications reviewed by Bean and Metzner showed a postive correlation between satisfaction and persistence. For purposes of the present study, External Degree students were asked :

Did you find the academic expectations of the External Degree more difficult than you liked? Options: Yes/No

Do you think taking standardized tests should have been required? Options: Yes/No

Was feedback on your assignments from your course instructors timely? Options: Yes/No

Was it dificult for you to ask your advisor for help when you needed it? Your instructors? options: not at all; small extent; some extent; great extent; very great extent

Do you feel the rules/procedures of the Program inhibited your progress toward completing the degree? Options: not at all; small extent; some extent; great extent; very great extent

One open-ended question related to this variable was also asked: If you had it to do all over again, what would you do differently "a second time around" in starting or returning to college in order to complete your degree?

Goal comitment is one psychological outcome that is difficult to validate in autopsy designs. Although the goal may have seemed very important at the time, the memory may fade after awhile. When asked in a survey several years following either graduation/dropout, the intensity of the commitment to the goal may be different. Especially fordropouts, it may be easier to cope with the reality of withdrawal by describing the goal of a college 
degree as unimportant. For graduates, completion of the degree may have opened doors that, at the time of participation, they were unaware of and may now be unable to be objective about. For the present study, therefore, rather than asking participants how important it was for them to complete their programs, they were asked:

Was a college degree required for continuation in your chosen career? Options: Yes/No

Stress is another psychological outcome in the Bean and Metzner model. It is defined as:

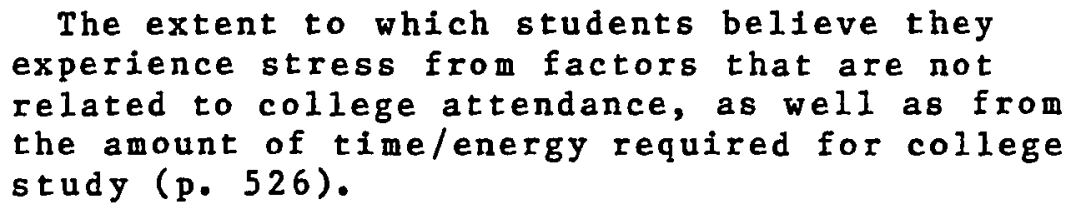

Bean and Metzner concluded that "outside stress

factors appeared with sufficient frequency to warrant a conclusion they may significantly affect commuter student attrition" (p. 526). In addition, research at a commuteroriented four-year institution as reported by Louis, (cited in Bean and Metzner, p. 526) indicated that "lack of time for school was one of the most frequent reasons that students reported for withdrawing at the end of a semester." Therefore, in the present study, External Degree students were asked: Which statement best describes your response to the amount of time that was required of you on a weekly basis to participate in the External Degree. Options: More time than I could possibly give; More time than I expected, but I found it; About the amount I had expected/planned for; Less time than expected; Hardly any time at all 
Also, with regard to the time needed for the External Degree, the present study sought to find if students had conscientiously adjusted their life styles/habits in order to accommodate the added demands of participating in a college degree program. Therefore, External Degree students were asked:

Did you cut back on any of the following activities while participating in the External Degree: paid employment; social activities with friends; alone time with spouse/ significant other; housework or home maintenance; involvement in children's activities; in civic responsibilities

Response options included: Yes/No/Not Applicable

The last step in the Bean and Metzner conceptual model of non-traditional student attrition is called "intent to leave, the best predictor of actual dropout" (p. 527). Although Bean and Metzner did not find any research that related intent to leave and attrition of older or part-time students, questions were asked of the External Degree students in the present study because "prior research has consistently shown intent to leave to be an extremely strong predictor of dropout" (p. 528) in other institutional settings. Students in the present study, therefore, were asked :

Did you, at any time while you were participating in the External Degree Program, discuss leaving the Program with anyone other than EOSC personnel? Options: Yes/No

Two additional perception of quality questions were asked of the participants: 
All in all, how good an education do you think you received through Eastern Oregon State?

Options included: unable to judge; rather poor; fair; good; very good; excellent

In your opinion, how high is the quality of Eastern oregon State College?

Options included: very low; fairly low; neither high nor low; fairly high; very high

DATA-GATHERING PROCEDURES AND INSTRUMENTS

\section{Identification of Population to Study}

A 1ist of allstudents admitted to the Eastern Oregon State College External Degree Program since accurate Program admissions records began in 1982 was obtained from the External Degree Program secretary. In consultation with Program advisors, leavers and finishers were identified "l" $n r$ "2," respectively, using the definitions given on pages 77-78 of this report. Transcripts in the Eastern Oregon State College registrar's office were used to verify the leaver/finisher classifications.

\section{Distribution of Survey}

Procedures explained in Dillman (1978) regarding the total design method for implementing mail-out surveys served as a guide for distribution of the surveys to the External Degree subjects. In order to enhance the return rate from study participants, Dillman's theme of personalization was followed. Specifically: 
(1) each envelope was individually stamped (first-class) and addressed to each of the 469 subjects; likewise the author's return address was also individually typed on each envelope;

(2) although the body of a cover letter which accompanied each survey was xeroxed, the date and inside address for each letter was individually added at the typewriter; also, each letter was individually signed by the author; and

(3) each envelope contained a stamped, individually typed return envelope for ease in mailing back the completed survey.

Regarding the purpose of the cover letter, Dillman

says:

The cover letter communicates the appeal to the study participants and emphasizes a reasonable explanation of the subject of the study, its benefit to a group with which the recipient identifies, and the individual importance of the respondent to the study's success. (p. 163)

Copies of the cover letters accompanying the leavers' and finishers' surveys are found in Appendix $A$ of this report.

Following a pilot test of the survey with several

External Degree participants (including finishers, leavers, and actives), the revised survey was printed on blue paper for finishers, yellow for leavers. The color coding aided in processing the completed surveys. (Copies are found in the Appendix A.) On Monday, March 13, 1989, the envelopes containing a cover letter, survey, return envelope, and author's business card were mailed to the 469 subjects. Exactly one week later, on Monday, March 20, 1989, a postcard follow-up was sent to all recipients of the first 
mailing. Following Dillman's personalization theme, these cards were also individually addressed and signed by the author. This postcard (copy in Appendix A) was witten as a thank you to those who had already returned their questionnaires and as a reminder to those who had not.

A second follow-up (Appendix A) was mailed to nonrespondents on April 3, 1989, exactly three weeks after the original mailout. It contained another cover letter (again individually addressed, dated, and signed) that informed subjects that their questionnaire had not yet been received. The letter included a restatement of the basic appeal from the original cover letter, a replacement questionnaire, and another first-class stamped, addressed return envelope.

\section{Receipt of Completed Surveys}

of the 469 surveys distributed, 402 or $85 \%$ were either completed and returned by study participants (316;67\%) or undeliverable due to out-of-date addresses, death, or general unavailability of subjects due to overseas travel, etc. $(86 ; 18 \%)$. Of the 383 deliverable surveys, the following return was obtained:

112 Returned of 159 Surveys to Leavers: $70 \%$ $\underline{204} " \underline{224} "$ "Finishers: $91 \%$ 316 Total of 383 Deliverable Surveys: $82.5 \%$

A geographic breakdown of these 316 respondents fo11ows. 


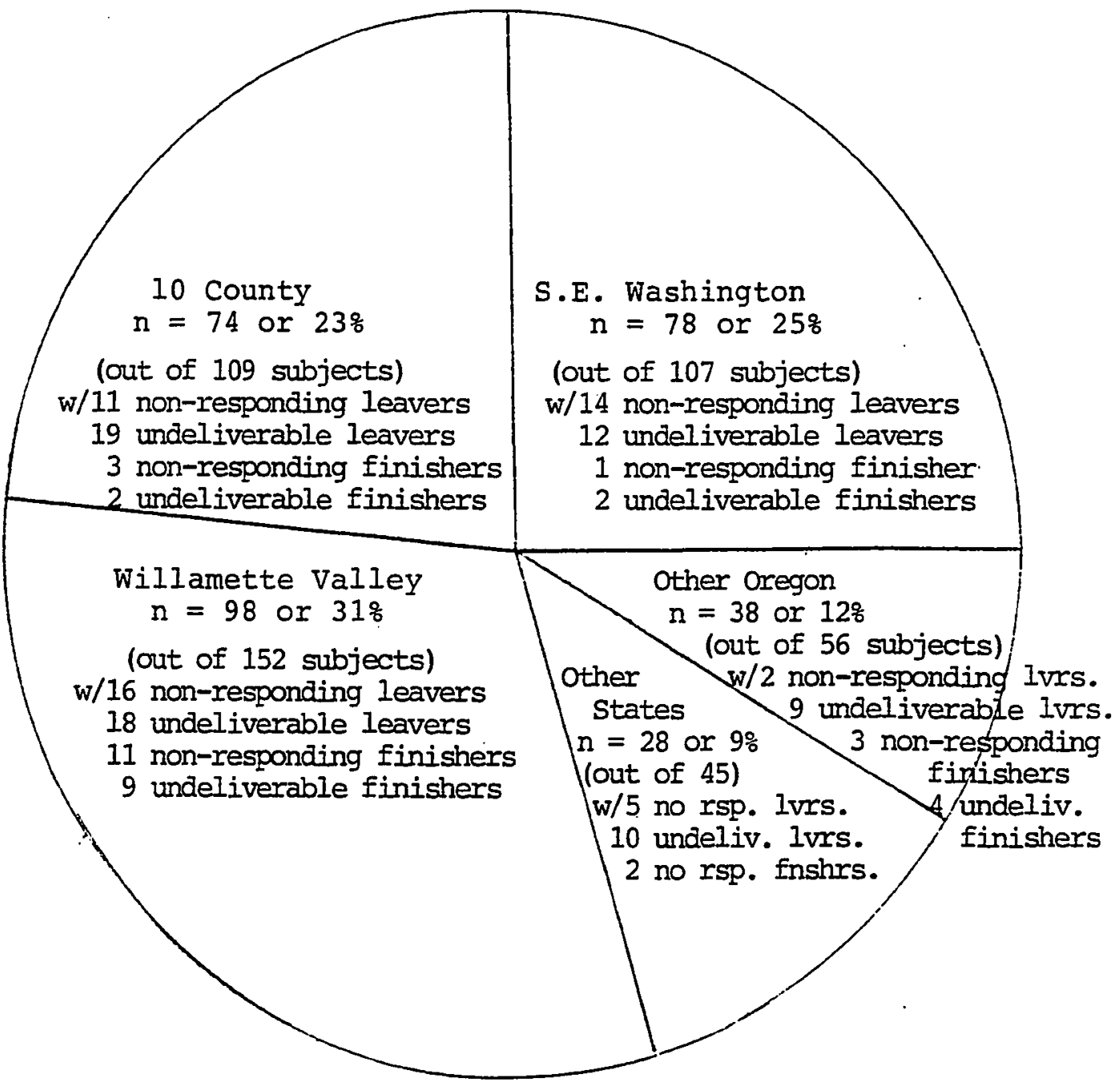

Figure 5. Geographic Distribution of 316 Respondents Definition of Categories

10 County: $\quad$ Eastern 408 of Oregon, including Baker, Gilliam, Grant, Harney, Malheur, Morrow, Umatilla, Union, Wallowa, and Wheeler counties. Designated by Oregon Legislature as "EOSC Service Region"

S.E. Washington: Close geographic proximity to La Grande, Oregon, including Tri-Cities area (Kennewick/Pasco/Richland), Prosser and Walla-Walla, Washington

Willamette Valley: Western Oregon/Southwestern Washington "corridor," including area bordered on south by Eugene, Oregon, and on north by Vancouver, Washington

Other Oregon: Other Oregon points not included in above categories Other States: Other points not included in above categories 


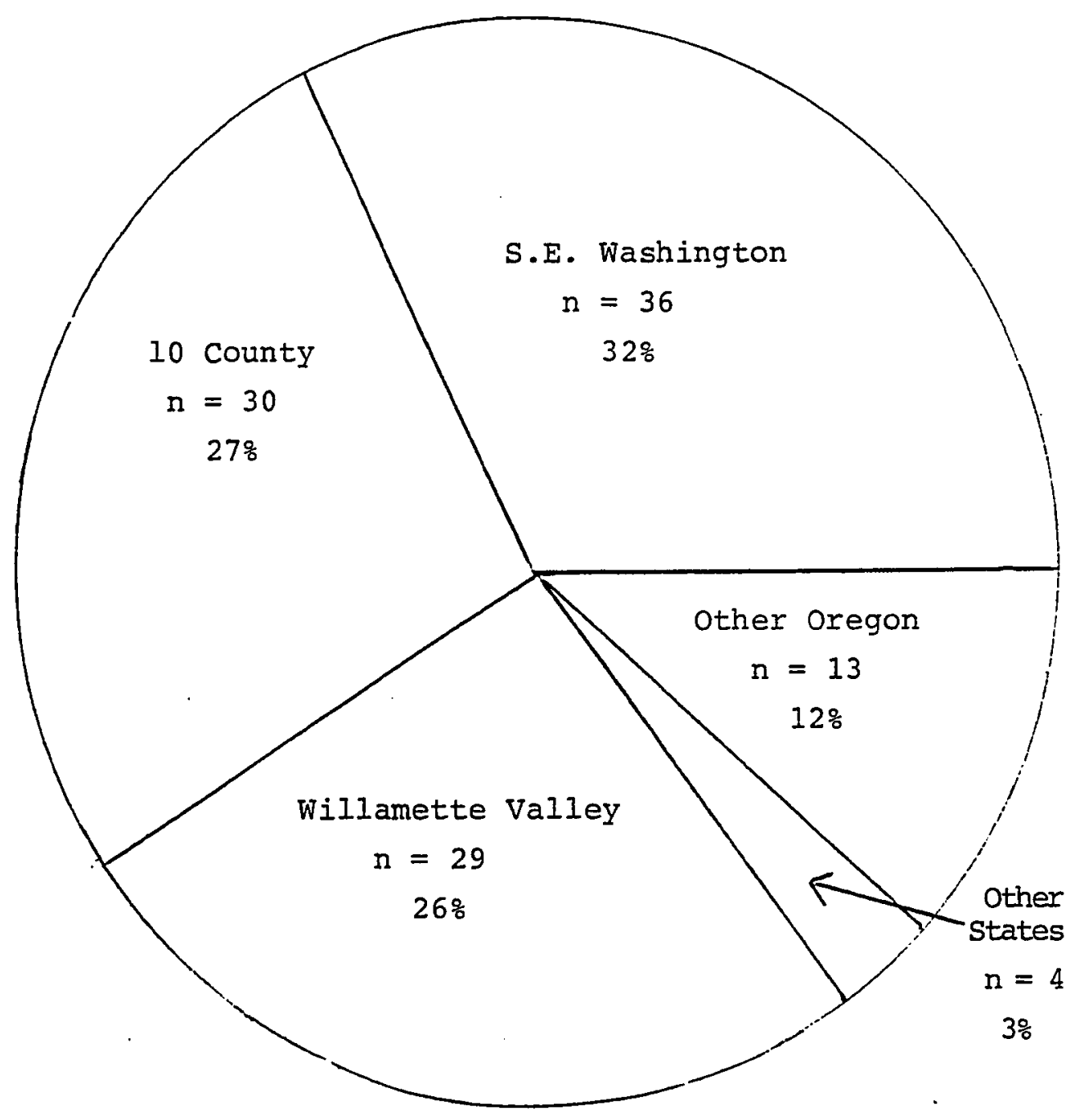

Figure 6. Geographic Distribution of 112 Responding Leavers Definition of Categories

10 county:

Eastern $40 \%$ of Oregon, including Baker, Gilliam, Grant, Harney, Malheur, Morrow, Umatilla, Union, Wallowa, and Wheeler counties. Designated by Oregon Legislature as "FOSC Service Region"

S.E. Washington: Close geographic proximity to La Grande, Oregon, including Tri-Cities area (Kennewick/Pasco/Richland), Prosser and Walla-Walla, Washington

Willamette Valley: Western Oregon/Southwestern Washington "corridor," including area bordered on south by Eugene, Oregon, and on north by Vancouver, Washington

Other Oregon: Other Oregon points not included in above categories Other States: Other points not included in above categories 


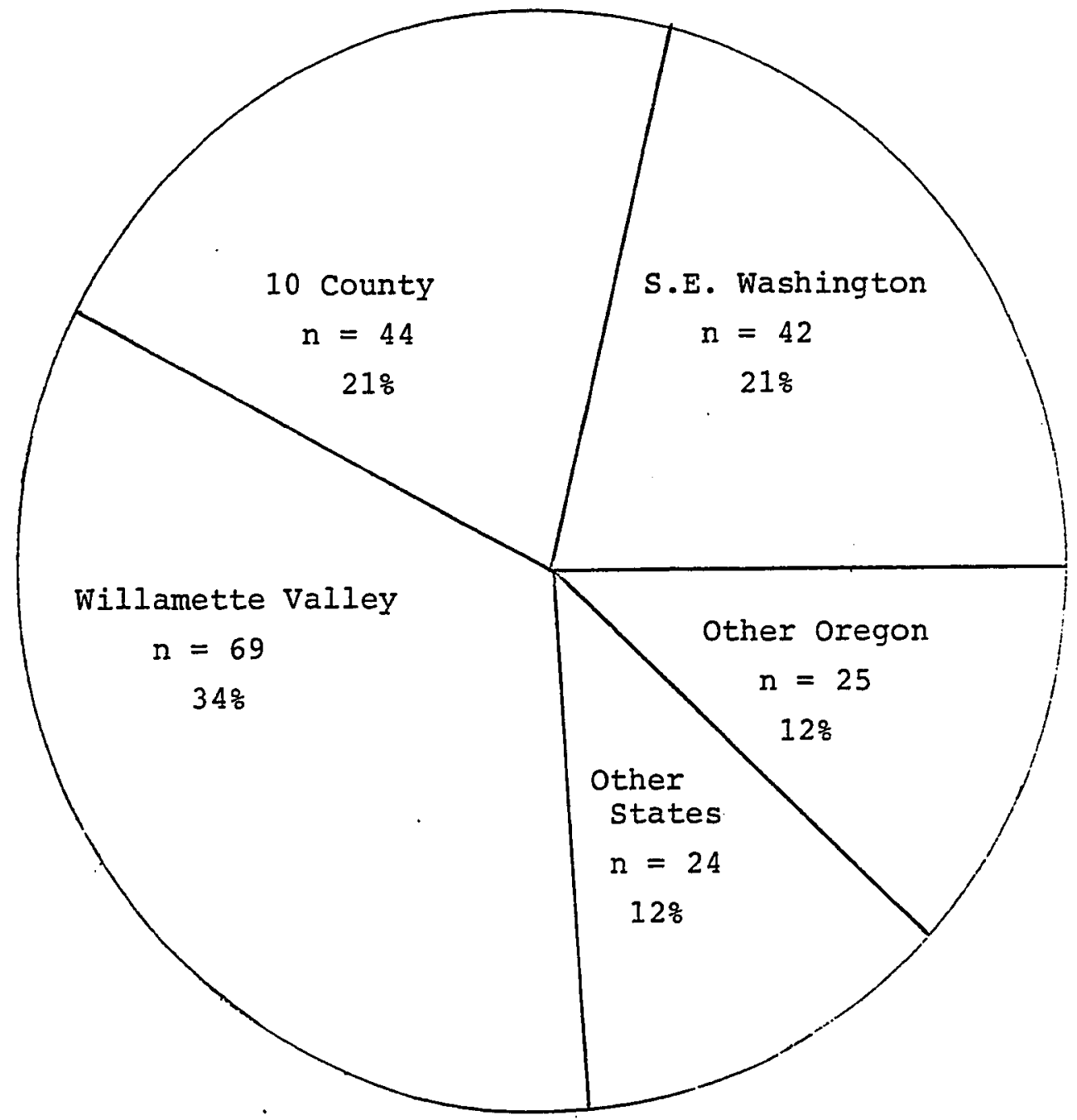

Figure 7. Geographic Distribution of 204 Responding Finishers Definition of Categories

10 county:

Eastern $40 \%$ of Oregon, including Baker, Gilliam, Grant, Harney, Malheur, Morrow, Umatilla, Union, Wallowa, and Wheeler counties. Designated by Oregon Iegislature as "EOSC Service Region"

S.E. Washington: Close geographic proximity to La Grande, Oregon, including Tri-Cities area (Kennewick/Pasco/Richland), Prosser and Walla-Walla, Washington

Willamette Valley: Western Oregon/Southwestern Washington "corridor," including area bordered on south by Eugene, Oregon, and on north by Vancouver, Washington

Other Oregon: other Oregon points not included in above categories Other States: other points not included in above categories 
Instrument

The survey instrument used in this study to differentiate finishers from leavers was adapted from (1) the Student Entry-Level Questionnaire (SEL-Q), copyright 1983 by John P. Bean; (2) and the Student Attitude Questionnaire (SAQ), copyright 1983 by John P. Bean. Permission was granted in the Fall of 1988 from Dr. Bean to use his instruments. (See Appendix A for the two questionnaires and permission from Dr. Bean to use/adapt them as necessary).

The survey contained information regarding background, defining, academic, and environmental variables, psychological and academic outcomes, and intent-to-leave questions. Changes in wording were primarily done to match the specific institutional setting of the Eastern Oregon State College External Degree Program.

STATISTICAL METHODS USED FOR ANALYSIS

Statistical analysis of the research questions was generated using the computer packages, statpac, copyright 1984 by David Walonick, and MINITAB, copyright 1987 by T.W. Anderson and B.P. Eynon.

Because most of the survey responses were in the form of nominal data (Yes/No; attitudes/perceptions on Likert scales; or best statement descriptions), chi-square analyses were most frequently used to compare leavers with finishers, rurals with urbans, and non-respondents with respondents. The level of significance was set at $p<.05$. 
With two variables, age and GPA, the data were parametric and t-tests and one-way ANOVA calculations were conducted.

Following an analysis of all chi-square and t-tests, stepwise multiple regression was used to statistically examine the amount of difference in leave/finish behavior that could be explained by responses to certain survey questions. A11 survey questions could have been regressed and a complete correlation matrix reviewed. However, for this study, only those questions which met two criteria were selected for the regression procedure. First, the question had to have produced significantly different responses between leavers and finishers at $p<.05$. Second, the question had to be one which asked about characteristics/opinions the respondents had either at the time of Program admission or shortly thereafter, rather than traits and/or opinions which would have been more affected by the length of time the respondent spent in the program. For example, though leavers responded significantly different than did finishers to questions regarding the Program's impact on knowing themselves, using interpersonal sk111s, and seeing alternative points of view (questions 78-80), responses to these questions were expected to have been affected by the amount of time the respondents had spent in the Program. On the other hand, a question which asked about the need to have a degree to pursue one's career was seen as more descriptive of the respondent's entry-1evel status. After screening each 
survey question on the two criteria cited above, the following ttems were selected for regression:

Survey

Number

19 Awareness of Other External Degrees

27 Career/Degree Bond

36 Grade Level at Admission to Program

37 Highest Degree Aspirations

50 Time Needed Weekly for Program
Variable or Outcome Category

Environmental Psychological Defining Background Psychological

NULL HYPOTHESES

The literature review, a theoretical base in Bean and Metzner's (1985) model of non-traditional student attrition, and the author's practical experience within the External Degree Program led to the formulation of the following null hypotheses which were tested in this study:

\section{Null Hypothesis 1}

There will be no significant differences between finfshers and leavers in the Eastern oregon State College External Degree Program on defining variables of age, enrollment status, or residency.

\section{Null Hypothesis 2}

There will be no signficant differences between finfshers and leavers in the Eastern Oregon State College External Degree Program on background variables of educational goals, high school performance, ethnicity, family educational levels, or gender. 
Nu11 Hypothesis 3

There will be no signficant differences between finishers and leavers in the Eastern Oregon State College External Degree Program on academic variables of the student's perception of their study habits, academic advising, course availability, major focus within the degree, or program involvement.

Nu11 Hypothesis 4

There will be no significant differences between finishers and leavers in the Eastern Oregon State College External Degree Program on environmental variables of finances, hours of outside employment, outside encouragement, family responsibilities, or perception of opportunities to transfer.

Nu11 Hypothesis 5

There will be no significant differences between finishers and leavers in the Eastern Oregon State College External Degree Program in psychological outcomes as measured by the student's sense of utility of the degree, satisfaction with themselves and the program, goal commitment (as measured by the linkage between career and degree completion), and perceptions of stress.

\section{Nul1 Hypothesis 6}

There will be no significant differences between finishers and leavers in the Eastern oregon State College 
External Degree Program in academic outcomes as measured by their college GPAs.

\section{Nul1 Hypothesis 7}

There will be no significant differences between finishers and leavers in the Eastern Oregon State College External Degree Program regarding their intent to leave, as measured by their having discussed with non-college personnel their plans to withdraw.

\section{Null Hypothesis 8}

There will be no significant differences between finishers and leavers in the Eastern Oregon State College External Degree Program in their perceptions about the quality of education they received through Eastern and of Eastern's reputation itself.

\section{SUPPLEMENTAL： RURAL VS. URBAN}

In addition to analyses between leavers and finishers, respondents were compared along a rural/urban dimension regarding their perception of barriers. Another hypothesis related to these comparisons was:

\section{Null Hypothesis 9}

There will be no significant difference between rural and urban respondents in the Eastern Oregon State College External Degree Program in their perception of barriers, including financial and academic expectations, thoroughness 
and clarity of advising, and adherence to Program rules/procedures.

SUPPLEMENTAL: MARITAL STATUS/FAMILY RESPONSIBILITIES

The effect of family responsibilities on differences in the leave/finish behavior of male and female External Degree respondents prompted the following supplemental hypotheses:

Null Hypothesis 10

There will be no significant difference in the leaving/ finishing behavior of females in the Eastern oregon State College External Degree Program as a result of marital status.

Nu11 Hypothesis 11

There will be no significant difference in the leaving/ finishing behavior of males in the Eastern Oregon State College External Degree Program as a result of marital status.

Nu11 Hypothesis 12

There will be no significant difference in the leaving/ finishing behavior of females in the Eastern Oregon State College External Degree Program as a result of having children or not having children in the home while participating in the Program. 
Nu11 Hypothesis 13

There will be no significant difference in the leaving/ finishing behavior of males in the Eastern Oregon State College External Degree Program as a result of having children or not having children in the home while participating in the Program.

Nu11 Hypothesis 14

There will be no significant difference in the leaving/ finishing behavior of females in the Eastern Oregon State College External Degree Program as a result of having $0-1$ child as opposed to having 2 or more children in the home while participating in the Program.

Null Hypothesis 15

There will be no significant difference in the leaving/ finishing behavior of males in the Eastern Oregon state College External Degree Program as a result of having $0-1$ child as opposed to having 2 or more children in the home while participating in the Program.

Nu11 Hypothesis 16

There will be no significant difference in the leaving/ finishing behavior between females and males in the Eastern Oregon State College External Degree Program as a result of marital status. 
Nu11 Hypothesis 17

There will be no significant difference in the leaving/ finishing behavior between females and males in the Eastern Oregon State College External Degree Program as a result of having children or not having children in the home while participating in the Program.

Nu11 Hypothesis 18

There will be no significant difference in the leaving/ finishing behavior between females and males in the Eastern Oregon State College External Degree Program as a result of having 0-1 child as opposed to having 2 or more children in the home while participating in the Program. 
CHAPTER IV

STUDY FINDINGS

REPRESENTATIVENESS OF RESPONDENTS

Representativeness of the respondent population was determined by comparing non-respondents with respondents on four known variables: (1) gender, (2) ethnicity, (3) age, and (4) college GPA.

Gender

Three comparisons by gender were conducted: (1) all respondents to all non-respondents, (2) responding leavers to non-responding leavers, and (3) responding finishers to non-responding finishers. No significant differences were observed in any of the three comparisons. Overall, a higher percentage of females responded and/or finished than did males; but, the differences were not significant at $p<.05$.

\section{$\underline{\text { Ethnicity }}$}

The three comparisons done regarding gender were also conducted for ethnicity. No significant differences were observed. The majority of all subjects, respondents or non-respondents, leavers or finishers, were white, nonHispanic. Slight group variations were not significant at $\mathrm{p}<.05$ 
Age

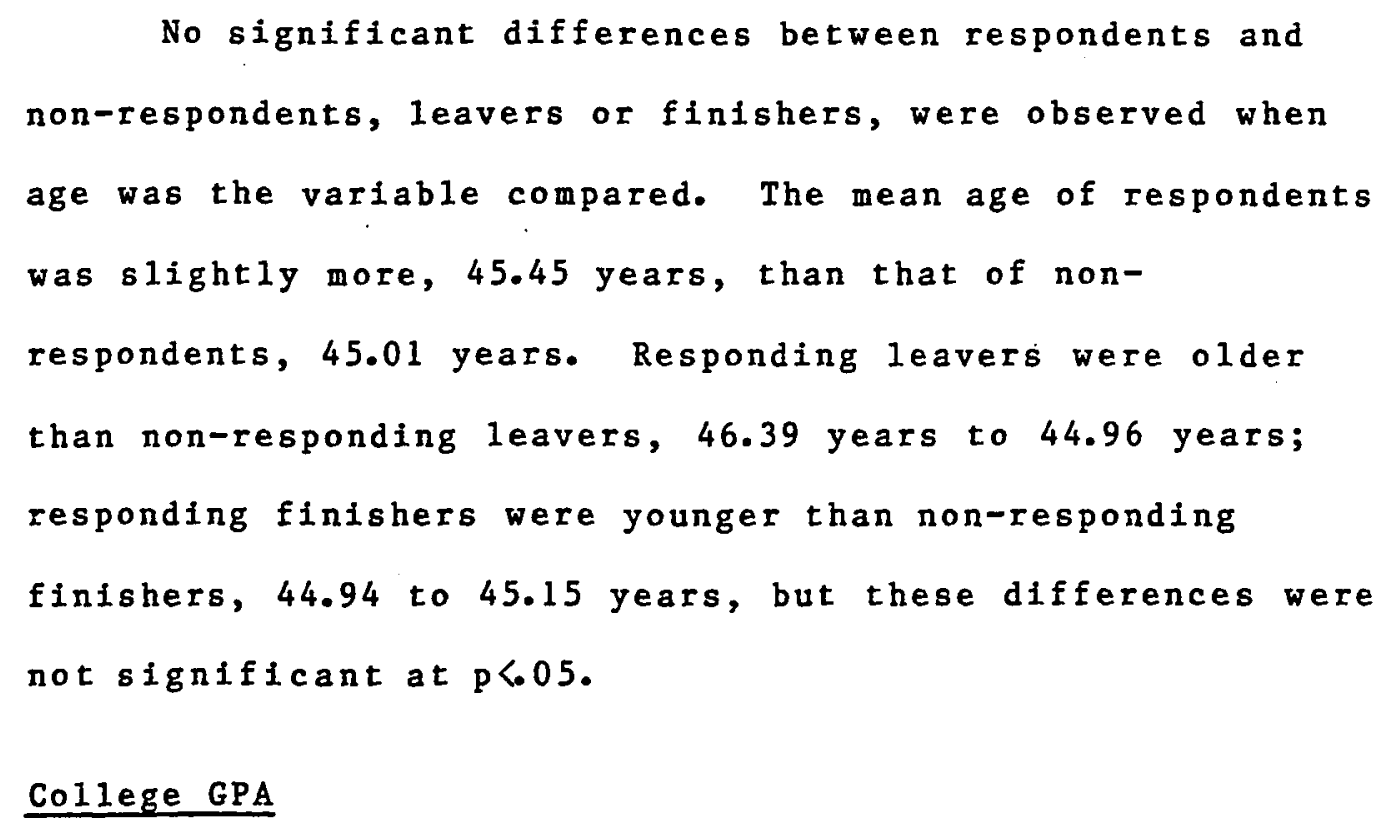

GPA information was available for 38 non-respondents and 207 respondents. The mean GPA for respondents was 3.25 ; for non-respondents, 3.07. This difference was significant on a one-tailed t-test, $(p=.049)$, but not on a two-tailed t-test, $(p=.098)$. When the population was distributed into leavers and finishers, the mean GPAs of 57 responding and 23 non-responding leavers (2.91 and 3.01 respectively) were not significantly different. Likewise, the mean GPAs of the 150 responding and 15 non-responding finishers ( 3.38 and 3.16 respectively), were not significant at $p<.05$.

Summary

Because no significant differences between respondents and non-respondents were observed on the four variables for which data were avallable, the 316 respondents are considered representative, at least in terms of age, sex, 
ethnicity, and academic outcome, of the total population of the study.

\section{COMPARISON OF LEAVERS WITH FINISHERS}

A summary of the results of comparisons between leavers and finishers on the four major variable categories (defining, background, academic integration, and environmental) is provided below and on the following page. Following this summary is a narrative description, category by category, of the responses to each of the 80 questions asked on the survey and of the four questions (age, ethnicity, sex, and GPA) determined from the student data base.

TABLE III

Results of Survey Using Bean/Metzner Variables

DEFINING VARIABLES ( 10 questions; 9 provided opportunity for comparing leavers/finishers; 1 or $11 \%$ was significantly different at $p(.05$.

\footnotetext{
A. 0 of 2 Age Questions

**B. 1 of 2 Enrollment Status Questions

C. 0 of 6 Residency Questions
}

BACKGROUND VARIABLES ( 8 questions; 1 or $12.5 \%$ was significantly different at $p(.05$.

**A. 1 of 1 Educational Goals Question

B. 0 of 2 High School Performance Questions

C. 0 of l Ethnicity Question

D. 0 of 3 Family Educational Level Questions

E. 0 of 1 Gender Question 
ACADEHIC VARIABLES ( 31 questions; 20 or $64.5 \%$ were significantly different at $p<.05$.)

$$
\begin{aligned}
& \text { **A. } 8 \text { of } 9 \text { Study Skills/Habits Questions } \\
& \text { **B. } 4 \text { of } 4 \text { Academic Advising Questions } \\
& \text { **C. } 1 \text { of } 1 \text { Major Certainty Question } \\
& \text { **D. } 2 \text { of } 2 \text { Course Availability Questions } \\
& \text { *E. } 5 \text { of } 15 \text { Program Involvement Questions }
\end{aligned}
$$

ENVIRONMENTAL VARIABLES ( 13 questions; 8 or $61.5 \%$ wete significantly different at $p(.05$.

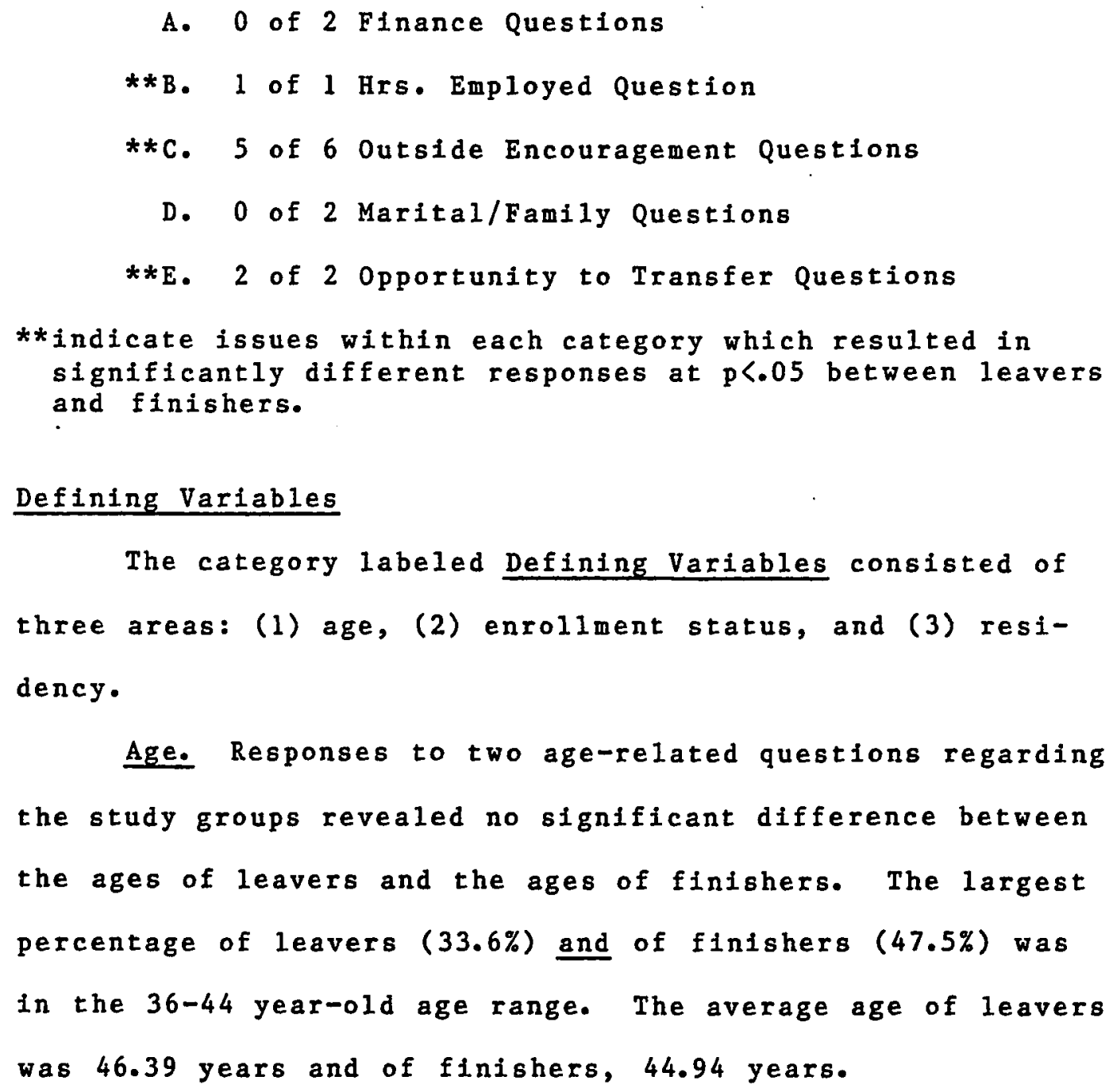

Defining Variables

The category labeled Defining Variables consisted of three areas: (1) age, (2) enrollment status, and (3) residency.

Age. Responses to two age-related questions regarding the study groups revealed no significant difference between the ages of leavers and the ages of finishers. The largest percentage of leavers $(33.6 \%)$ and of finishers (47.5\%) was in the 36-44 year-old age range. The average age of leavers was 46.39 years and of finishers, 44.94 years. 
Enrollment Status. Two questions on the survey related to the enroliment status of the study participants. The first (No. 36), regarding the grade level at which the subjects entered the External Degree Program, did result in a difference between the two groups of students that was significant at p<.05. Specifically, as the following table shows, a higher percentage of the finishers ( $75 \%$ ) entered the program at a more advanced level (either funtors or senfors) than did leavers (61\%). For both groups, however, the largest percentage of entrants was juniors; $20 \%$ of the finishers began as sentors, whereas on 1 y $9 \%$ of leavers entered as seniors.

TABLE IV

GRADE LEVEL UPON ADMISSION TO THE EXTERNAL DEGREE

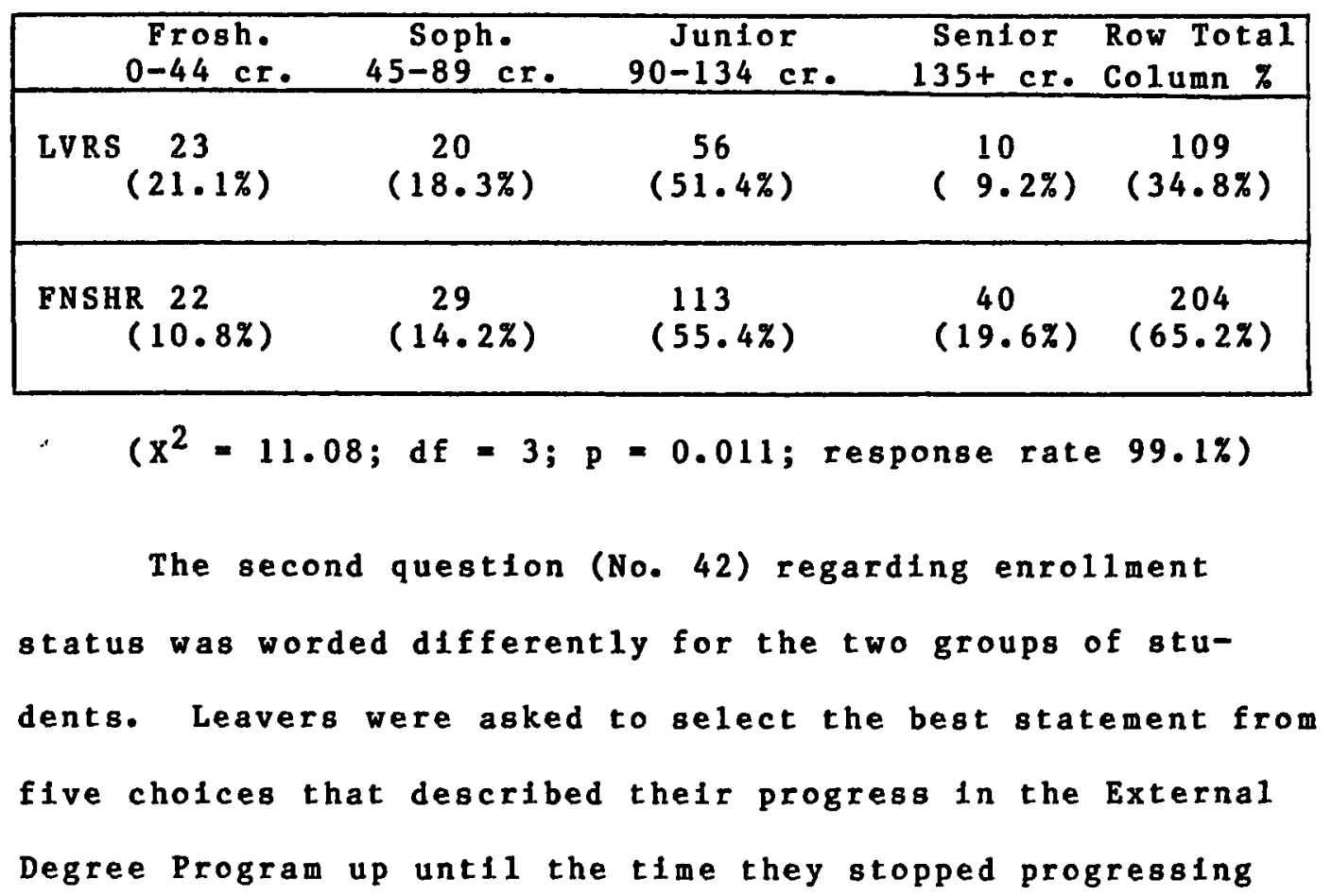


toward graduation. Fintshers were asked to select the best statement from four choices that described their level of progress in the External Degree unt1l they graduated. A frequency distribution of the leavers' responses indicated that the majority ( $52 \%)$ felt they "never really got started In the program" before deciding to cease participating. On the other hand, $53.8 \%$ of the finishers indicated that, including portfolio-awarded credit recommendations, they averaged at least 12 credits per quarter as they progressed toward graduation.

Residency. Six questions were asked related to residency status of the subjects. None produced significant differences between the leavers and the finishers.

While in the program, a majority from both groups of students: (1) were Oregon residents a11/most of the time (leavers, 55.6\%; finishers, 55.9\%); (2) lived in communities with populations less than 50,000 (1eavers, 69.3\%; finishers, 67.2\%); and (3) 11ved 0-59 miles from a post-secondary school (leavers, 82.0\%; finishers, 87.2\%).

On a fourth question (No. 54), the largest percentage of respondents in both the leaver group (28.3\%) and in the finisher group (29.9\%) 11ved 250-499 miles from the La Grande campus. Low percentages from both groups, $14.1 \%$ of leavers and $11.2 \%$ of finishers, reported living within 59 miles of La Grande. In addition, the two groups were nearly equally split on Question No. 2 in their responses to whether or not any regional outreach center was within 10 
miles of their home. The leavers were exactly $50 / 50$ on this question; $54.2 \%$ of finishers sald yes, $45.8 \%$ no. The sixth residency-related question (No. 55) asked subjects to identify the most difficult barrier they faced to participating in the External Degree. For both groups of subjects, not enough time was cited most frequently. Though not significantly different, thirty-four of the finishers ( $17 \%$ ) cited no barriers, whereas on $1 y 10$ of the leavers ( $9 \%$ ) did not.

\section{TABLE V}

BARRIERS TO PARTICIPATING IN THE EXTERNAL DEgREE PROGRAM

Response

Frequency Leavers

Pintshers
\#1 Lack of Time
(36 responses)
$(37.9 \%)$
Lack of Time
(64 responses)
$(37.6 \%)$
\#2 other, with program-related disappointments and/or criticism most frequently c1ted ( 18 out of 21 times).
$(22.1 \%)$
Other, with times) and program- personal disci- pline cited most often ( 16 of 36 related complaints second ( 11 of 36 ).
\#3 Unexpected crises (17.9\%)
Distance from La (18.2\%) Grande Campus

$$
\text { (17 responses) }
$$
( 31 responses)
\#4 Distance from La Grande Campus (11 responses)
$(11.6 \%)$
Unexpected cribes ( $8.8 \%)$
(15 responses)
\#51nances ( 6 responses)
$(6 \cdot 3 \%)$
Finances
(13 responses)
\#6 No Encouragement ( $4.2 \%)$ ( 4 responses)
No Encouragement $(6.5 \%)$
(11 responses) 
In summary, therefore, regarding the ability of defining variables to discriminate between leavers and finishers in this study, it was found that only one of the nine questions which could be compared from this category produced a significantly different result. The more advanced entry-level status of finishers than of leavers was significantiy different at $p<.05$. All other definingvariable questions resulted in no significant differences between leavers and finishers.

Background Variables

The category labeled Background Variables consisted of five areas: (1) educational goals, (2) high school performance, (3) race, (4) family educational levels, and (5) gender.

Educational Goals. of the eight questions asked in the category of Background Variables, only the one from educational goals resulted in a significant difference in responses from the two groups of subjects. The question (No. 37), asked subjects what degree expectations they had upon admission to the External Degree Program. As the table below shows, a majority in both groups reported the BS/BA as the degree expected, but the difference in response patterns was significant at $p<.05$. Significantly more leavers than finishers indicated they either aspired to no degree or to the associate only. 
TABLE VI

HIGHEST DEGREE EXPECTED TO OBTAIN

\begin{tabular}{|c|c|c|c|c|c|}
\hline No & Degree & Associate & $\mathrm{BS} / \mathrm{BA}$ & Graduate & Row Total \\
\hline LVRS & ${ }^{4}(3.6 \%)$ & $\begin{array}{c}6 \\
(5.4 \%)\end{array}$ & $\begin{array}{c}93 \\
(83.8 \%)\end{array}$ & ${ }^{8}\left(7^{8} .2 \%\right)$ & 111 \\
\hline FNSHR & $\left(0^{1} .5 \%\right)$ & $\begin{array}{c}0 \\
(0.0 \%)\end{array}$ & $\begin{array}{l}183 \\
(89.7 \%)\end{array}$ & $\begin{array}{l}20 \\
(9.8 \%)\end{array}$ & 204 \\
\hline
\end{tabular}

$\left(x^{2}=16.24 ;\right.$ df $=3 ; p=0.001 ;$ response rate $\left.99.7 \%\right)$

High School Performance. Two questions asked for high school performance data and neither resulted in significant differences between the two subject groups. With regard to high school GPA (No. 39), the most frequent response from both groups was in the 3.00-3.49 range, $34 \%$ for finishers and $31.5 \%$ for leavers. A higher percentage of the leavers (19.8\%) than of the finishers (13.3\%) reported a high school GPA of 3.76 or higher. The second performance question (No. 41) asked the subjects to select the rank (upper $20 \%$, middle $60 \%$, lower $20 \%$, GED) that described their high school background. The response trend was identical for both subject groups with a majority in both reporting their high school rank in the upper $20 \%--52.3 \%$ for 1 eavers and $55.2 \%$ for finishers.

Ethnicity. Ethnic differences were also not significantly different between the two subject groups. The majority of subjects were white, non-Hispanic-- $88.4 \%$ for leavers, $86.6 \%$ for finishers. 
Family Educational Levels. Family educational levels were also not significantly different between the two subject groups. The largest percentage of both the leavers' and finishers' mothers had obtained a high school diploma or GED; $37.6 \%$ leavers and $42.2 \%$ finishers. The second most frequent response for both subject groups' mothers was less than a high school diploma; $26.6 \%$ leavers and $24.5 \%$ finishers. A higher percentage of the leavers' mothers (26.6\%) than of the finishers' mothers $(21.6 \%)$ had attended and/or graduated from college. In contrast, however, to the higher educational level obtained by more leaver/finisher mothers, the most frequent response for fathers was less than a high school diploma. Almost $41 \%$ of the leavers' and $37 \%$ of the finishers' fathers had not graduated from high school. The second most frequent response for both groups was high school diploma/GED with $28.8 \%$ of leavers' fathers and $32.0 \%$ of finishers' fathers graduating from high school or obtaining the GED. Though not significantly different, a higher percentage of the finishers' spouses ( $43.1 \%$ ) had completed a college degree than of the leavers' spouses (32.6\%). For both groups, the majority of spouses had attended and/or graduated from college--66.3\% of the leavers' spouses and $75.5 \%$ of the finishers'. Gender. Gender did not account for statistically significant differences in leaving/finishing the program. However, for this study group, more of the finishers were 
women than men ( 109 vs.95) and more of the leavers were men than women ( 57 v8. 55).

Overall, therefore, background variables provided 1ittle differentiation between leavers and finishers except where a degree-aspiration question was asked. Finishers had a higher percentage aspiring to the BS/BA or beyond than did leavers, and the difference was significant at $p<.05$.

Academic Variables

Five areas constituted the category called academic variables: (1) study habits and skills, (2) advising, (3) course availability, (4) major certainty, and (5) program involvement. Numerous cases of significant differences between the two subject groups were reported from the 31 questions comprising this variable. Responses involving eight of the nine study skill questions, five of the fifteen program interaction questions, all four advising questions, both course avallability questions, and the one major certainty question, resulted in significant differences at $p<.05$.

Study Habits and Skills. The only question which did not produce a significant difference was one (No. 62) asking students to identify to what extent they were confident with their writing ability upon admission to the program. The majority of subjects in both groups (1eavers $69.7 \%$ and finishers $74.0 \%$ ) felt elther great or very great confidence with this ski11. 
Though significantly different in overall numbers, the majority of responses from both subject groups were in the same direction on five other study habits/skills questions. For example, in both groups of subjects, a majority indicated that they did complete assignments on time (No. 20). However, more finishers (97.1\%) than leavers (63.7\%) affirmed their timeliness and the difference was significant.

TABLE VII

DO YOU GENERALLY COMPLETE ASSIGNMENTS ON TIME?

\begin{tabular}{|lccc|}
\hline & YES & NO & ROW TOTAL \\
\hline LEAVERS & $\begin{array}{c}65 \\
(63.7 \%)\end{array}$ & $\begin{array}{c}37 \\
(36.3 \%)\end{array}$ & 102 \\
\hline FINISHERS & $\begin{array}{c}198 \\
(97.1 \%)\end{array}$ & $\begin{array}{c}6 \\
(2.9 \%)\end{array}$ & 204 \\
\hline
\end{tabular}

$\left(x^{2}=59.82 ;\right.$ df $=1 ; p=0.000 ;$ response rate $\left.96.8 \%\right)$

Likewise, a higher percentage of leavers (21.4\%) than of finishers $(6.9 \%)$ reported procrastinating to a great or very great extent when doing their work and this difference, too, was significant (No. 58).

TABLE VIII

DO YOU PROCRASTINATE WITH DOING YOUR WORK?

\begin{tabular}{|ccccc|}
\hline & $\begin{array}{c}\text { Not at } \\
\text { All }\end{array}$ & $\begin{array}{c}\text { Smal1/Some } \\
\text { Extent }\end{array}$ & $\begin{array}{c}\text { Great/Very } \\
\text { Great Extent }\end{array}$ & $\begin{array}{c}\text { Row Total } \\
\text { Column } \%\end{array}$ \\
\hline LEAVERS & 26 & 55 & 22 & 103 \\
& $(25.2 \%)$ & $(53.4 \%)$ & $(21.4 \%)$ & $(33.7 \%)$ \\
\hline EINISHERS & 76 & 113 & 14 & 203 \\
& $(37.4 \%)$ & $(55.7 \%)$ & $(6.9 \%)$ & $(66.3 \%)$ \\
\hline
\end{tabular}

$$
\left(x^{2}=15.26 ; \mathrm{d} f=2 ; p=0.000 ; \text { response rate } 96.8 \%\right)
$$


The two groups' responses to three perception-ofconfidence questions also produced significant differences-again, though, with response trends in the same direction. For example, as the next table shows, more leavers (7.3\%) than finishers $(.5 \%)$ reported they were not at all confident with their study skills (No. 60) even though a majority in both groups ( $54.1 \%$ of leavers and $71.6 \%$ of finishers) were confident to a great or very great extent.

\section{TABLE IX}

DEGREE OF CONEIDENCE WITH STUDY SKILLS

\begin{tabular}{|c|c|c|c|c|}
\hline & $\begin{array}{l}\text { Not at } \\
\text { All }\end{array}$ & $\begin{array}{c}\text { Small/Some } \\
\text { Extent }\end{array}$ & $\begin{array}{c}\text { Great/Very } \\
\text { Great Extent }\end{array}$ & $\begin{array}{l}\text { Row Total } \\
\text { Column \% }\end{array}$ \\
\hline LEAVERS & $\begin{array}{c}8 \\
(7.3 \%)\end{array}$ & $\begin{array}{c}42 \\
(38.5 \%)\end{array}$ & $\begin{array}{c}59 \\
(54.1 \%)\end{array}$ & $\begin{array}{c}109 \\
(34.8 \%)\end{array}$ \\
\hline F INISHERS & $(0.5 \%)$ & $\begin{array}{c}57 \\
(27.9 \%)\end{array}$ & $\begin{array}{c}146 \\
(71.6 \%)\end{array}$ & $\begin{array}{c}204 \\
(65.2 \%)\end{array}$ \\
\hline
\end{tabular}

$$
\left(x^{2}=17.4 ; \text { df }=2 ; p=0.000 ; \text { response rate } 99.1 \%\right)
$$

Also, both groups reported a majority of subjects confident to a great/very great extent with their ability to cope with stress (No. 64). However, the finishers reported a higher percentage $(76.4 \%)$ than leavers $(61.1 \%)$, and the difference was significant. 
TABLE $X$

DEGREE OF CONFIDENCE WITH ABILITY TO COPE WITH STRESS

\begin{tabular}{|lcccc|}
\hline & $\begin{array}{c}\text { Not at } \\
\text { AlI }\end{array}$ & $\begin{array}{c}\text { Smal1/Some } \\
\text { Extent }\end{array}$ & $\begin{array}{c}\text { Great/Very } \\
\text { Great Extent }\end{array}$ & $\begin{array}{c}\text { Row Total } \\
\text { Column } \%\end{array}$ \\
\hline LEAVERS & 3 & 39 & 66 & 108 \\
& $(2.8 \%)$ & $(36.1 \%)$ & $(61.1 \%)$ & $(34.7 \%)$ \\
\hline FINISHERS & 1 & 47 & 155 & $(76.4 \%)$ \\
& $(0.5 \%)$ & $(23.2 \%)$ & $(65.3 \%)$ \\
\hline
\end{tabular}

$\left(x^{2}=9.44 ; \mathrm{df}=2 ; \mathrm{p}=0.009 ;\right.$ response rate $\left.98.4 \%\right)$

A fifth study habits/skills question yielded results

in the same direction though with numbers that were significantly different. This question referred to the subjects' perception of their ability to cope with academic challenges. Although a majority of respondents in both groups reported great/very great confidence, the higher percentage of finishers with this response $(82.3 \%$ ) than leavers $(52.8 \%)$ was significant.

\section{TABLE XI}

DEGREE OF CONFIDENCE WITH COPING WITH ACADEMICS

\begin{tabular}{|lcccc|}
\hline & $\begin{array}{c}\text { Not at } \\
\text { Al1 }\end{array}$ & $\begin{array}{c}\text { Smal1/Some } \\
\text { Extent }\end{array}$ & $\begin{array}{c}\text { Great/Very } \\
\text { Great Extent }\end{array}$ & $\begin{array}{c}\text { Row Totals } \\
\text { Column } \%\end{array}$ \\
\hline LEAVERS & $\begin{array}{c}3 \\
(2.8 \%)\end{array}$ & $\begin{array}{c}48 \\
(44.4 \%)\end{array}$ & $\begin{array}{c}57 \\
(52.8 \%)\end{array}$ & $\begin{array}{c}108 \\
(34.7 \%)\end{array}$ \\
\hline FINISHERS & $\begin{array}{c}0 \\
\text { (0.0\%) }\end{array}$ & $\begin{array}{c}36 \\
(17.7 \%)\end{array}$ & $\begin{array}{c}167 \\
(82.3 \%)\end{array}$ & $\begin{array}{c}203 \\
(65.3 \%)\end{array}$ \\
\hline
\end{tabular}

$\left(X^{2}=32.77 ;\right.$ df $=2 ; p=0.000 ;$ response rate $\left.98.4 \%\right)$ 
Three study habits/skills questions resulted in differences that were both significant and in different directions for the two subject groups. As the next table shows, a majority of finishers ( $74.8 \%$ ) reported they were able to find the time to do their assignments, whereas only $26.2 \%$ of the leavers were. The majority of leavers (53.3\%) reported they were rarely able or only to a limited extent able to find the necessary time, and $20.6 \%$ of the leavers (compared to $0.5 \%$ of finishers) said they were not at a11 able to find the time.

TABLE XII

ABLE TO FIND TIME TO DO ASSIGNMENTS?

\begin{tabular}{|lcccc|}
\hline & $\begin{array}{c}\text { Not at } \\
\text { All }\end{array}$ & $\begin{array}{c}\text { Small/Some } \\
\text { Extent }\end{array}$ & $\begin{array}{c}\text { Great/Very } \\
\text { Great Extent }\end{array}$ & $\begin{array}{c}\text { Row Total } \\
\text { Column } \%\end{array}$ \\
\hline LEAVERS & $\begin{array}{c}22 \\
(20.6 \%)\end{array}$ & $\begin{array}{c}57 \\
(53.3 \%)\end{array}$ & $\begin{array}{c}28 \\
(26.2 \%)\end{array}$ & $\begin{array}{c}107 \\
(34.6 \%)\end{array}$ \\
\hline FINISHERS & $\begin{array}{c}1 \\
(0.5 \%)\end{array}$ & $\begin{array}{c}50 \\
(24.8 \%)\end{array}$ & $\begin{array}{c}151 \\
(74.8 \%)\end{array}$ & $\begin{array}{c}202 \\
(65.4 \%)\end{array}$ \\
\hline
\end{tabular}

$$
\left(x^{2}=82.76 ; d f=2 ; p=0.000 ; \text { response rate } 97.8 \%\right)
$$

More finishers ( $85.3 \%$ ) than leavers ( $78 \%$ ) reported they were confident to a great/very great extent with their reading ability; this difference was significant. Finishers also exhibited more qualitative confidence levels than did leavers. As the following table shows, nearly half ( $48.5 \%$ ) of finishers (compared to just $29.4 \%$ of the finishers) reported a very great extent of reading confidence. 
TABLE XIII

DEGREE OF CONFIDENCE WITH READING ABILITY

\begin{tabular}{|cccc|}
\hline $\begin{array}{c}\text { Small/ } \\
\text { Some Extent }\end{array}$ & Great & Very & Row Total \\
Extent & Great Extent & Column $\%$ \\
\hline $\begin{array}{c}\text { LEAVERS } 24 \\
(22.0 \%)\end{array}$ & $(48.6 \%)$ & $(29.4 \%)$ & $(34.8 \%)$ \\
\hline $\begin{array}{c}\text { FINISHERS } 30 \\
(14.7 \%)\end{array}$ & $(36.8 \%)$ & $(48.5 \%)$ & $(65.2 \%)$ \\
\hline
\end{tabular}

$$
\left(x^{2}=10.88 ; \text { df }=2 ; p=0.004 ; \text { response rate } 99.1 \%\right)
$$

In the area of confidence with verbal expression, a significant difference in overall responses was found, as was a trend difference. Though both groups reported a majority of subjects claiming great or very great confidence with their verbal expression ability $(75.2 \%$ of leavers and $82.3 \%$ of finishers), a higher percentage of leavers ( $24.8 \%$ ) than finishers $(17.6 \%)$ said they were confident to only a small or limited extent.

TABLE XIV

DEGREE OF CONFIDENCE WITH VERBAL EXPRESSION

\begin{tabular}{|ccccc|}
\hline & $\begin{array}{c}\text { Smal1 } \\
\text { Some Extent }\end{array}$ & $\begin{array}{c}\text { Great } \\
\text { Extent }\end{array}$ & $\begin{array}{c}\text { Very } \\
\text { Great Extent }\end{array}$ & $\begin{array}{c}\text { Row Total } \\
\text { Column } \%\end{array}$ \\
\hline LEAVERS & $\begin{array}{c}27 \\
(24.8 \%)\end{array}$ & $\begin{array}{c}57 \\
(52.3 \%)\end{array}$ & $\begin{array}{c}25 \\
(22.9 \%)\end{array}$ & $\begin{array}{c}109 \\
(34.8 \%)\end{array}$ \\
\hline FINISHERS & 36 & 87 & 81 & 204 \\
& $(17.6 \%)$ & $(42.6 \%)$ & $(39.7 \%)$ & $(65.2 \%)$ \\
\hline
\end{tabular}

$\left(x^{2}=9.12 ; \mathrm{df}=2 ; \mathrm{p}=0.010 ;\right.$ response rate $\left.99.1 \%\right)$ 
In summary, therefore, regarding the ability of study habits/skills to discriminate between leavers and finishers, it was found that all areas, except self-perception of writing ability, did contribute to differences.

Advising. Four advising questions were asked of the subjects and all produced significant differences. For three questions, the response trends for the two groups were in the same direction. For example, though the majority of subjects in both groups $(75.7 \%$ of leavers and $94.1 \%$ of finishers) agreed that degree requirements were made clear to them by their advisors, the higher percentage of finishers was significant.

TABLE XV

DEGREE REQUIREMENTS MADE CLEAR TO YOU BY YOUR ADVISOR?

\begin{tabular}{|lccc|}
\hline & YES & No & $\begin{array}{l}\text { Row Total } \\
\text { Column } \%\end{array}$ \\
\hline LEAVERS & $\begin{array}{c}84 \\
75.7 \%)\end{array}$ & $\begin{array}{c}27 \\
(24.3 \%)\end{array}$ & $\begin{array}{c}111 \\
(35.4 \%)\end{array}$ \\
\hline FINISHERS & $\begin{array}{c}191 \\
(94.1 \%)\end{array}$ & $\begin{array}{c}12 \\
(5.9 \%)\end{array}$ & $\begin{array}{c}203 \\
(64.6 \%)\end{array}$ \\
\hline
\end{tabular}

$\left(x^{2}=20.7 ;\right.$ df $=1 ; p=0.000 ;$ response rate $\left.99.4 \%\right)$

Likewise, though the majority of subjects in both groups $(74.5 \%$ of leavers and $62.6 \%$ of finishers) did not feel La Grande campus meetings between Program Staff and students should be required, the smaller percentage of finishers feeling that way was significant. 
TABLE XVI

SHOULD LA GRANDE CAMPUS MEETINGS W/YOUR ADVISOR BE REQUIRED?

\begin{tabular}{|cccc|}
\hline & YES & No & $\begin{array}{l}\text { Row Tota 1 } \\
\text { Column } \%\end{array}$ \\
\hline LEAVERS & 28 & 82 & 110 \\
& $(25.5 \%)$ & $(74.5 \%)$ & $(35.1 \%)$ \\
\hline FINISHERS & 76 & 127 & 203 \\
& $(37.4 \%)$ & $(62.6 \%)$ & $(64.9 \%)$ \\
\hline
\end{tabular}

$\left(x^{2}=4.09 ; \mathrm{df}=1 ; \mathrm{p}=0.043 ;\right.$ response rate $\left.99.1 \%\right)$

Also, though the pattern of responses from subjects in both groups was identical to a question regarding their satisfaction with the quality of academic advising they received (No. 59), the larger percentage of finishers expressing satisfaction $(77.8 \%)$ than of leavers $(49.1 \%)$ was significant.

TABLE XVII

SATISFACTION' WITH QUALITY OF ACADEMIC ADVISING RECEIVED

\begin{tabular}{|ccccc|}
\hline & $\begin{array}{c}\text { Not at } \\
\text { All }\end{array}$ & $\begin{array}{c}\text { Small/Some } \\
\text { Extent }\end{array}$ & $\begin{array}{c}\text { Great/Very } \\
\text { Great Extent }\end{array}$ & $\begin{array}{c}\text { Row Total } \\
\text { Column \% }\end{array}$ \\
\hline LEAVERS & $\begin{array}{c}13 \\
(12.3 \%)\end{array}$ & $\begin{array}{c}41 \\
(38.7 \%)\end{array}$ & $\begin{array}{c}52 \\
(49.1 \%)\end{array}$ & $\begin{array}{c}106 \\
(34.3 \%)\end{array}$ \\
\hline FINISHERS & 4 & 41 & 158 & 203 \\
& $(2.0 \%)$ & $(20.2 \%)$ & $(77.8 \%)$ & $(65.7 \%)$ \\
\hline
\end{tabular}

$\left(X^{2}=30.86 ;\right.$ df $=2 ; p=0.000 ;$ response rate $\left.97.8 \%\right)$

And, as the following table shows, a difference in response numbers and in response trend was reported by finishers and leavers on the question (No. 56) regarding 
their satisfaction with the amount of academic advice they received. Whereas the majority of finishers $(76.4 \%)$ were satisfied to a great/very great extent, only $37.6 \%$ of the leavers were.

TABLE XVIII

SATISFACTION WITH QUANTITY OF ACADEMIC ADVISING RECEIVED

\begin{tabular}{|c|c|c|c|c|}
\hline & $\begin{array}{c}\text { Not at } \\
\text { A11 }\end{array}$ & $\begin{array}{c}\text { Smali/Some } \\
\text { Extent }\end{array}$ & $\begin{array}{c}\text { Great/Very } \\
\text { Great Extent }\end{array}$ & $\begin{array}{l}\text { Row Total } \\
\text { Column \% }\end{array}$ \\
\hline LEAVERS & $\begin{array}{c}14 \\
(12.8 \%)\end{array}$ & $\begin{array}{c}54 \\
(49.5 \%)\end{array}$ & $\begin{array}{c}41 \\
(37.6 \%)\end{array}$ & $\begin{array}{c}109 \\
(34.9 \%)\end{array}$ \\
\hline FINISHERS & $\begin{array}{c}4 \\
(2.0 \%)\end{array}$ & $\begin{array}{c}44 \\
(21.7 \%)\end{array}$ & $\begin{array}{c}155 \\
(76.4 \%)\end{array}$ & $\begin{array}{c}203 \\
(65.1 \%)\end{array}$ \\
\hline
\end{tabular}

$\left(x^{2}=49.01 ;\right.$ df $=2 ; p=0.000 ;$ response rate $\left.98.7 \%\right)$

In summarizing the ability of responses to advising questions to discriminate between leavers and finishers, this study showed that even though majorities in both groups of subjects were satisfied with the no-La Grande campus meeting requirement and with the clarity and quality of academic advising, they differed significantly in numbers on these questions and, more noticeably, in the quantity of advising they sought.

Course Availability. Two questions in the category of Academic Variables referred to the students' perceptions of course access for degree completion. Both resulted in significant differences in responses from the two groups. When asked about how frequently desired courses were offered 
and whether/not they were at convenient times, the largest response from leavers to both questions was not applicable (36\%). On the other hand, the largest response from finishers to the same questions was most of the time, 45-47\%). It would appear that the leavers had withdrawn from the program prior to seeking additional coursework to complete their degree. However, for those who did seek courses, a larger percentage of leavers (11.9\%) than of finishers $(.5 \%)$ said that classes were not at all offered for them. The following two tables reflect the differences in responses from the study groups to these two questions (No. 76 and 77 ).

TABLE XIX

FREQUENCY OF DESIRED COURSES BEING OFFERED

\begin{tabular}{|c|c|c|c|c|c|}
\hline $\mathrm{N} / \mathrm{A}$ & $\begin{array}{c}\text { Not at } \\
\text { All }\end{array}$ & $\begin{array}{l}\text { Some of } \\
\text { Time }\end{array}$ & $\begin{array}{l}\text { Most of } \\
\text { Time }\end{array}$ & $\begin{array}{l}\text { All of } \\
\text { Time }\end{array}$ & $\begin{array}{l}\text { Row Total } \\
\text { Column } \%\end{array}$ \\
\hline 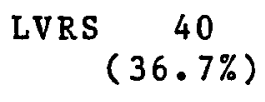 & $(11.9 \%)$ & $\begin{array}{c}39 \\
(35.8 \%)\end{array}$ & $\begin{array}{c}16 \\
(14.7 \%)\end{array}$ & $\begin{array}{c}1 \\
(0.9 \%)\end{array}$ & $\begin{array}{c}109 \\
(34.8 \%)\end{array}$ \\
\hline $\begin{array}{r}\text { FNSHRS } 40 \\
(19.6 \%)\end{array}$ & $\left(\begin{array}{c}1 \\
0.5 \%\end{array}\right)$ & $\begin{array}{c}51 \\
(25.0 \%)\end{array}$ & $\begin{array}{c}97 \\
(47.5 \%)\end{array}$ & $\begin{array}{c}15 \\
(7.4 \%)\end{array}$ & $\begin{array}{c}204 \\
(65.2 \%)\end{array}$ \\
\hline
\end{tabular}

$$
\left(x^{2}=58.77 ; d f=4 ; p=0.000 ; \text { response rate } 99.1 \%\right)
$$


TABLE XX

CONVENIENCE OF TIME WHEN COURSES WERE OFFERED FOR YOU

\begin{tabular}{|cccccc|}
\hline N/A & $\begin{array}{c}\text { Not at } \\
\text { A1I }\end{array}$ & $\begin{array}{c}\text { Some of } \\
\text { Time }\end{array}$ & $\begin{array}{c}\text { Most of } \\
\text { Time }\end{array}$ & $\begin{array}{c}\text { All of } \\
\text { Time }\end{array}$ & $\begin{array}{c}\text { Row Total } \\
\text { Column } \%\end{array}$ \\
\hline LVRS $\begin{array}{c}39 \\
(36.1 \%)\end{array}$ & $\begin{array}{c}22 \\
(20.4 \%)\end{array}$ & $\begin{array}{c}36 \\
(33.3 \%)\end{array}$ & $\begin{array}{c}10 \\
(9.3 \%)\end{array}$ & $\begin{array}{c}1 \\
(0.9 \%)\end{array}$ & $\begin{array}{c}108 \\
(34.6 \%)\end{array}$ \\
\hline $\begin{array}{r}\text { FNSHRS } 40 \\
(19.6 \%)\end{array}$ & $(1.5 \%)$ & $(27.5 \%)$ & $(45.6 \%)$ & $\begin{array}{c}12 \\
(5.9 \%\end{array}$ & $\begin{array}{c}204 \\
(65.4 \%)\end{array}$ \\
\hline
\end{tabular}

$\left(x^{2}=2.29 ; d f=4 ; p=0.000 ;\right.$ response rate $\left.98.7 \%\right)$

Major Certainty. Though the External Degree provides for a generalized degree, opportunities within the degree structure do allow for an academic focus of approximately $50 \%$ of the total credits needed for graduation. When asked (No. 18) if they focused on a specific area while participating in the program, a higher percentage of finishers (69.1\%) than of leavers $(51.4 \%)$ indicated that they had and this difference was significant.

TABLE XXI

DID YOU FOCUS IN A SUBJECT AREA WHILE PURSUING DEGREE?

\begin{tabular}{lccc|}
\hline & YES & No & $\begin{array}{l}\text { Row Tota } \\
\text { Column } \%\end{array}$ \\
\hline LEAVERS & 57 & 54 & 111 \\
\hline FINISHERS & $(51.4 \%)$ & $(48.6 \%)$ & $(35.2 \%)$ \\
\hline & $(69.1 \%)$ & $(30.9 \%)$ & $(64.8 \%)$ \\
\hline
\end{tabular}

$\left(x^{2}=8.97 ;\right.$ df $=1 ; p=0.003$; response rate $\left.99.7 \%\right)$ 
Program Involvement. Fifteen questions regarding the subjects' interaction with program options were asked. Five produced significant differences, and two of these five showed differences not only in number but in direction. The ten program interaction questions which did not produce significant differences were:

1. Did you participate in outreach center classes? ( $82.6 \%$ of leavers and $73.9 \%$ of finishers did not)

2. Did you take the portfolio workshop in La Grande? ( $81.1 \%$ of leavers and $74.9 \%$ of finishers did not)

3. Did you take the portfolio workshop in a non-La Grande location?

( $60.4 \%$ of leavers and $65.2 \%$ of finishers did)

4. Did you take the portfolio class by correspondence? ( $87.5 \%$ of leavers and $79.7 \%$ of finishers did not)

5. Did you receive credit for cooperative education? ( $91.0 \%$ of leavers and $86.3 \%$ of finishers did not)

6. Did you receive credit through CLEP? ( $93.8 \%$ of leavers and $87.3 \%$ of finishers did not)

7. Did you receive credit through challenging courses? ( $97.3 \%$ of leavers and $97.0 \%$ of finishers did not)

8. Did you receive credit through military evaluation? ( $88.3 \%$ of leavers and $81.3 \%$ of finishers did not)

9. Did you take evening/daytime classes at Eastern? ( $95.5 \%$ of leavers and $88.2 \%$ of finishers did not)

10. Did you receive credit for any agency-sponsored training not otherwise included in a portfolio of prior learning? ( $90.6 \%$ of leavers and $85.6 \%$ of finishers did not)

As this list shows, no significant difference resulted from asking students if they had participated in an Assessment of Prior Learning Portfolio Workshop (the majority of leavers and finishers had not taken the workshop in La 
Grande or by correspondence but had taken it in non-La Grande locations). However, when asked if they received credit for essays submitted through the portfolio process, $88.7 \%$ of the finishers compared to only $43.8 \%$ of the leavers had. In other words, the majority of leavers either did not complete a portfolio or at least did not receive credit for any portfolio essays they did complete.

TABLE XXII

DID YOU RECEIVE CREDIT THROUGH PORTFOLIO ESSAYS?

\begin{tabular}{|lccc|}
\hline & YES & No & $\begin{array}{l}\text { Row Total } \\
\text { Colum } \%\end{array}$ \\
\hline LEAVERS & $\begin{array}{c}49 \\
(43.8 \%)\end{array}$ & $\begin{array}{c}63 \\
(56.3 \%)\end{array}$ & $\begin{array}{c}112 \\
(35.6 \%)\end{array}$ \\
\hline \multirow{2}{*}{ FINISHERS } & 180 & 23 & 203 \\
& $(88.7 \%)$ & $(11.3 \%)$ & $(64.4 \%)$ \\
\hline
\end{tabular}

$\left(x^{2}=71.13 ; \mathrm{df}=1 ; \mathrm{p}=0.000 ;\right.$ response rate $\left.99.7 \%\right)$

Another area of program interaction in which leavers and finishers differed significantly was in their use of correspondence studies to meet degree requirements (No. 8). The majority (57.4\%) of finishers did participate in correspondence, whereas only $22.5 \%$ of the leavers did.

TABLE XXIII

DID YOU RECEIVE CREDIT BY CORRESPONDENCE COURSES?

\begin{tabular}{|lccc|}
\hline & YES & No & $\begin{array}{l}\text { Row Total } \\
\text { Column } \%\end{array}$ \\
\hline LEAVERS & 25 & 86 & 111 \\
& $(22.5 \%)$ & $(77.5 \%)$ & $(35.2 \%)$ \\
\hline FINISHERS & 117 & 87 & 204 \\
& $(57.4 \%)$ & $(42.6 \%)$ & $(64.8 \%)$ \\
\hline $\mathrm{X}^{2}=33.83 ; \mathrm{df}=1 ; \mathrm{p}=0.000 ;$ response rate $\left.99.7 \%\right)$
\end{tabular}


Significant differences were found in the responses to three other program interaction questions. Though the majority in both study groups had not participated in Eastern's Weekend College Program (either in La Grande or in other locations, No. 13 and 14), the differences in the number responding either yes or no from the two groups was significant.

TABLE XXIV

DID YOU TAKE WEEKEND COLLEGE IN NON-LA GRANDE SITES?

\begin{tabular}{|c|c|c|c|}
\hline & YES & No & $\begin{array}{l}\text { Row Total } \\
\text { Column \% }\end{array}$ \\
\hline LEAVERS & $\begin{array}{c}21 \\
(18.8 \%) \\
\end{array}$ & $\begin{array}{c}91 \\
(81.3 \%) \\
\end{array}$ & $\begin{array}{c}112 \\
(35.4 \%) \\
\end{array}$ \\
\hline FINISHERS & $\begin{array}{c}92 \\
(45.1 \%) \\
\end{array}$ & $\begin{array}{c}112 \\
(54.9 \%) \\
\end{array}$ & $\begin{array}{c}204 \\
(64.6 \% \\
\end{array}$ \\
\hline
\end{tabular}

$\left(x^{2}=20.71 ;\right.$ df $=1 ; p=0.000 ;$ response rate $\left.100 \%\right)$

TABLE XXV

DID YOU TAKE WEEKEND COLLEGE CLASSES IN LA GRANDE?

\begin{tabular}{|cccc|}
\hline & YES & NO & $\begin{array}{l}\text { Row Tota1 } \\
\text { Column } \%\end{array}$ \\
\hline LEAVERS & 24 & 88 & 112 \\
& $(21.4 \%)$ & $(78.6 \%)$ & $(35.6 \%)$ \\
\hline FINISHERS & 95 & 108 & 203 \\
& $(46.8 \%)$ & $(53.2 \%)$ & $(64.4 \%)$ \\
\hline
\end{tabular}

$\left(X^{2}=18.69 ; \mathrm{d} f=1 ; \mathrm{p}=0.000 ;\right.$ response rate $\left.99.7 \%\right)$

The final program interaction question on which leavers and finishers significantly differed was No. 15, "Did you receive credit through transfer from other 
institutions?" Even though the majority of subjects in both study groups did, the larger percentage of finishers receiving credit through transfer was significant.

TABLE XXVI

DID YOU RECEIVE CREDIT THROUGH TRANSFER COURSES AT OTHER INSTITUTIONS?

\begin{tabular}{|cccc|}
\hline & YES & No & $\begin{array}{c}\text { Row Total } \\
\text { Column } \%\end{array}$ \\
\hline LEAVERS & 80 & 31 & 111 \\
& $(72.1 \%)$ & $(27.9 \%)$ & $(35.2 \%$ \\
\hline FINISHERS & 198 & 6 & 204 \\
& $(97.1 \%)$ & $(2.9 \%)$ & $(64.8 \%$ \\
\hline
\end{tabular}

$\left(x^{2}=40.91 ; d f=1 ; p=0.000 ;\right.$ response rate $\left.99.7 \%\right)$

A summary of the findings from this study related to

the discriminating ability of program interaction questions

regarding leavers and finishers indicates three things:

1. Leavers and finishers were significantly

different in what participation in the portfolio development process produced. For example, the finishers received credit for portfolio essays more often than did the leavers.

2. Leavers and finishers were also significantly different in their use of correspondence studies to meet degree requirements; i.e., finishers accessed this option more frequently than did leavers.

3. Though majorities in both subject groups responded the same, significantly more finishers than leavers used EOSC Weekend College courses and transfer credits from other institutions to progess toward degree completion. 
Environmental Variables

The category labeled Environmental Variables consisted of 5 areas: (1) finances, (2) outside employment,

(3) outside encouragement, (4) family responsibilities, and (5) perception of one's ability to transfer.

Finances. Responses to two directly related finance questions (No. 52 and 66) plus one indirectly related question (No. 55) resulted in no significant differences between the leavers and finishers in the (1) manner in which educational expenses were funded; (2) extent of problem with financing education; or (3) placement of finances in a hierarchy of barriers regarding pursuing one's education. Specifically, the $\# 1$ and $\left.\right|_{2}$ responses received from both leavers and finishers when asked how their educational expenses were funded were self/spouse job-related income (73.2\% leavers; $70.7 \%$ finishers) and employer reimbursement (16.5\% leavers; $19.6 \%$ finishers). When asked to what extent they had financial problems while participating in the program, the largest percentage of subjects in both study groups ( $34.5 \%$ leavers; $40.4 \%$ finishers) said "not at a11." Though not statistically significant, $19.1 \%$ of the leavers responded that finances posed a great or very great problem, whereas only $11.3 \%$ of the finishers did. As shown on page 121 in this chapter, finances ranked fifth out of six categories the study groups indicated posed the greatest barrier to their participation in the External Degree Program. 
Outside Employment. The effect of outside employment on leaving/finishing decisions of External Degree students was assessed in survey question number 47. As the following table shows, both study groups reported sizable numbers working over a 40-hour week, but leavers reported a larger percentage $(68.5 \%)$ than did finishers $(45.6 \%)$, and the difference was significant at $p<.05$.

TABLE XXVII

HOURS PER WEEK EMPLOYED OUTSIDE THE HOME

\begin{tabular}{|c|c|c|c|c|c|c|c|}
\hline & 0 & $1-10$ & $11-20$ & $21-30$ & $31-40$ & $40+$ & $\begin{array}{l}\text { Row Total } \\
\text { Column } \%\end{array}$ \\
\hline LVRS & $\begin{array}{c}3 \\
(2.7 \%)\end{array}$ & $(1.8 \%)$ & $\begin{array}{c}3 \\
(2.7 \%)\end{array}$ & $\begin{array}{c}2 \\
(1.8 \%)\end{array}$ & $\begin{array}{c}25 \\
(22.5 \%)\end{array}$ & $\begin{array}{c}76 \\
(68.5 \%)\end{array}$ & $\begin{array}{c}111 \\
(35.2 \%)\end{array}$ \\
\hline FNSHRS & $\begin{array}{c}13 \\
(6.4 \%)\end{array}$ & ${ }^{5}(2.5 \%)$ & $\begin{array}{c}12 \\
(5.9 \%)\end{array}$ & $\begin{array}{c}10 \\
(4.9 \%)\end{array}$ & $\begin{array}{c}71 \\
(34.8 \%)\end{array}$ & $\begin{array}{c}93 \\
(45.6 \%)\end{array}$ & $\begin{array}{l}204 \\
(64.8 \%)\end{array}$ \\
\hline
\end{tabular}

$\left(x^{2}=15.95 ; d f=5 ; p=0.007 ;\right.$ response rate, $\left.99.7 \%\right)$

Outside Encouragement. Six potential sources of outside encouragement for the subjects were assessed: (1) spouse/significant other, (2) parents, (3) siblings, (4) children, (5) friends, and (6) employer. In all areas except sibling support, leavers and finishers responded differenty and the differences were significant. The largest percentage of responses for both groups regarding the extent of sibling support was "not applicable," $46.7 \%$ for leavers and $32.7 \%$ for finishers. Support from one's 
spouse/significant other was stronger for finishers than for leavers as the following table shows.

TABLE XXVIII

EXTENT OF ENCOURAGEMENT FROM SPOUSE/SIGNIFICANT OTHER

\begin{tabular}{|ccccc|}
\hline & Not at & Smal1/ & Great/Very & \multicolumn{2}{c|}{$\begin{array}{c}\text { Row Total } \\
\text { N/A }\end{array}$} & Al1 & Some Extent & Great Extent & Colum $\%$ \\
\hline LVRS $\begin{array}{c}20 \\
(18.3 \%)\end{array}$ & $\begin{array}{c}9 \\
(8.3 \%)\end{array}$ & $\begin{array}{c}34 \\
(31.2 \%)\end{array}$ & $\begin{array}{c}46 \\
(42.2 \%)\end{array}$ & $\begin{array}{c}109 \\
(34.8 \%)\end{array}$ \\
\hline $\begin{array}{c}\text { FNSHRS } 16 \\
(7.8 \%)\end{array}$ & $\begin{array}{c}5 \\
(2.5 \%)\end{array}$ & $\begin{array}{c}41 \\
(20.1 \%)\end{array}$ & $\begin{array}{c}142 \\
(69.6 \%)\end{array}$ & $\begin{array}{c}204 \\
(65.2 \%)\end{array}$ \\
\hline
\end{tabular}

$\left(X^{2}=24.7 ;\right.$ df $=3 ; p=0.000 ;$ response rate $\left.99.1 \%\right)$

Likewise, support from parents was stronger for

finishers than it was for leavers:

TABLE XXIX

EXTENT OF ENCOURAGEMENT FROM PARENTS

\begin{tabular}{|c|c|c|c|c|c|}
\hline \multirow{2}{*}{\multicolumn{2}{|c|}{ N/A }} & \multirow{2}{*}{$\begin{array}{l}\text { Not at } \\
\text { All }\end{array}$} & SmaI1/ & Great/Very & Row Total \\
\hline & & & Some Extent & Great Extent & Column \% \\
\hline LVRS & $\begin{array}{c}45 \\
(42.1 \%)\end{array}$ & $\begin{array}{c}16 \\
(15.0 \%)\end{array}$ & $\begin{array}{c}28 \\
(26.2 \%)\end{array}$ & $\begin{array}{c}18 \\
(16.8 \%)\end{array}$ & $\begin{array}{c}107 \\
(34.4 \%)\end{array}$ \\
\hline FNSHI & $\begin{array}{c}54 \\
(26.5 \%)\end{array}$ & $\begin{array}{c}39 \\
(19.1 \%)\end{array}$ & $\begin{array}{c}59 \\
(28.9 \%)\end{array}$ & $\begin{array}{c}52 \\
(25.5 \%)\end{array}$ & $\begin{array}{c}204 \\
(65.6 \%)\end{array}$ \\
\hline
\end{tabular}

$\left(x^{2}=8.57 ;\right.$ df $=3 ; p=0.035 ;$ response rate $\left.98.4 \%\right)$

So, too, was encouragement from one's children

stronger for finishers than it was for leavers: 
TABLE XXX

EXTENT OF ENCOURAGEMENT FROM CHILDREN

\begin{tabular}{|cccccc|}
\hline & Not at & Smal1/ & Great/Very & Row Total \\
N/A & A11 & Some Extent & Great Extent & Column $\%$ \\
\hline LVRS & 32 & 21 & 35 & 22 & 110 \\
& $(29.1 \%)$ & $(19.1 \%)$ & $(31.8 \%)$ & $(20.0 \%)$ & $(35.1 \%)$ \\
\hline FNSHRS 50 & 21 & 69 & 63 & 203 \\
$(24.6 \%$ & $(10.3 \%)$ & $(34.0 \%)$ & $(31.0 \%)$ & $(64.9 \%)$ \\
\hline
\end{tabular}

$$
\left(x^{2}=7.9 ; \text { df }=3 ; p=0.048 \text {; response rate } 99.1 \%\right)
$$

Friends and employers were also identified by

finishers as providing more support than they were by leavers as the following two tables show.

TABLE XYXI

EXTENT OF ENCOURAGEMENT FROM FRIENDS

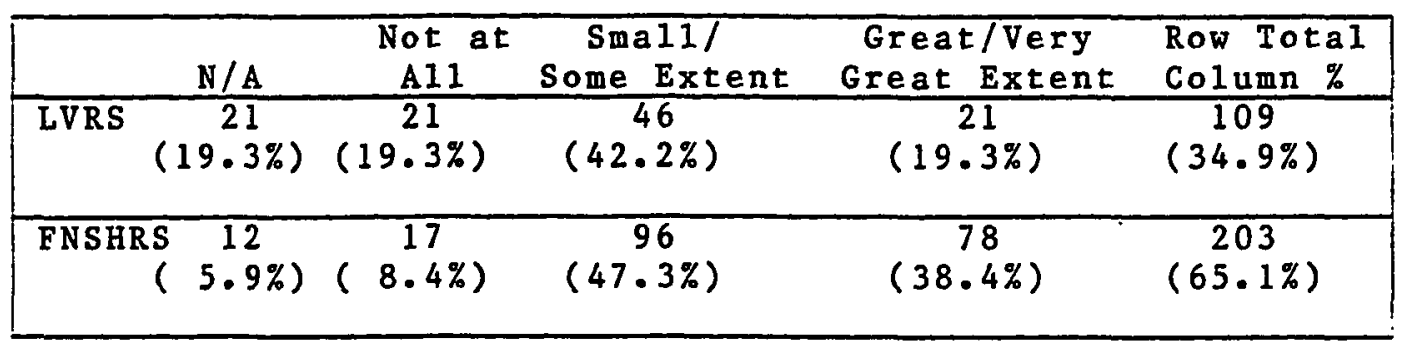

$$
\left(x^{2}=27.47 ; d f=3 ; p=0.000 ; \text { response rate } 98.7 \%\right)
$$

TABLE XXXII

EXTENT OF ENCOURAGEMENT FROM EMPLOYER

\begin{tabular}{|cccccc|}
\hline & N/A & Not at & Smalil & Great/Very & Row Total \\
\hline LVRS & 26 & 27 & Some Extent & Great Extent & Column $\%$ \\
$(23.9 \%)$ & $(24.8 \%)$ & $(35.8 \%)$ & $(15.6 \%)$ & $(34.9 \%)$ \\
\hline $\begin{array}{r}\text { FNSHRS } 31 \\
(15.3 \%)\end{array}$ & $(15.3 \%)$ & $(35.5 \%)$ & $(34.0 \%)$ & $(65.1 \%)$ \\
\hline
\end{tabular}

$$
\left(x^{2}=15.00 ; d f=3 ; p=0.002 ; \text { response rate } 98.7 \%\right)
$$


As shown in the preceding tables, with the exception of sibling support, finishers reported receiving significantly more encouragement than did leavers from people in their lives--spouses/significant others, parents, children, friends, and employers. Also, in every case, a higher percentage of leavers than of finishers responded "n/a" when asked about support from all sources: spouse/significant other, parents, siblings, children, friends, and employer.

Family Responsibilities. These environmental issues were assessed for the two study groups by survey questions no. 48 and 49 . Specifically, there was no significant difference at p<.05 between the two groups on the number of children at home while in the program nor on the respondent's marital status. Even so, the highest percentage of leavers, $31.8 \%$, reported having two children at home while in the program, whereas the highest percentage of finishers, $34.8 \%$, reported that no children were at home while they were in the program. Though not statistically significant at $p<.05$, responses to this question showed movement toward significance as the following table indicates: 
TABLE XXXIII

NO. CHILDREN AT HOME WHILE IN EXTERNAL DEGREE PROGRAM

\begin{tabular}{|ccccccc|}
\hline & none & 1 & 2 & 3 & $4+$ & $\begin{array}{c}\text { Row Total } \\
\text { Column } \%\end{array}$ \\
\hline LEAVERS & $\begin{array}{c}30 \\
(27.3 \%)\end{array}$ & $\begin{array}{c}18 \\
(16.4 \%)\end{array}$ & $\begin{array}{c}35 \\
(31.8 \%)\end{array}$ & $\begin{array}{c}17 \\
(15.5 \%)\end{array}$ & $\begin{array}{c}10 \\
(9.1 \%)\end{array}$ & $\begin{array}{c}110 \\
(35.0 \%)\end{array}$ \\
\hline FINISHERS & $\begin{array}{c}71 \\
(34.8 \%)\end{array}$ & $(22.1 \%)$ & $(30.4 \%)$ & $\left(\begin{array}{l}6.8 \%) \\
(3.9 \%)\end{array}\right.$ & $\begin{array}{c}204 \\
(65.0 \%)\end{array}$ \\
\hline
\end{tabular}

$\left(X^{2}=8.61 ; d f=4 ; p=0.072 ;\right.$ response rate $\left.99.4 \%\right)$

Marital Status. The majority of subjects in both study groups were married, $73.6 \%$ of leavers and $84.3 \%$ of finishers. Though not statistically significant, leavers almost doubled the finishers' percentage of single and/or divorced respondents: $23.7 \%$ of leavers were single or divorced whereas $13.3 \%$ of finishers were.

Perception of Ability to Transfer. The final environmental variable evaluated in this study referred to the subjects' perception of their ability to transfer out of the External Degree. The two questions asked of subjects regarding transfer (No. 19 and 21 ) did produce significantly different responses. A higher percentage of finishers were aware of similar programs at other schools as the following table shows. 
TABLE XXXIV

AWARENESS OF OTHER EXTERNAL DEGREE PROGRAMS

\begin{tabular}{|cccc|}
\hline & YES & NO & $\begin{array}{l}\text { Row Total } \\
\text { Column } \%\end{array}$ \\
\hline LEAVERS & 57 & 54 & 111 \\
& $(51.4 \%)$ & $(48.6 \%)$ & $(35.2 \%$ \\
\hline FINISHERS & 139 & 65 & 204 \\
& $(68.1 \%)$ & $(31.9 \%)$ & $(64.8 \%$ \\
\hline
\end{tabular}

$\left(X^{2}=7.91 ;\right.$ df $=1 ; p=0.005 ;$ response rate $\left.99.7 \%\right)$

Though neither of the two study groups reported a majority considered transferring, significantly more leavers (38.7\%) than finishers $(4.4 \%)$ did:

TABLE XXXV

DID YOU CONSIDER TRANSFERRING TO ANOTHER INSTITUTION?

\begin{tabular}{|c|c|c|c|}
\hline & YES & NO & $\begin{array}{l}\text { Row Total } \\
\text { Column \% }\end{array}$ \\
\hline LEAVERS & $\begin{array}{c}43 \\
(38.7 \%) \\
\end{array}$ & $\begin{array}{c}68 \\
(61.3 \%) \\
\end{array}$ & $\begin{array}{c}111 \\
(35.2 \%) \\
\end{array}$ \\
\hline F INISHERS & $\begin{array}{c}9 \\
(4.4 \%)\end{array}$ & $\begin{array}{c}195 \\
(95.6 \%)\end{array}$ & $\begin{array}{c}204 \\
(64.8 \%)\end{array}$ \\
\hline
\end{tabular}

$\left(x^{2}=58.99 ;\right.$ df $=1 ; p=0.000 ;$ response rate $\left.99.7 \%\right)$

A summary of the effect that environmental variables have on leave/finish decisions of External Degree students indicates that neither finances nor family responsibilities discriminate between leavers and finishers. However, outside employment, espectaliy where the work week is longer than 40 hours, did discriminate leavers from finishers. Also, leavers reported less encouragement to pursue their 
education from others in their lives than did finishers, and these results were significantly different. Awareness of transfer opportunities was more pronounced in the finishers than in the leavers but did not result in actual transfer.

Academic Outcomes

College GPA was the measure by which Academic Outcome was studied. With information obtained from the Eastern Oregon State College active and archive student data bases, GPAs of 57 of the 112 leavers and 150 of the 204 finishers were obtained. The average GPA for leavers was 2.91; for finishers, 3.38 , resulting in a t-statistic between the two means that was significantly different on both a one-tailed and a two-talled test at $p=0.000$. In other words, the performance, as measured by college GPA, of the External Degree finishers was significantly better than that of Program leavers, and the probability of finding this difference in GPA was due to something other than chance. A further statistical calculation using a one-way ANOVA resulted in a significant $F$ ratio with $p=0.00$, and determined that the source of the variation in means was between, rather than within, the two groups of subjects.

\section{Psychological Outcomes}

The Psychological Outcomes felt by the two study groups as a result of their participation in the External Degree Program were assessed in four areas: (1) utility of degree, (2) satisfaction with the role of being a student, 
(3) commitment to goal as it relates to career needs, and

(4) stress.

Utility of Degree. Four questions (No. 51, 78-80)

comprised the utility area. Three resulted in statistically significant differences at $p<.05$ for leavers and finishers. The one which did not asked subjects to cite the main reason they enrolled in the program. For both the 108 leavers and 203 finishers who responded to this question, the ranking of nearly $90 \%$ of their responses was in the same order:

TABLE XXXVI

REASON ENROLLED IN EXTERNAL DEGREE

\begin{tabular}{|c|c|c|c|}
\hline \multicolumn{2}{|c|}{$\begin{array}{l}\text { Response } \\
\text { Frequency }\end{array}$} & \multirow{2}{*}{$\begin{array}{l}\text { Leavers } \\
\begin{array}{l}31.5 \% \\
(n=34)\end{array}\end{array}$} & \multirow{2}{*}{$\begin{array}{r}\text { Finishers } \\
29.6 \% \\
(n=60)\end{array}$} \\
\hline$\# 1$ & To improve myself & & \\
\hline$\# 2$ & For personal challenge & $\begin{array}{l}28.7 \% \\
(n=31)\end{array}$ & $\begin{array}{l}25.1 \% \\
(n=51)\end{array}$ \\
\hline$\# 3$ & To get better job & $\begin{array}{l}24.1 \% \\
(n=26)\end{array}$ & $\begin{array}{l}17.2 \% \\
(n=35)\end{array}$ \\
\hline$\# 4$ & Required in my work & $\begin{array}{l}10.2 \% \\
(n=11)\end{array}$ & $\begin{array}{l}16.7 \% \\
(n=34)\end{array}$ \\
\hline
\end{tabular}

When reasons 1 and 2 are combined, over $60 \%$ of the leavers and $55 \%$ of the finishers cited personal, versus vocational, reasons as the primary motivator.

Questions 78-80 asked subjects to assess the impact that participating in the External Degree Program had on knowing themselves, using interpersonal skills, and seeing alternative points of view. All three questions resulted in 
statisticaliy significant differences at $p<.05$. Though responses to the "knowing myself" question resulted in similar response trends between the two study groups, the following table shows that significantly more finishers than leavers felt the impact was great.

TABLE XXXVII

EXTERNAL DEGREE'S IMPACT ON KNOWING MYSELF

\begin{tabular}{|lcccc|}
\hline & $\begin{array}{c}\text { 11ttle/ } \\
\text { none }\end{array}$ & some & much & $\begin{array}{c}\text { Row Total } \\
\text { Column }\end{array}$ \\
\hline LEAVERS & 36 & 36 & 37 & 109 \\
& $(33.0 \%)$ & $(33.0 \%)$ & $(33.9 \%)$ & $(34.8 \%)$ \\
\hline FINISHERS & 13 & 51 & 140 & 204 \\
& $(6.4 \%)$ & $(25.0 \%)$ & $(68.6 \%)$ & $(65.2 \%$ \\
\hline
\end{tabular}

$\left(X^{2}=49 ; \mathrm{df}=2 ; p=0.000 ;\right.$ response rate, $\left.99.1 \%\right)$

The trend was just the opposite, however, when leavers' and finishers' responses to the impact on using interpersonal skills and seeing alternate points of view were compared. Whereas the majority of finishers reported much impact, the majority of leavers reported little/none.

TABLE XXXVIII

EXTERNAL DEGREE'S IMPACT ON USING INTERPERSONAL SKILLS

\begin{tabular}{|lcccc|}
\hline & $\begin{array}{c}\text { Iittle } \\
\text { none }\end{array}$ & some & much & $\begin{array}{c}\text { Row Total } \\
\text { Co1umn }\end{array}$ \\
\hline LEAVERS & 41 & 33 & 35 & 109 \\
& $(37.6 \%)$ & $(30.3 \%)$ & $(32.1 \%)$ & $(34.8 \%)$ \\
\hline FINISHERS & 10 & 58 & 136 & 204 \\
& $(4.9 \%)$ & $(28.4 \%)$ & $(66.7 \%)$ & $(65.2 \%)$ \\
\hline
\end{tabular}

$\left(x^{2}=62.26 ; d f=2 ; p=0.000 ;\right.$ response rate, $\left.99.1 \%\right)$ 
TABLE XXXIX

EXTERNAL DEGREE'S IMPACT ON SEEING ALTERNATE POINTS OF VIEW

\begin{tabular}{|lcccc|}
\hline & $\begin{array}{c}\text { Ifttle/ } \\
\text { none }\end{array}$ & some & much & $\begin{array}{c}\text { Row Total } \\
\text { Column } \%\end{array}$ \\
\hline LEAVERS & 40 & 30 & 38 & 108 \\
& $(37.0 \%)$ & $(27.8 \%)$ & $(35.2 \%)$ & $(34.8 \%)$ \\
\hline FINISHERS & 11 & 57 & 134 & 202 \\
& $(5.4 \%)$ & $(28.2 \%)$ & $(66.3 \%)$ & $(65.2 \%$ \\
\hline
\end{tabular}

$\left(x^{2}=55 ;\right.$ df $=2 ; p=0.000 ;$ response rate, $\left.98.1 \%\right)$

Satisfaction with Student Role. The subjects' level

of satisfaction with several aspects of the External Degree

was determined from six survey questions, No. $23,26,34$,

67-69. Responses to all six questions resulted in statisti-

cally significant differences at $p<.05$. Question 23 asked

subjects if they felt the academic expectations were more

difficult than they liked. Though a majority in both groups said no, more leavers $(23.9 \%)$ than finishers (5.4\%) said yes.

TABLE XL

ACADEMIC EXPECTATIONS MORE DIFFICULT THAN YOU LIKED?

\begin{tabular}{|cccc|}
\hline & & & Row Total \\
\hline LES & NO & Column $\%$ \\
\hline FINISHERS & 26 & 83 & 109 \\
& $(23.9 \%)$ & $(76.1 \%)$ & $(34.9 \%)$ \\
\hline & $(5.4 \%)$ & $(94.6 \%)$ & $(65.1 \%)$ \\
\hline
\end{tabular}

$\left(x^{2}=21.32 ;\right.$ df $=1 ; p=0.000 ;$ response rate $\left.98.7 \%\right)$

Leavers differed significantly from finishers in response to their attitude regarding the need for required standardized testing. The finishers were nearly equally split in their yes/no responses. The leavers, however, had over twice as many no responses as yes ones. 
TABLE XLI

SHOULD STANDARDIZED TESTING BE REQUIRED IN THE PROGRAM?

\begin{tabular}{|cccc|}
\hline & & & Row Total \\
\hline & YES & No & Column $\%$ \\
\hline LEAVERS. & 35 & 75 & 110 \\
& $(31.8 \%)$ & $(68.2 \%)$ & $(35.0 \%)$ \\
\hline FINISHERS & 110 & 94 & 204 \\
& $(53.9 \%)$ & $(46.1 \%)$ & $(65.0 \%)$ \\
$\left(\mathrm{X}^{2}=13.17 ; \mathrm{df}=1 ; \mathrm{p}=0.000 ;\right.$ response rate $\left.99.4 \%\right)$
\end{tabular}

When asked if instructor feedback on course

assignments had been timely, over $25 \%$ of the leavers, compared to only $3 \%$ of the finishers, stated not applicable. The majority of subjects in both groups, however, stated yes, $54.1 \%$ of the leavers and $85.6 \%$ of the finishers.

TABLE XLII

INSTRUCTOR FEEDBACK ON COURSES TIMELY?

\begin{tabular}{|ccccc|}
\hline & Yes & No & $\begin{array}{c}\text { Not } \\
\text { Applicable }\end{array}$ & $\begin{array}{c}\text { Row Total } \\
\text { Column } \%\end{array}$ \\
\hline LEAVERS & $\begin{array}{c}59 \\
(54.1 \%)\end{array}$ & $\begin{array}{c}22 \\
(20.2 \%)\end{array}$ & $\begin{array}{c}28 \\
(25.7 \%)\end{array}$ & $\begin{array}{c}109 \\
(35.2 \%)\end{array}$ \\
\hline FINISHERS $\begin{array}{c}172 \\
(85.6 \%)\end{array}$ & $\begin{array}{l}23 \\
(11.4 \%)\end{array}$ & $(3.0 \%)$ & $\begin{array}{c}201 \\
(64.8 \%)\end{array}$ \\
\hline
\end{tabular}

$\left(x^{2}=46.31 ;\right.$ df $=2 ; p=0.000$; response rate $\left.98.1 \%\right)$

The last three questions in the area of student satisfaction dealt with the subjects' perception of their difficulty obtaining information from (1) advisors and (2) Instructors and (3) with progressing in the program because of, or in spite of, certain rules and procedures. 
All questions resulted in statistically significant differences at $p<.05$ between leavers and finishers. In all cases as the following three tables show, the majority of finishers responded not at all to perceptions of difficulty but the largest percentage of leavers responded to some/small extent.

TABLE XLIII

DIFEICULTY WITH ASKING ADVISOR FOR HELP

\begin{tabular}{|ccccc|}
\hline & $\begin{array}{c}\text { Not at } \\
\text { A11 }\end{array}$ & $\begin{array}{c}\text { Small/Some } \\
\text { Extent }\end{array}$ & $\begin{array}{c}\text { Great/Very } \\
\text { Great Extent }\end{array}$ & $\begin{array}{c}\text { Row Total } \\
\text { Column } \%\end{array}$ \\
\hline LEAVERS & $\begin{array}{c}37 \\
(33.9 \%)\end{array}$ & $\begin{array}{c}51 \\
(46.8 \%)\end{array}$ & $\begin{array}{c}21 \\
(19.3 \%)\end{array}$ & $\begin{array}{c}109 \\
(34.8 \%)\end{array}$ \\
\hline FINISHERS & $\begin{array}{c}142 \\
(69.6 \%)\end{array}$ & $\begin{array}{c}54 \\
(26.5 \%)\end{array}$ & $(3.9 \%)$ & $\begin{array}{c}204 \\
(65 \%)\end{array}$ \\
\hline
\end{tabular}

$$
\left(x^{2}=42.59 ; \text { df }=2 ; p=0.000 ; \text { response rate } 99.1 \%\right)
$$

TABLE XLIV

DIFFICULTY WITH ASKING INSTRUCTORS FOR HELP

\begin{tabular}{|ccccc|}
\hline & $\begin{array}{c}\text { Not at } \\
\text { All }\end{array}$ & $\begin{array}{c}\text { Sma11/Some } \\
\text { Extent }\end{array}$ & $\begin{array}{c}\text { Great/Very } \\
\text { Great Extent }\end{array}$ & $\begin{array}{c}\text { Row Total } \\
\text { Column }\end{array}$ \\
\hline LEAVERS & $\begin{array}{c}39 \\
(37.5 \%)\end{array}$ & $\begin{array}{c}41 \\
(39.4 \%)\end{array}$ & $\begin{array}{c}24 \\
(23.1 \%)\end{array}$ & $\begin{array}{c}104 \\
(34.1 \%)\end{array}$ \\
\hline FINISHERS & $\begin{array}{c}109 \\
(54.2 \%)\end{array}$ & $\begin{array}{c}76 \\
(37.8 \%)\end{array}$ & $\left(\begin{array}{c}16 \\
8.0 \%)\end{array}\right.$ & $\begin{array}{c}201 \\
(65.9 \%)\end{array}$ \\
\hline
\end{tabular}

$$
\left(x^{2}=15.94 ; \text { df }=2 ; p=0.000 ; \text { response rate } 96.5 \%\right)
$$


TABLE XLV

DID RULES/PROCEDURES OF PROGRAM INHIBIT YOUR PROGRESS?

\begin{tabular}{|ccccc|}
\hline & $\begin{array}{c}\text { Not at } \\
\text { Al1 }\end{array}$ & $\begin{array}{c}\text { Sma11/Some } \\
\text { Extent }\end{array}$ & $\begin{array}{c}\text { Great/Very } \\
\text { Great Extent }\end{array}$ & $\begin{array}{c}\text { Row Total } \\
\text { Column }\end{array}$ \\
\hline LEAVERS & $\begin{array}{c}42 \\
(39.6 \%)\end{array}$ & $(40.6 \%)$ & $(19.8 \%)$ & $(34.2 \%)$ \\
\hline FINISHERS & $\begin{array}{c}165 \\
(80.9 \%)\end{array}$ & $\begin{array}{c}35 \\
(17.2 \%)\end{array}$ & $(2.0 \%)$ & $(65.8 \%)$ \\
\hline
\end{tabular}

$\left(x^{2}=60.53 ; d f=2 ; p=0.000 ;\right.$ response rate $\left.98.1 \%\right)$

Linkage of Degree to Career. Whether or not a college degree was required for the subject's continuation in their career was used to measure the subjects' goal commitment. A significant difference in leavers' and finishers' responses to this question resulted with more finishers ( $43.2 \%)$ than leavers $(27.1 \%)$ indicating that a degree was required for career continuation. On the other hand, the majority of leavers $(64.5 \%)$ stated that it was not.

TABLE XLVI

DEGREE REQUIRED FOR CAREER CONTINUATION?

\begin{tabular}{|ccccc|}
\hline & Yes & No & Not Applicable & $\begin{array}{c}\text { Row Total } \\
\text { Column } \%\end{array}$ \\
\hline LEAVERS & $\begin{array}{c}29 \\
(27.1 \%)\end{array}$ & $\begin{array}{c}69 \\
(64.5 \%)\end{array}$ & $\left(\begin{array}{c}9 \\
8.4 \%)\end{array}\right.$ & $\begin{array}{c}107 \\
(35.0 \%)\end{array}$ \\
\hline FINISHERS $\begin{array}{c}86 \\
(43.2 \%)\end{array}$ & $\begin{array}{c}98 \\
(49.2 \%)\end{array}$ & $\left(\begin{array}{c}15 \\
7.5 \%)\end{array}\right.$ & $\begin{array}{c}199 \\
(65.0 \%)\end{array}$ \\
\hline
\end{tabular}

$\left(x^{2}=7.83 ; \mathrm{df}=2 ; \mathrm{p}=0.020 ;\right.$ response rate $\left.96.8 \%\right)$ 
Stress. To determine any differences in the level of stress felt by leavers and finishers, seven questions (No. 28-33, 50) were asked. Spectfically, subjects were asked to indicate whether/not they had had to cut back on six different aspects of their life and to what level they had been able to commit the time that the program required. Two of the six life aspects, amount of paid employment and time with their children, resulted in no statistically significant differences between leavers and finishers. A majority of responses in both groups of subjects indicated that they had not reduced time spent on either of these two activities. In the other areas, however, responses were different. For example, a majortty of finishers indicated they had cut back on social activities with friends, but a majority of leavers had not.

- TABLE XLVII

CUT BACK ON SOCIAL ACTIVITIES WITH FRIENDS?

\begin{tabular}{|ccccc|}
\hline & Yes & No & Not Applicable & $\begin{array}{c}\text { Row Total } \\
\text { Column } \%\end{array}$ \\
\hline LEAVERS & $\begin{array}{c}44 \\
(40.4 \%)\end{array}$ & $\begin{array}{c}57 \\
(52.3 \%)\end{array}$ & $\begin{array}{c}8 \\
(7.3 \%)\end{array}$ & $\begin{array}{c}109 \\
(34.8 \%)\end{array}$ \\
\hline FINISHERS $\begin{array}{c}123 \\
(60.3 \%)\end{array}$ & $\begin{array}{c}81 \\
(39.7 \%)\end{array}$ & $(0.0 \%)$ & $\begin{array}{c}204 \\
(65.2 \%)\end{array}$ \\
\hline
\end{tabular}

$\left(x^{2}=22.81 ;\right.$ df $=2 ; p=0.000 ;$ response rate $\left.99.1 \%\right)$ 
Likewise, $56.9 \%$ of finishers but only $45.5 \%$ of leavers indicated they had cut back on time with their spouse or significant other while participating in the program.

TABLE XLVIII

CUT BACK ON ALONE TIME WITH SPOUSE/SIGNIFICANT OTHER?

\begin{tabular}{|ccccc|}
\hline & Yes & No & Not Applicable & $\begin{array}{c}\text { Row Tota1 } \\
\text { Column } \%\end{array}$ \\
\hline LEAVERS & 50 & 47 & 13 & 110 \\
& $(45.5 \%)$ & $(42.7 \%)$ & $(11.8 \%)$ & $(35.0 \%)$ \\
\hline FINISHERS $\begin{array}{c}116 \\
(56.9 \%)\end{array}$ & $(40.2 \%)$ & $(2.9 \%)$ & $(65.0 \%)$ \\
\hline
\end{tabular}

$\left(x^{2}=11.17 ; d f=2 ; p=0.004 ;\right.$ response rate $\left.99.4 \%\right)$

Respondents from the two groups were somewhat more similar, though still statistically different at p<.05 in responding to whether or not they had cut back on housework or home maintenance during their participation in the program. A majority (53.9\%) of finishers had, while a majority $(50.9 \%)$ of leavers had not.

TABLE XLIX

CUT BACK ON HOUSEWORK/HOME MAINTENANCE?

\begin{tabular}{|cccccc|}
\hline & Yes & No & Not Applicable & $\begin{array}{c}\text { Row Tota1 } \\
\text { Column } \%\end{array}$ \\
\hline LEAVERS & 46 & 55 & 7 & 108 \\
& $(42.6 \%)$ & $(50.9 \%)$ & $(6.5 \%)$ & $(34.6 \%)$ \\
\hline FINISHERS & 110 & 93 & 1 & $(0.5 \%)$ & $(65.4 \%)$ \\
& $(53.9 \%)$ & $(45.6 \%)$ & $(04$ & $(0.5 \%)$ \\
\hline
\end{tabular}

$$
\left(x^{2}=12.12 ; \text { df }=2 ; p=0.002 ; \text { response rate } 98.7 \%\right)
$$

The largest area of difference regarding cutting back on responsibilities resulted from asking the study groups 
about their civic commitments. While more finishers ( $47.5 \%)$ than leavers $(19.1 \%)$ said they had cut back, the percentage of responses from leavers saying "not applicable" doubled that response from finishers.

TABLE L

CUT BACK ON CIVIC RESPONSIBILITIES?

\begin{tabular}{|ccccc|}
\hline & Yes & No & Not Appl1cable & $\begin{array}{c}\text { Row Tota1 } \\
\text { Column } \%\end{array}$ \\
\hline LEAVERS & 21 & 65 & 24 & 110 \\
& $(19.1 \%)$ & $(59.1 \%)$ & $(21.8 \%)$ & $(35.0 \%)$ \\
\hline FINISHERS & 97 & 86 & 21 & 204 \\
& $(47.5 \%)$ & $(42.2 \%)$ & $(10.3 \%)$ & $(65.0 \%)$ \\
\hline
\end{tabular}

$$
\left(x^{2}=26.28 ; d f=2 ; p=0.000 ; \text { response rate } 99.4 \%\right)
$$

The final stress-related question asked subjects about the amount of time they found the program required of them. The \#1 response from both groups to this question was "about as expected," $40 \%$ leavers; $53.2 \%$ finishers. However, whereas $32.4 \%$ of leavers sald the demands of the program required more time than they had, only .5\% of the finishers felt that way.

TABLE LI

AMOUNT OF TIME REQUIRED FOR PROGRAM

\begin{tabular}{|cccccc|}
\hline $\begin{array}{c}\text { more than } \\
\text { I had }\end{array}$ & $\begin{array}{c}\text { more, but } \\
\text { I found it }\end{array}$ & $\begin{array}{c}\text { about as } \\
\text { expected }\end{array}$ & $\begin{array}{c}\text { less than } \\
\text { expected }\end{array}$ & $\begin{array}{c}\text { hard1y } \\
\text { at a11 }\end{array}$ & $\begin{array}{c}\text { Row } \\
\text { Co1 }\end{array}$ \\
\hline $\begin{array}{c}\text { LVRS } 34 \\
(32.4 \%)\end{array}$ & $\begin{array}{c}25 \\
(23.8 \%)\end{array}$ & $\begin{array}{c}42 \\
(40.0 \%)\end{array}$ & $\begin{array}{c}0 \\
(0.0 \%)\end{array}$ & $\begin{array}{c}4 \\
(3.8 \%)\end{array}$ & $\begin{array}{c}105 \\
(34.1 \%)\end{array}$ \\
\hline $\begin{array}{c}\text { FNSH } \\
(0.5 \%)\end{array}$ & $(43.3 \%)$ & $\begin{array}{c}108 \\
(53.2 \%)\end{array}$ & $(2.5 \%)$ & $(0.5 \%)$ & $\begin{array}{c}503 \\
(65.9 \%)\end{array}$ \\
\hline
\end{tabular}

$\left(x^{2}=78.88 ; d f=4 ; p=0.000 ;\right.$ response rate $\left.97.5 \%\right)$ 
A summary of the ability of psychological outcomes to differentiate between leavers and finishers indicates that there are many differences between these two groups of individuals. of 18 questions asked in this category, only 3 resulted in no statistically significant differences at p<.05. For example, similar percentages of both leavers and finishers indicated the prime reason for participating in the program was for self-improvement. Also, similar percentages from both groups indicated they had not cut back on time on their jobs or with their children. Beyond these three issues, however, the similarities stop. Though majorities from both groups agreed, significantly more finishers than leavers felt that participation in the External Degree Program resulted in knowing themselves much better than before. Likewise, significantly more finishers than leavers felt program expectations were not that difficult. Also, more leavers than finishers indicated a degree was not required for continuation in their career. And, even though the highest percentage from both groups claimed to have cut back on alone time with their spouse/significant other while in the program, significantly more finishers than leavers indicated that they had.

Clearer differences between the two groups of subjects emerged on other dimensions of psychological outcomes. For example, whereas a majority of finishers felt External Degree participation impacted their use of interpersonal 
skills and ability to see alternate points of view "a great deal," the highest percentage of leavers felt participation had done little, if anything, to impact them in these areas. Likewise, a majority of finishers felt standardized basic skills tests should be a required part of the Program, whereas a majority of leavers did not. More leavers than finishers expressed significantly more difficulty in obtaining information from advisors and instructors, and the leavers felt than the rules and procedures of the Program inhibited their progress a great deal more than did finishers. In addition, significantly more leavers than finishers indicated the Program required more time than they had, but they were also less apt to cut back on social activities with friends, alone time with spouse/significant other, housework/home maintenance, or civic responsibilities.

\section{Intent-to-Leave}

One question which was asked of the subjects dealt with any discussions they may have had with individuals, other than EOSC personnel, regarding the possibility of their leaving the program. Though neither group had a majority stating that they had ever discussed this possibility with non-EOSC personnel, more leavers (14.4\%) than finishers (3.4\%) had, and the difference was significant at $p<.05$. 
TABLE LII

ANY DISCUSSION WITH NON-EOSC PERSONNEL ABOUT LEAVING?

\begin{tabular}{|lccc|}
\hline & YES & NO & $\begin{array}{c}\text { Row Tota1 } \\
\text { Column } \%\end{array}$ \\
\hline LEAVERS & 16 & 95 & 111 \\
& $(14.4 \%)$ & $(85.6 \%)$ & $(35.2 \%)$ \\
\hline EINISHERS & 7 & 197 & 204 \\
& $(3.4 \%)$ & $(96.6 \%)$ & $(64.8 \%)$ \\
\hline
\end{tabular}

$\left(X^{2}=11.24 ; \mathrm{df}=1 ; \mathrm{p}=0.001 ;\right.$ response rate $\left.99.7 \%\right)$

\section{Quality Issues}

Another area on which leavers and finishers were compared referred to the quality that subjects perceived receiving from their education at Eastern and their impressions of the overall reputation of Eastern oregon State College itself. The majority of leavers indicated they were unable to judge the quality of their Eastern education, whereas the majority of finishers felt they received a good or excellent education.

\section{TABLE LIII}

QUALITY OF EOSC EDUCATION RECEIVED

\begin{tabular}{|lcccc|}
\hline & $\begin{array}{c}\text { Unable to } \\
\text { Judge }\end{array}$ & $\begin{array}{c}\text { Poor } \\
\text { Fair }\end{array}$ & $\begin{array}{c}\text { Good } \\
\text { Excellent }\end{array}$ & $\begin{array}{c}\text { Row Total } \\
\text { Column }\end{array}$ \\
\hline LEAVERS & 60 & 14 & 38 & 112 \\
& $(53.6 \%)$ & $(12.5 \%)$ & $(33.9 \%)$ & $(35.4 \%$ \\
\hline FINISHERS & 9 & 7 & 188 & 204 \\
& $(4.4 \%)$ & $(3.4 \%)$ & $(92.2 \%)$ & $(64.6 \%$ \\
\hline
\end{tabular}

$$
\left(x^{2}=123.24 ; \text { df }=2 ; p=0.000 ; \text { response rate } 100.0 \%\right.
$$

With regard to the question about the overall quality of Eastern Oregon State College, $50 \%$ of the leavers felt it 
was fairly or very high, as did $84.8 \%$ of the finishers. of the leavers, $44.6 \%$ felt the reputation was neither high nor 1ow. Small percentages of both groups, as the following table shows, felt the overall quality was either very or fairly low.

TABLE LIV

HOW HIGH IS THE QUALITY OF EASTERN OREGON STATE?

\begin{tabular}{|c|c|c|c|c|}
\hline $\begin{array}{c}\text { Veryl } \\
\text { Fairly Low }\end{array}$ & $\begin{array}{l}\text { Not High } \\
\text { ox Low }\end{array}$ & $\begin{array}{l}\text { Fairly } \\
\text { High }\end{array}$ & $\begin{array}{l}\text { Very } \\
\text { High }\end{array}$ & $\begin{array}{l}\text { Row Total } \\
\text { Column \% }\end{array}$ \\
\hline $\begin{array}{c}6 \\
(5.4 \%)\end{array}$ & $\begin{array}{c}50 \\
(44.6 \%)\end{array}$ & $\begin{array}{c}45 \\
(40.2 \%)\end{array}$ & $\begin{array}{c}11 \\
(9.8 \%)\end{array}$ & $\begin{array}{c}112 \\
(35.4 \%)\end{array}$ \\
\hline $\begin{array}{lc}\text { FNSHRS } & 1 \\
& (0.5 \%)\end{array}$ & $\begin{array}{c}30 \\
(14.7 \%)\end{array}$ & $\begin{array}{c}126 \\
(61.8 \%)\end{array}$ & $\begin{array}{c}47 \\
(23.0 \%)\end{array}$ & $\begin{array}{c}204 \\
(64.6 \%)\end{array}$ \\
\hline
\end{tabular}

$$
\left(x^{2}=46.43 ; \mathrm{df}=3 ; p=0.000 ; \text { response rate } 100.0 \%\right)
$$

\section{Changes if Re-entering College}

One open-ended question was asked on the survey: "If you had it to do alloveragain, what would you do differently a 'second-time around' when returning to college?" The majority of leavers' comments could be organized into four categories:

(1) Seek a more structured curriculum/program with more traditional requirements and deadlines. (21 responses)

(2) Set personal deadines; develop a clear degree-completion plan; and maintain selfdiscipline even if the program allows for - more flexibility. ( 17 responses)

(3) Analyze and make conscientious choices about stress points that could distract me from my studies or postpone college until finances, employment responsibilities, and family obligations are less demanding. (13 responses) 
(4) Be more assertive in asking questions ahead of time to determine what the Program really was and what it was going to expect of me, so that I felt the end product was what $I$ wanted and the process was something I could handle. ( 9 responses)

Comments from the other leavers to this "second-timearound" question were either isolated responses or not given at a11.

When finishers responded to the same question, their comments shared some of the categories as the leavers but added a few new ones. For example, like responses from 21 leavers, 14 finishers said they would:

"seek a more structured Program or start out the External Degree with more traditional coursework rather than the assessment-of-priorlearning portfolio."

And, like 13 responses from leavers, 52 finishers said they would:

\footnotetext{
"startearlier inmy life or at least at a time when other responsibilities (family, job) were less stressful."
}

Nine leavers, as well as 9 finishers, said they would:

"be more assertive with Program and College staff when they didn't agree with the review of their portfolio essays, transfer credit standing, or interpretation of policies."

In addition, finishers added the following new categories of responses:

Choose a Program that either results in a specific degree (not General Studies) and/or has more visibility in the major academic area I pursued. (29 responses)

Try to find a way to return on a ful1-time basis or at least finish faster. ( 14 responses) 
Not be so obsessed with hurriedly finishing up; slow down and enjoy the process and classes more. (12 responses)

As with the leavers, a number of other isolated comments were offered. Of the finishers who responded to this question, 51 stated, in effect, that they would not do anything different. For example, the following comments were recelved from several of these individuals:

"I had a plan; the Program was there, and I saw it through. Everything worked out just right for me."

"You just have to make up your mind and go for it; the Program options are all right there."

"I had to just do it for me; no one else. It has to be that way."

"I only had 35 credits to complete my BS; I feel getting a degree through this Program was the best way."

"I wouldn't change a thing. I can't say enough good things about this Program."

"I can't imagine doing it differently. I think all the various options avallable now are valid ways to get a real meaningful degree. My portfolio essays and independent study classes were every bit as valuable and equal in quality to the four-year liberal arts college classes I also took."

"I'd do nothing differently. For all my purposes, the EOSC External Degree was exactly the right thing at the right time and in the right place."

"Tho I'd rather have finished college without interruption when I was young, you play life as it comes. I feel very fortunate to have participated in the Program; it was an excellent experience." 


\section{Letters Received From Respondents}

In adition to the comments included on the survey about what the respondent would do a second-time around when returning to college, 50 supplemental pieces of correspondence were received from study participants. These items ranged from brief notes attached to the completed survey to two-page typewritten letters. A breakdown of the content of these communications showed that:

16 included endorsements or compliments of the External Degree Program itself

15 provided an update on the personal and/or professional changes in the life of the respondent following graduation

9 were personal greetings to the author and External Degree Program staff

4 criticized the Program citing delays with feedback, misinterpretations, etc.

The balance mentioned various items, including requests for information about graduate programs, indications that tney (the leavers) were still interested, and suggestions for changes in the Program to enhance completion. One especially poignant letter was received from the daugher of a recently deceased External Degree participant. She wrote, "Mom didn't particularly care for every instructor or every assignment; however, I've never known a college student (myself included) who didn't, at some time during college, have these same feelings. Your program helped to make a dream come true." 
COMPARISON OF RURAL WITH URBAN RESPONDENTS

Literature cited in Chapter 2 regarding rural adult

learners indicated that they perceive more barriers to participating in education than do their urban counterparts. Therefore, the answers to several questions related to barriers were compared between rural and urban respondents in the present study. Specifically, using question 38 from the survey, respondents were first divided into two groups: (1) those living in eitherarural area/farm 15+miles from a city or in a town or small city under 50,000 and (2) those living in cities of $50,000+$ population or suburbs near large cities. This division resulted in 213 rural and 100 urban subjects with 3 missing the necessary data to categorize. Seven questions were then analyzed using the chi-square statistic:

1. Did you find the academic expectations more difficult than you liked?

2. Were degree requirements made clear to you by your advisor?

3. What was the most difficult barrier you faced to participating in the External Degree?

4. Were you satisfied with the amount of academic advising you received?

5. Were you satisfied with the guality of academic advising you received?

6. Were finances a problem for you?

7. Do you feel the rules and procedures of the Program Inhibited your progress toward completing the degree? 
Only one question, number 2 , resulted in a statistically significant difference between rural and urban respondents.

TABLE LV

WERE DEGREE REQUIREMENTS MADE CLEAR TO YOU BY YOUR ADVISOR?

\begin{tabular}{|cccc|}
\hline & YES & NO & $\begin{array}{c}\text { Row Total } \\
\text { Column } \%\end{array}$ \\
\hline $\begin{array}{c}\text { Rural } \& \text { Town } \\
\langle 50,000\end{array}$ & 181 & 33 & 214 \\
\hline Urban, $>50,000$ & $94.6 \%)$ & $(15.4 \%)$ & $(68.2 \%)$ \\
& $(94.0 \%)$ & $(6.0 \%)$ & $(31.8 \%)$ \\
\hline
\end{tabular}

$\left(X^{2}=4.72 ;\right.$ df $=1 ; p=0.030 ;$ response rate $\left.99.4 \%\right)$

When asked if the academic expectations of the program were more difficult than they liked, 211 rural and 101 urban subjects responded. Majorities in both groups, $87.7 \%$ rural and $89.1 \%$ urban, said no.

When asked about the most dificult barrier to participating in the External Degree Program, the largest percentage in both groups, $35.2 \%$ rural and $43.0 \%$ urban, cited time. Though not statistically significant, distance was cited as the most difficult barrier by $20.1 \%$ of the rural respondents but by only $7 \%$ of the urban respondents. Also, the unexpected was cited by $13.4 \%$ of the rural respondents, but by only $9.3 \%$ of the urban respondents. Finances were listed fifth by rural respondents and fourth by urban respondents. When asked specifically about any problem the respondents had with finances while participating in the External Degree Program, 
majorities in both groups, $62.5 \%$ rural and $56 \%$ urban, said either "not at all" or "to only a small extent."

Advising issues were asked in the fourth and

fifth questions. The majority of both rural and urban respondents, $63.5 \%$ and $61.4 \%$ respectively, were satisfied to a great or very great extent with the guantity of advising they had received and with the quality, $69.0 \%$ rural and $65.7 \%$ urban.

The last question compared rural and urban respondents on whether they felt the rules and procedures of the External Degree Program inhibited their progress toward completing the degree. Majorities in both groups, $64.3 \%$ rura 1 and $72.0 \%$ urban said "not at al1." Because towns/cities of populations up to 50,000 may not seem rural in the sense of isolation, a further distinction between respondents was made. This time, rural meant only those respondents indicating they lived in a rural area or farm $15+$ miles from a city; all other respondents were considered urban. This distinction produced 52 rural and 261 urban respondents, with 3 missing the necessary data for classification. Again, the seven questions were analyzed. All, including the clarity of degree requirements question, yielded no significant differences between the two categories of respondents. Response trends were identical to those described above when a broader definition of rural was used. On the question about degree clarity, $82.7 \%$ of the rural/farm respondents and 
88.5\% of the urban town/city respondents said advisors were clear in communicating degree requirement information.

\section{COMPARISON OF LEAVERS/FINISHERS BY GENDER \& FAMILY STATUS}

The effect of two environmental variables, marital and family status, on the leaving/finishing behavior of men and women was the subject of another comparison. The first step in this procedure involved twelve chi-square tests:

(1) effect of married/single status on leaving/ finishing females (for this comparison, single status included never married, as well as separated, divorced, or widowed)

(2) same as test (1) on leaving/finishing males

(3) effect of absence/presence of any children in the home on leaving/finishing females

(4) same as test (3) on leaving/finishing males

(5) effect of 0-1 child versus 2 or more children in the home on leaving/finishing females

(6) same as test (5) on leaving/finishing males

(7) effect of married/single status on leaving females and leaving males

(8) same as (7) on finishing females/males

(9) effect of absence/presence of any children in the home on leaving females and leaving males

(10) same as (9) on finishing females/males

(11) effect of $0-1$ child versus 2 or more children in the home on leaving females/males

(12) same as (11) on finishing females/males 
Using the above numbers, the comparisons which resulted in statistically significant differences at $p<.05$ were:

(1) A higher percentage of female finishers than female leavers was married.

(7/8) A higher percentage of males, whether leavers or finishers, was married than was leaving/finishing females.

(11/ A higher percentage of males than

12) females, whether leavers or finishers, had two or more children.

TABLE LVI

EFFECT OF MARITAL STATUS ON LEAVING/FINISHING FEMALES

\begin{tabular}{|c|c|c|c|}
\hline & Single & Married & $\begin{array}{l}\text { Row Total } \\
\text { Column \% }\end{array}$ \\
\hline Female Leavers & $\begin{array}{c}24 \\
(44.4 \%)\end{array}$ & $\begin{array}{c}30 \\
(55.6 \%)\end{array}$ & $\begin{array}{c}54 \\
(33.1)\end{array}$ \\
\hline Female Fnshrs. & $\begin{array}{c}24 \\
(22.0 \%)\end{array}$ & $\begin{array}{c}85 \\
(78.0 \%)\end{array}$ & $\begin{array}{c}109 \\
(66.9 \%)\end{array}$ \\
\hline
\end{tabular}

$\left(x^{2}=7.69 ;\right.$ df $=1 ; p=0.006$; response rate $\left.99.4 \%\right)$

The marital status of male respondents, whether leavers or finishers, was almost identical: $91.1 \%$ of the male leavers were married as were $91.6 \%$ of the male finishers.

The absence or presence of children in the homedid not significantly discriminate between leaving or finishing behavior of either males or females. The majority of leaving and finishing males and females had at least one child at home while they were participating in the External Degree Program. Though not significant, a higher percentage 
of leavers (both males and females) had children at home than did finishers.

Two more statistical comparisons sought to determine if the number of children affected the leaving/finishing benavior of either female or male External Degree subjects. Neither comparison resulted in statistically significant differences. However, whereas the majority of both leaving and finishing females had either none or just one child at home while participating in the External Degree, the majority of leaving and finishing males had at least two.

The final set of analyses regarding any effect of marrlage and children on the leaving/finishing behavior of External Degree subjects compared female leavers with male leavers and female finishers with male finishers. Both comparisons related to marital status resulted in statistically significant differences. For example, more male leavers than female leavers were married; so too, though, more male finishers than female finishers were also married.

TABLE LVII

EFFECT OF MARITAL STATUS ON LEAVING BEHAVIOR OF MEN/WOMEN

\begin{tabular}{|c|c|c|c|}
\hline & Single & Married & $\begin{array}{l}\text { Row Total } \\
\text { Column \% }\end{array}$ \\
\hline Female Leavers & $\frac{24}{(44.4 \%)}$ & $\begin{array}{c}30 \\
(55.6 \%)\end{array}$ & $\begin{array}{c}54 \\
(49.1)\end{array}$ \\
\hline Male Leavers & $(8.9 \%)$ & $\begin{array}{c}51 \\
(91.1 \%)\end{array}$ & $\begin{array}{c}56 \\
(50.9 \%)\end{array}$ \\
\hline
\end{tabular}

$\left(x^{2}=16.07 ; d f=1 ; p=0.000 ;\right.$ response rate $\left.98.2 \%\right)$ 
TABLE LVIII

EFFECT OF MARITAL STATUS ON FINISHING BEHAVIOR OF MEN/WOMEN

\begin{tabular}{|cccc|}
\hline & Single & Married & $\begin{array}{c}\text { Row Total } \\
\text { Column } \%\end{array}$ \\
\hline Female Finishers 24 & 85 & 109 \\
& $(22.0 \%)$ & $(78.0 \%)$ & $(53.4)$ \\
\hline Male Finishers & 8 & 87 & 95 \\
& $(8.4 \%)$ & $(91.6 \%)$ & $(46.6 \%)$ \\
\hline
\end{tabular}

$\left(x^{2}=6.10 ; d f=1 ; p=0.013 ;\right.$ response rate $\left.100.0 \%\right)$

No statistically significant difference resulted from comparing female leavers with male leavers on whether or not children were present in the home while the subject was participating in the External Degree Program. For both the female and male leavers, the majority did have at least one child at home. For finishers, the same trend was true but the larger percentage of female finishers than of male finishers without children approached significance with $\mathrm{p}=.053$.

TABLE LIX COMPARISON OF MEN/WOMEN FINISHERS ON CHILDLESS/CHILD STATUS

\begin{tabular}{|cccc|}
\hline & $\begin{array}{c}\text { No } \\
\text { Children }\end{array}$ & $\begin{array}{l}\text { l or More } \\
\text { Children }\end{array}$ & $\begin{array}{c}\text { Row Total } \\
\text { Column } \%\end{array}$ \\
\hline Female Finishers & $\begin{array}{c}45 \\
(41.3 \%)\end{array}$ & $\begin{array}{c}64 \\
(58.7 \%)\end{array}$ & $\begin{array}{c}109 \\
(53.4 \%\end{array}$ \\
\hline Male Finishers & 26 & 69 & 95 \\
& $(27.4 \%)$ & $(72.6 \%)$ & $(46.6 \%)$ \\
\hline
\end{tabular}

$\left(x^{2}=3.74 ; \mathrm{df}=1 ; \mathrm{p}=.053\right.$; response rate $\left.100.0 \%\right)$

When the comparison of female vs male leavers and female vs. male finishers was based on the number of children 
(either 0-1 or 2+), significant differences resulted. For example, the majority of female finishers reported $0-1$ child at home, while the majority of male finishers had two or more children.

\section{TABLE LX}

COMPARISON OF MEN/WOMEN FINISHERS WITH

EITHER 0-1 CHILDREN OR 2 OR MORE

\begin{tabular}{|c|c|c|c|}
\hline & $\begin{array}{c}0-1 \\
\text { Children }\end{array}$ & $\begin{array}{l}2 \text { or More } \\
\text { Children }\end{array}$ & $\begin{array}{l}\text { Row Total } \\
\text { Column } \%\end{array}$ \\
\hline Female Finishers & $\begin{array}{c}71 \\
(65.1 \%) \\
\end{array}$ & $\begin{array}{c}38 \\
(34.9 \%) \\
\end{array}$ & $\begin{array}{c}109 \\
(53.4 \%)\end{array}$ \\
\hline Male Finish & $\begin{array}{c}45 \\
(47.4 \%)\end{array}$ & $\begin{array}{c}50 \\
(52.6 \%)\end{array}$ & $\begin{array}{c}95 \\
(46.6 \%)\end{array}$ \\
\hline
\end{tabular}

$\left(x^{2}=5.82 ;\right.$ df $=1 ; p=.016 ;$ response rate $\left.100.0 \%\right)$

The majority of female leavers, however, also reported having either nochildren or only one at home while they were participating in the program. The majority of male leavers, on the other hand, had at least two children at home.

\section{TABLE LXI}

COMPARISON OF MEN/WOMEN LEAVERS WITH

EITHER 0-1 CHILDREN OR 2 OR MORE

\begin{tabular}{|lccc|}
\hline & $\begin{array}{c}0-1 \\
\text { Children }\end{array}$ & $\begin{array}{c}\text { Or More } \\
\text { Children }\end{array}$ & $\begin{array}{l}\text { Row Total } \\
\text { Column \% }\end{array}$ \\
\hline Female Leavers & $\begin{array}{c}30 \\
(55.6 \%)\end{array}$ & $\begin{array}{c}24 \\
(44.4 \%)\end{array}$ & $\begin{array}{c}54 \\
(49.1 \%)\end{array}$ \\
\hline \multirow{2}{*}{ Male Leavers } & 18 & $\begin{array}{c}38 \\
(67.9 \%)\end{array}$ & $\begin{array}{c}56 \\
(50.9 \%)\end{array}$ \\
\hline
\end{tabular}

$$
\left(x^{2}=5.21 ; \text { df }=1 ; p=.022 \text {; response rate } 98.2 \%\right)
$$


PREDICTION OF LEAVING USING STEPWISE MULTIPLE REGRESSION

The goal of conducting the stepwise multiple regression analysis with the data from the External Degree surveys was to determine what percent of the variation in leaving/finishing behavior could be accounted for from a set of selected explanatory variables. Stepwise multiple regression is one of several procedures grouped under the broad classification of general linear statistical models. Analysis of variance (ANOVA) and discriminant analysis are the more commonly known terms within linear models. For this study, the discriminant analysis function used regression, spectically stepwise multiple regression, as a convenient, computational technique for carrying out the calculations on the nominal data obtained.

Generally the stepwise procedure starts with a simple correlation matrix and enters into regression the predictor variable that is most highly correlated with the outcome variable, in this case, differences between leaving/ finishing the External Degree Program. After this step, partial correlation coefficients are computed and a second varlable is selected. This procedure continues with the selection of the next largest contributor to the variance in the outcome variable until no more contribution is made or until the researcher decides that the contribution is too small to consider. As described in Chapter I, two criteria (statistical significance at $p<.05$ and independence of time 
In Program) had to be met before the questions in this study were selected for regression. The following table displays the explanatory variables used in the present study.

TABLE LXII

PREDICTOR VARIABLES OF STEPWISE MULTIPLE REGRESSION PROCEDURE

Survey Number Content \# Response Options

19 Awareness of Other Programs. 2 Yes/No

36 Grade Level Upon Admission

4 Frosh/Soph/Jr/Sr

37 Degree Aspirations

$40, \mathrm{AS}, \mathrm{BS} / \mathrm{BA}, \mathrm{Grad}$

27 Career/Degree Reqm't.

3 Yes/No/Not Applic.

50 Time Required in Program

4 Options ranged from "Too Much" to "Very Little"

After eliminating surveys where there were no responses to any one of the five questions cited above, 297 records were analyzed in the stepwise procedure. As the table in Appendix $D$ shows, $31.76 \%$ of the variation between leaving and finishing behavior was explained by seven of the question/response possibilities:

\section{TABLE LXIII}

\section{BEST SEVEN PREDICTORS OF VARIANCE IN LEAVE/FINISH BEHAVIOR}

Q. 50, Rsp. 1: Degree required more time than I could give.

Q. 37, Rsp. 2: Aspired to the Associate Degree.

Q. 27, Rsp. 1: Yes, continuation in career required degree.

Q. 37, Rsp. 1: Aspired to no degree.

Q. 50, Rsp. 4: Degree required less time than expected.

Q. 50, Rsp. 2: Degree required more time than expected,

Q. 50, Rsp. 3: Degree required about the time expected. 
Adding the next four largest contributions to vari-

ation:

Q. 36, Rsp. 1: Grade level upon admission: Frosh.

Q. 36, Rsp. 2: Grade level upon admission: Soph.

Q. 36, Rsp. 3: Grade level upon admission: Jr.

Q. 19, Rsp. 1: Awareness of other External Programs

only increased the percentage of explanation of variation by

$1.98 \%(31.76 \%$ to $33.64 \%)$. Since this contribution was

considered minor, the regression procedure was discontinued. 


\section{CHAPTER V}

CONCLUSIONS AND RECOMMENDATIONS

\section{SUMMARY}

\section{Comparisons: Leavers and Finishers}

A comparison of the responses from this study showed that both academic and environmental variables have extensive discriminating ability between leavers and finishers in the Eastern Oregon State College External Degree Program. Limited discrimination between leavers and finishers resulted from comparing background and defining variables. All the primary null hypotheses described on pages 122-123 are, therefore, rejected, but with the following explanations.

Defining Variables. Only one of the defining variables, enrollment status, resulted in a statistical difference between leavers and finishers. Overal1, a higher percentage of finishers was admitted to the External Degree Program at a more advanced level than leavers. No statistical differences in the other defining vartables, age and residency, were found between leavers and finishers. Background Variables. Likewise, only one background variable, educational goal, resulted in a statistical 
difference between leavers and finishers. Again, a larger percentage of finishers aspired to higher levels of education than did the leavers. No statistical differences in the other background variables of high school performance, ethnicity, family educational level, and gender were detected when leavers and finishers were compared.

Academic Variables. The category, academic variables, produced a number of differences between leavers and finishers. Overall, a larger percentage of fintshers than of leavers expressed more confidence with their skills and their ability to cope with stress and to find the time to do the Program. As a group, finishers were significantly more satisfied than were the leavers with the quality and quantity of academic advising in the Program and with the frequency and convenience of courses they wished to take to complete their degree. Finishers also indicated, statistically more often than did leavers, that they had an academic focus to their degree. And, with regard to program involvement, the finishers were more likely to produce a portfolio that received academic credit than were the leavers, even though a majority of both groups attended the portfolio workshop. Although leavers may have left before availing themselves of many opportunities to participate in other Program options, (over 50\% Indicated "they left before they really got started"), a chi-square comparison on the use of correspondence classes also resulted in a significant difference between leavers and finishers. A majority of 
finishers (but a minority of leavers) received credits through correspondence. All other program involvement questions resulted, even if significantly different, in either the same trend (i.e., majorities in both groups did not participate) or in no significant difference at all.

Environmental Variables. Five areas within environmental variables were studied: (1) finances, (2) outside employment; (3) outside encouragement, (4) family responsibilities, and (5) perception of one's ability to transfer. All but finances and family responsibilities resulted in significant differences between leavers and finishers. Financing of college expenses was handled simllarly by leavers and finishers; i.e., most often by either the subject's or spouse's employment. Neither group cited financiai problems as a major hindrance to its participating in college. No difference in marital status between leavers and finishers was observed, nor in the number of children at home while leavers and finishers were participating in the External Degree Program.

A significantly higher percentage of leavers than of finishers reported working over a 40-hour week while attempting to participate in the External Degree Program. Coupled with these self-reported longer working hours, leavers also cited less encouragement from others in their lives to continue with college studies. Significantly more finishers than leavers reported being aware of simflar External Degree Programs at other 
institutions. Even though fewer leavers were aware of similar programs, they considered transferring to another institution in a larger percentage than did the finishers. Academic and Psychological Outcomes. Because a majority of leavers left "before they really got started," summarizing the academic and psychological outcome differences between leavers and finishers must be done cautiously. Though finishers had a significantly higher GPA than did leavers, the finishers' academic interactions were likely distributed over (1) a longer perlod of time and (2) over more Program options. Likewise, their investment to the end of the Program (graduation) may have been the cause of the finishers' significantly more positive satisfaction levels than was any specific Program feature(s) itself. Finishers were more satisfied with what they percelved as positive impacts on knowing themselves better, using interpersonal skills, and seeing alternative points of view, as we 11 as in their ability to get the kind of prompt feedback from advisors and instructors they needed. Also, perhaps because of their early departure, over half of the leavers were unable to judge the quality of education they received at Eastern, and $45 \%$ were unable to describe the overall quality of the College at all.

Leavers and finishers were alike in their motivations for enroling in the Program. Personal improvement/ challenge was cited most often by participants in both categories. Only $2 \%$ of finishers, but $20 \%$ of leavers, 
however, felt their progress in the Program was hindered a great or very great deal by rules and procedures. One psychological outcome difference which probably is independent of length of time in the program is the finishers' significantly more frequent response linking career and degree than that reported by leavers.

Because lack of time appeared as the \#1 difficulty for finisiers and 1 barrier for leavers to participating in the External Degree, comparing the two groups' time management decisions produced expected results. For example, other than unaltered time spent with children and in paid employment, finishers reported significantly more often than did leavers, that they had cut back on social activities with friends, alone time with their spouse or significant other, time spent on home maintenance, and in civic responsibilities. Further, finishers reported more often than did leavers ( $99.5 \%$ vs. $67.6 \%$ ) that they were able (perhaps, though, only after cutting back on other responsibilities) to commit the amount of time required in the Program.

\section{Comparisons: Rural and Urban Respondents}

Though the primary purpose of this research was to determine if, in general, External Degree leavers differed from finishers on a number of characteristics, a further breakdown of respondents into rural and urban categories was 
conducted because of Eastern Oregon State College's regional mission into 10 rural counties of oregon.

The Eastern Oregon State College External Degree was specifically designed to accommodate the time- and placebound constraints of adult learners. In so doing, the Program seeks to overcome the barriers that are cited in the literature regarding rural access to educational programs: distance, inadequate finances, and inadequate advice and counseling.

With regard to distance barriers, the Program was designed without requiring any attendance in La Grande. In addition, (1) a liberal transfer policy, (2) information and referral offices in Eastern's six Regional Centers, and (3) extensive outreach opportunities in the form of telecourses, correspondence studies, and regional classes have eliminated the necessity of travel to/from the main campus for External Degree students.

In responding to a potential financial barrier, the External Degree Program features several payment options. First, a portfolio-awarded credit is assessed at about $45 \%$ of what is charged for a traditional credit of instruction. This decreased fee recognizes that instruction in academic content is not provided by the institution when a student prepares a prior-learning portfolio essay, though instruction in the process/verification of translating experience into content is. A second feature that decreases the Immediate impact on a family of financing college expenses 
is a deferred payment plan for tuition ( $1 / 3$ due at the beginning of each month of the quarter) and/or an installment plan for paying fees incurred in awarding portfolio credit. In addition, improvements in federal guidelines regarding financial aid for part-time learners have broacened educational access to many adults, including the External Degree student.

The establishment of Eastern's Regional Centers in six communities of the 10-county Eastern region, the placement (by Portland State University's invitation) of a branch of the Eastern Oregor External Degree office on the PSU campus, and the availability of a toll-free telephone number for Oregon students have attempted to respond to distance learners' complaints about inadequate advice and counseling. With all these features built into a comprehensive degreecompletion plan, it was encouraging to find that rural and urban learners did not differ in their responses to several critical questions on the survey.

For example, time, rather than distance, was the most frequentiy cited barrier for both rural and urban subjects. Though not statistically significant, distance was, however, the second most frequent response from rural respondents but fifth from urban.

Finances were not considered any more of a burden for rural respondents than they were for urban respondents. In fact, a higher percentage of rural than of urban respondents 
indicated that finances were not at all or only a small problem while they were in the Program.

Sufficient and accurate advice and counseling also did not really present any greater barier for the rural External Degree respondents than it did for urban. Respondents from both groups indicated satisfaction with the quantity and quality of advising. only when rural was defined to include residents of communities $<50,000$ population did significantly more rural than urban respondents indicate that degree requirements were not made clear to them by their advisors. Even then, the percentages dissatisfied with degree clarity were small, $15.4 \%$ rural and $6.0 \%$ urban. Likewise, majorities in both the rural and urban groups indicated that the Program's rules and procedures had not hindered their progress in the degree. It appears, therefore, that certain aspects of the External Degree design have appropriately responded to barriers that are normally faced by rural adult learners. The absence of significant differences between rural and urban respondents' perceptions of barriers to continuing their studies through the Eastern Oregon State College External Degree will facilitate the implementation of any Program changes that could improve retention of all participants, regardless of geographic residence or isolation. 


\section{Comparisons: Gender and Family Status}

Most of the significant differences which resulted when family status and leaving/finishing behavior was compared occurred when gender differences entered the equation. That is, male leavers were not statistically different from male finishers on family status questions. Female leavers were similar to female finishers, differing only in marital status; significantly more female finishers than leavers were married.

When family status questions were compared between the

sexes, however, numerous differences resulted. Overall, female participants, whether leavers or finishers, reported more often that they had 0-1 child; males, whether leavers or finishers, more often had two or more children. Though the majority of both female and male participants, leavers or finishers, were married, significantly more males were than females.

In conclusion, marriage and families of two or more children were more evident in the lives of the male respondents than of the females. In other words, married females and/or females with two or more children were less likely to be participants in the External Degree Program than were males with the same family responsibilities.

\section{CONCLUSIONS}

The dominant factors related to persistence of this non-traditional student group in the Eastern Oregon State 
College External Degree Program come from academic and environmental variables. Background and defining variables contributed little to predicting persistence/withdrawal. This conclusion provides exciting opportunities for the College to intervene with corrective Program changes which should enhance the retention/completion rate of participants. (Specific recommendations are shared at the end of this chapter.)

In addition to triggering Program changes, this study helped to create a profile of the "typical" External Degree student. This individual, whether leaver or finisher, is usually Caucasian, married with children, approximately 45 years old and lives in an oregon community of $<50,000$ in population close to (within 60 miles) of a post-secondary institution, but not necessarily Eastern Oregon State College. He/she did well in high school, earning between a 3.00 and $3.50 \mathrm{GPA}$, and enrolied in the External Degree Program primarily for personal, rather than professional, reasons. However, he/she receives little, if any, encouragement to continue college from friends or employers.

The mother of the typical External Degree student has usually received a high school diploma; the father, less than such. The spouse of the External Degree student has probably attended or even graduated from college. The student pays for educational expenses from employment income but is not particularly stressed financially by these added expenses. He/she works at least 30 hours a week, and while 
in the Program, may have cut back on other obligations, but did not cut back on hours worked or time spent with children.

Upon entering the Program (most often as a junior), the typical External Degree student is modestly aware of other External Degrees but does not consider transferring to them, is confident of his/her abilities in writing, reading, expressing thoughts verbally, and coping with stress and with academic challenges. Perhaps because he/she feels that degree requirements were clearly explained by his/her advisor, the External Degree student sees no reason to require La Grande campus attendance for periodic meetings. The student was expecting the level of academic rigor in the Program and was satisfied with the timeliness of instructor feedback and with the ease in asking for help from either instructors or advisors. In spite of struggling to devote the necessary time to the Program, the typical External Degree student feels that participation, whether it ended in withdrawal or graduation, did have some impact on getting to know him/herself better, on using their interpersonal skills more, and on seeing alternate points of view. Most frequently, he/she focused on a particular academic area while pursuing the degree, transferred in credit from other institutions, and participated in an assessment-of-prior-learning workshop as part of the External Degree process toward graduation. The student did not receive directly transcripted credit through military evaluations or from any 
agency-sponsored training, nor did he/she participate in outreach center classes, cooperative education, course challenges, or day or evening classes at Eastern Oregon State College.

Beyond this common description of External Degree participants in general, leavers differed in several respects from finishers. For example, even though they, like the finishers, voiced satisfaction with the clarity of degree requirements as expressed by their advisors, they were dissatisfied with the overall quality and quantity of the academic advising they received and also felt the rules and procedures of the Program inhlbited their progress toward graduation. In contrast to finishers, the leavers generally did not recelve credit for any portfolio essays following attendance at a portfolio workshop, nor did they receive much encouragement to continue college studies. from anyone in their lives. They terded to work longer hours at their jobs (frequently over 40 hours a week) and did not cut back on other obligations while trying to participate in the Program.

Several conclusions, therefore, on which recommendations for change will be based, may be drawn from the findings of this study:

1. Leavers and finishers alike struggled with finding or managing their time so that progress toward completion of the External Degree could happen.

2. Sizeable numbers in both groups of subjects volced anxiety over maintaining a balance 
in their various responsibilities as spouse, parent, employer, and civic person, as well as student.

3. Though several respondents wholeheartedly endorsed the flexible nature of the Program, large numbers in both groups yearned for more structure, even if self-imposed, in the form of a visible degree completion plan.

4. Little encouragement from people in the External Degree student's environment to continue college studies is received by participants; it is especially lacking in the lives of the leavers, and only strongly felt from spouses of the finishers.

5. Though most respondents from both groups participated in an assessment of prior learning portfolio workshop, only large numbers of finishers managed to earn credits through this option. Large numbers of leavers left the Program quickly without integrating more thoroughly into other Program options.

6. Female participants were less likely than male participants to be married and/or to have children.

7. Rather than perceiving different barriers to education as the literature review asserts, rural External Degree respondents shared with their urban counterparts that the \#l concern was finding enough time to commit to college studies.

\section{RECOMMENDATIONS}

In response to the preceding summary and conclusions, and in order to enhance the completion rate of the Eastern Oregon State College External Degree participants, the following recommendations are made. 


\section{PROGRAM IMPROVEMENT CHANGES}

\section{Develop Two Separate Degree-Completion Tracks}

It is apparent from the study findings that many

External Degree participants struggle with what they perceive in the portfolio workshop to be an unstructured, intangible, open-ended, process requiring more time, writing ability, and tolerance for ambiguity than they are comfortable with. Although a number of External Degree participants may be able to begin the Program with this option, many should not. Program staff should clearly identify two tracks for degree completion in the Eastern Oregon External Degree Program: one begins with the assessment of prior learning portfolio, the other with more traditional coursework, even if offered in non-traditional formats (correspondence, weekends, evenings).

\section{Adult Development/Degree-Planning Seminars}

Since early integration into the academic culture is missing for a number of the External Degree leavers (i.e., over $50 \%$ claimed to have left the Program without ever really getting started), Program staff should restructure the existing four-credit-hour assessment of prior learning workshop. "If students are not selected/socialized early, they are likely to drop out" (Bean, 1983, p. 53). To promote earlier, stronger integration and, therefore, enhance retention and completion, it is recommended that guidelines developed by Brookfield (1986) be followed 
in restructuring the introductory phase of the External Degree Program. That is, the program should provide for (1) a collaborative spirit within the learning environment, (2) a sense of alteration between activity and reflection, (3) a critical reflection time, and (4) an opportunity for the learners to become self-directed and empowered. Tinto (1987) recommends an orientation program to assist adult learners to integrate. For example, the first part of the revised portfolio workshop, in which all External Degree students would participate, could be a one-credit-hour, oneweekend Adult Learner Seminar which participants would take prior to enrolling in any of the Program options. Although already done on a somewhat informal, one-on-one interview basis (in person or by phone), the seminar format would provide for more efficient use of Program staff time and for the adults to start acknowledging that others, just like themselves, are interested in continuing their education. This group identity may also serve as the emotional support to continue on with college studies that is missing in the lives of many External Degree participants. Several activities shouid take place during this seminar:

1. Readings/lecturettes about adult development, specifically about transitions that adults experience when beginning a new phase in their lives, and about adults as learners, should be provided to help the External Degree participants place themselves into the larger picture from a theoretical perspective. 
The importance of understanding, even if only on a limited basis, some notion about age- and stage-related theories regarding their development and about differences in learning between children and adults, may help the participant affirm the commitment to completing the degree prior to becoming immersed in the paperwork, assignments, and expectations that tend to overwhelm the less-than-committed.

2. Information about all known options for adults to continue their college studies should be provided. Included in this comprehensive information and referral step should be data about other institutions' programs as wellas all of the Eastern Oregon State External Degree Program options.

3. The student's writing ability should be assessed with, for example, the Test of Standard Written English. Also, one essay writing assignment, related to the adult development/adult learner literature, should be written and critiqued for witing style as well as content.

4. All transfer credits should be accurately evaluated, petitions filed, military evaluation forms completed, etc. prior to conclusion of the seminar.

The post-weekend assignments should include preparation of the essay on adult development/learning and of a draft for the student's degree-completion plan using options described during the weekend.

The second part of the revised portfolio workshop would occur approximately one month following this seminar, (allowing sufficient time for petitions to be processed, transcripts officially evaluated, and the assignments from the seminar to be sent in for evaluation). At this onecredit hour Degree-Completion Planning seminar, participants 
from the first seminar who have decided to pursue the Program would reconvene to (1) discuss their degreecompletion plan with an advisor, (2) receive instruction/ advice on time management, and ( 3 ) meet several of the faculty involved with many of the degree-completion options. The final degree-completion plan should identify (1) the program option(s) that the student will begin with, (2) the term-by-term progress/courses the student intends to take to meet degree requirements, and (3) the follow-up arrangements with Program staff that will be conducted to support/revise the degree-completion plan as the student moves through the Program.

The third part of this revised introductory phase of the Program consists of the actual workshop in which those External Degree students who have decided to begin with the portfolio receive instruction in the portfolio-development process. Others who have opted for a more courseworkoriented beginning to the Program would defer participation in this workshop until a later time or not at all.

This three-part revision recognizes, as Bridges (1980) notes that the process of reaching a goal ii.e., completing the baccalaureate) is as important as the goal itself. Further, the "easing" in to the Program with a more organized, planned approach may especially assist the female participants who, as Belenky (1986) notes, may struggle more than their male classmates with commiting themselves to the rigor that being a student, in addition to being wife, 
mother, friend, etc. requires. Likewise, because a number of adults may have difficulty backing off somewhat from a self-imposed independency (Kegan, 1982), this revised process would more clearly identify the network of faculty, advisors, and peers available to help the External Degree participant succeed in finishing the Program.

\section{Peer Mentoring}

A third recommendation which evolved from a review of the study findings is toestablish a peer mentor for new students in the Program. Parelius (1979) recognizes the helpful, supportive nature of providing student peer groups as an aid in retention/completion of degree programs. This mentor should be an adult who graduatedin the External Degree Program, preferably lives in or near the same community as the new student, and has volunteered to serve in the capacity of mentor. Numerous responding finishers offered, in the letters/notes they sent in with their completed surveys, to provide this kind of support for others just beginning the Program. Since many leavers indicate a lack of encouragement from others in their lives to continue on with their education, the peer mentor may fill a void that could make the difference between leaving and finishing the Program.

\section{Two-Year General Studies Degree}

Because significant differences between leavers and finishers were revealed when degree aspiration and entry- 
level status questions were asked, a fourth recommendation from this study is to develop an Associate of Arts Degree in General Studies using the same degree-completion options that already exist for the four-year Program. When the non-traditional student enters the current Program with few credits (less than Junior standing) and must, because of environmental responsibilities (family, finances, employment) proceed on a part-time basis, the road to completion looks very long. Providing a two-year degree will meet the needs of those adults who indicate that the Associate is all they aspire to, as well as enabling others to achieve a tangible symbol of success while moving on toward the BS/BA.

\section{Decrease Turn-around Time on Assignments/Feedback}

Numerous respondents complained of the delays they experienced in awaiting word on the status of their portfolio essays andor course assignments. on-going efforts, which have already been started, to improve the paperflow from student to instructor should be monitored carefully. For example, "logging in" assignments at the External Degree Program office has reduced the frequency of the lost-paper syndrome. In addition, changes in the way faculty are pald for evaluating and grading the work of External Degree students has improved the turn-around time on Individualized Studies assignments (for which faculty are usually paid overload). However, more improvement in the turn-around time for portfolio essays (for which faculty are 
frequentiy assigned by their Dean to evaluate inload) should be pursued.

\section{Follow-up with Responding Leavers}

Because a numer of the leavers may have left when the Program was in its infancy, and because recent Program changes and an expanded curriculum of correspondence and weekend college courses are now available, the sixth recommendation of this study is to the Program staff. Specifically, they should follow up with those External Degree leavers who cared enough to take the time to complete and return a survey and, in many cases, write additional notes and letters about their specific experiences in the Program. Their willingness to share their opinions and recommendations for change should be seen as a potential sign of renewed interest in pursuing the degree. A phone call or letter from the Program Director offering to assist with updating the status of their educational pursuits would be in order.

\section{ADDITIONAL RESEARCH}

The final recommendation of this study is for more research. Improved advising practices, more articulate publications, more informal mentoring, limiting the number of portfolio-awarded credits that may be used toward graduation, and an expanded curriculum now available to External Degree students, would probably have changed the withdrawal path for a number of leavers who joined the Program in the 
early years. Follow-up, longitudinal studies of the current

External Degree student body would provide information that would help Program staff continue to improve the program so that even more non-traditional students could pursue their educational goals through non-traditional means. Specific types of research/procedures which may lend themselves to providing enriched data about non-traditional students are:

1. Include social integration variables in the model used to see if there isn't some element of socialization that is related to persist/withdrawal behavior of the non-traditional student.

2. Survey rural potential students to test the hypothesis that indicates this group of students perceives more/different barriers to continuing their education than do their urban counterparts.

3. Incorporate learning style preferences into the study to evaluate any difference in leave/finish behavior from groups of auditory, tactile, and visual learners.

4. Expand the investigation into the motivational factors that lead nontraditional students to participate in programs like the External Degree. For example, do the younger non-traditional participants tie their involvement in educational programs more closely to vocational goals than do the older ones? Are there differences by age between intrinsic and extrinsic goals?

5. Test the path analysis theory of researchers like Bean and Metzner to determine the validity of direct vs. indirect effects on leaving behavior of non-traditional students. 
6. Enrich the data qualitatively by conducting indepth personal interviews with a randomly selected group of respondents in order to pursue strands of thought that could then be linked more thoroughly to adult development theory.

7. Incorporate multiple measures into a longitudinal study to determine the effect of changes in one's personal circumstances over time that may affect leave/finish behavior; determine where, if appropriate, the institution should be expected to intervene to assist with life transitions.

8. Expand on the stepwise regression procedure after controlling for entry-level characteristics to see if any sizeable variation in leave/finish behavior can be explained from any individual/set of variables.

9. Analyze the leavers in the present study more carefully to determine when they left. Though most indicated it was shortly after they entered the Program, further research into the nature of their specific interactions during their brief stint may add improved/new information that could affect Program interventions. For example, did leavers attempt the College's required exit writing exam earlier in the Program than did finishers and because of an intial failure, leave the Program entirely?

10. Investigate the nature of "encouragement." Does the presence in a non-traditional student's life of disharmony in the home (resentment of the spouse/parent for taking time for school studies) have a bigger influence on leaving a Program than positive vibes do in supporting the student's finishing?

There is still much to be done to enhance the learning environment for today's non-traditional student on America's college and university campuses. The present study has provided information to the Eastern Oregon State 
College administration that should improve the setting for such students in that College's External Degree Program. It is the hope of this researcher, however, that the findings from this study will be helpful well beyond this particular program and that the sensitivity and understanding by higher educational personiel about the increasing numbers of adult students on our campuses will have been enhanced by this research. 
SOURCES CONSULTED

Astin, A.W. (1973). The impact of dormitory living on students. Educational record, 54, 204-210.

Astin, A.W. (1975a). Dropouts, stopouts, and persistence: a national profile. Los Angeles: Laboratory for Research on Higher Education, University of California.

Astin, A.W. (1975b). Preventing students from dropping out. San Francisco, CA: Jossey-Bass.

Barker, B. (1985). Understanding rural adult learners: characteristics and challenges. Lifelong learning, 4-7.

Barker, B. (1986a). Interactive satellite instruction: how can rural schools benefit. Annual Conference of the Rural Education Association. (ERIC Document Reproduction Service No. ED 274-499)

Barker, B. (1986b). Technolog1cal innovations impacting instruction in rural and small schools. Organization of Rural 0klahoma Schools. (ERIC Document Reproduction Service No. ED 274-498)

Batey, A., \& Cowell, R.N. (1986). Distance education: an overview. Portland, OR: Northwest Regional Labs. (ERIC Document Reproduction Service No. ED 278-519)

Bean, J.P. (1980). Dropouts and turnover: the synthesis and test of a causal model of student attrition. Research in higher education, 12, 155-187.

Bean, J.P. (1982). Conceptual models of student attrition: how theory can help the institutional researcher. In E.T. Pascarella (Ed.), Studying student attrition (pp. 17-33). San Francisco: Jossey-Bass.

Bean, J.P. (1985). Interaction effects based on class level in an explanatory model of college student dropout syndrome. American educational research journal, $\underline{22}(1), 35-6 \overline{4}$.

Bean, J.P., \& Bradley, R.K. (1986). Untangling the satisfaction-performance relationship for college students. Journal of higher education, 57, 393-412. 
Bean, J.P., \& Metzner, B.S. (1985). A conceptual model of nontraditional undergraduate student attrition. Review of educational research, 55, 485-540.

Belenky, M.F., Clinchy, B.Mc., Goldberger, N.R., \& Tarule, J.M. (1986). Women's ways of knowing: the development of self, volce, and mind. New York: Basic Books.

Benson, G.M., \& Hirschen, W. (1987). Distance learning: new windows for education. Technological horizons in education, 63-67.

Bentler, P.M., \& Speckart, G. (1979). Models of attitudebehavior relations. Psychological review, 86, 452-464.

Berkove, G. (1976). Returning women students: a study of stress and success. Paper presented at the annual convention of the Western Social Science Association, Tempe, AZ. (ERIC Document Reproduction Service No. ED 156-971)

Bisesi, M., \& Felder, B.D. (1986). Interactive television. In P.S. Brelwak (Ed.), New directions for higher education: managing programs for learning outside the classroom (PP. 37-45). San Franc18co: Jossey-Bas8.

Bostick, R.N. (1987). Why use instructional television? Tech Trends, $32(4), 32-33$.

Bridges, W. (1980). Transitions: making sense of 11fe's changes. Reading, MA: Addison-Wesley.

Brookfjeld, S.D. (1986). Undergtanding and facilitating adult learning. San Francisco: Jossey-Bass.

Buck1in, R.W., \& Buck1in, M.L. (1970). The psychological characteristics of the college persister and leaver: a review. Washington, D.C.: U.S. Department of Hea1th, Education, and Welfare. (ERIC Document Reproduction Service No. Ed 049-709)

Burnham, B.R., \& Seamons, R.A. (1987). Exploring the landscape of electronic distance education. Lifelong learning: an omnibus of practice and research, 11 (2), 8-11.

Cassier, H.R. (1985). Cooperation between the media and adu1t education bodies. Paris, France: U.N. Educational, Scientific, and Cultural organization, Division of Literacy, Adult Education, and Rural Development. (ERIC Document Reproduction Service No. ED 259-196) 
Coker, D.L. (1968). Diversity of intellective and nonintellective characteristics between persisting and non-persisting students among campuses. Stevens Point: Wisconsin State University. (ERIC Document Reproduction Service No. ED 033-645)

Coldeway, D.A. (1980). Factors effecting learner motivation in distance education: the interaction between learner attributes and learner course performance. Athabasca University: Alberta, Canada: Project REDEAL. (ERIC Document Reproduction Service No. 249-346)

Collins, V.A., \& Murphy, P.J. (1987). A new adult student: learning by interactive satelite. Continuing higher ed review, $51,(2), 29-37$.

Costa, A.E. (1984). Selected correlates of achievement and persistence of adult community college students. Dissertation abstracts international, 44, 2989A. (University Microfilms No. 84-01,974)

Darkenwa1d, G.G., \& Larson, G.A. (Eds.). (1980). Overcoming barriers to communication: reaching hard-toreach adults. New directions for continuing education, (No. 8), San Francisco, CA: Jossey-Bass.

Deloughry, T. (1988, Apr11 20). Remote instruction using computers found as effective as classroom sessions. Chronicle of higher education.

Dillman, D. (1978). Ma11 and telephone surveys: the total design method. New York: Wiley-Interscience.

Durkhe1m, E. (1954). Sulcide. (translated by J.A. Spaulding and G. Simpson). Giencoe, IL: The Free Press.

Ehrmann, S. (1988). Technologies for access and quality: an agenda for three conversations. Unpub1ished manuscript, Annenberg/CPB Project, Washington, DC.

Erikson, E.H. (Ed.). (1978). Adulthood. New York: W.W. Norton.

Erikson, E.H. (1980). Identity and the Life Cycle. New York: W.W. Norton.

Feasley, C.E. (1983). Serving learners at a distance: a guide to program practices. ASHE-ERIC Higher Education Research Report \#5, ERIC Clearinghouse on Higher Education, Washington, DC: George Washington University. 
Ferguson, D.K. (1987). Electronic information delivery systems: reports on five projects sponsored by the Fred Meyer charitable trust. Library hi tech, 18, 65-93.

Fetters, W.B. (1977). National longitudinal study: withdrawal from institutions of higher education. Washington, D.C.: U.S. Department of Health, Education, and Welfare, National Center for Education Statistics (ERIC Document Reproduction Service No. ED 150-913)

Fishbein, M., \& Ajzen, I. (1975). Belief, attitude, Intention, and behavior: an introduction to theory and research. Reading, MA: Addison, Wesley.

Flaherty, E.G. (1978). Higher education responds to the needs of the part-time student. College student journa1, 12, 375-378.

Fowler, J.W. (1981). Stages of faith: the psychology of human development and the quest for meaning. San Francisco: Harper \& Row.

Gilligan, C. (1982). In a different volce: psychological theory and women's development. Cambridge, MA: Harvard University Press.

Gould, R.L. (1978). Transformations: growth and change in adult life. New York: Touchstone Books.

Greenberg, E. (1980). The UWW program at Loretto Heights Coliege: individualization for adults. In E.Greenberg; K.M. O'Donnell; \& W. Bergquist (Eds.), New directions for higher education: educating learners of allages. San Francisco: Jossey-Bass.

Greer, L.R. (1980). Persistence and academic success among nontraditional age students at a funior college. Paper presented at the annual forum of the Association for Institutional Research, Atlanta, GA. (ERIC Document Reproduction Service No. ED 189-942)

Havighurst, R.J. (1972). Developmental tasks and education (3rd ed.). New York: Longman.

Herndon, S. (1984). Factors that differentiate between persisters and dropouts among recipients of financial a1d. Journal of college student personne1, 25,367-368. 
Hershfield, A.F. (1986). Distance education: the promise and the confusion. $12 \mathrm{th}$ Annual International Conference on Improving University Teaching. Heidelberg, West Germany. (ERIC Document Reproduction Service No. ED 278-166)

Hudspeth, D.R., \& Brey, R.G. (1986). Instructional telecommunications: principles and applications. New York: Praeger Publications.

Hughes, R. (1983). The nontraditional student in higher education: a synthesis of the 1iterature. National association of student personnel administrators fourna1, 20, 51-64.

Kasworm, C.E. (1980). The older student as an undergraduate. Adult education, $31,30-47$.

Kegan, R. (1982). The evolving self: problem and process in human development. Cambridge, MA: Harvard University Press.

Kellogg, W.K. Foundation. (1988). Project f1les: providing educational opportunities for rural residents $I_{2}(2)$.

Kimbal1, R.L., \& Sedlacek, W.E. (1971). Characteristics of older undergraduates at the University of Maryland. College Park: University of Maryland Counseling Center. (ERIC Document Reproduction Service No. ED 165-523)

Kohlberg, L., Levine, C., \& Hewer, A. (1983). Moral stages: a current formulation and a response to critics. Basel, Switzerland: Karger.

Krebs, R.E., \& Liberty, P.G., Jr. (1971). A comparative study of withdrawal students on ten factor variables derived from a 36-problem self-report inventoryAustin: University of Texas. (ERIC Document Reproduction Service No. ED 052-690)

Kuh, G.D., \& Ardaiolo, F.P. (1979). Adult learners and traditional age freshmen: Comparing the "new pool with the "old" pool of students. Research in higher education, 10, 207-219.

Kunsela, W.R. (1983). Education: challenges facing policy makers in the $1980^{\prime} \mathrm{s}$. Paper presented at the First Statewide Legislative symposium on Rural Development. New York. (ERIC Document Reproduction Service No. 277-504) 
Lenning, 0.T. (1982). Variable selection and measurement concerns. In E.T. Pascarella (Ed.), New directions for institutional research: studying student attrition (pp. 35-52), San Francisco: Jossey-Bass.

Lenning, 0.T., Bea1, P.E., \& Sauer, K. (1980). Retention and attrition: evidence for action and research. Boulder, Co: National Center for Higher Education Management Systems.

Levine, T.K. (1987). Teaching telecourses: opportunities and options: a faculty handbook. Annenberg/CPB Project and Public Broadcasting Service, Washington: D.C.

Levinson, D.J., Darrow, C.N., Klein, E.B., Levinson, M.H., \& Mckee, B. (1978). The seasons of a man's life. New York: Ballantine.

Lewis, R.J. (1983). Meeting learners' needs through telecommunications: a directory and guide to programs. Washington, D.C.: AAHE Center for Learning and Telecommunications.

Loevinger, J., \& B1asi, A. (1976). Ego development: conceptions and theories. San Francisco: Jossey-Bass.

Lowentha1, M.F., Thurnher, M., \& Chiriboga, D. (1975). Four stages of life: a comparative study of women and men facing transitions. San Francisco: Jossey-Bass.

Malin, J.T., Bray, J.H., Dougherty, T.W., \& Skinner, W.K. $(1980)$. Factors affecting the performance and satisfaction of adult men and women attending college. Research in higher education, 13, 115-130.

Manburg, A. (1983). Program delivery in distance education: one successful strategy. Annual Conference of the University without Walls International Council. Canada. (ERIC Document Reproduction Service No. 235-884)

McCannon, R. (1977). Analys1s of adu1t learning experiences in rural settings. Adult Education Research Conference: Minneapolis, MN.

McCannon, R. (1985). Serving the rural adult adult: a demographic portrait of rural adult learners. Action Agenda for Improvement of Rural Adult Post Secondary Education: Washington, D.C.: Fund for the Improvement of Post Secondary Education. (ERIC Reproduction Service No. ED 140-008) 
McDaniel, R.H. (Ed.) (1986). Barriers to rural adult education: a survey of seven northwest states. A report of the Northwest Action Agenda Project. Pullman, Washington: Washington State

University. (ERIC Reproduction Service No. 275-462)

McFarland, M.B. (1988). An analysis of the relationship between learning style perceptual preferences and attitudes toward computer-assisted instruction. Unpublished dissertation, Portland State University, Portland, OR.

Meyers, E.M., III. (1981). A comparative analysis of persisters, permanent dropouts, dropouts who transfer, and stopouts at St. Cloud State University. Dissertation abstracts international, 42, 105A. (University Microfilms No. 81-13,988).

Moore, M.G. (1987). University distance education of adults. Tech Trends, 32(4), 13-18.

National University Continuing Education Association (NUCEA). (1987). Challenges for continuing higher education leadership: the transformation of rural America. Washington, DC: author.

Neugarten, B.L. (Ed.). Middle age and aging: a reader in social psychology. Chicago: University of Chicago Press.

Newman, M.A. (1965). The student and the college community: a study of attrition on persistence in a highly selective liberal arts college. Cooperative Research Project No. S-130. Chicago: University of Chicago Press.

0aks, M. (1986). Interactive microwave: extending the institution to the state. Joint Northwest Adult Education Association and Pacific Association for Continuing Education. (ERIC Document Reproduction No. 275-279)

O'Donnell, K.M. (1980). Older learners: a viable clientele. In E. Greenberg, K.M. O'Donnel1, W. Bergquist (Eds.), New directions for higher education: educating learners of all ages, $8,(1)$. San Francisco: Jossey-Bass.

Ostman, R., \& Wagner, G. (1987). New Zealand management students' perceptions of communtcation technologies in correspondence education. Distance Education, 8 (1), 47-63. 
PBS Adult Learning Service. (1988). Announcing the PBS adult learning satellite service for colleges and universtifies. Alexandria, VA: Author.

Pantages, T.J., \& Creedon, C.F. (1978). Studles of college attrition: 1950-1975. Review of educational research, 48, 49-1011.

Parelius, A.P. (1979). Age Inequality in educational opportunity: the needs of adult students in higher education. Adult education, 29, 180-193.

Pascarel1a, E.T. (1980). Student-faculty Informal contact and college outcomes. Review of educational research, 50, 545-595.

Pascarella, E.T. (1985). The influence of on-campus living vs commuting to college on intellectual and interpersonal self-concept. Journal of college student personne1, 26, 292-299.

Pascarella, E.T., Duby, P.B., \& Iverson, B.K. (1983). A test and reconceptualization of a theoretical model of college withdrawal in a commuter institution setting. Soclology of education, 56, 88-100.

Pascarella, E.T., Duby, B., Miller, V.A., \& Rasher, S.P. (1981). Preenrollment variables and academic performance predictors of freshman year persistence, early withdrawal, and stopout behavior in an urban, nonresidential university. Research in higher education, $15,329-349$.

Pascarella, E.T., \& Terenzint, P. (1977). Patterns of student-faculty informal interaction beyond the classroom and voluntary freshman attrition. Journal of higher education, 48, 540-552.

Pascarella, E.T., \& Terenz1ni, P. (1979). Interaction effects in Spady's and Tinto's conceptual models of college dropouts. Soctology of education, 52, 197-210.

Pascare11a, E.T., \& Terenzinf, P. (1980). Student-faculty and student-peer relationship as mediators of the structural effects of undergraduate residence arrangement. Journal of educational research, 73, 344-353.

Paulet, R. (1987). Counseling distance learners. Tech Trends, 32, (4), 26-28. 
Perry, W.G., Jr. (1970). Forms of intellectual and ethical development in the college years: a scheme.

New York: Holt, Rinehart and Winston.

Phipps, T.C. (1988). Causes of adult learning. Continuing higher education review, 52(3), 133-139.

Piaget, J., \& Inhelder, B. (1969). The psychology of the child. (trans. by H. Weaver). New York: Basic Books.

Purdy, L.N. (1986). Telecourses: more than meets the eye. In P.S. Breiwak (Ed.), New directions for higher education: managing programs for learning outside the classroom (pp. 27-36). San Franc1sco, CA: Jossey-Bass.

Rauch, D.B. (1981). Education for the growing majority: adults. Lifelong learning: the adult years, 5, 10-13.

Reehling, J.E. (1980). They are returning: but, are they staying? Journal of college student personnel, 21, $491-497$.

Rootman, I. (1972). Voluntary withdrawal from a total adult socializing organization: a model. Soctology of education, 45, 258-270.

Sargent, N. (1987). Learners and television: the next ten years. In A. Stock (Ed.), Adult education, (16-27). London, England: National Institute for Adult and Continuing Education, Publishers.

Schlossberg, N.K. (1984). Counseling adults in transition: linking practice with theory. New York: Springer.

Sha1e, D.G. (1985). Innovation in higher education: the case of distance education. Conference of the Canadian Society for Studies in Higher Education. (ERIC Document Reproduction Service No. ED 275-293)

Smith, A.D. (1980). A study of selected variables among student persisters and nonpersisters enrolled in the general and the communtty and technical colleges. Dissertation abstracts international, 41, 963A. (University Microfilms No. 80-19,117)

Spady, W.G. (1970). Dropouts from higher education: an interdisciplinary review and synthesis. Interchange, 1, 64-85.

Spears, J.D., \& Maes, S.C. (1985). Postsecondary and adult education in rural communities. National Rural Education Forum. Kansas C1ty, MO. (ERIC Document Reproduction Service No. ED 258-790) 
Spencer, S. (1986). A model for selecting distance education delivery systems. In J.L. Kramer (Ed.), Continuum, 50(3), 143-152.

Stennick, J.S. (1988). Unpublished, untitled dissertation proposal. Portland State University, Portland, OR.

Stern, C.M. (1986-87). Teaching the distance learner using new technology. In T.T. Liao (Ed.), Journal of educational technology systems, $15(4), 407-418$.

Sul11ns, W.R., Vogler, D.E., \& Mays, S.B. (1987). Increasing access to postsecondary education for adults in rural Appalachia. In T.A. Tollefson (Ed.), Community college review, 15(1), 46-53.

Tate, P.J., \& Kressel, M. (Eds.). (1983). The expanding role of telecommunications in higher education. New directions for higher education, 44, San Francisco, CA: Jossey-Bass.

Terenzini, P.T. (1982). Designing attrition studies. In E. Pascarella (Ed.), New directions for institutional research: studying student attrition (55-71), San Francisco: Jossey-Bass.

Tinto, v. (1975). Dropout from higher education: a theoretical synthesis of recent research. Review of educational research, 45, 89-125.

Tinto, V. (1982a). Defining dropout: a matter of perspective. In E.T. Pascarella (Ed.), New directions for Institutional research: studying student attrition $(6-14)$, San Francisco: Jossey-Bass.

Tinto, V. (1982b). Limfts of theory and practice in student attrition. Journal of higher education, 53, 687-700.

Tinto, V. (1987). Leaving College. Chicago: University of Chicago Press.

Tinto, V. (1988). Stages of student departure: reflections on the longitudinal character of student leaving. Journal of higher education, 59, 438-455.

Treadway, D.M. (1984). Higher education in rural America: serving the adult learner. New York, NY: College Entrance Examination Board.

Valliant, G.E. (1977). Adaptation to Life. Boston: Little, Brown and Company. 
Von der Embse, T.J., \& Ch11ds, J.M. (1979). Adults in transition: a profile of the older college student. Journal of college student personnel, 20, 475-479.

Voorhees, R.A. (1987). Toward bullding models of community college persistence: a logit analysis. Research in higher education, 2, 115-129.

Wisconsin idea in the electronic age: extending university resources through telecommunications. (1985, Apri1). Final Report of the University of Wisconsin Extension Telecommuniations Strategic planning Task Force.

Wolfgang, M.E., \& Dowling, W.D. (1981). Differences in motivation of adult and younger undergraduates. Journal of higher education, 52, 640-648.

Zucker, H. (1986). Distance education in rural areas. An information analyses. (ERIC Document Reproduction Service No. ED 277-514) 
APPENDIX A

\section{SURVEY MATERIALS}

This appendix includes the survey instruments used by Dr. John Bean from which the Eastern oregon State college survey Instruments (also included) were prepared, and the cover letters which accompanied the Eastern surveys. 
STUDENT ATTITUDE DR STIJDENT ENTRY LEUE! RLSSTIONNAIRE USE

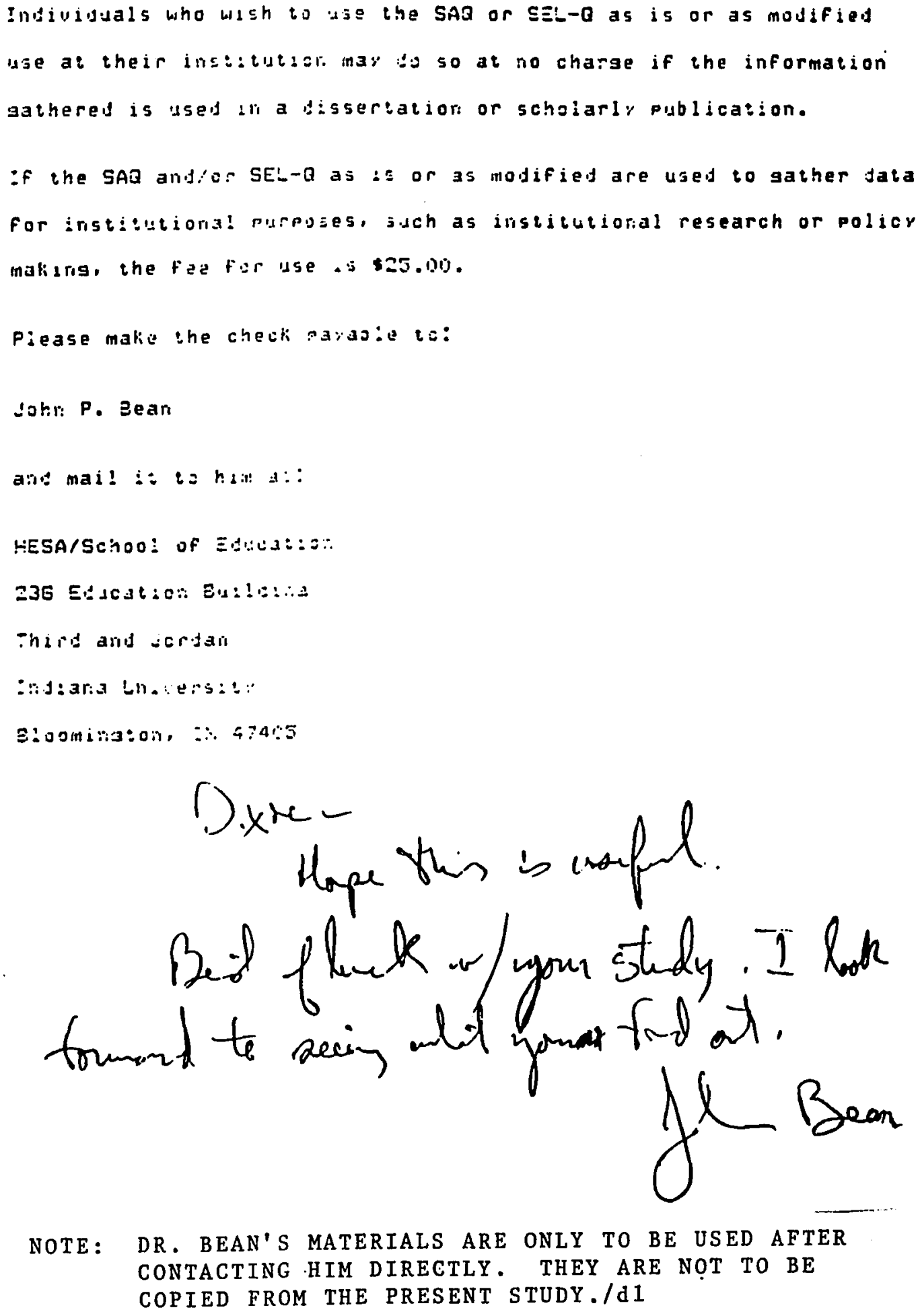

NOTE: DR. BEAN'S MATERIALS ARE ONLY TO BE USED AFTER CONTACTING HIM DIRECTLY. THEY ARE NỌT TO BE COPIED FROM THE PRESENT STUDY./d1 


\section{STLEIT ATTILE CATICHAIE (EMO)}

Iustruictions

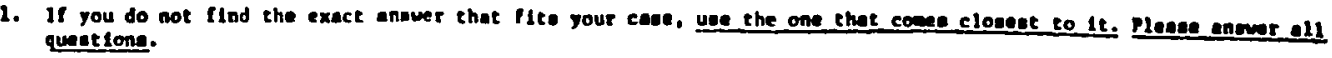

2. Nleane anvwer the questione in order. Do not oktp around.

3. The questione can be anewered by putting - circla around the nusber that correaponde to the anewer of your eholee like $1230 \mathrm{~S}$, or by puting a number in the LJ, 21ke US.

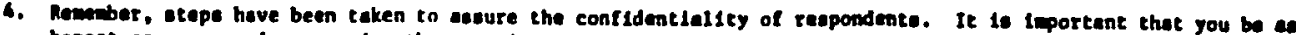
honet as you can in ancuerink the queations.

In order to atudy the ectuel leaving of atudente In future conthe, and to see if your ateltudes have changed elnes

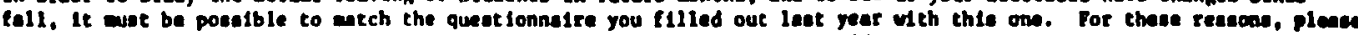
urite your etudene I.D. number (cociel cecurlty nuber) 10 the npaces proulded below.

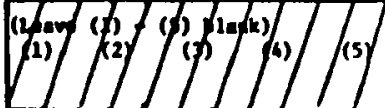

Seudant 1.D. Musper

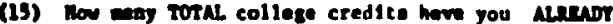
completed at any college or univerosty

$\begin{array}{lll}\text { 1. Mone 3. 6-11 } & \text { 3. 16-31 }\end{array}$
2. 1-5
6. 32 or more

(16) How wany credite are you enrolled lor this eanater (enter the nubber)?

$$
\text { (16) L l(17) }
$$

(18) Thle ecaseter, where do you live?

1. Dornitory

2. Praternlty or morority

3. Vith paremte or guardian

4. Apartenat, motel roos, rented house

3. Other (Specify:

(19) What is the hlphast degree you expect to recelve?

1. Do not expect to recelve degres

2. nenoclate (M)

3. Machelore (WA or BS)

4. Mastere (HA or MS)

5. Doctorate (Th.D. or Ed.D.)

6 H.D., D.D.S., D.V.H. (Eedleel)

7. U.s. on J.D. (1ew)

b. Oehar

(20) That best deseribes your intended anjor?

1. Uodecided

2. Uberal arte or Selence

3. Pre-profecetionel (a.g., education, cediclne, law, nuralng, englnearink, otc.)

1. Iuptanas

(21) How ming emeneters In a rou do you expect to attend this Inotitution (not count Ing eurmer cenelons) (Including two oementers this year)?

1234561899010 or

(22) In a typleal week, how any clasees did you wa

(ulthout a - adical or legltimate excuse)?
1. Howe 4. About three

2. About one

4. About three

3. About two

Da cure to angwer quest lonn (23) to (35).
(6) (1) (8) (9) (10) (11) (12) (13) (14) Involved in the tollowing ectivitefest

10ne

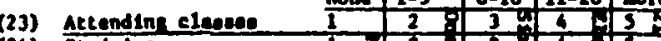

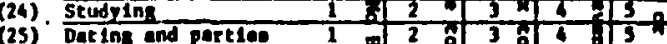

(26) Canue ortenleatione (non-oporte)

(27) Sporte (varelty)

(20) Sporte Con engonos

(29) Job to enro wnis

(30) How ensy of rour bant friende presenty attend the achooli 0 l 23 i 3 or ente

(31) What was your flect sceseter arade polat averap haref 1. $3.76-4.00$

2. $3.30=3.75$

3. $3.00=3.49$

5. $2.00 \cdot 2.49$

6. $1.50-1.95$

$0.00-0.4$

(32) How weh tic hove you atudted in college so conernd to hish echool?

1. Much leat then hith achool

2. Wase than hith ochool

3. About the cene

4. Hore thes hish ochool

(13) All In e11, how nood en edvestion do you think you can pot at thin Inatitution?

1. Tether poor

2. 7als

3. Cood

4. Vor gool

3. Enellent

(34) In your opinlon, hor bigh te the quality of thle Inetitutiont
1. Vary 100
4. Falriy high
2. Talrly low
5. Vary high
3. Melehet high ox $10 \mathrm{w}$

(35) Whot is your preant encitel statue?

2. Mot enreled

-Copyrtghe O1983 by Joha P. Waen. All righte recorvad. 


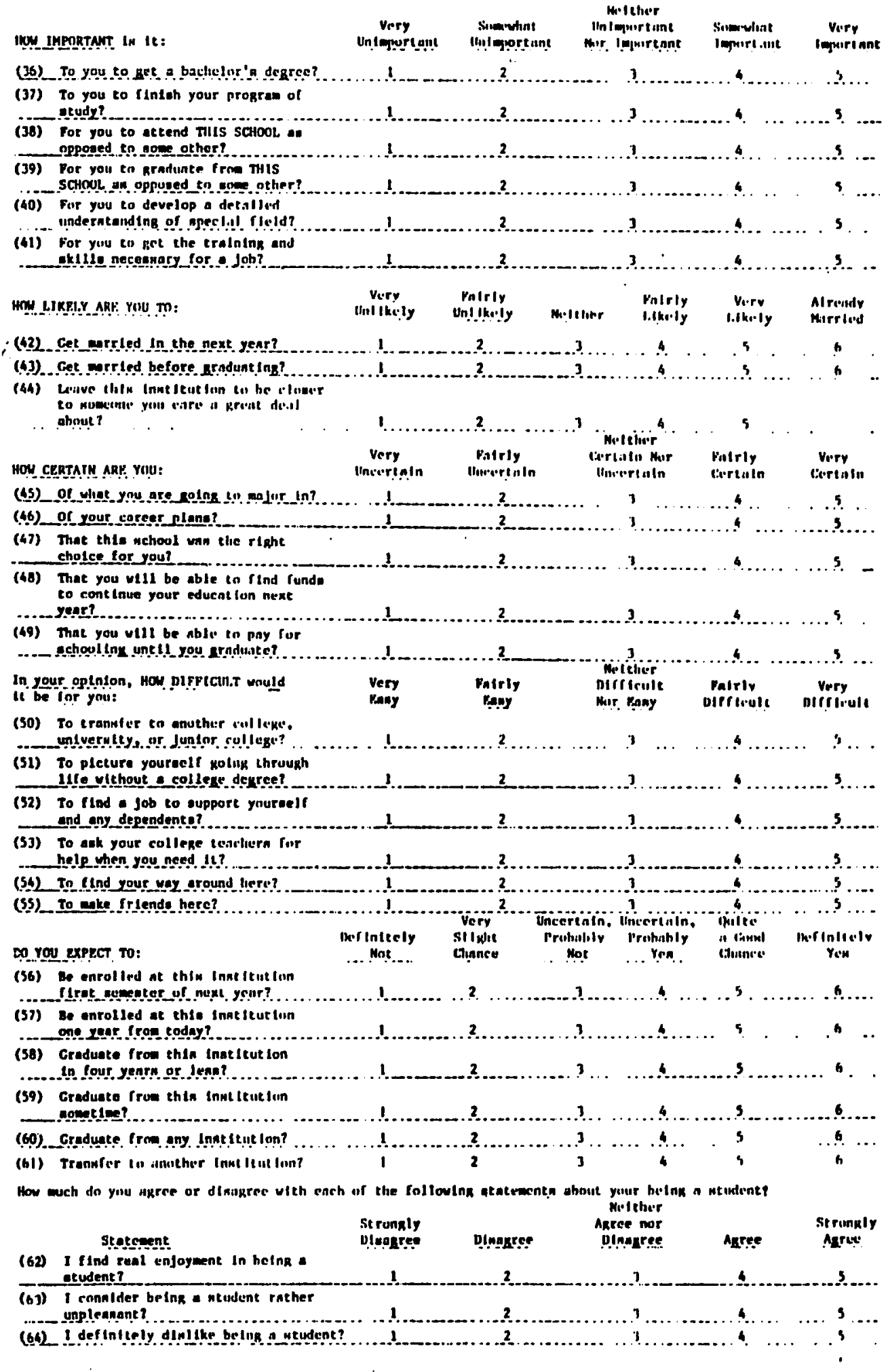




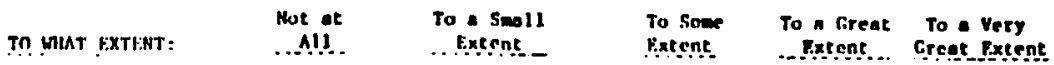

(h5) Doen this Inntitution uffer cournew ynu wnt_to tnke?

(fit) Do you walt to complete acndemls anelignenen unt 11 the I ant ponstble

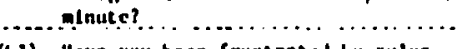

2-1

I) Have you been Irustrnted by rulin and regulatelons here?

(6B) Do you feel that the ruins and

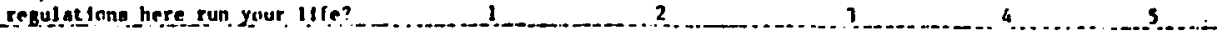

(69) Do you feel you think thr anar why

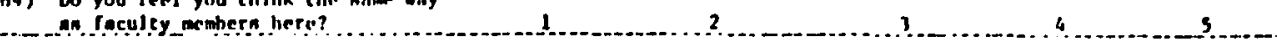

(70) Do youl feel you think the nnwe way

Nother_atudenten here?

(71) Do you feel you belong here? _ _ _ n

(72) Do you feel able to contrnl your ocadentc_life here?

(7.) Do you teel able to ront rul your norla! li!r here?

(74) Have you had nome really new acndemle expertences?

(75) Have you had nome renlly new nucial

(Q6) Do you enfoy livin ayny from home? 1

(71) Are yous parenta willing in pay tlie conten of your attendling this Inmt!tut lon? .

(78) Have ynu nertounly dincunard lenving thla nchonl wlth people here? . . . . .

(79) Have you aerlounty dincunand leaving thin

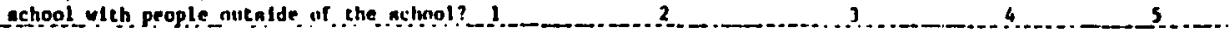

(15)_Do you foel out of place ne thi4 nchoo!? 1 _

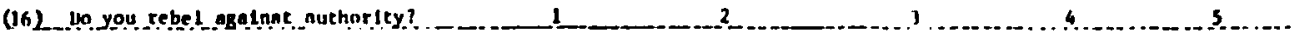

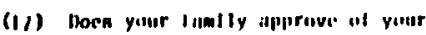
ntcending thin schoul?

(18) Do you complete homovirk anslunamen on tier?

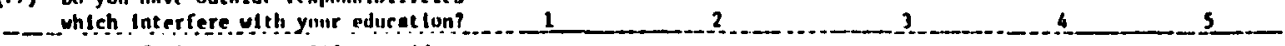
(20) In ynu frel that your life outelde

af achnol is at rensful?

Are the callege enurgen yni hive inken here:

(21) Excit!ng?

(?2) st!mulat!ng?

(2.1) Mnre_difrteult than you like?

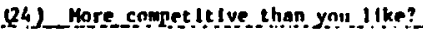

Q5) Noring?

(2h) Dul11

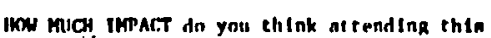

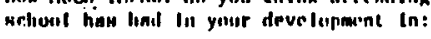

(21) Knowing yourne!l??

(28) Ualns Interperaonal ak111s?

(29) Seetng alternatlue polncs of vifu?

How uneful do you think your wilueat inn here will be for getting:

(30) Puture employment?

(31) A real1y sood. Job?

(32) A vell paying Jub?

Ine thin
In:




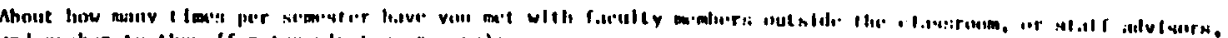

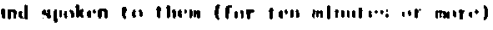

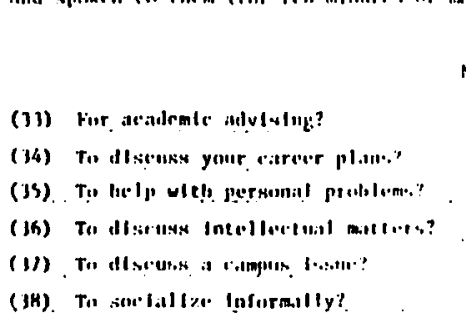

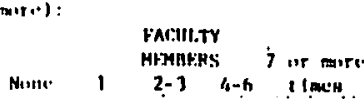

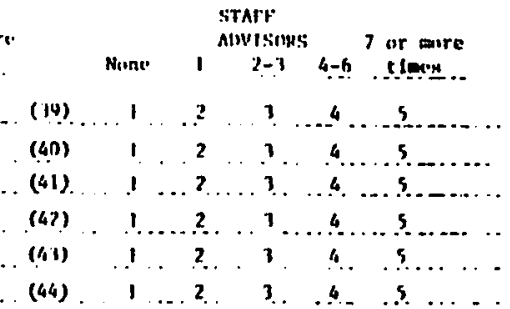

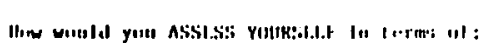

$\begin{array}{lllllll}1 & 2 & 1 & 4 & 5 & \ldots \\ 1 & 2 & 1 & 4 & 5 & \\ 1 & 2 & 1 & 4 & 5 & \ldots \\ 1 & 2 & \ldots & 4 & 5 & \ldots \\ 1 & 2 & \ldots & 4 & 5 & \\ 1 & 2 & \ldots & \ldots & 4 & & 5\end{array}$

(44)

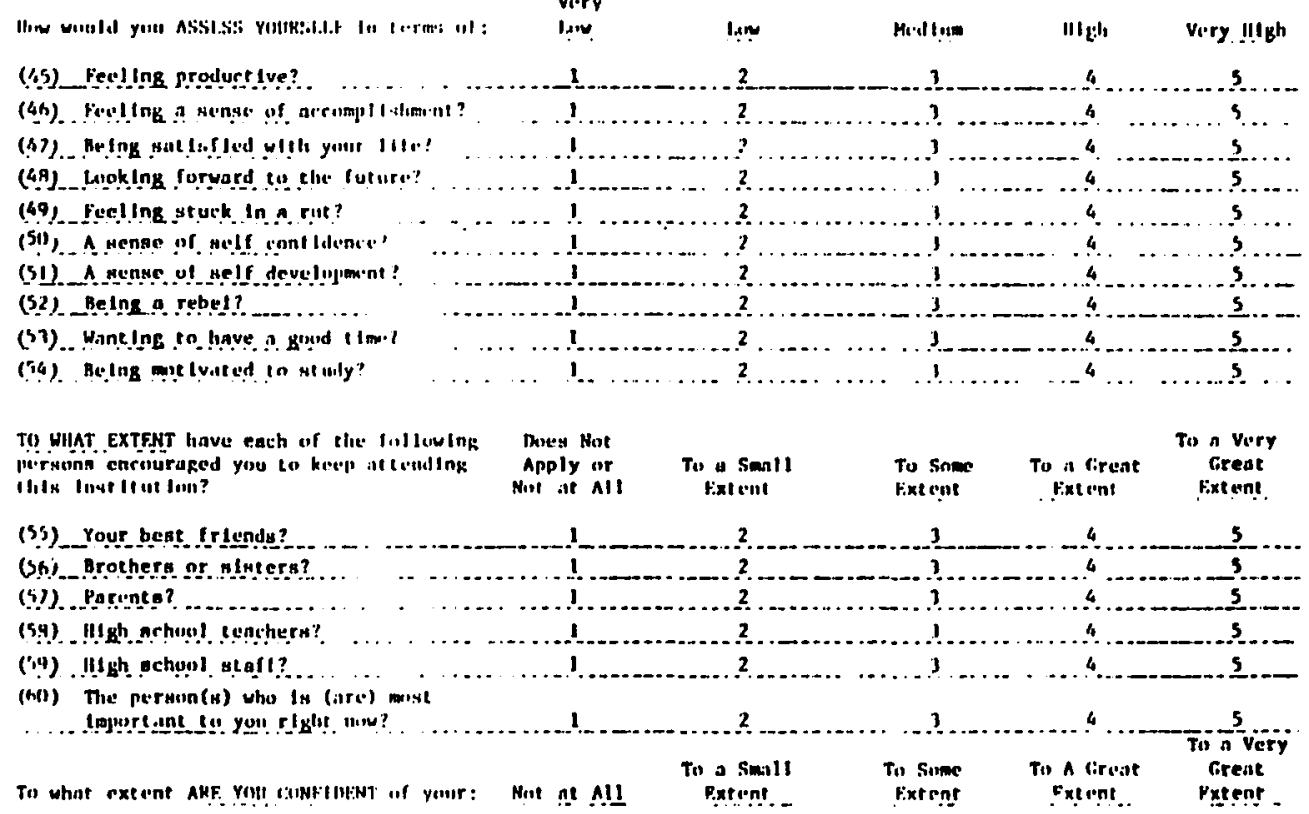

(61) scudy skl11:?

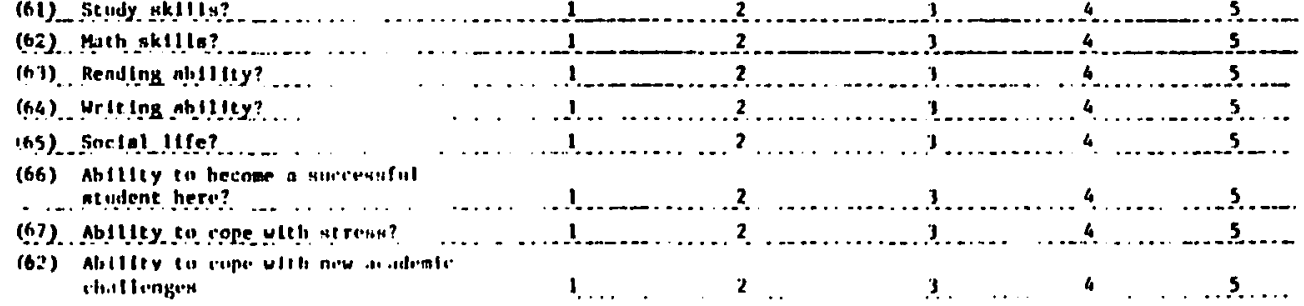

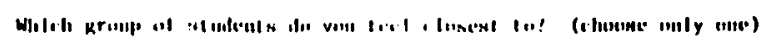

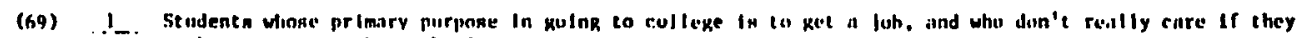
to here or to sumblier nillubl.

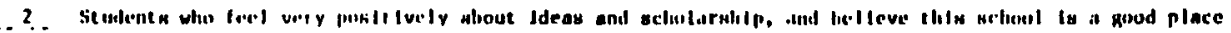

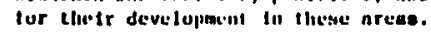

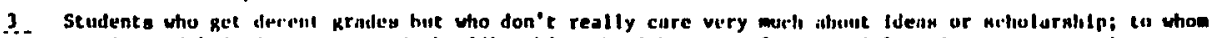

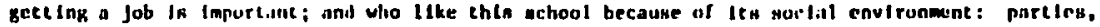

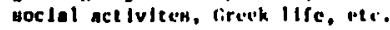

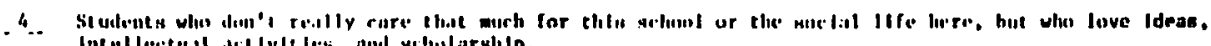

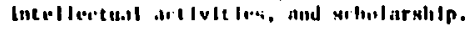

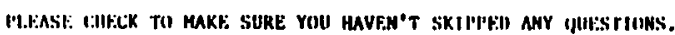

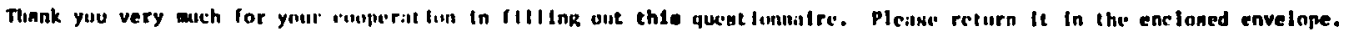




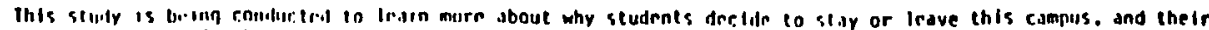

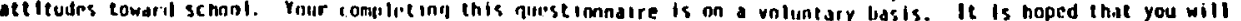
heip provide intormatiun which will be impiortune In determining what types of services are most useful to students and to better understand student concerns. Ynur completing this questionnitre wlli indicale that you have cansented

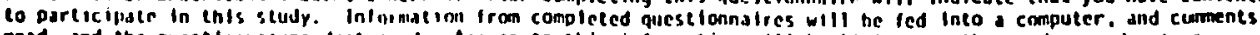
read, and the questlonnalress dirstrnyed. Acress to this information wlll be i imited to the scudy coordinators.

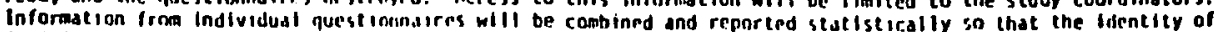

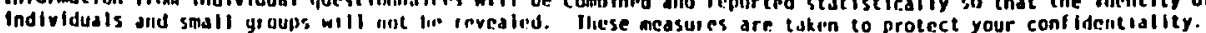

IHSTRUCIIOHS

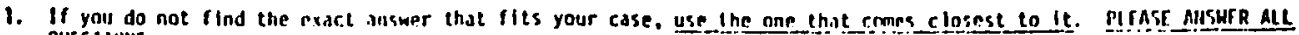
Quesiluers.

2. Please answer the qupstions in order. Do not sklp around.

2. The questinns ran he answrred by cuuttinn a clrcle around the mumber that rorresponds to the answer of your cholce. like 1 (2) 3 , 5, or by putting onumber in llie LL]. 11ke [2,5].

4. reel free to wrlte in any explunations no corments you may have in the margins.

5. Remember. steps have liren tislen to disure the confident lallity of respondents. It is important that you be as honest as you can in answering the quipstimnatre.

In order to study the actual leaving of students in future months, and to see if attleudes change. It must be possible to mutch the questionnaire that a stuilent fills out at inis tIme wleh the fact that a student stays or leaves this institution suid wlth later surveys of student oninlon. For this reason. please write your student I.D. numbrr (suctal securlity number) in the spaces provided below.

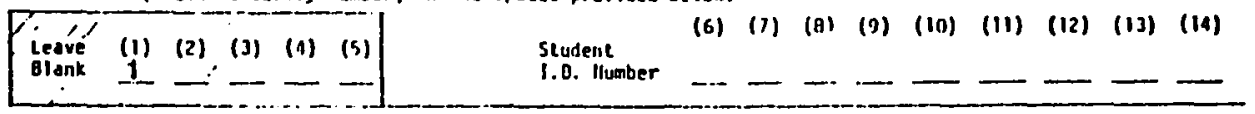

(15) What is your sex?

1. Hale

2. Fensle

What was your ane at your last blrthday? (16) Lل (17)

(18) What ts vour prenemt marlest stalus: 1. Hot marries

2. llarried

(19) Are you a restident of the stuce where

this school is larstirist

(20) Nlow many milirs away is your permanerut home from ethis school?

1. O-49 miles 4. $250-499$

2. 50-149 5. 500 miles or more

3. 150.249

(21) For the most part, what kind of communlty have you lived in?

1. Rural ares or farm

2. Iown or small ciey (uniter 50,000)

3. Hedfum sized cily (50,000 to 250.000)

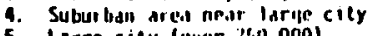

5. Large city (uver 220,000$)$

F(22) About how many students were in your high school graduat ing class?

1. 1.9 4. $100-199$

2. $10: 49$ 5. 200 or more

3. $50=99$

What best describes the religlous preference of:

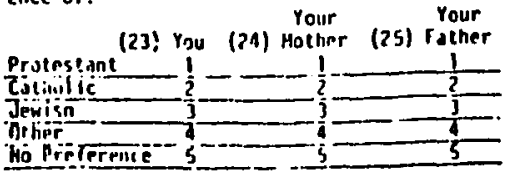

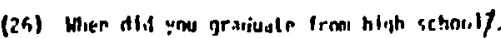

1. inis y=ar 4. liree years ago

2. I year ago 5. lour

Be sure to answer questinn: (21) 10 (34).
(21) How many TOIAL college credits have you ALREAOY completed at any college or unlversity?

1. None and colle 12.15

$\begin{array}{ll}\text { 2. } 1-5 & 5 . \\ \text { 3. } & \text { 6. } 32 \text { or mare }\end{array}$

(2B) Ilnw many credites are you enrolled for thls semester?

$$
\text { (20) \لـ(29) }
$$

(30) Ihis semester. where will you live?

1. Dormitary

2. Iraternity or sorority

3. With parents or quardian

4. Aparement, motel rocm, rented house

5. Other (Specify:

(31) Have you ever attended a collene or unlversity other than this one?

(32) What is the highest deqree you expect to recelvei

1. Do not expect to receive degree

2. Assoriace (aA)

2. Assoriate (AA)

3. Auchillors ( $\mathrm{NA}$ nr $B S)$
4. Hasters (Ma or $M S$ )

4. Hasters (Ma or MS)

5. Doctorste (Ph.0. or Cd.D.

i. M.D.B. or J.o. (iaw)

8. Other

(33) What best describes your intended major?

1. Undec ided

2. Llberdi arts or Science

3. Pre-professional le.g., education, medicine,

law, nursing. engineering. etc.)

4. Bus incss

(34) How many sempsters in a row do you expect to attend this Instltution (not counting suamer sesslans)?

1234567899 or more 
About how many hours per wert ifs mu rapece to involved in the lollowing activilits? Hone. 1 i i | 11. in $\mid 11$, 21 in or

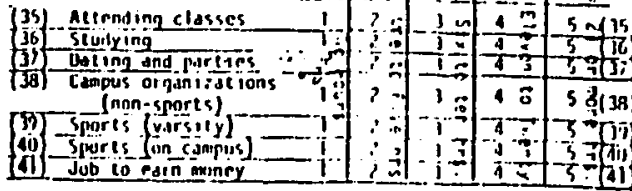

(42) How many of your best frimuls presently attend this school? A 121 a sur mip (ai)

(4) Now many of your acqua intane es are planning to seterd this institution? 0 1 2 3 45 or nore (13)

(4a) Now many members of your lmardiate Iamily (parents. brothers. sisters) dtended or still attend this Insticution? 0 I 2,5 or more (ea)

(45) What was your hlgh selioal qride point average fon a 4-ooint scale whre A.4, n-3, i: ?, 0.11? (quess if you don't know enarely.

l. $3.76-4.00 \quad 5.2 .010 .299$

2. $3.50-3.15$

6. $1.30=1.99$

3. $3.00-3.49$

7. $1.00 \cdot 1.49$

(46) What do you think your qrade inint average will be

at this school dt the end al irrit irnirster?
1. $3.16=4.00 \quad 5.2 .00=2.49$
I. $3.16=4.100$
2. $3.50-3.15$
3. $3.00-3.49$
$\begin{array}{ll}\text { 5. } 2.00 \cdot 2.49 \\ 6 . & 1.50-1.99\end{array}$
7. $0.00=0.99$

(4) In a tyotcal wapk in high schnol, haw many classes did you miss (withuut aedical or legltimate excusel?

i. Hone 4. Mioul three

2. Ahout one 5. More thin three

3. Atrout two

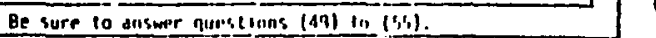

(95) Here ynu crerollod in collene coures for

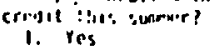

3. 110

(49) Wire you carollad In moncredit collegeprepardeney courses this summerl
I. Yes

(50) Abunt when lid you flirst decide to go to culterje?

1. Anfore higll school

2. High schusil Iresh.

3. Minn/sophomine

4. Hligh :chool senior
siter high
sctioni

(5I) Ahout when alld you first declde to attend IIISS IIISIIIUUIIOU?

i. Belore high school 4. Iligh school

2. IIijh sclinal fresh-

3. Wigh school Junior

5. After high

(52) Wnat was your ACl composite score? (Guess If you don't rememer exactly)

1. Did not take ACI 4. 16 to 20

$\begin{array}{lll}\text { j. } 10 \text { to } 15 & \text { 5. } 21 \text { to } 25 \\ & \text { 6. } 26 \text { to } 36\end{array}$

(53) What was your comblned (math - verbal) SAT score? (Guess If you don't remember exuctlyl

$\begin{array}{lllll}\text { i. Dild not t.1ke SAT } & \text { 4. } 1000 \text { to } 1299 \\ \text { 2. } 400 \text { to } 693 & \text { 5. } 1300 \text { to } 1600\end{array}$ 3. 700 10 693

(54) How much $t$ lme do you expect to study in calleype as compared to high school?

1. Huch less than hinh school

2. Less than high school

3. About the same

4. More than high school

5. Hurh more than high school

(55) In anpiyten to collonges, was this Institution your I. Ist choice 3. Jrd cholce
2. 2nd cholce

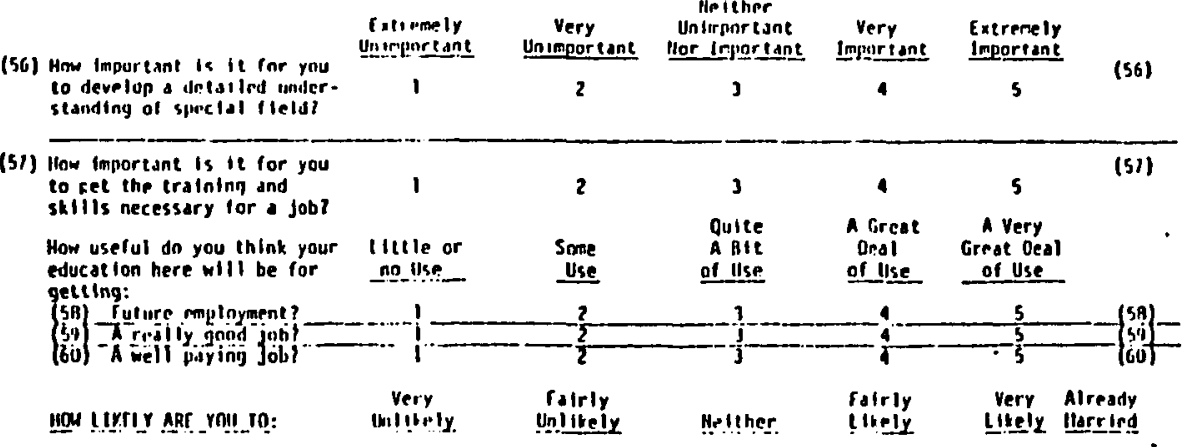

(61) Get asrriod in the

\begin{tabular}{|c|c|c|c|c|c|c|}
\hline next year? & 1 & 2 & 3 & 4 & 5 & $6 \quad(61)$ \\
\hline $\begin{array}{l}\text { (62) Get aerripil terore } \\
\text { graduating? }\end{array}$ & 1 & 2 & 3 & 4 & 5 & \\
\hline $\begin{array}{l}\text { (6) Lave inclinstitidinn } \\
\text { to be clnser to sume- } \\
\text { one you care a great }\end{array}$ & 1 & 2 & J & 1 & 5 & (63) \\
\hline
\end{tabular}

deal you care a great

Melliner

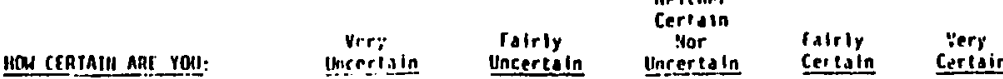

- (64) of what you are qotrug

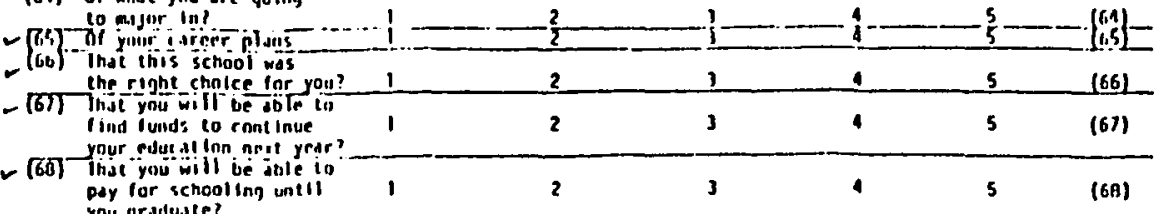




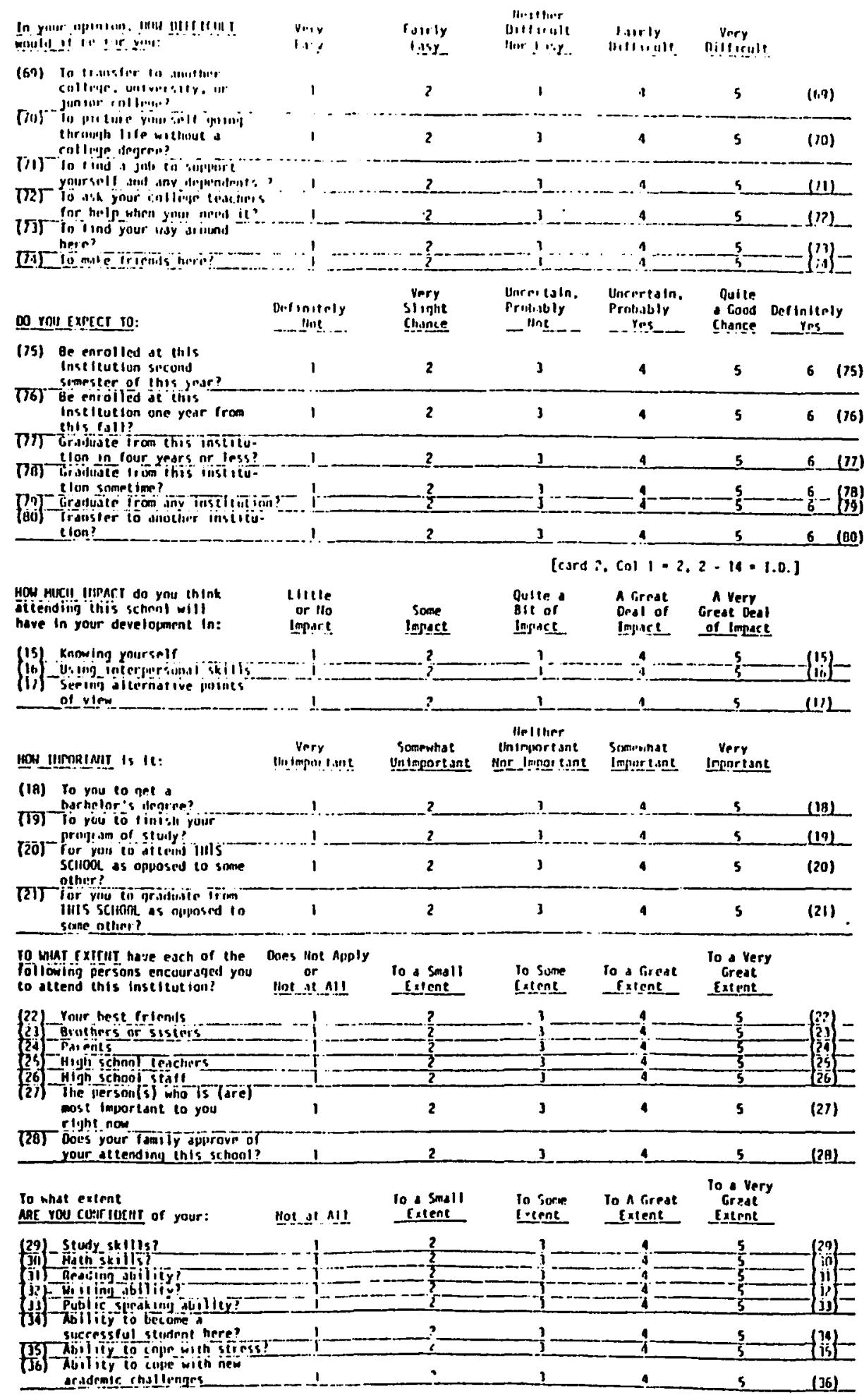


$-4$.

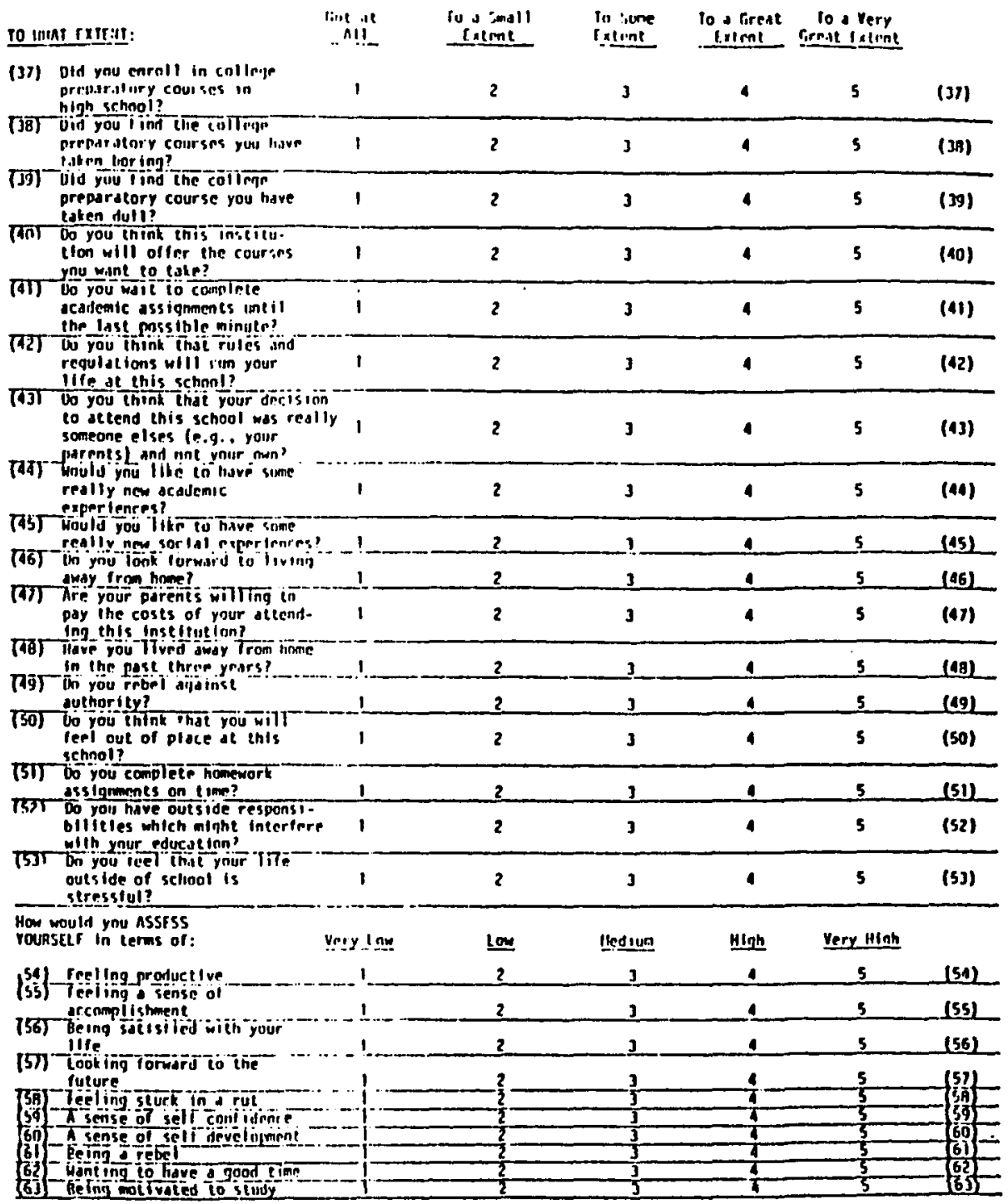

(6e) All in all, how qnod an pelurali inn do you think your can get at this inst leuetiont

1. Rather poor

2. Poir

3. riood

5. Yery good

What was your parnnt:" hinhest Inurl ne education? (65) llo:nere lilthre (66) Elrmentary schon! onileter $n$ ij Sompine colleje coter devilee dey-ee compiet

(67) Which of the following phrasos bese describes your raclal/ethinic grnup?

1. Alro-Mertcan/Biact

2. Hispenic American

3. Caucasian Merican/uhlice

i. Asian Americancoriental 5. Other that is the primary occupatton of your parentst

(69)

Business/Profess ional/Handgerlal Business/Profess ional/Managerial
Sent-professional/frehnicaliskilied remi-proness ionalyer or manager simats cunflied or unstilled

yot emplayed (Ineluding unemployed.

houserife, rellred, decessed

(60) Wother rollher $(69$

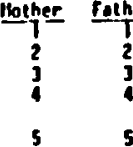

is the total yeariy income of your parml(s) before taxz? and other deductions, nure tien (please ansiner both):

(iii) $\begin{array}{lll}\$ 10.0007 & \text { 10 } & \text { VES } \\ 530.0007 & 1 & \frac{1}{2}\end{array}$

(22) In yeur eginlon. hoou hlogh is the qualley of this Insitieution?
1. Very low
2. Foirly low
4. Tairly hing
3. Very high

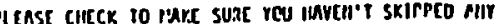
nuesiliois.

Thank you very much for your cooperation in 1111 inn out this questionnatre.

Be sure to answer questions $\mid$ fi:l $\ln |m|$. 
IST COVER LITTTER SENT TO EXTERNAL DEGREE LEAVERS

You and I know what it's like to return to college and to also try to manage a number of other responsibilities in addition to that of student. It's a big challenge! Sometimes our needs and goals match with what the college we choose is offering, but other times, they do not. Eastern Oregon State College's records indicate that al though you were admitted to the EOSC External Degree Program, you have not yet graduated in it. As a former student, your opinions and experiences in the External Degree are important to a study about nontraditional students like us. I'm conducting this study about adults as learners in concluding a doctoral program in education from Portland State University. The information you provide will be used to help improve programs for ddult students like you and me.

Little information is currently available that provides a way to compare students who finished the External Degree with those who have not. The only way to obtain this information so it can be used to improve the program for you and others is to ask--thus, the enclosed survey. In order for the study results to truly represent the opinions and experiences of External Degree participants in particular, and adult students in general, it is important that each survey be completed and returned. It should only take about 10-15 minutes to answer the questions, and an envelope is provided for your ease in returning the survey to me.

You may be assured of complete confidentiality. The identification number on your survey is used for mailing purposes only. The number simply allows me to check your name off my mailing list when the survey is returned. Your name will never be placed on the survey. If you wish to receive a sunmary of the study results, write "Copy of Results Requested" on the back of the return envelope and print your name and address below it. If you wish to receive updated information about the External Degree Program, please write "Program Information Requested" on the back of the return envelope, print your name and address below $i t$, and I'll forward your request to the office that will send this information back to you.

l'd be happy to answer any questions you might have. Please write or call. You may use the EOSC toll-free (in Oregon) number, 1-800-452-8639, Ext. 1378, to leave a messaye for me to call you back, or you can reach me directly at my home, (503) 963-0678, in La Grande.

Thank you for helping with this study. I'll appreciate your taking the time now to complete and return the survey and will look forward to hearing from you.

Sincerely,

Dixie Lund

P.0. Box 777

La Grande, OR 97850 


\section{ST COVER IETTER SENT TO EXTERNAL DEGREE FINISHERS}

You and I know what it's like to return to college and to also try to manage a number of other responsibilities in addition to that of student. It's a big challenge! Eastern Oregon State College's records indicate that you met the challenge and graduated in the External Degree. Congratulations! As a former External Degree student, your opinions and experiences with the Program are important to a study about nontraditional students like us. I'm conducting this study about adults as learners in concluding a doctoral program in education from Portland State University. The information you provide will be used to help improve programs for adult students like you and me.

Little information is currently available that provides a way to compare students who finished the External Degree with those who have not. The only way to obtain this information so it can be used to improve the program for others like you is to ask--thus, the enclosed survey. In order for the study results to truly represent the opinions and experiences of External Degree participants in particular, and adult students in general, it is important that each survey be completed and returned. It should only take about 10-15 minutes to answer the questions, and an envelope is provided for your ease in returning the survey to me.

You may be assured of complete confidentiality. The identification number on your survey is used for inailing purposes only. The number simply allows me to check your name off my mailing list when the survey is returned. Your name will never be placed on the survey. If you wish, you can receive a summary of the results by writing "Copy of Results Requested" on the back of the return envelope and printing your name and address below it. Please do not put this request on the survey itself.

I'd be happy to answer any questions you might have. Please write or call. You may use the EOSC toll-free (in Oregon) number, 1-800-452-8639, Ext. 1378, to leave a message for me to call you back or you can reach me directly at my home, (503) 963-0678, in La Grande.

Thank you for helping with this study. I'll look forward to hearing from you.

Sincerely,

Dixie Lund

P.0. Box 777

La Grande, OR 97850

Enclosures 
MESSAGE ON FOLLUW-UP POSTCARD SENT TO 469 STUDY SUBJECTS

March 20, 1989

Last week a survey seekf ng your oplnion about the EOSC External Degree Program was malled to you. If you have already completed and returned it to me, please accept my sincere thanks. If not, please do so today.

Because 1 t was sent to only a small, but representatjue, sample of External Degree students, it is extremely important that yours also be included in the study so the results can accurately represent the opinions and experiences of all students in the Program.

If by some chance you did not recelve the survey, or it was misplaced, please call me right now (503) 963-0678 or toll-free In Oregon, 1-800-452-8639, Ext. 1378, and I'll Immediately get another one in the mall to ynu.

Sincerely,

Dixie Lund

Study Director 
2ND COVER LETTER SENT TO NON-RESPONDENTS

About three weeks ayo, I wrote to you seeking your opinion on the expertences you had while enrolled in Eastern Oregon State College's External Degree Program. As of today, I've not yet received your completed questionnaire.

Little information is currently avallable about how adult learners interact with the External Degree Program. I've undertaken this study of External Degree students because I believe that nontraditional students like you and me approach our college studies different from our younger, on-campus, fulltime counterparts. For some of us, programs 1ike Eastern's External Degree meet our needs, and we persist until graduation. For others of us, however, our needs/interests/time/access do not match with the degree program options, and thus, we do not finish.

Your opinions and experiences are important to this study and will be incorporated into recommendations for program changes that could assist other adult students like you and me.

I'm writing to you aga in because of the significance each questionnaire has to the usefulness of this study. In order for the results of this study to truly represent the opinions of all External Degree students, it is essential that each person in the study return the questionnaire.

If your original questionnaire has been misplaced or discarded, a replacement is enclosed along with a stamped envelope for its return. I'li very much appreciate your cooperation and will look forward to receiving your completed questionnatre soon.

Thank you,<smiles>CCCC1C=CC1C</smiles>

Dixie Lund

Study Director

P.0. Box 777

La Grande, OR 97850

(503) 963-0678

Message: (tol1-free in Oregon, 1-800-452-8639)

Enclosures 


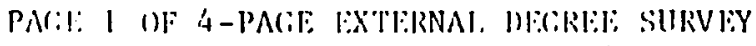

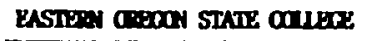

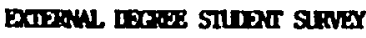

Sirvey 1.D. bo.

Instructions

1 If you do not find the exnct answer that fits your case, use the one thilt comes closest to it. Please answer all questifoss by patting a circle around the single numier that correspends with your cholce.

B. Please angwer the questionis in order. Do not okip around.

C. Remember, steps have been taken to assine the confidentlullty of your respunses plesse be as honest and complete as you can in answering the questions. Thank you

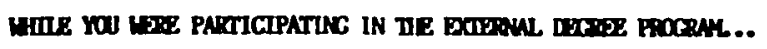

1. Were you a resident of Origion all or most of the time?

Yes in

2. Has there a regfonial out reach center provided by either ENSC or another commity college or 4year col lege/university withln 10 malles of your home? $\quad 1 \quad 2$

3. Did you take any classes at an outreach oenter aponsored by Eisstern Origon State College In either Buker, Burny, Enterprise, John Day, Ontarlo, or Pendleton? I

Did you recelve credit throush any of the following program options:

4. FOSC Port follo workshup held In La Grande?

5. EOSC Portfollo workshop held In a location other than La Grande?

6. EOSC Hortfollo courbe dont by tape/workbouk correspondesice mithat?

7. EOSC Forrfollo essays?

8. Individualized/Correspondence Studles throush EOSC or anuther Institut Ion?

9. basc Couperative pdicil lion (on the-job work experience w/faculty supervision?

10. Carp (Col lege level tiximlint lon Progran)?

11. Callenging by exim of auy FOSC courses?

12. Milltary evaluit ion by Fusc?

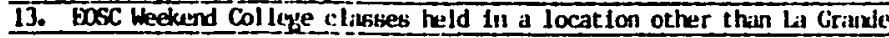

14. EOSC Heckerd Colleyse clisstey held in la Grande?

15. Credits transferrad to Fific from another Institurlon?

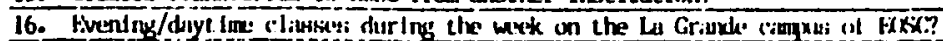

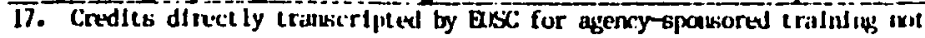

Included in a portfollo of prtor leaming (e.g., Aoxrican lusitlute of

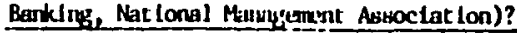

18. Did you focus on any part lcular subject area whl le accimulat ling credlts toward

your degree? (e.g., busfikss, writing, of flce adminlat rat (ox), science, history)

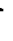

9. Were you aware of any other External neyree type prograns that you cuuld huve enrolled in other thwut the one sponsored by Eastern Onegon State cullege?

20. Did you wstally complete your college assigrments an time?

\begin{tabular}{|l|l}
\hline & 2 \\
\hline 1 & 2 \\
\hline 1 & 2 \\
\hline 1 & 2 \\
\hline 1 & 2 \\
\hline 1 & 2 \\
\hline 1 & 2 \\
\hline 1 & 2 \\
\hline 1 & 2 \\
\hline 1 & 2 \\
\hline 1 & 2 \\
\hline 1 & 2 \\
\hline 1 & 2 \\
\hline
\end{tabular}

21. Did you conilder trunsif urring to mother Institution before couplet Ing or leaving Uhe busc External Degree Progrem?

22. OAd you ever discuss leaving the program with anyone other than basC personnel?

1

23. Did you find the acadkailc expectations avre difficult than you liked?

24. Were degree requit raments mude clent to you by your atvisor?

25. Do you think any Le Grande campus neet Ings with Program personnel should hive been requilred of you?

$\begin{array}{ll}1 & 2 \\ 1 & 2 \\ 1 & 2 \\ 1 & 2\end{array}$

26. Do you think tuklng any standurdized tests (for example, in writing, reading, and/or math) slowld have been requl red? 


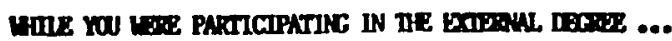

27. Has a college degree required for continuation in your chosen career?

Did you cut back on any of the following activities:
28. Pald emplovment? Program?
1. under 23 yeara
2. 24-35 years
3. 36-44 years
4. 45-54 years
5. 55-64 years
6. over 64 years

29. Social activities with friends?

30. Alane time with spouse or Blgnificant other?

31. Hougework/home malnt enance?

32. Involvement in children's activities?

33. Involvement in civic responsibilittles?

34. Has feedback on your uss $f_{\text {pimelith }}$ frow your course inatructors timely?

35. What age interval best describes you whlle you were partlctpating in the ExLemal Degree

36. Which teru beat describes the grade level at which you entered the External Degree?

1. Freahnan (0-44 quarter credits)

2. Sophowore (45-89 quarter credits)

3. Jundor (90-134 quarter credita)

4. Sentor (135 or more crodita)

37. What was the highest degree you expected to recelve?

1. Did not expect to recelve degree

2. Aseoclate Degree

3. Beccalsureste Degree

4. Gratuate Degree (e.g., Masters, Educational/Medical Iuctorate, law)

38. Por the moat part, what type of comminity did you live in while particlpating in the Extemal Degree Progrem?

1. Parral area or farm, 15t oiles from city

2. Toun or amil city under 50,000

3. Medlum-8ized city $(50,010-250,000)$

4. Suburben area near large city

5. Large elty over 250,000

39. What was your high school grade polnt average (on a 4point Bcile where $A-4, B-3,(-2, D-1)$ ? crese, if you don't rementer exactly.
1. $3.76-4.00$
6. $1.50-1.99$
2. $3.50-3.75$
7. $1.00-1.49$
3. $3.00-3.49$
8. $0.00-0.99$
4. $2.50-2.99$
9. $N / A$, recelved a
5. $2.00-2.49$
Ceneral Ed. Diplona (CED)

4a All in all, how good an evlucation do you think you recelved through Eastem Oregon State College?
1. unable to fud
4. $\operatorname{good}$
2. rathe
5. very good
6. excellent

41. What ranking in your high school gratuating clase best describes you?

1. upper 200 of grachating class

2 in the siddle 602 of my gratuating cless

3. lower $20 \%$ of grachuating class

$4 \mathrm{~N} / \mathrm{A}_{\text {, }}$ received a Ceneral Education Diploma

42. Which statement best describes your progress In the External Degree Progran up until the tive you stopped progressing toand graduation? (Include credit recommendations on your portfallo essays, if applicabled I earned:

1. basically 0; I never really got started.

2 up to about 25 credits before atoppins

3. between 25 and 75 credits before stopping.

4. between 76 and 125 credits before atopping.

5. over 125 credits before stopping.

43. In your opinion, how high is the quallty of Eosc?

1. Very low

2. Pairly low

3. Neither high nor low

4. Fairly high

5. Very high

Using the descriptions below, mark the nuber that correspands to the highest educational level of:
44. Your wother
(1) Leas than High School
45. Your father
(2) High School/OED Diplam
46. Your spouse
(3) Post High School, non- college vocationel school training
(4) Sane College
(5) College Degree

47. How many hours per week were you employed outalde your home while you participated in the External Degree

1. 0 , did mot work outside wy home

2. 1-10 hours

3. 11-20 hours

4. 21-30 hours

5. $31-40$ hours

6. over $\mathbf{4 0}$ hours 
48. How many children did you have living at howe with you while you participated in the Extermal Degree?

0. nane

1. I child

2. 2 children

3. 3 chdldren

4. 4 or wre children

49. That wour marital status while in the Program?

1. Single

2. Married

3. Separated

4. Divorced

5. Hidowed

50. Whdch otatement best describes your respanse to the anount of time that was required of you on a weekly basis to participate in the External Degree.

1. Hore tive than I could poesible give.

2. More time then expected, but 1 found it.

3. About the amount I had expected.

4. Lese time than I had expected.

5. Hardly any time at all.

51. Which factor below best describes the reason you enrolled in the Extemal Degree Program?

1. Degree wes requlred in wy career

2. To Inprove myself

3. To get a job

4. To get a better job

5. For the personal challenge

6. Ocher

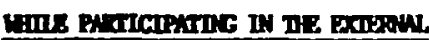

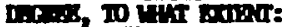

S6. Here you antiafled with the amount of codeenlc atvising you recelved?

57. Were you able to find the neceseary time to ocmplete your college assignments?

58. Dud you procrestinate until the last winute with doing your college assigrmenta?

59. Here you satiofled with the quality of acadealc advising you recelved?
52. Which statement best degcribes how your educational expenses were funded

1. By celf and/or spouse's employwent income

2. College-provided financial aid

3. Bank loans

4 Loans/gifte from famlly or friends

5. Employer relmbursement prograw

6. GI Bill

7. Other

53. How many alles away from any comenity or 4 year college/university is the home in whdch you lived while in the External Degree?

1. $0-59$ milles

2 60-149 viles

3 150-249 alles

4 250-499 olles

5. 500 or more miles

5h How many miles away from the La Grande carpus of bosc is the howe in which you lived while participating In the External Degree?

1. 0-59 milles

2 60-149 wlles

3 150-249 alles

4. $250-499$ milles

5. 500 or more miles

55. What was the soat difflcult barrler you faced to participarting in the Extemal Degree?

1. Lack of Adequate Finances

2. Too Great a Distance from College(s)

3. Not Enough Time to Comit to School Absignents

4. Lack of Encouragement from People in ay Life

5. Thexpected Personal/Fendly Crlsis

6. Ocher

Were you confident with:

60. Your atudy giet11s?

61. Your reading abillty?

62. Your writing abllity?

63. Your abillty to express yourself verbally?

64. Your abllity to cope with atress?

65. Your ablity to cope whth new acadentc challenges?

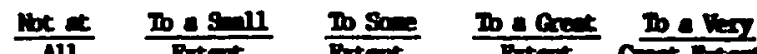

All Btert Bont

1

3

4

5

1

2

3

4

5

2

3

4

5

1

2

3

4

5

66. Were finences a problem for you?

12

2

3

4

5 


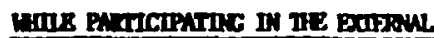

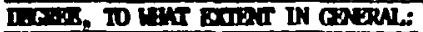

67. It difficult for you to ask your atvisor for help when you needed It?

68. Wea It diffiault for you to ask your instructors for help when you needed 1t?

69. Do you feel the rules and procedures of the Extemal Degree Program inhibited your progress tarard completing the degree?

\section{libe at bo a sall Ali.$~ \underline{\text { Beit }}$}

Tb sore to a cate to

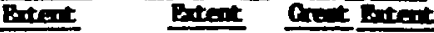

Do varr rower did each of the following persons encourage you in pursuing your college education:

\begin{tabular}{|c|c|c|c|c|c|c|c|}
\hline 70. & Spouse/significant other & $\frac{\operatorname{Dog} \text { ont }}{\frac{\operatorname{sgn} 2}{0}}$ & $\frac{\mathrm{mt} t}{\frac{\mathrm{Al}}{1}}$ & $\frac{m a s+11}{\frac{B+1-1}{2}}$ & $\frac{\frac{105}{2+s_{1}}}{3}$ & 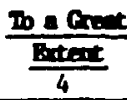 & 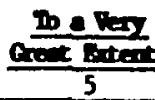 \\
\hline 71. & Parents & 0 & 1 & 2 & 3 & 4 & 5 \\
\hline 72. & Brotherg/SLoterB & 0 & 1 & 2 & 3 & 4 & 5 \\
\hline 73. & Childnen & 0 & $T$ & 2 & 3 & 4 & 5 \\
\hline 74. & Frtends & 0 & 1 & 2 & 3 & 4 & 5 \\
\hline 75. & Duploger & 0 & 1 & 2 & 3 & 4 & 5 \\
\hline
\end{tabular}

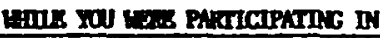

Its Briven Dafer ...

76. Hou often were courses that you desired to take in order to complete your degree offered to you?

77. Here the courber you wanted to take offered at comvenient times for you?

How axh in act do you think that particlpating In the Bosc Boternil Degree Progra hed on:

78. Knowing yourself?

79. Uaing interpersonal skills?

80. Seeing alternative points of view?

\begin{tabular}{|c|c|c|c|}
\hline$\frac{\text { Dos not }}{\text { haly }}$ & $\frac{\text { lot at }}{\text { All }}$ & Sone of & $\frac{\text { whet of }}{\text { the } T}$ \\
\hline
\end{tabular}

1

2

4

0

1

2

3

4

Litele or tone

sone

Quite AGout Dit Del

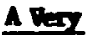
Crex Dol

Plesse use the epace below to answer the following question: "If you had it to do all over agaln, what would you do differently a 'second time around' when returning to college?"

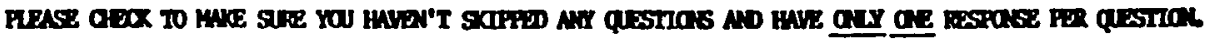

There gou very mach for completing this aurvey. Plense return it in the enclowed anvelopen 


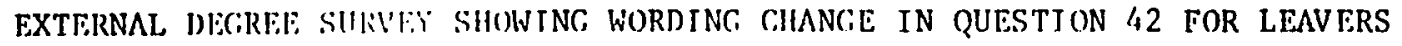

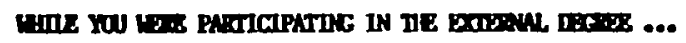

27. Was a college degree requlred for continuation in your chosen career?

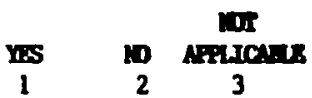

Did you cut back on any of the following activities:

28. Pald emloyent?

29. Soctal octivitles with friends?

30. Alone time with epouse or significant other?

31. Havework/hane malntenauce?

32. Involvewent in childrei's activitles?

33. Involvenent In clvic renponsibllitles?

34. Wag feedback on your assignments from your course instructors timely?

41. What ranking in your high school, graduating clase best descrlbes you?

1. upper 200 of graduating clase

2. In the aiddle $60 \%$ of ay graduating class

3 lower 202 of graduating clase

4. N/A, recelved a Ceneral Education Diploas

3. $36-44$ years

4. 45-54 years

5. 55-64 years

6. over 64 years

36. Which term best describes the grade level at which you entered the Extermil Degree?

1. Freshan (0-44 quarter credits)

2. Sophare (45-89 quarter credits)

3. Juntor ( $90-134$ quarter credits)

4. Senior (135 or more credilo)

37. What was the highest degrex you expected to recelve?

1. Did not expect to receive degree

2. Arsoclate Degree

3 Beccalnureate Degrea

4 Graduate Degree (e.g., Masters, Educational/Medical Dxctorate, Law)

38. For the most part, what tyme of community did you Live in while partlclput ing in the Extemal Degree Program?

1. Rural ares or farm, $15+$ miles from city

2. Town or enall city under 50,000

3. Medturatzed clly $(50,000-250,000)$

4. Suburben area near large clty

5. Large city over 250,000

39. What was your high school grade polnt average

(an a 4 -point scale where $A=4, B-3, O-2, D=1$ )? Qrese, If you don't rmmber exactly.

1. $3.76-4.00$ 6. $1.50-1.99$

2. $3.50-3.75$ 7. $1.00-1.49$

3. $3.00-3.49$ 8. $0.00-0.99$

4. $2.50-2.99 \quad$ 9. N/A, recelved a

5. 2.00-2.49 Cuserol Ed. Diplawe (CBD)

$40 \mathrm{All}$ in all, how good an education do you thirik you recelved through Eestem Oregon State College?

1. Unable to Juige 4. good

2. racher poor 5. very good

3. fair

6. excellent

42. Which otatenent best describes your progrese toward graduation in the Bxternal Degree Progran? (Include credit recomendat lans on your portfollo eseays, If applicableh I averaged:

1. less than 6 credits per term.

2. between 6 and 8 credits per term

3. between 9 and 11 credits per ter.

4. at lesst 12 credits per term.

43. In your opinion, how high is the quality of EasC?

1. Very 10 w

2. Fatrly low

3. Nelther high nor low

4. Fairly high

5. Very high

Usins the descriptions below, mark the nuber that corresponds to the highest educational level of:
44. Your wother
(1) Lese then High School
45. Your father
(2) Hgh School/GD Dpla
46. Your spouse
(3) Post Hoh Schol , college vocation 1 school trainin:
(4) Sone Colleg
(5) College Degree

47. How wary hours per woek were you enployed cutedde your home while you particlpated in the Extemel Degree

1. 0, did not work outside wy trowe

2. 1-10 hours

3. 11-20 hour:

4. 21-30 hours

5. 31-40 hours

6. over 40 hours 


\title{
APPENDIX B
}

\section{OFFICIAL STATISTICAL TABLES RELATED TO SIGNIFICANTLY \\ DIFFERENT COMPARISONS ( $p<.05)$ DESCRIBED}

\section{IN CHAPTERS IV-V}

\begin{abstract}
This first section of this appendix includes tables of comparisons between leavers and finishers, presented in the numerical order in which survey questions were asked. The second section includes tables of comparisons between rural and urban respondents, and the third section includes comparisons between males and females.
\end{abstract}




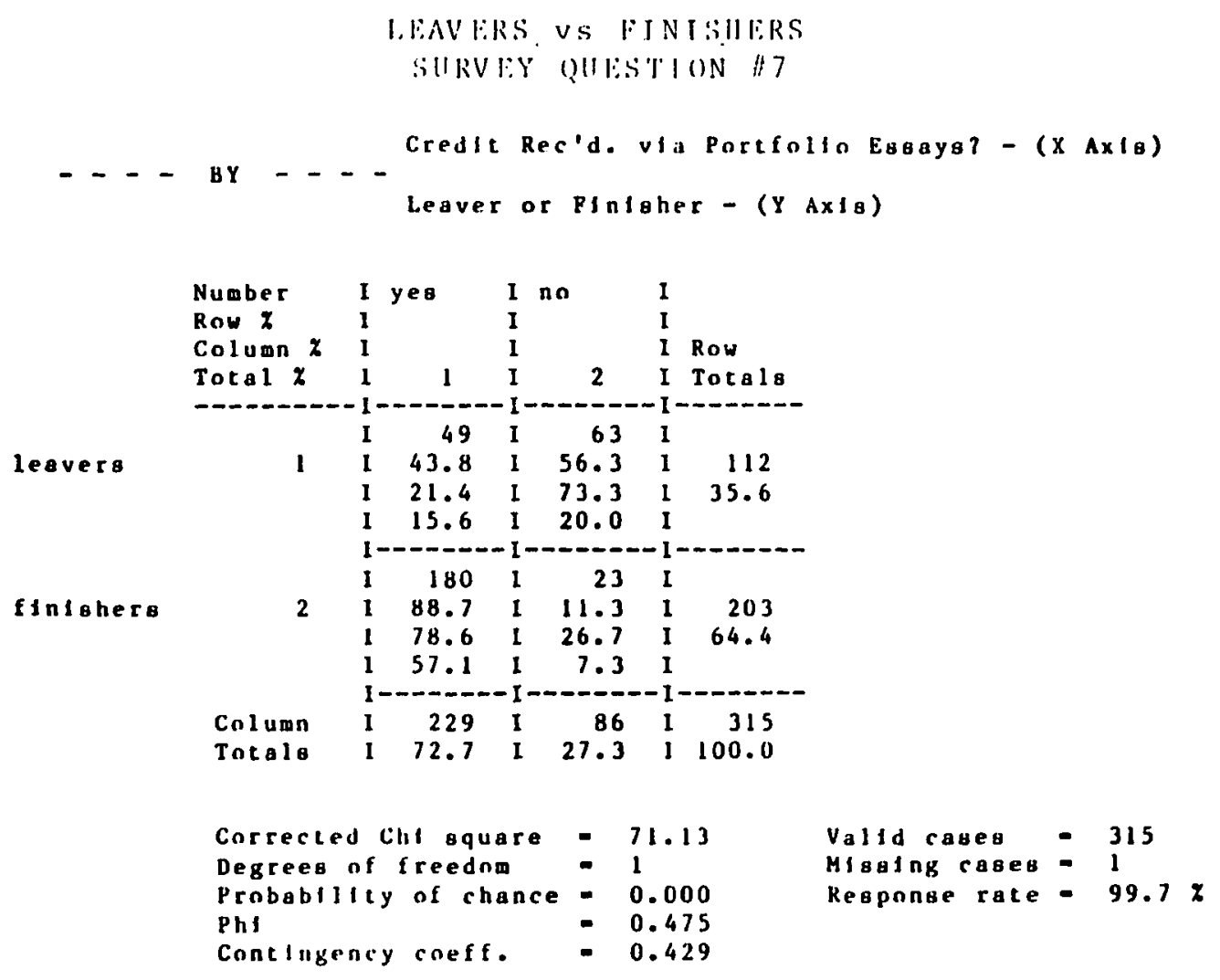




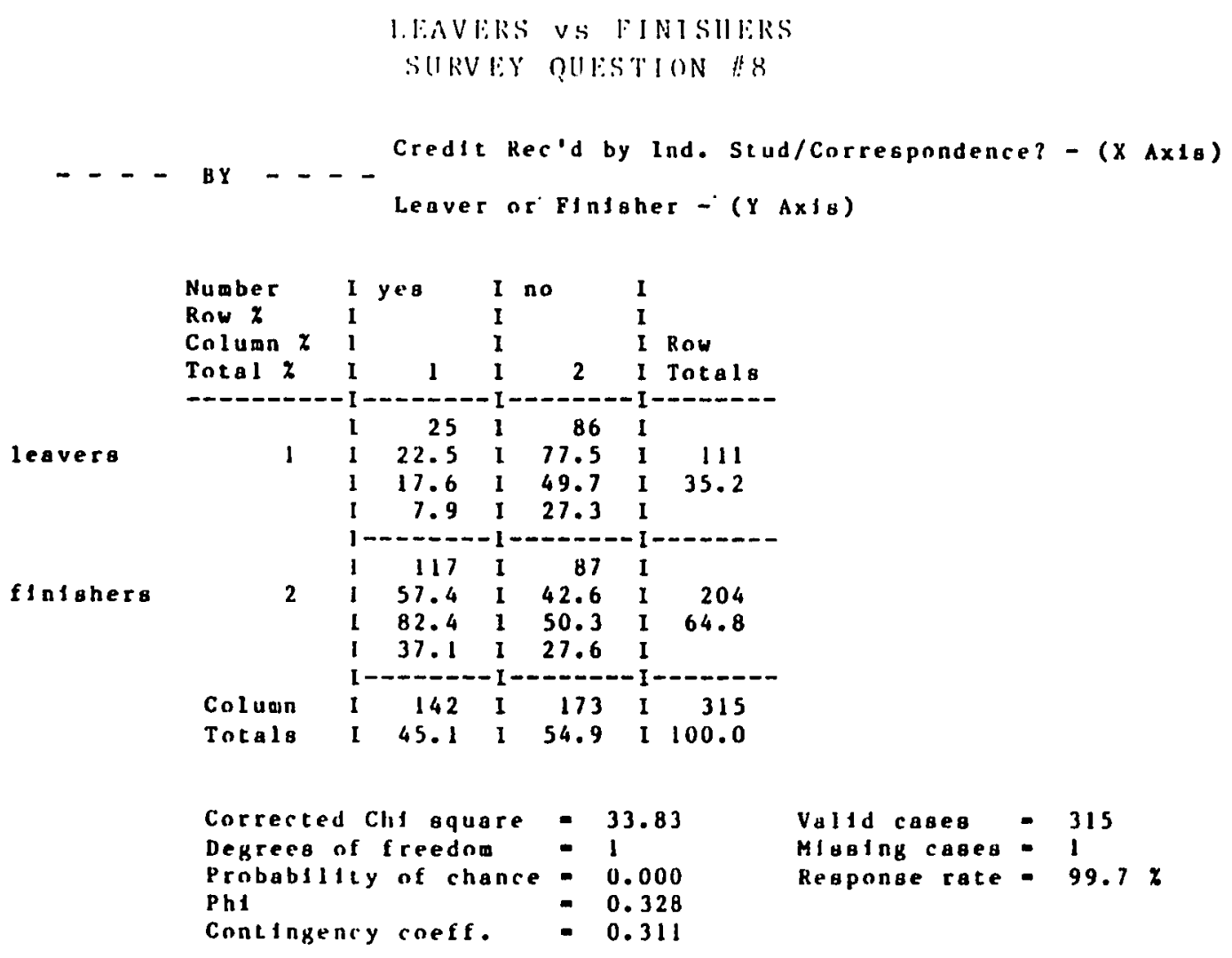




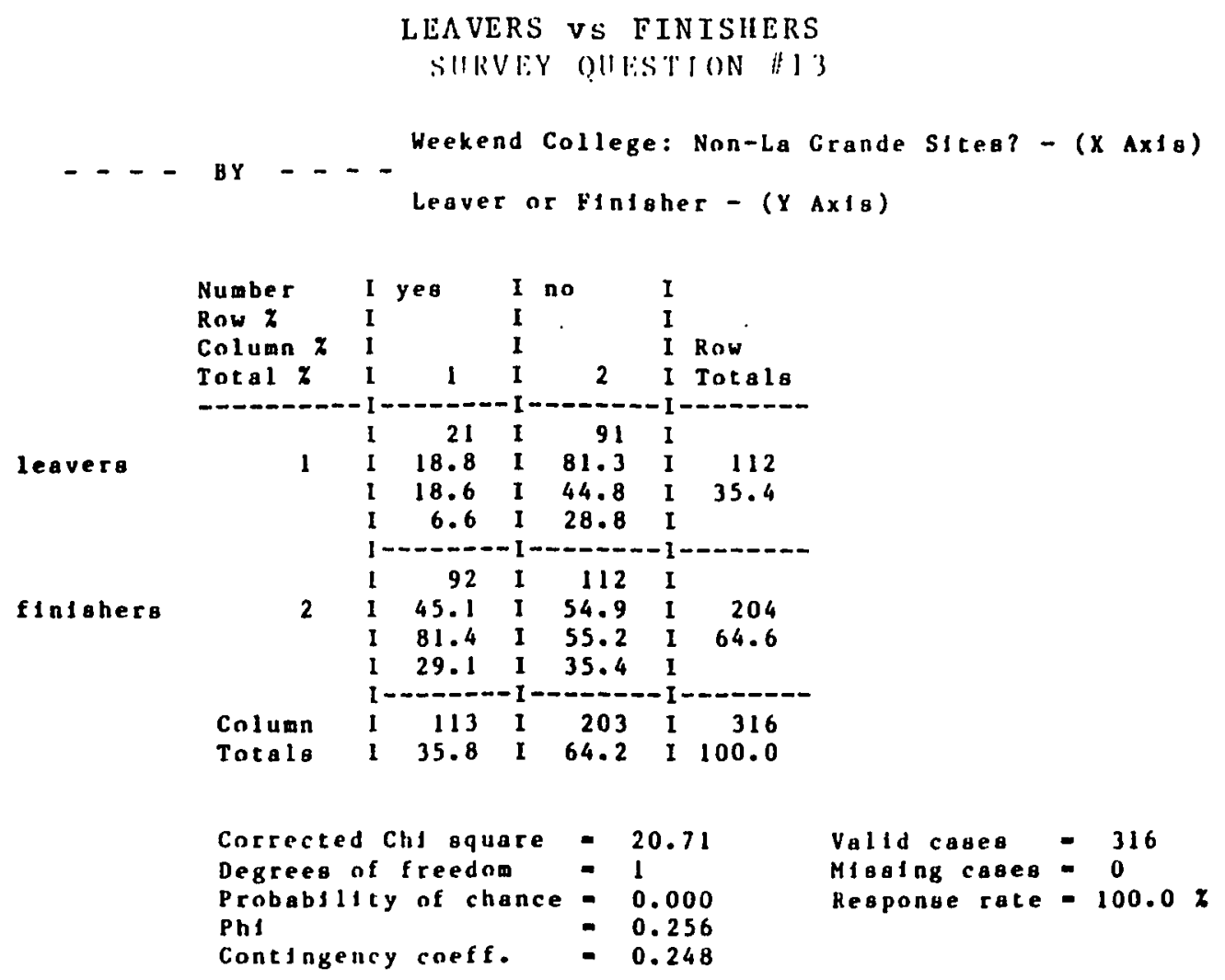




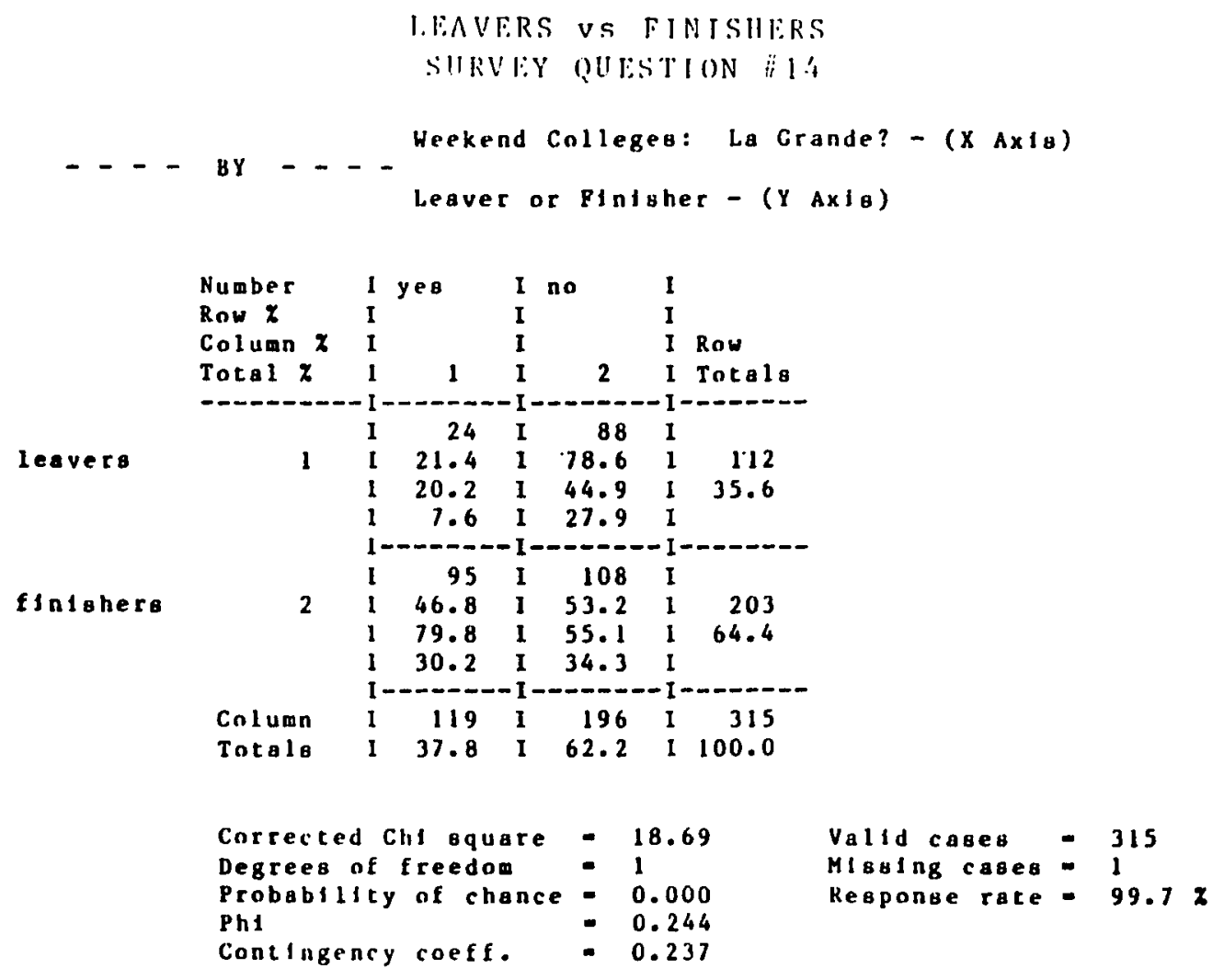




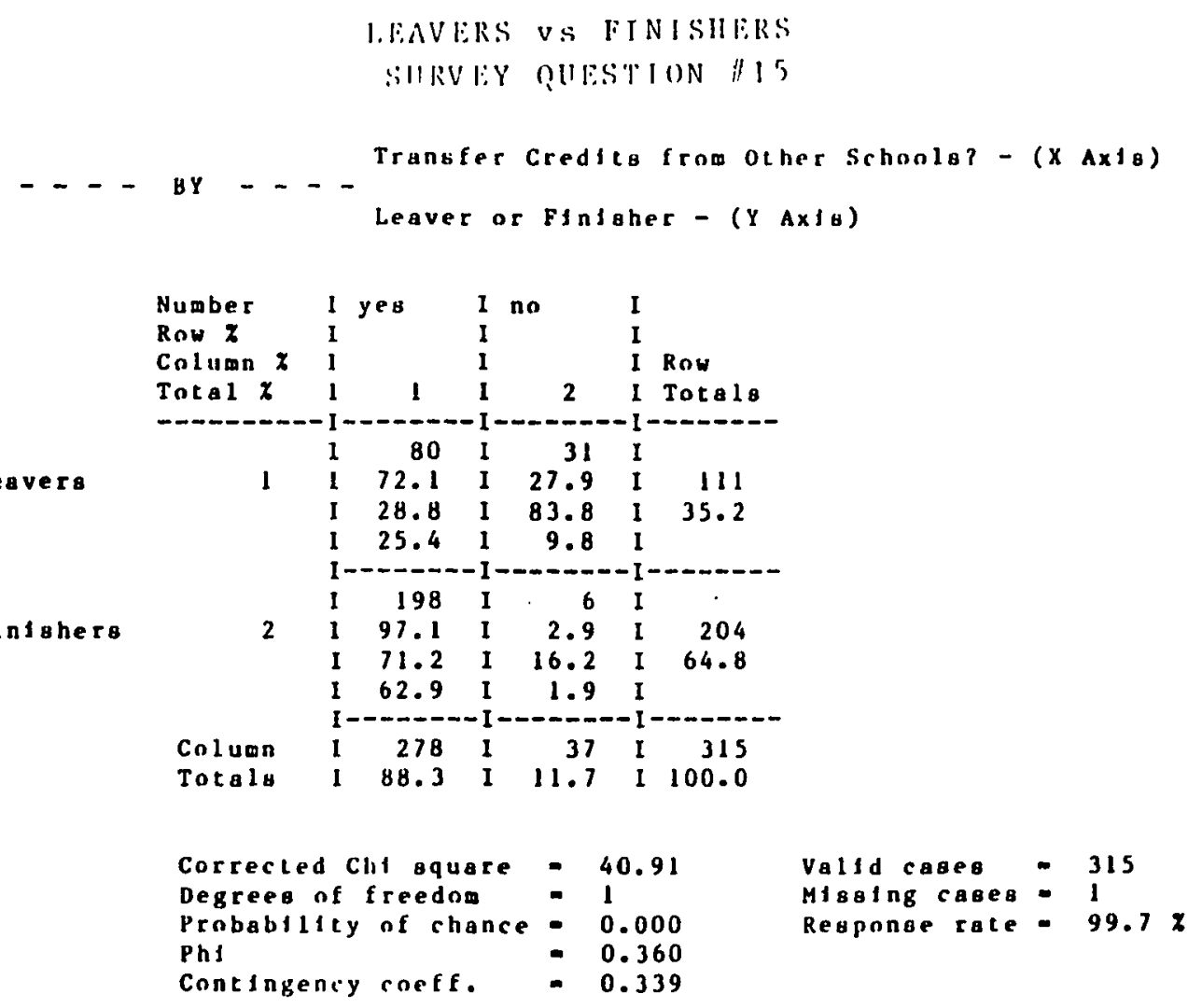




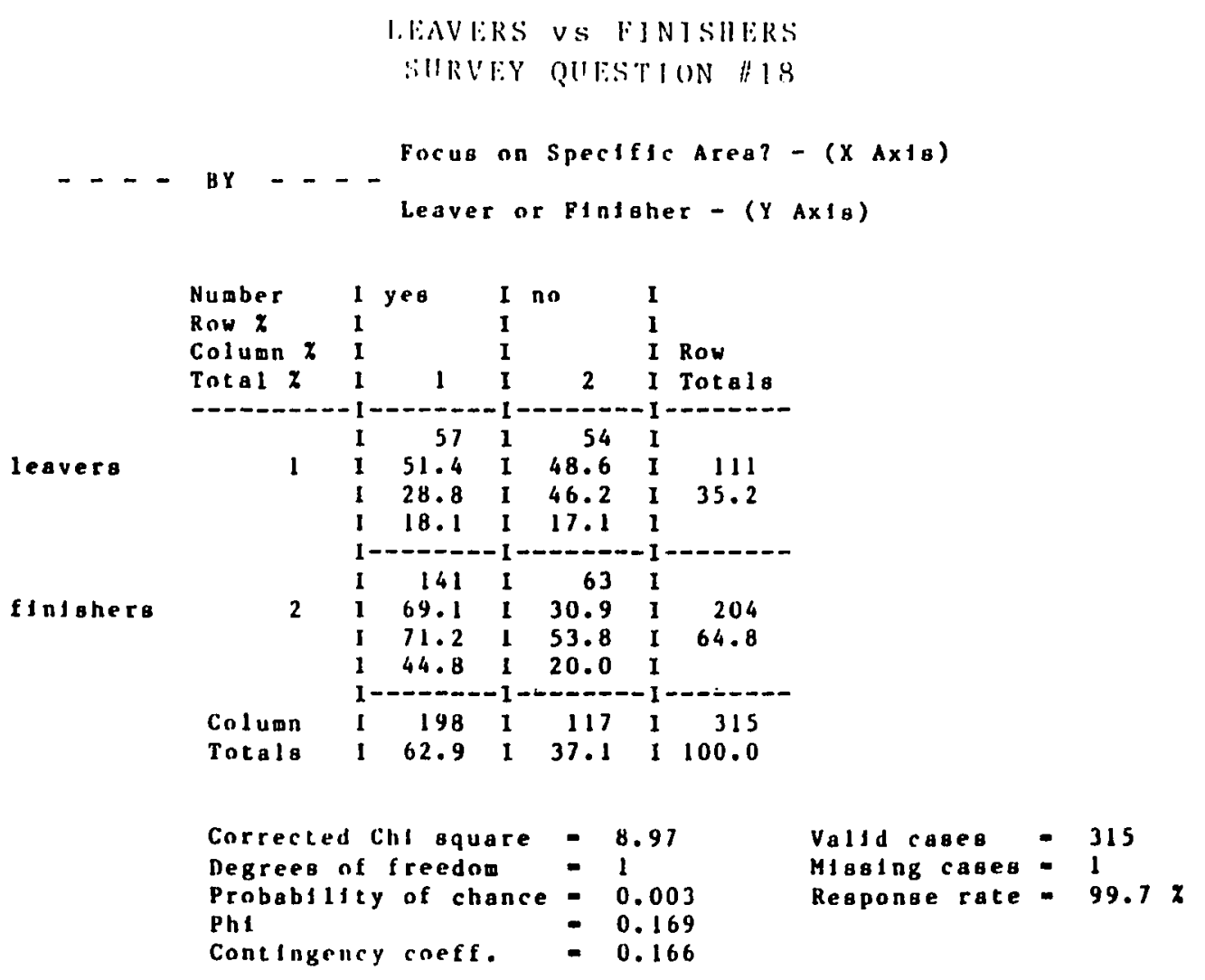




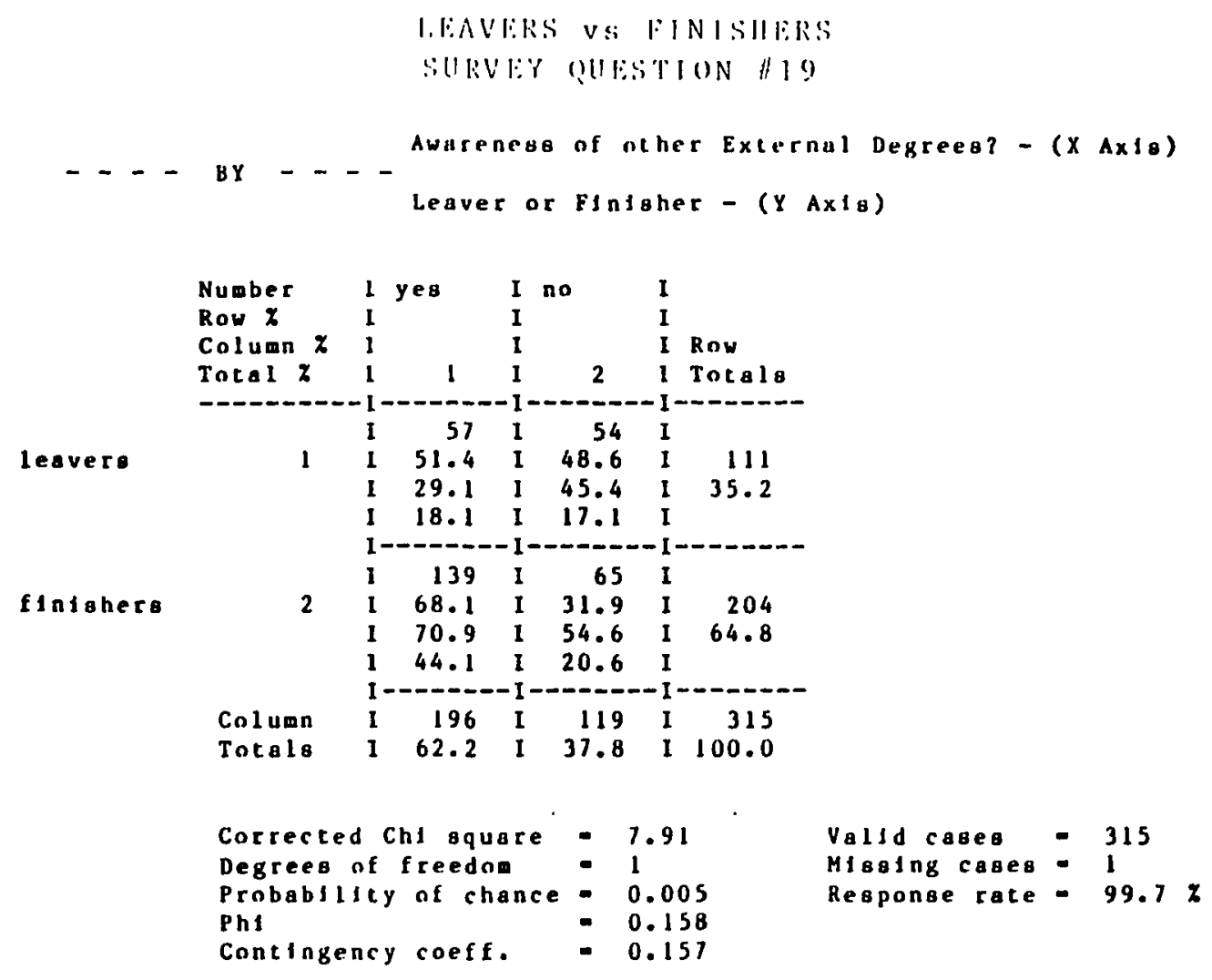




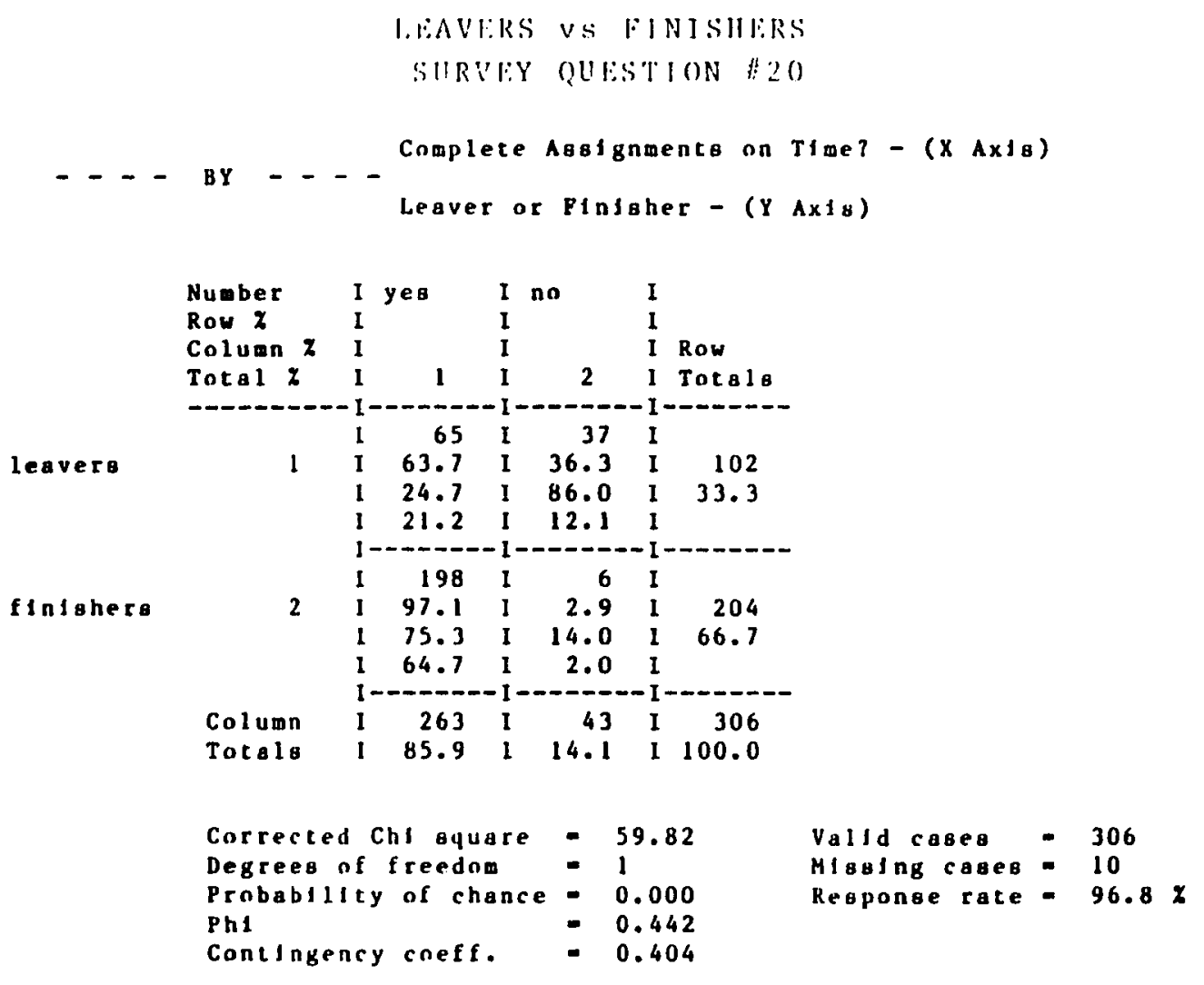




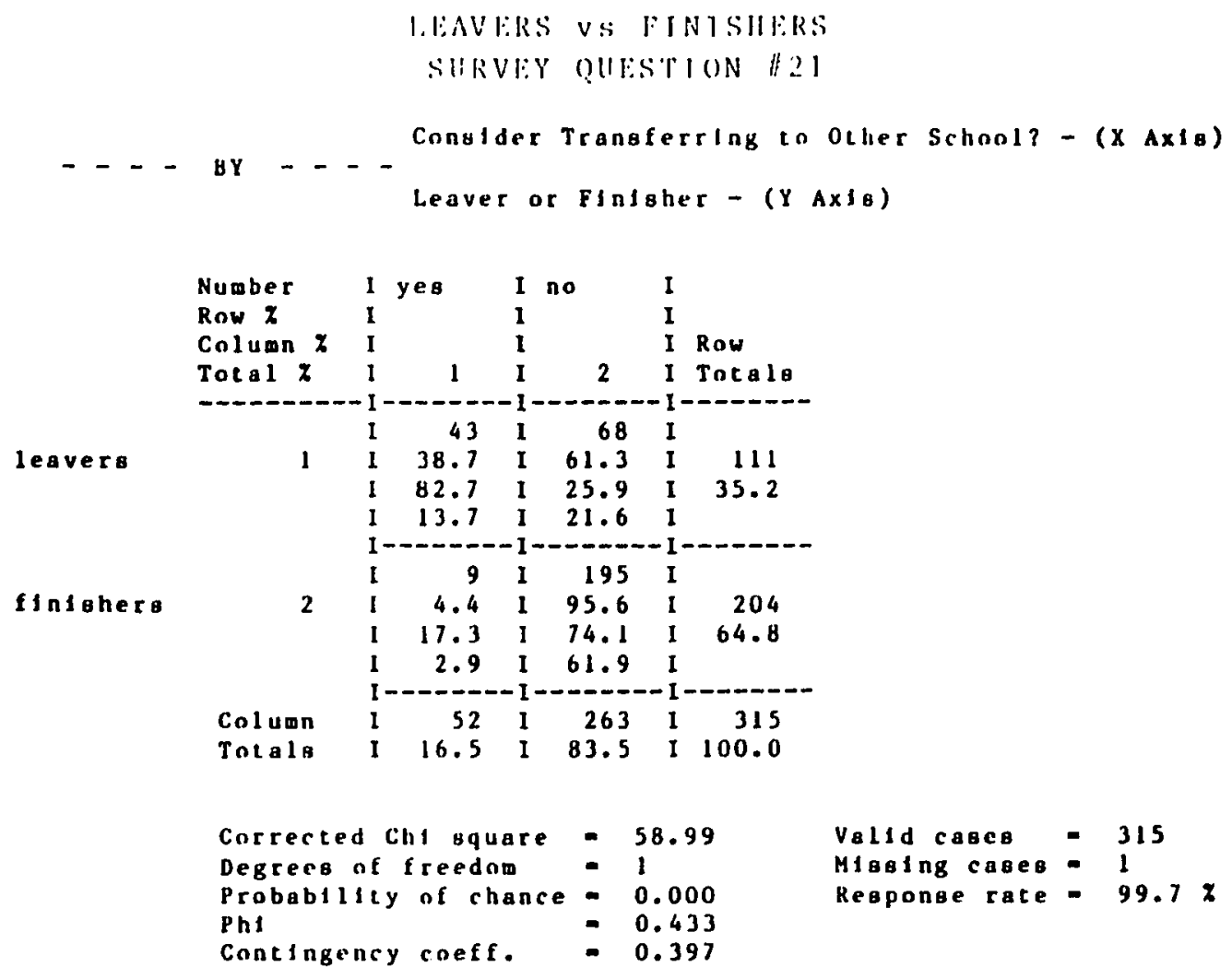




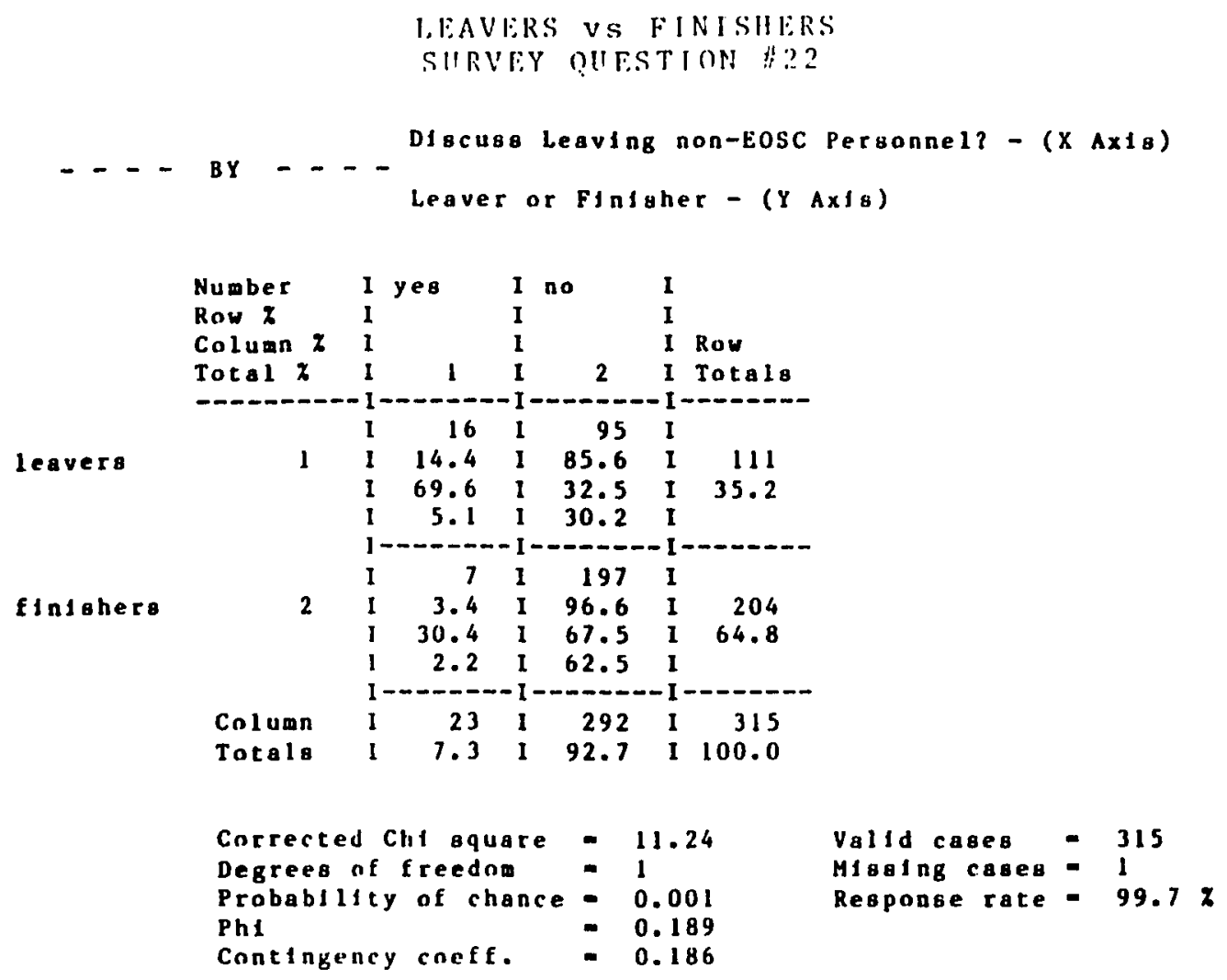




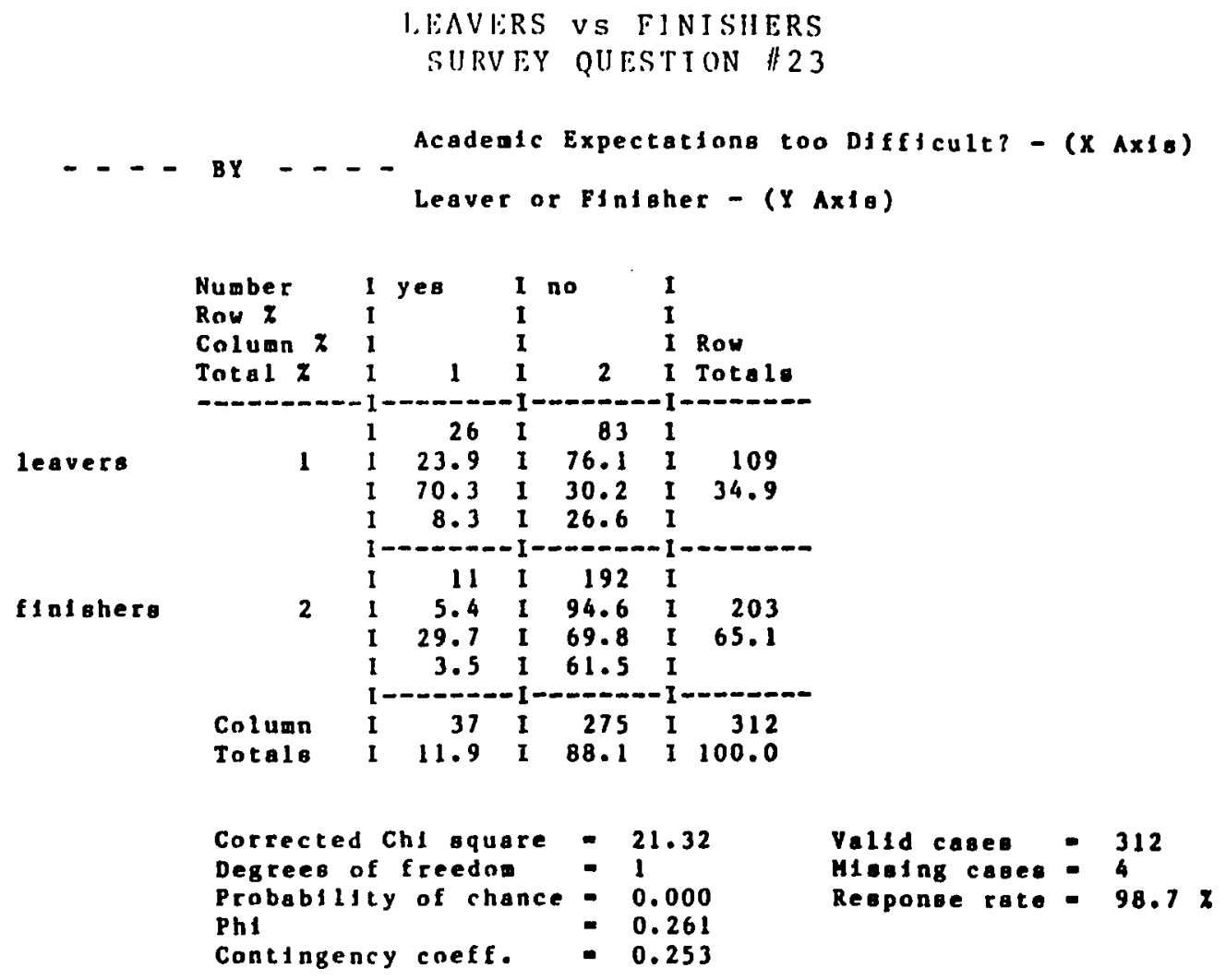




\section{I:AVERS VS FINISHERS \\ SIIRVEY UUFSTTUN \#2\%}

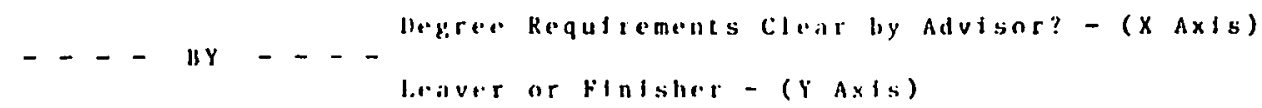

V.111 coses $=314$

MIssillh iasos $=2$

kesponse rate = $94.4 \%$ 


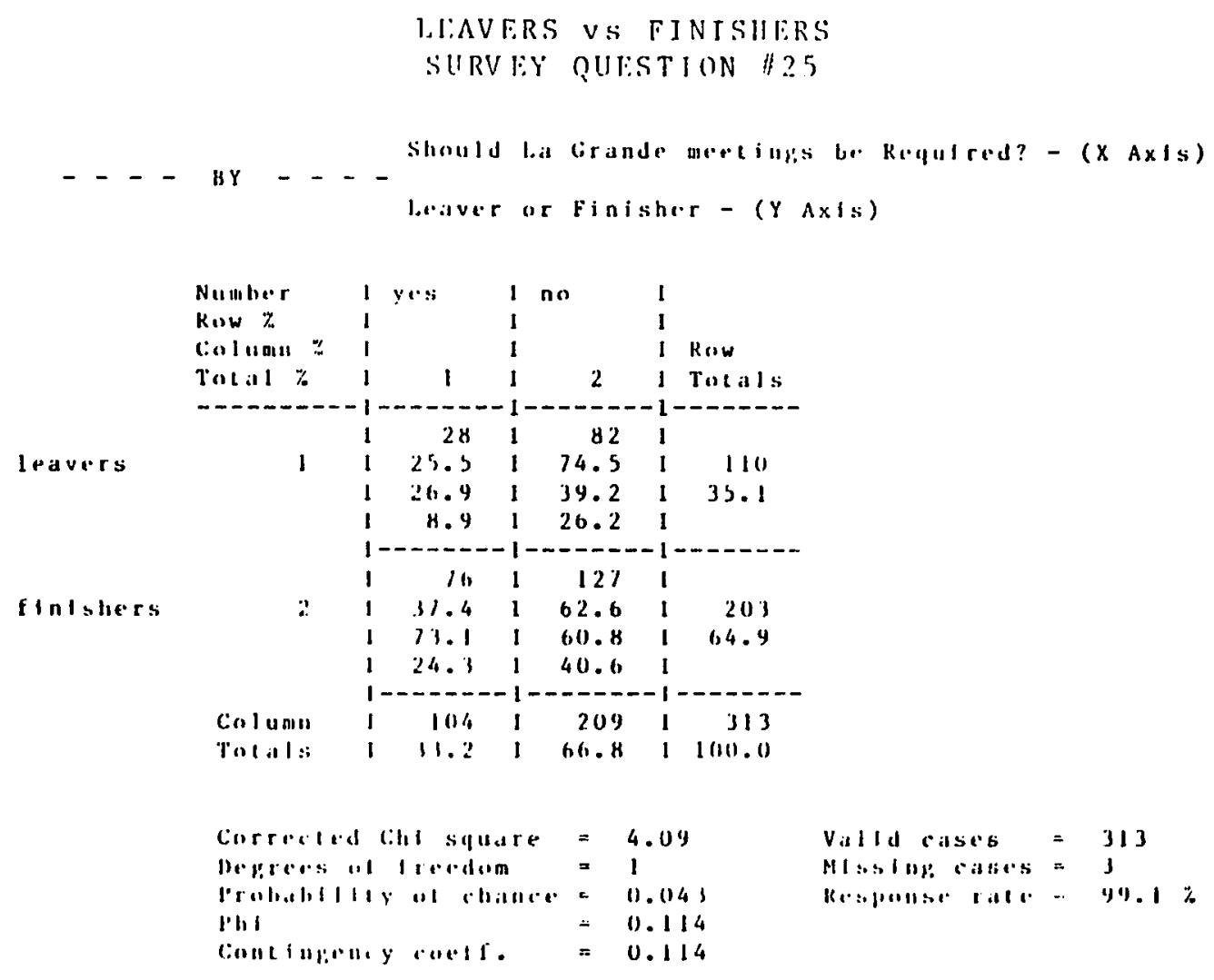




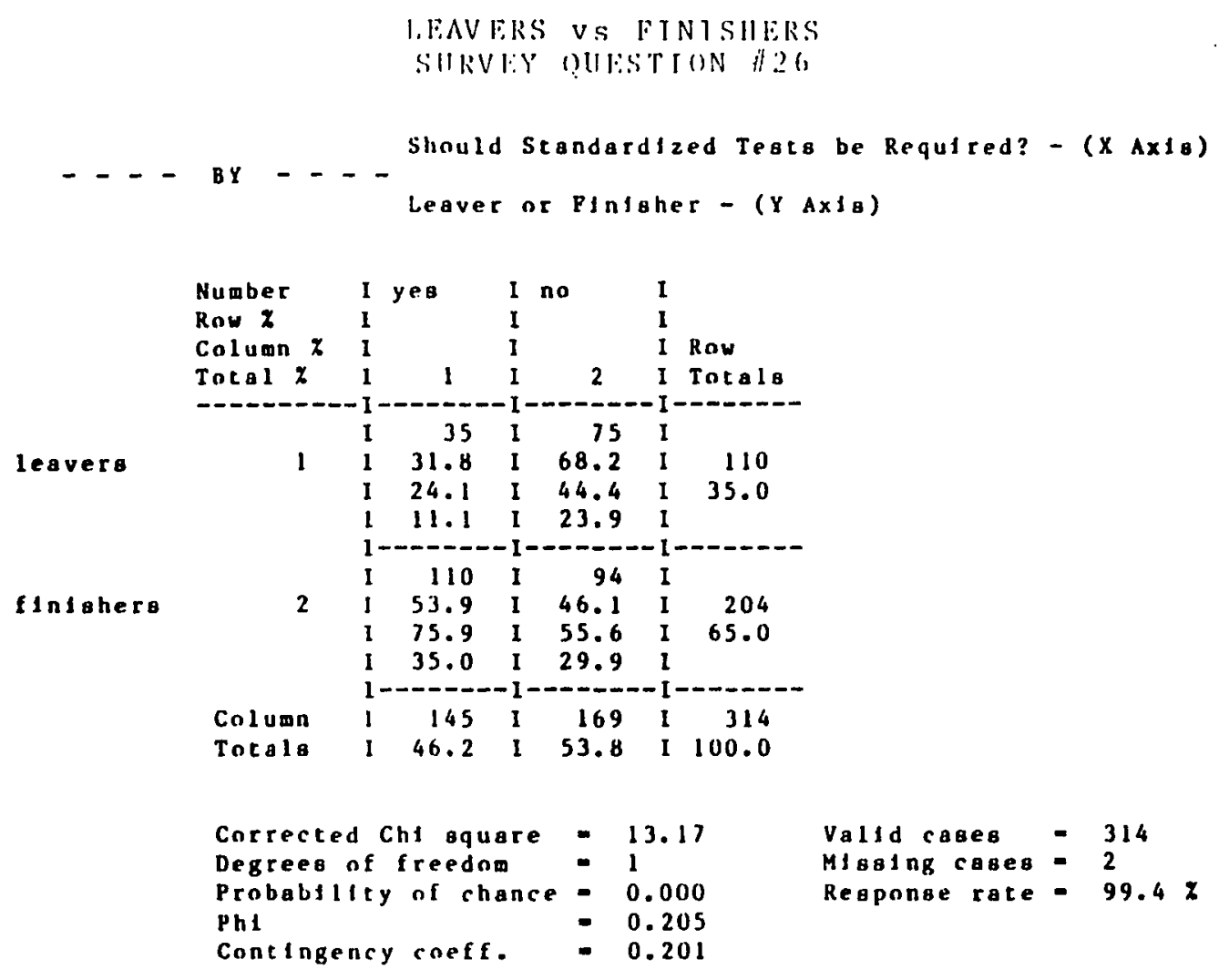




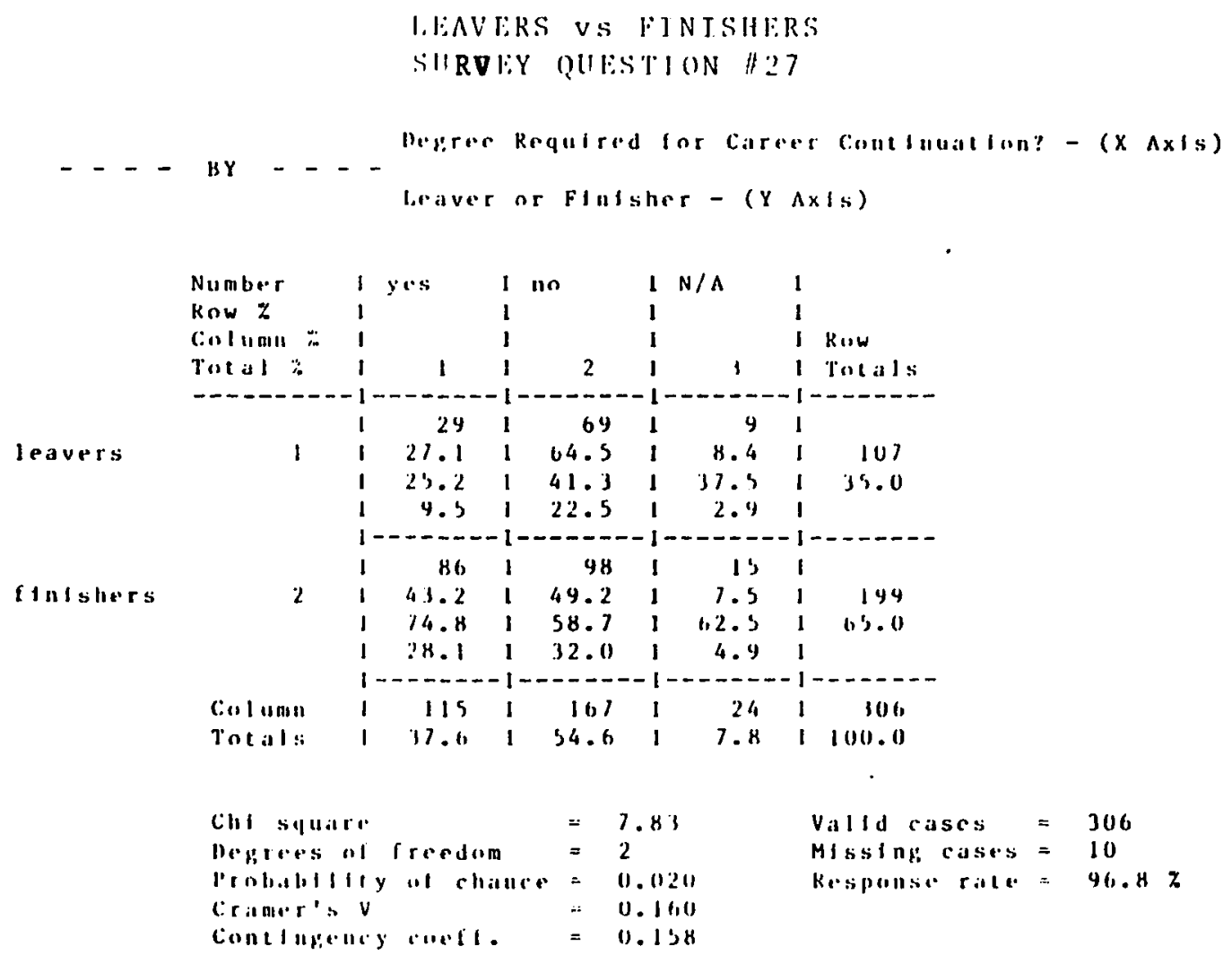




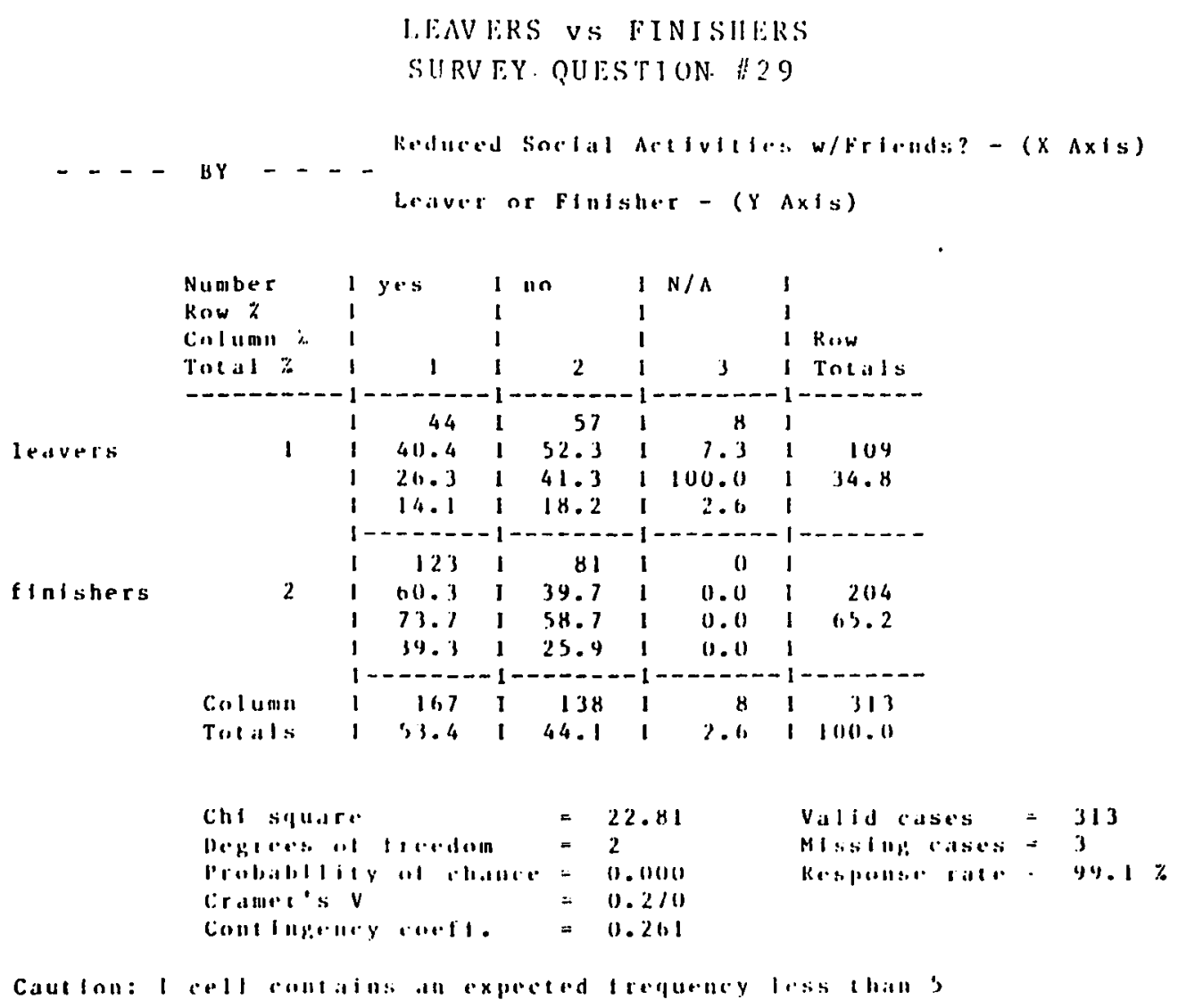




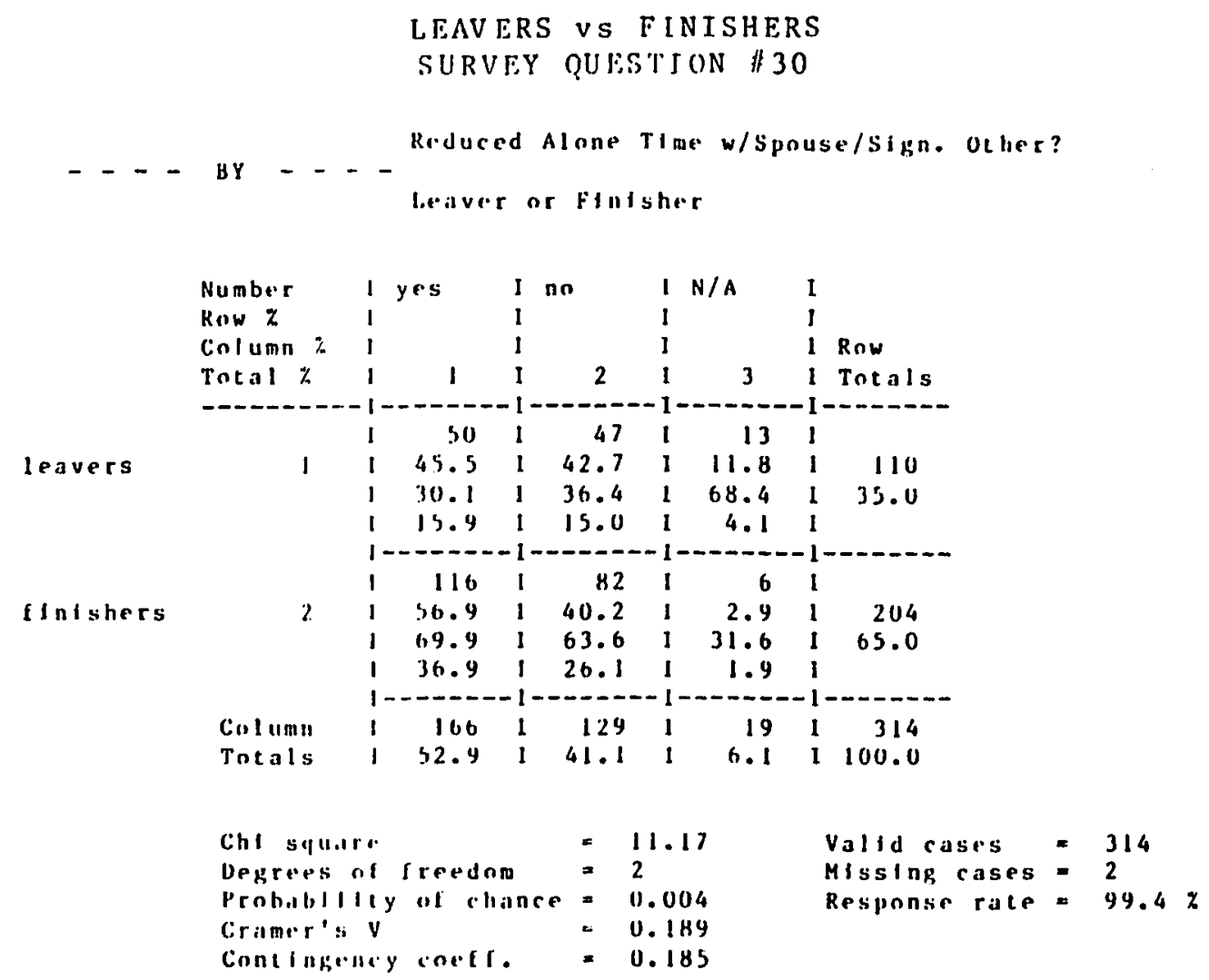




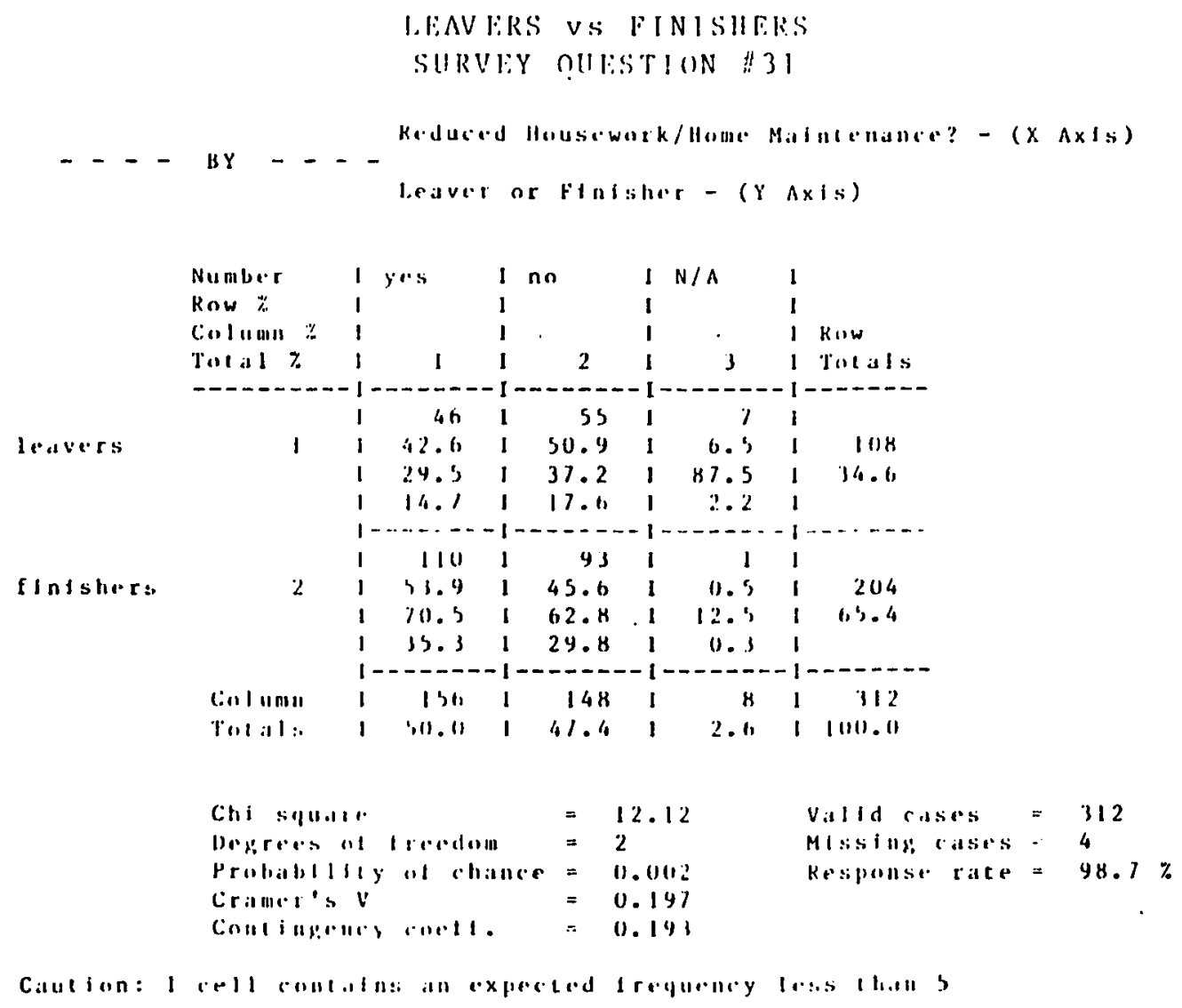




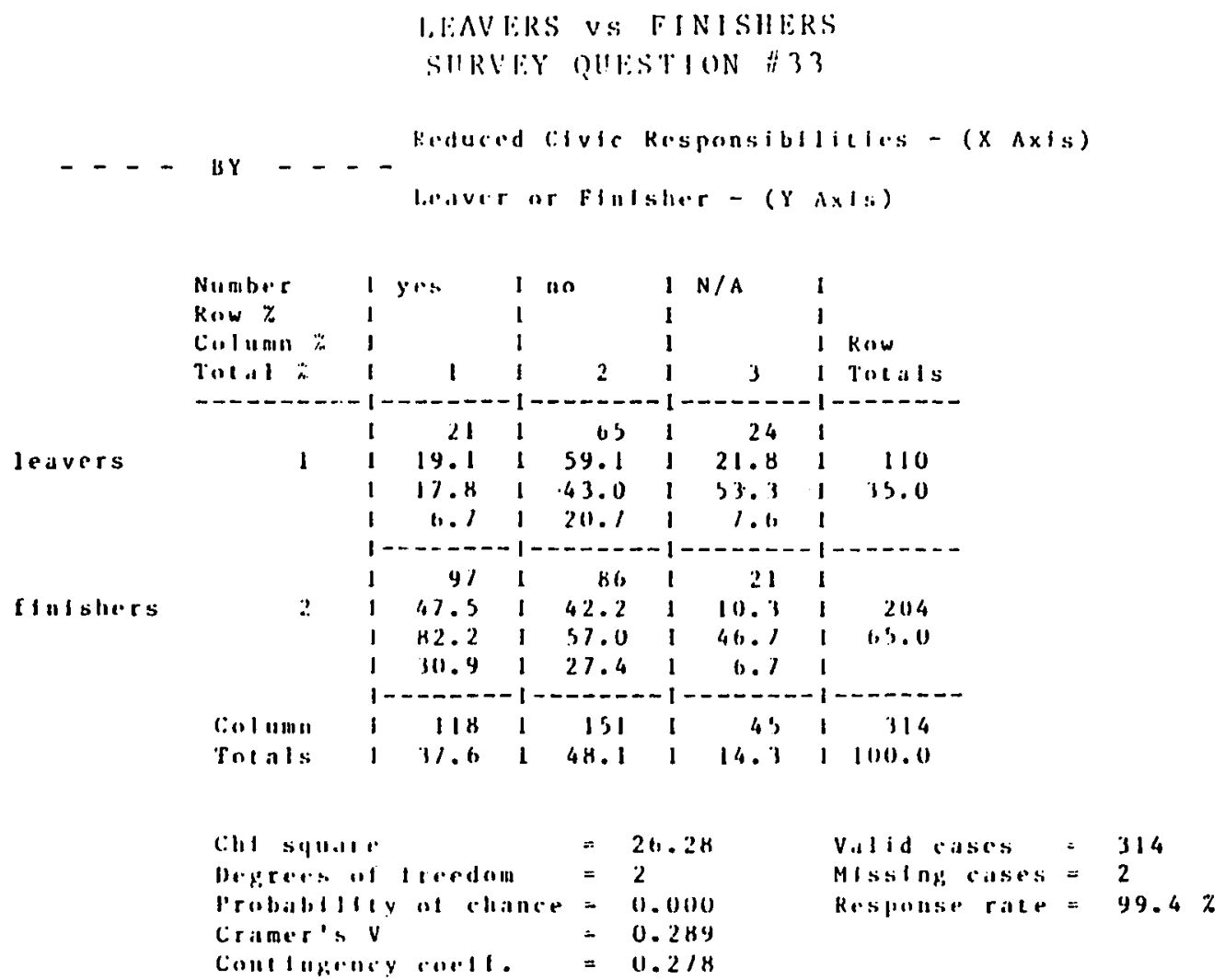




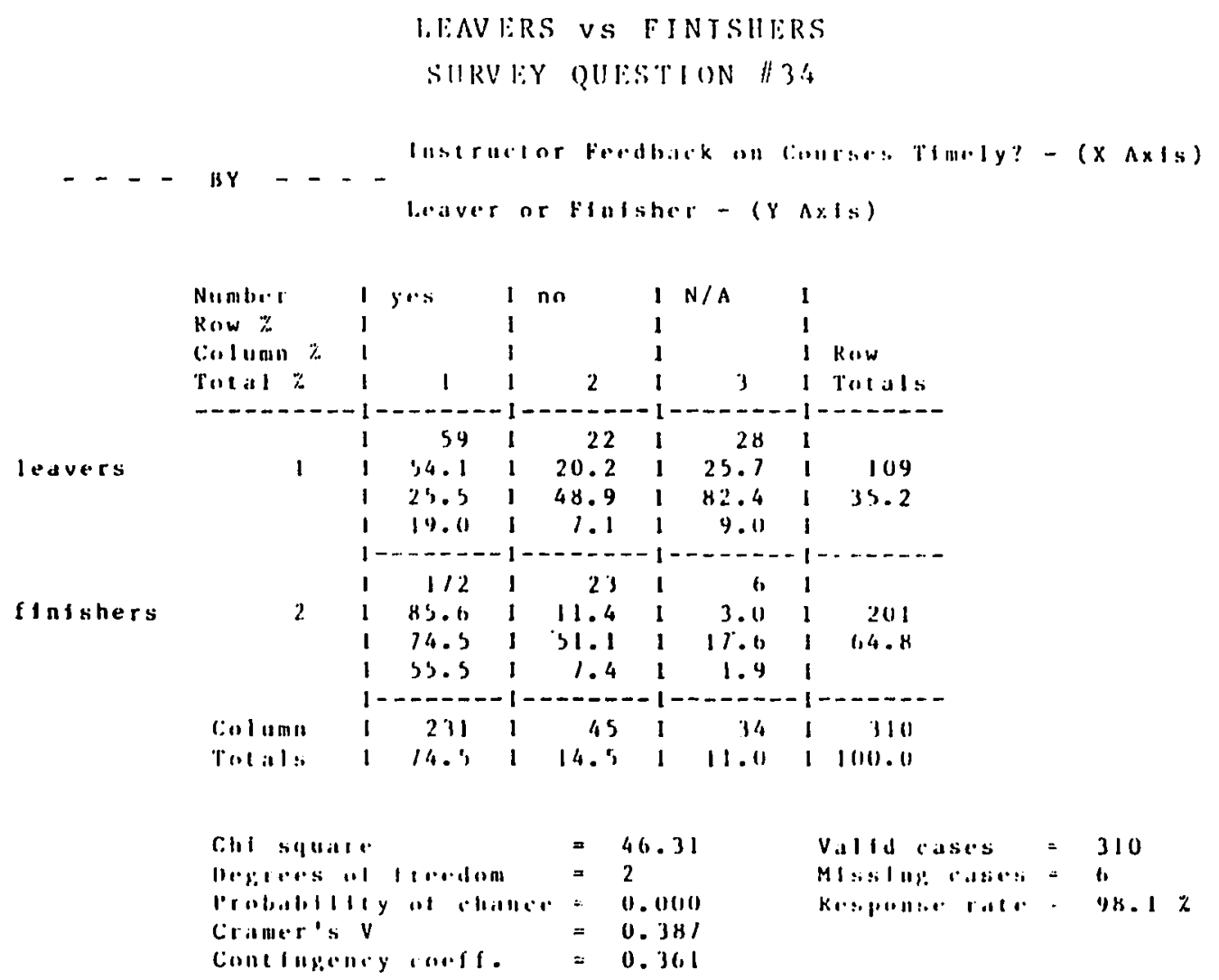




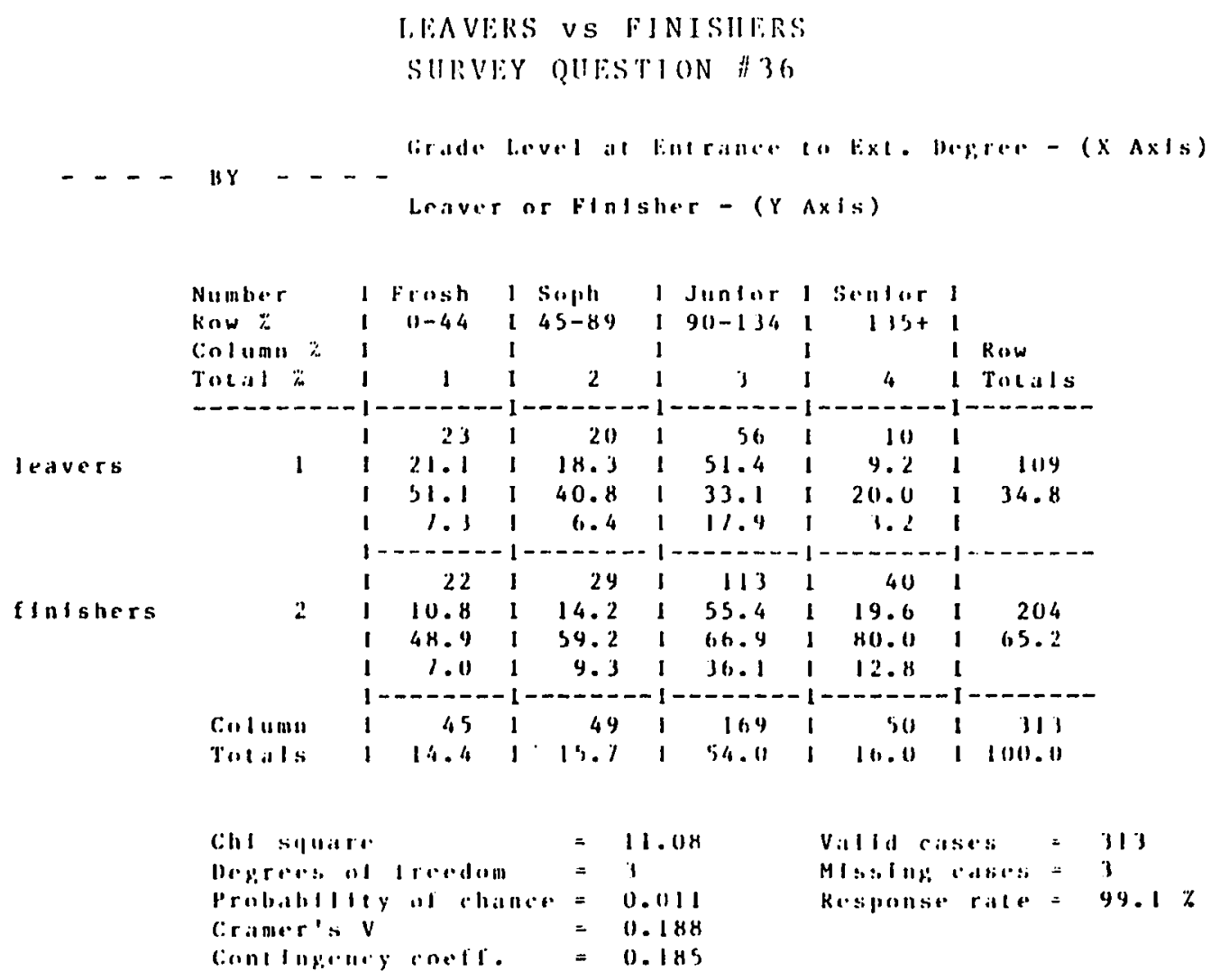




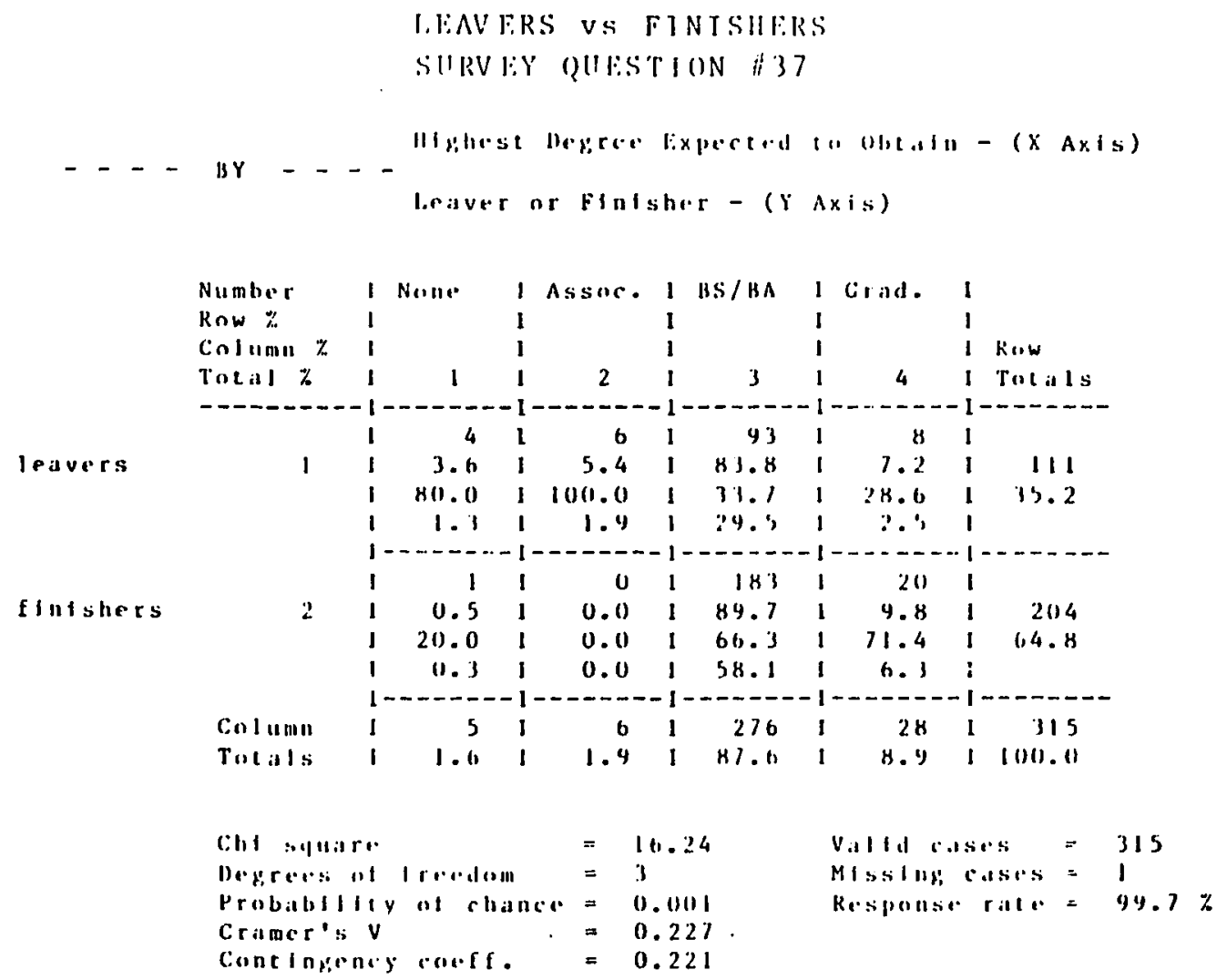

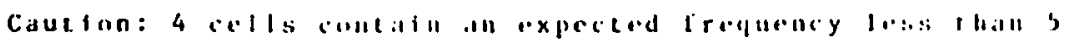




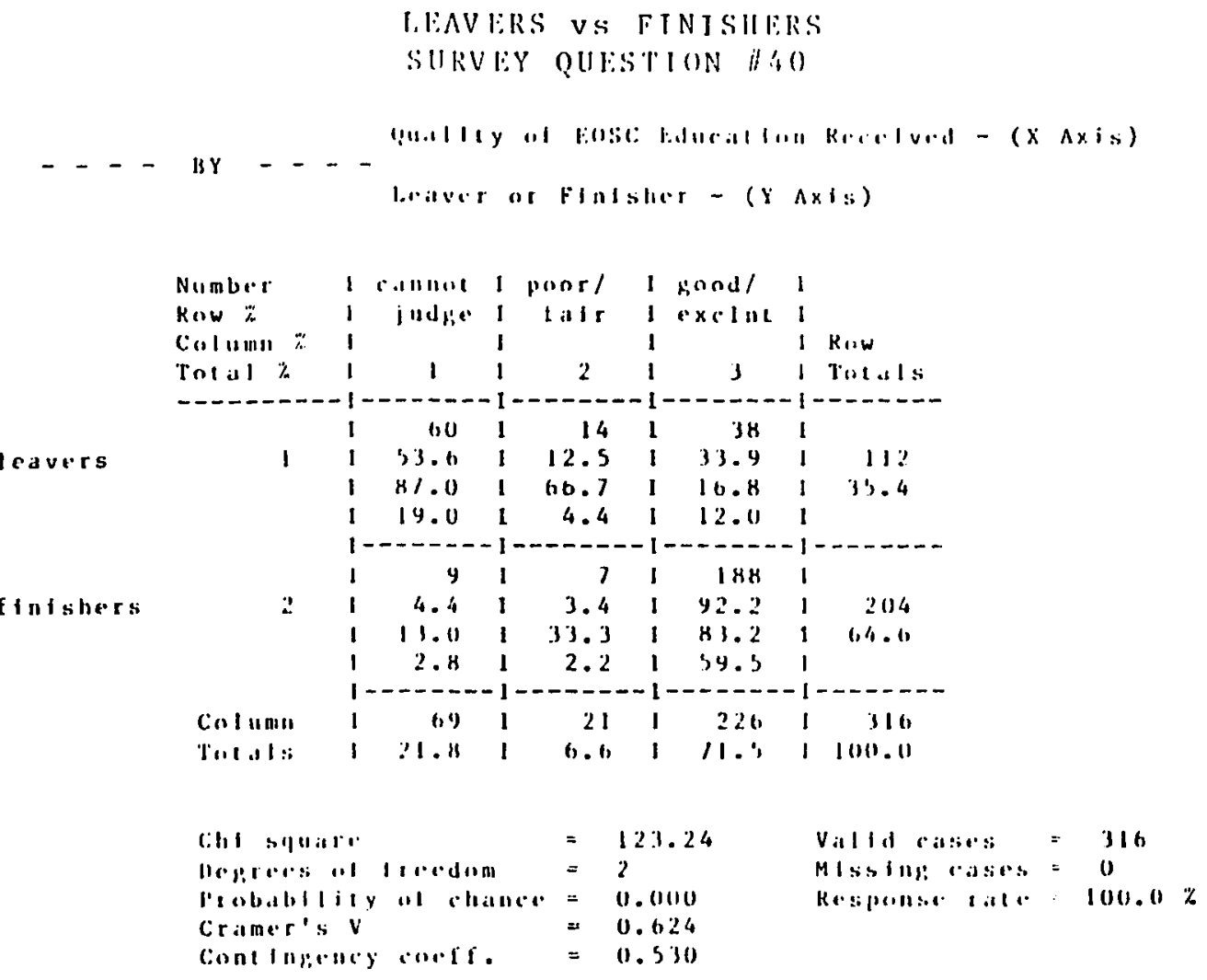




\section{SURVI:Y QUESTION \#42: FINISIIERS}

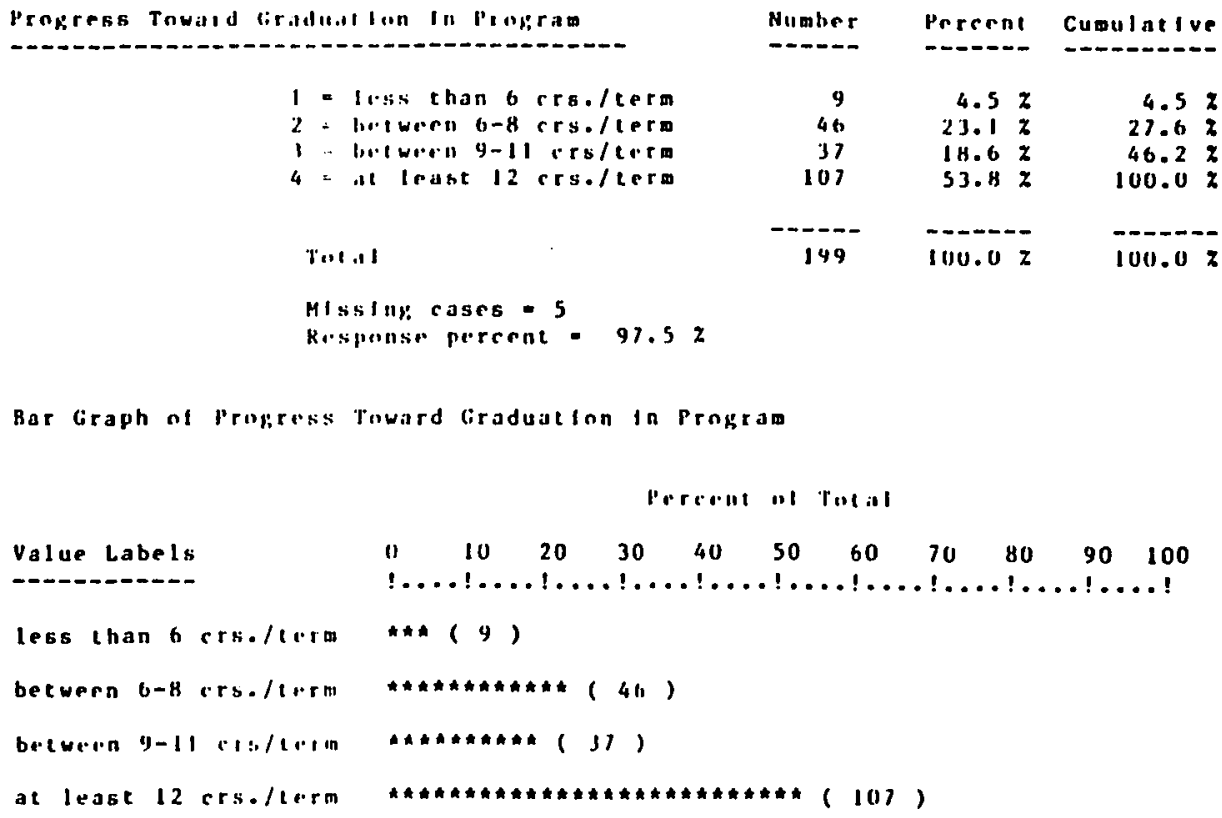

\section{SURVFY QUESTION \#42: LEAVERS}

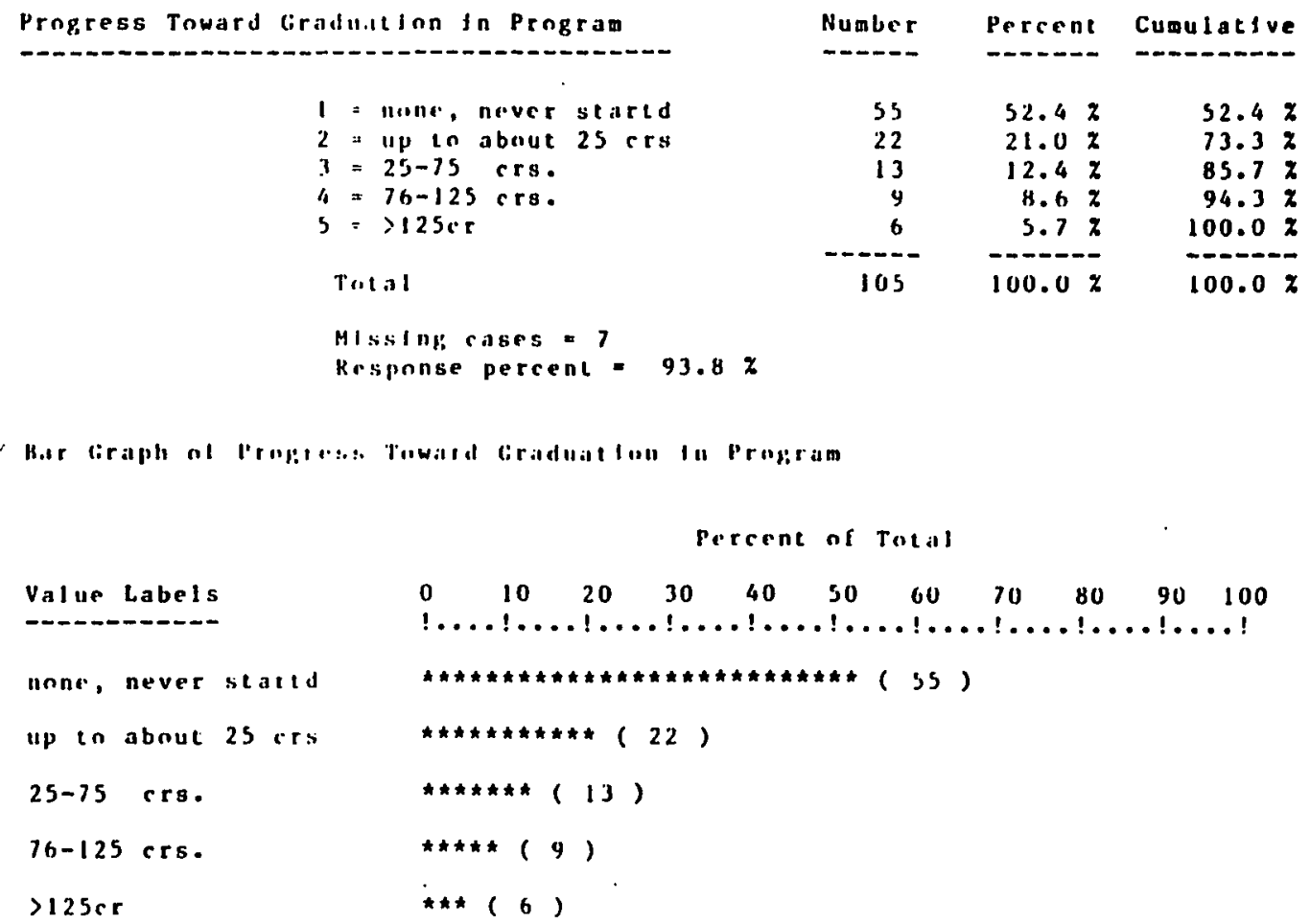




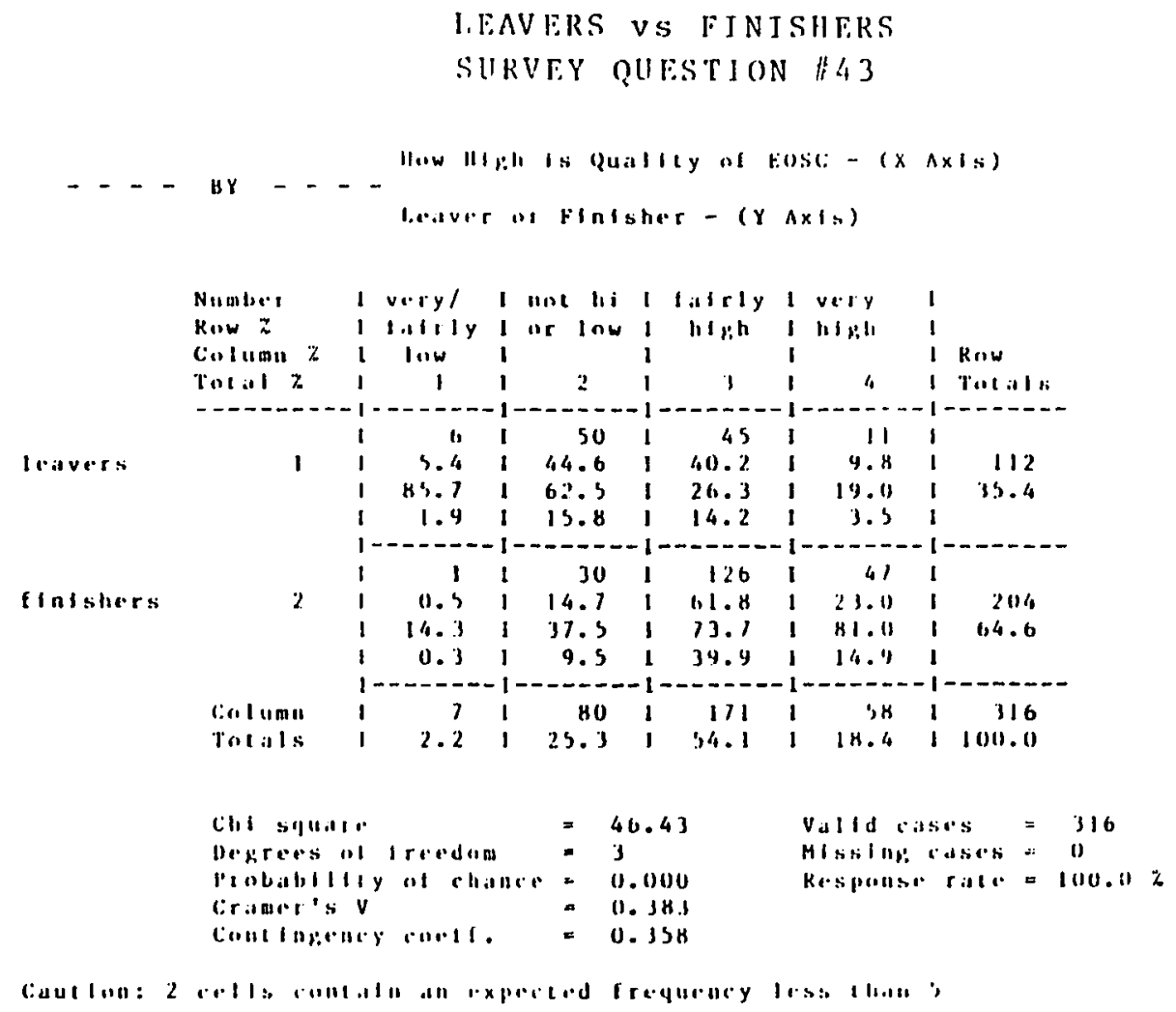




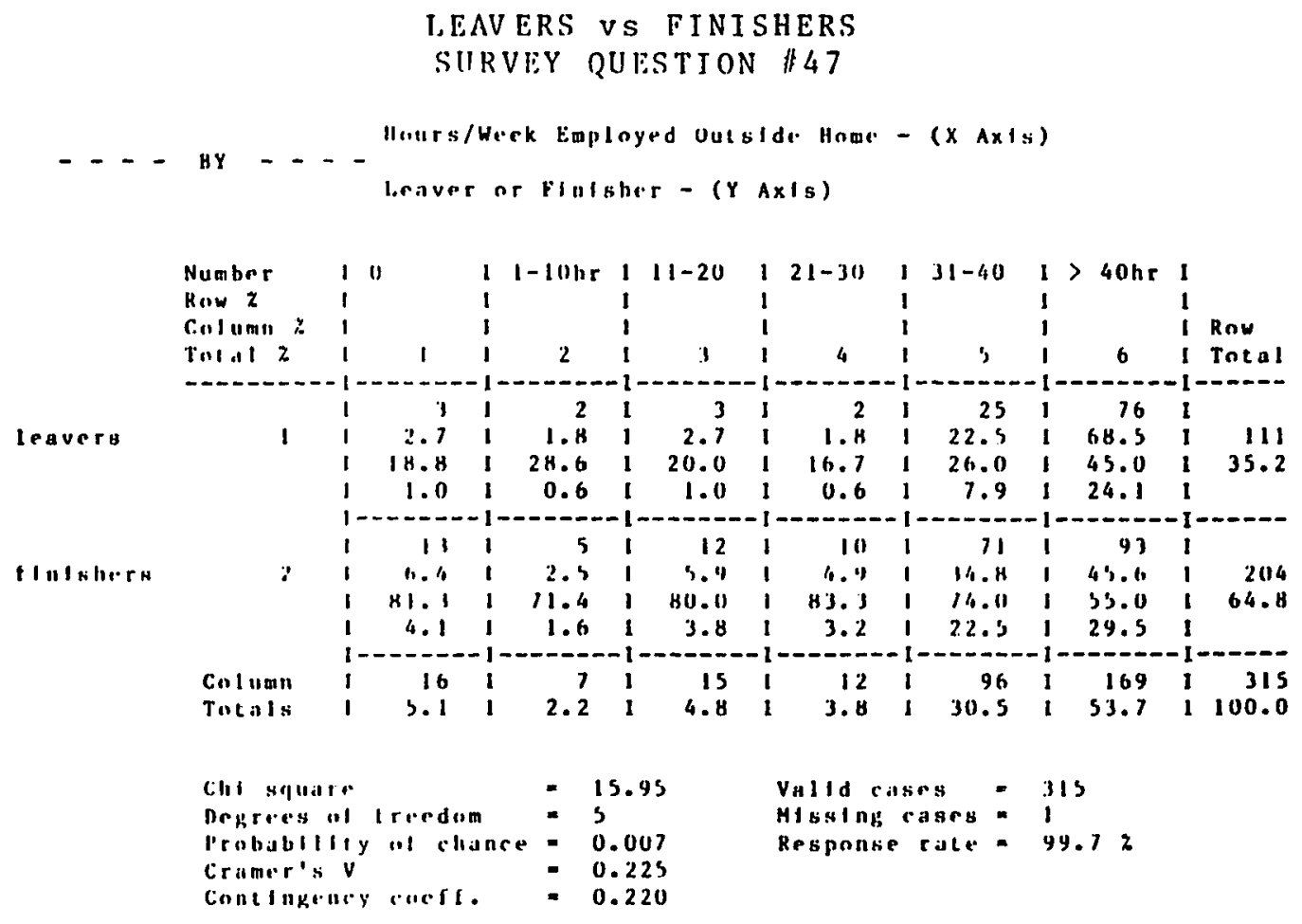

Caution: J crll:i conlell an expected frequency less thall 


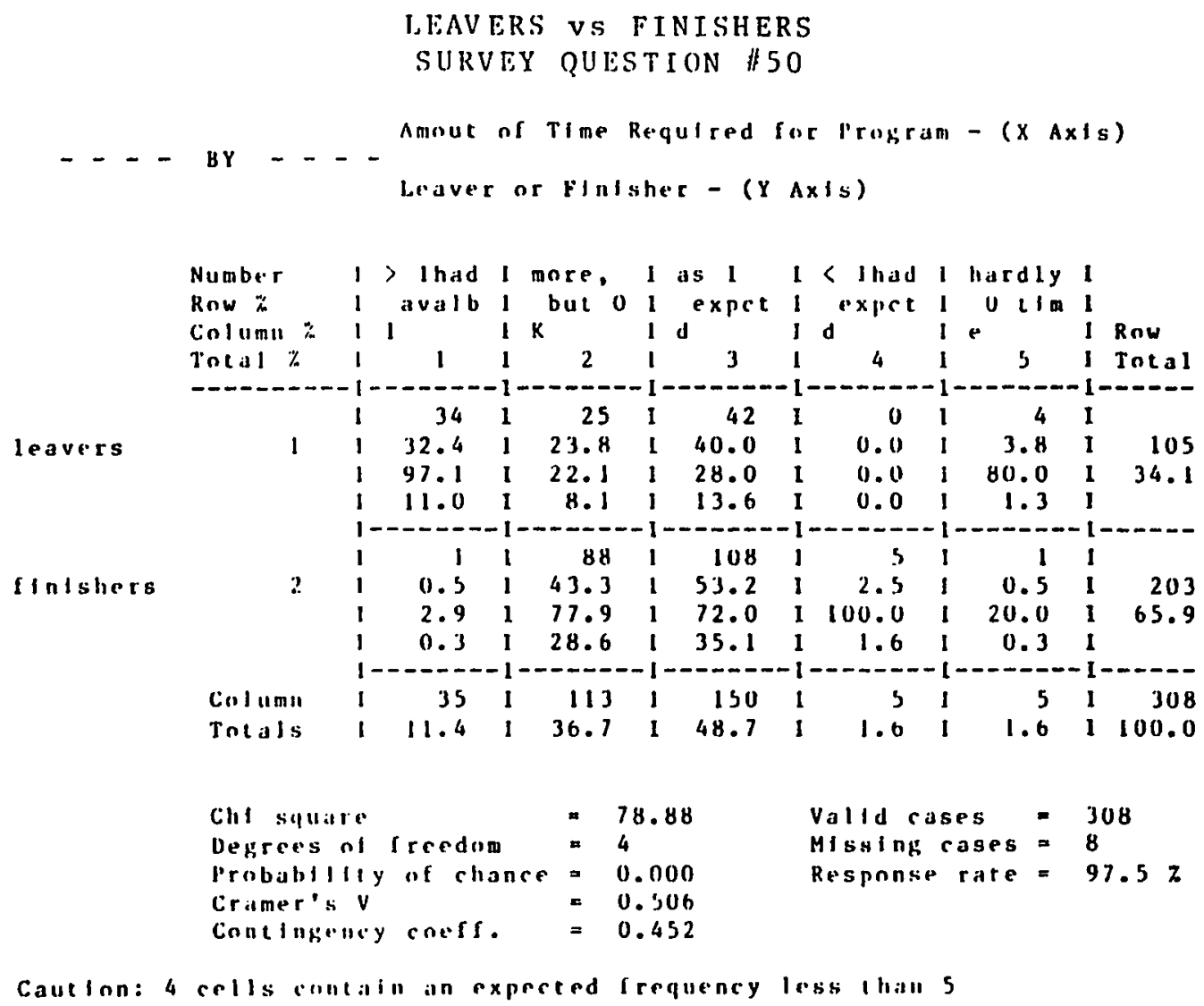




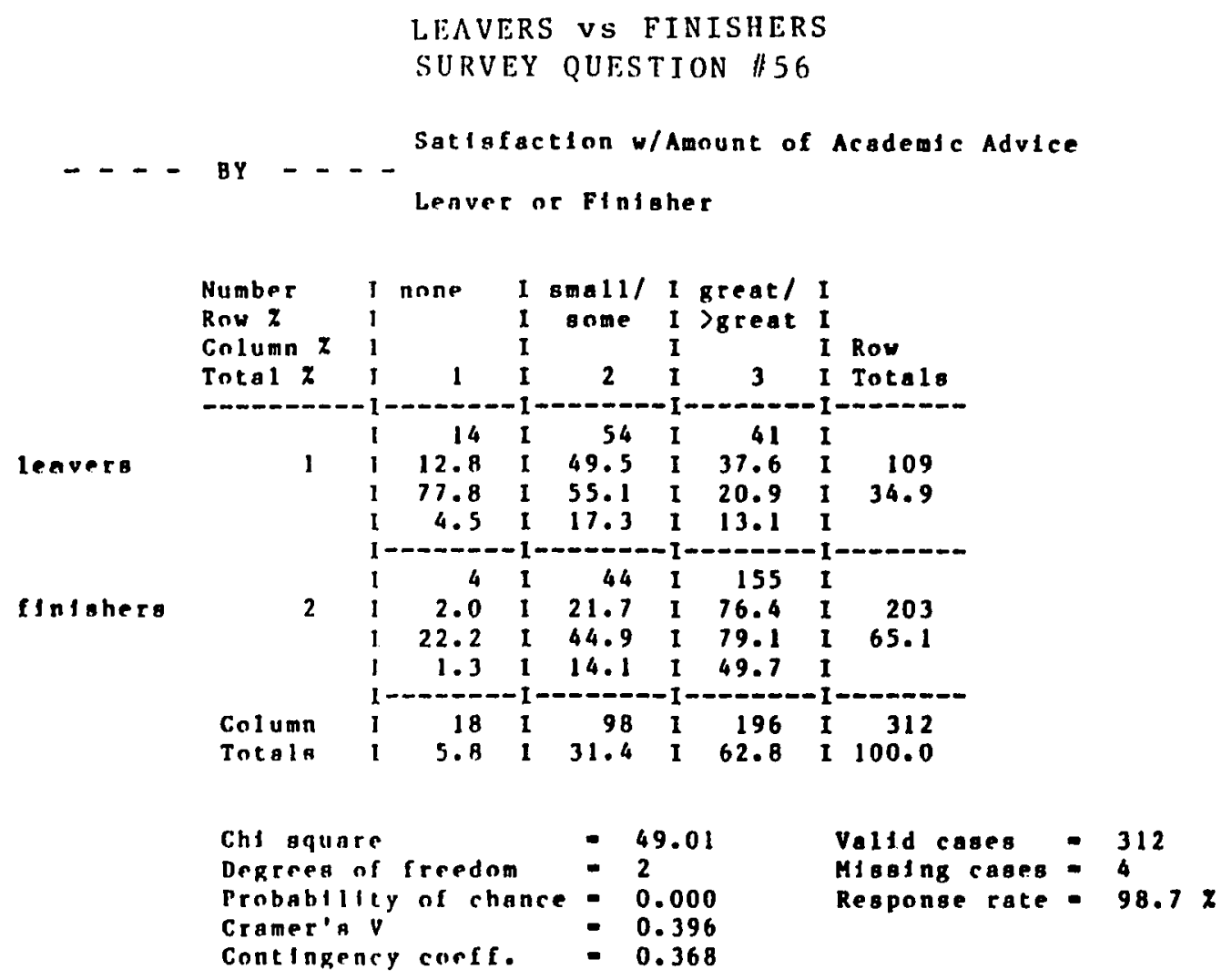




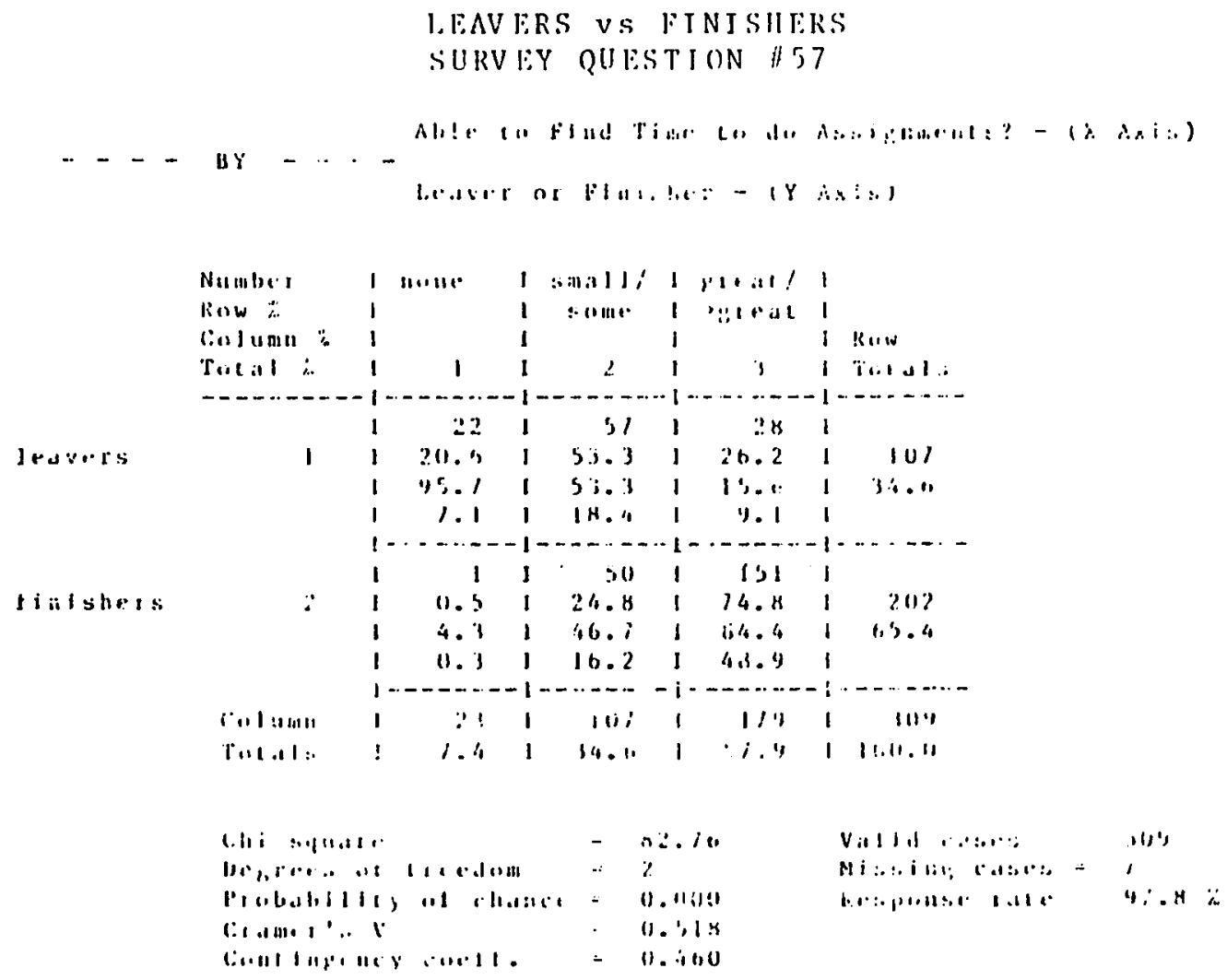




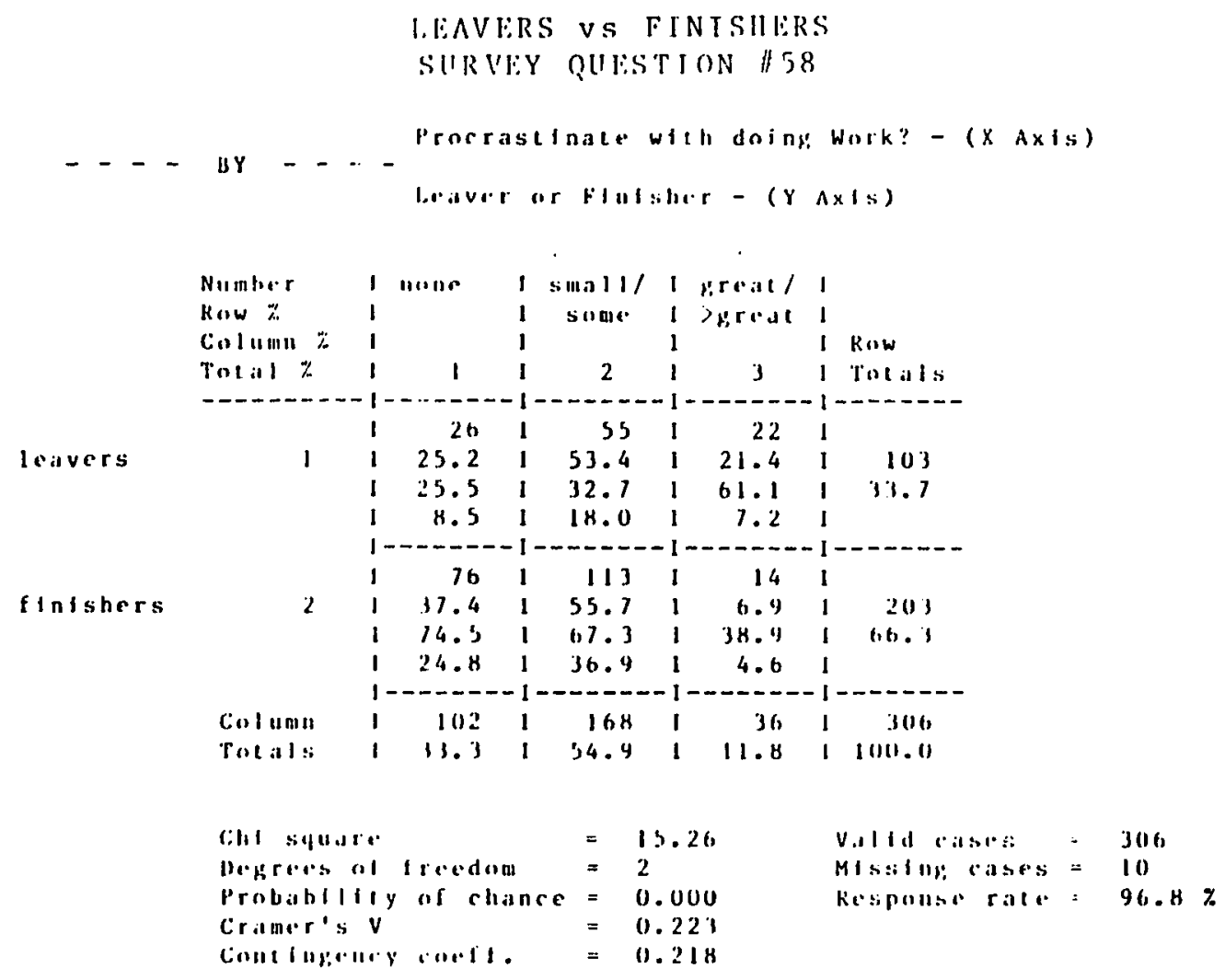




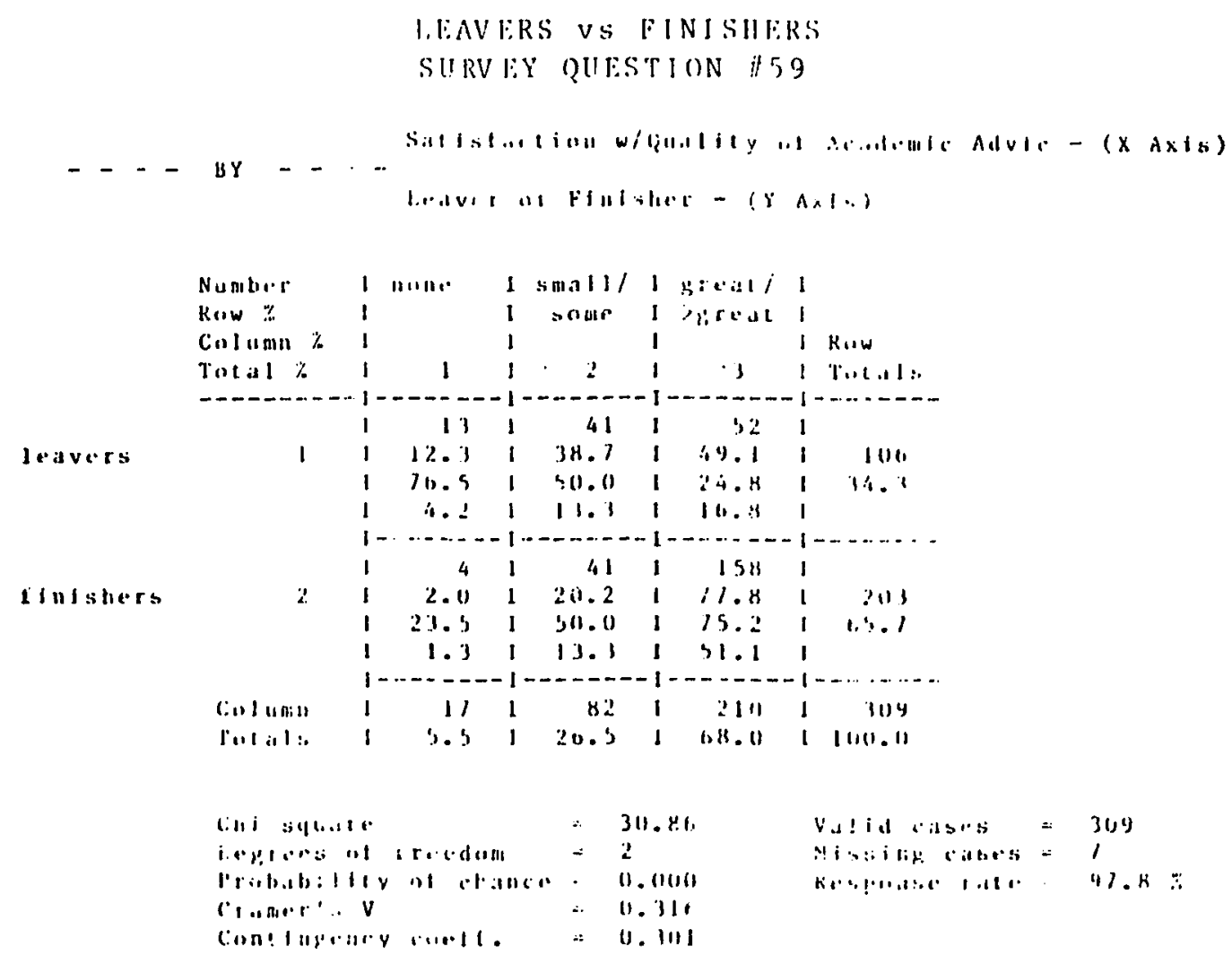




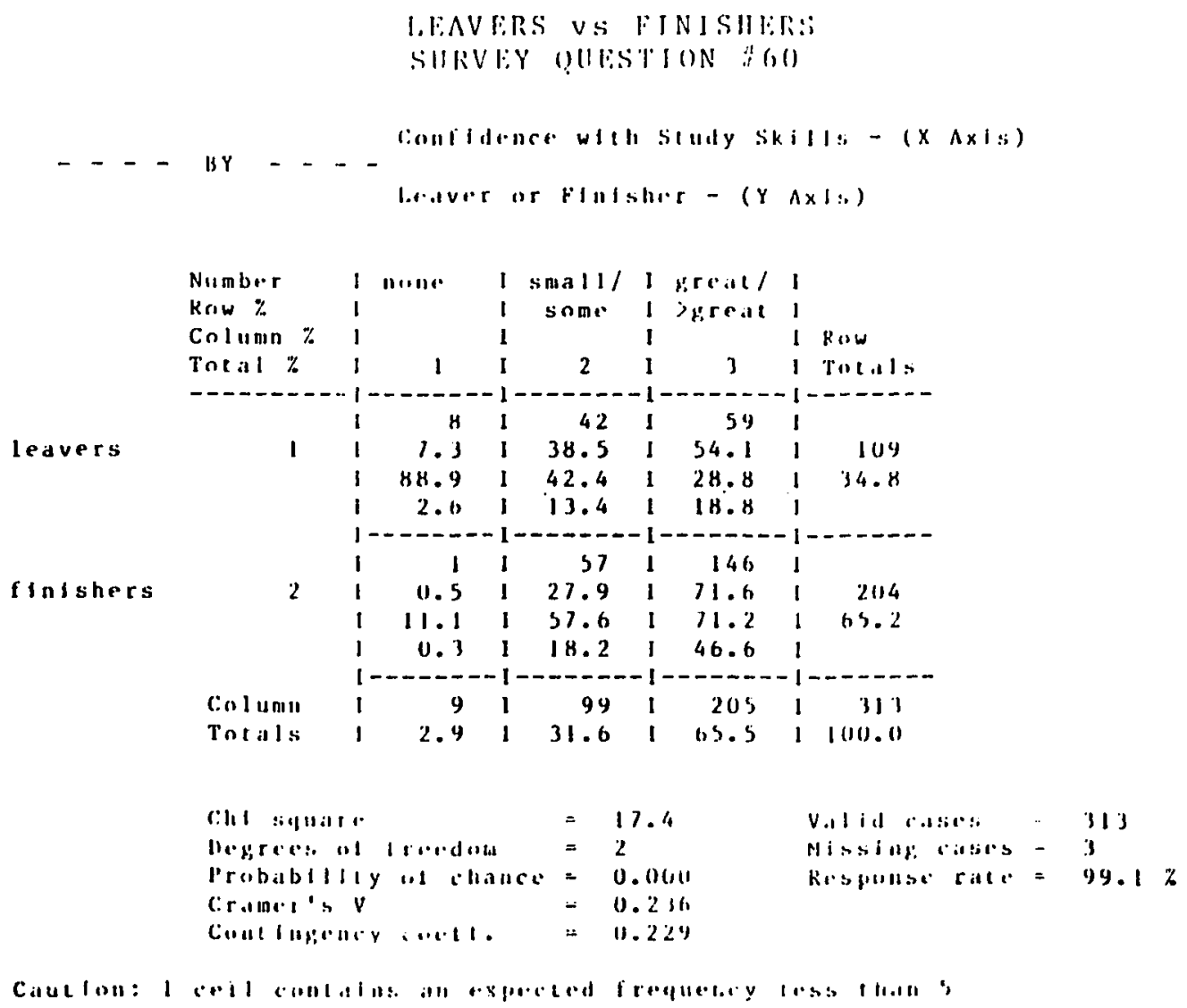




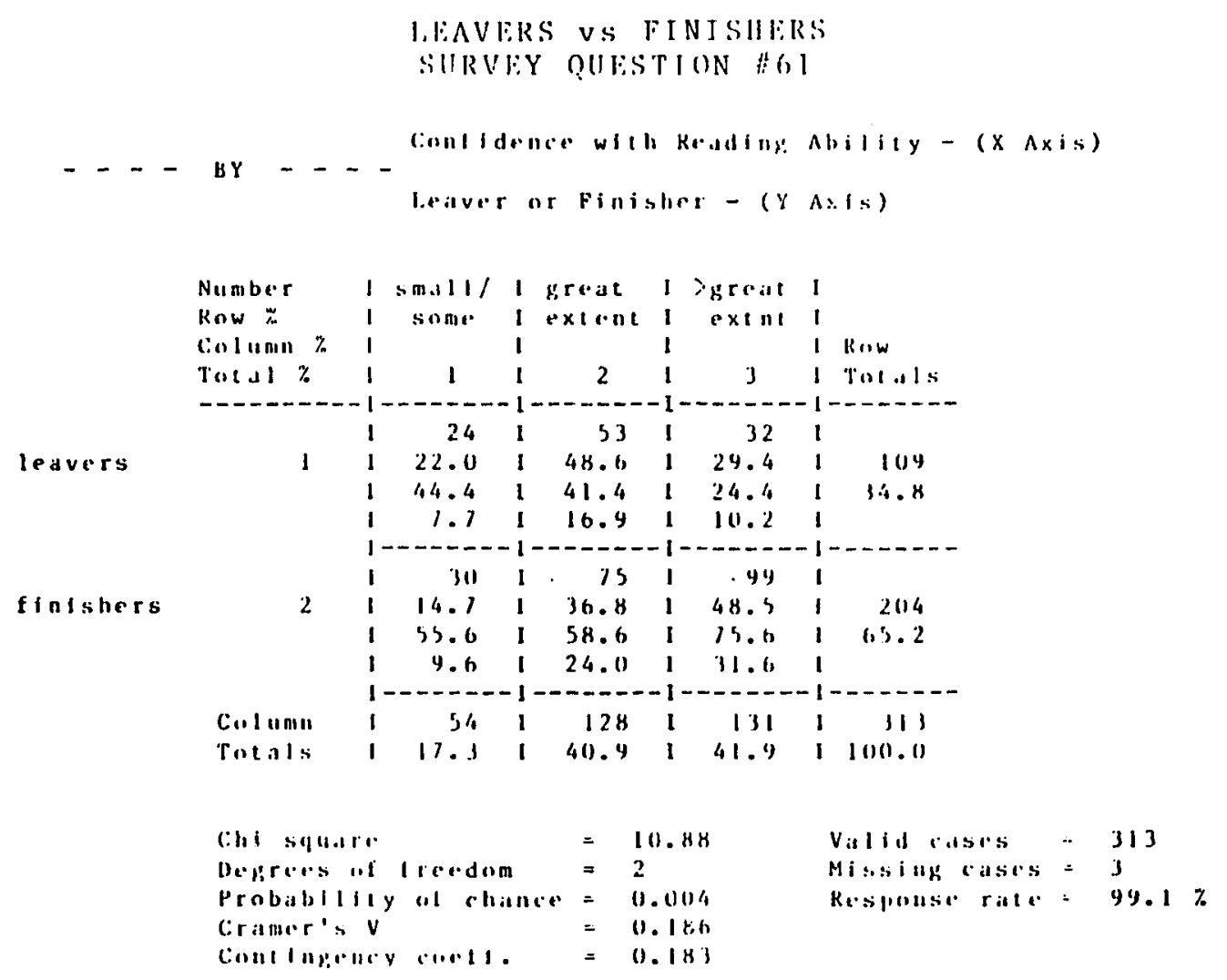




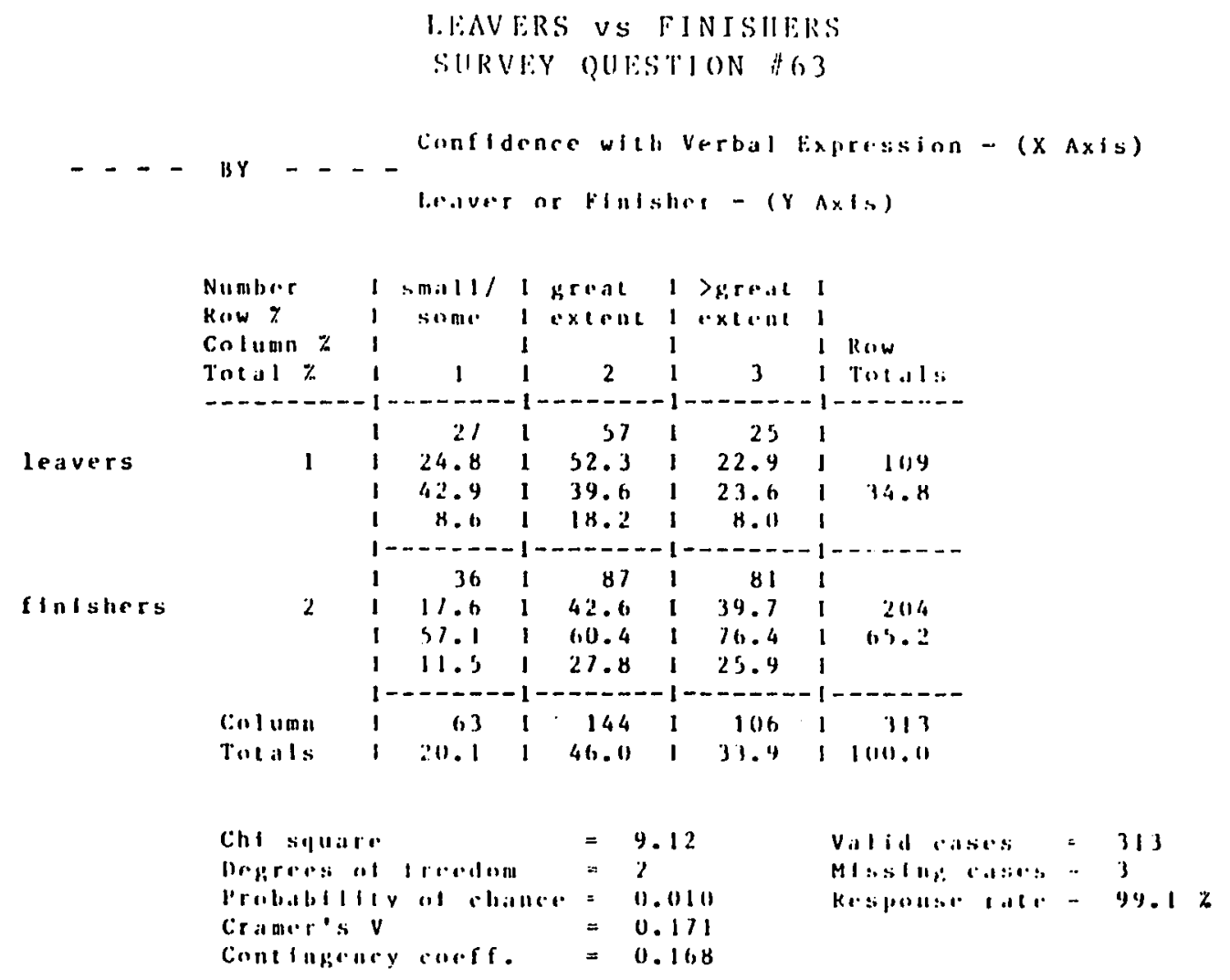




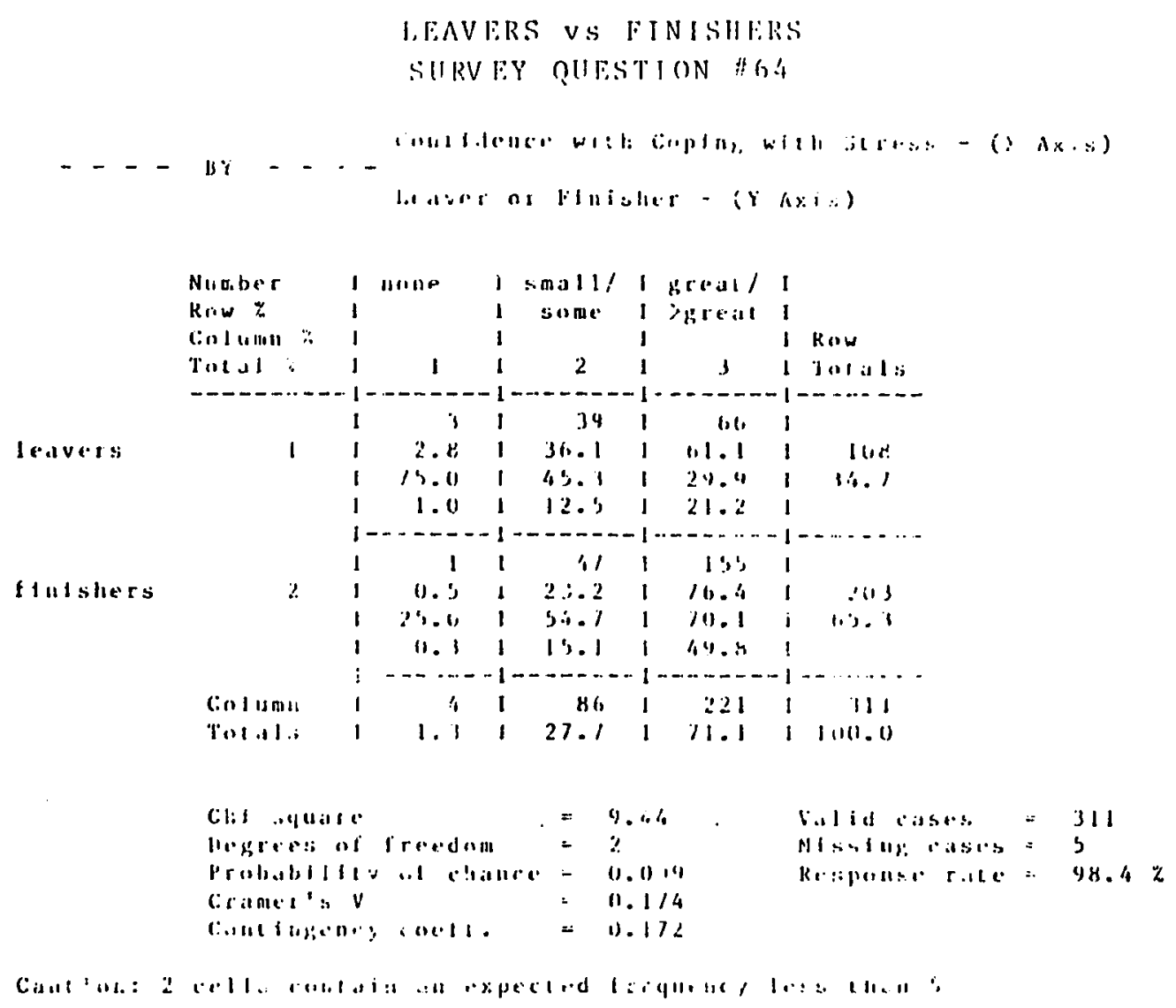




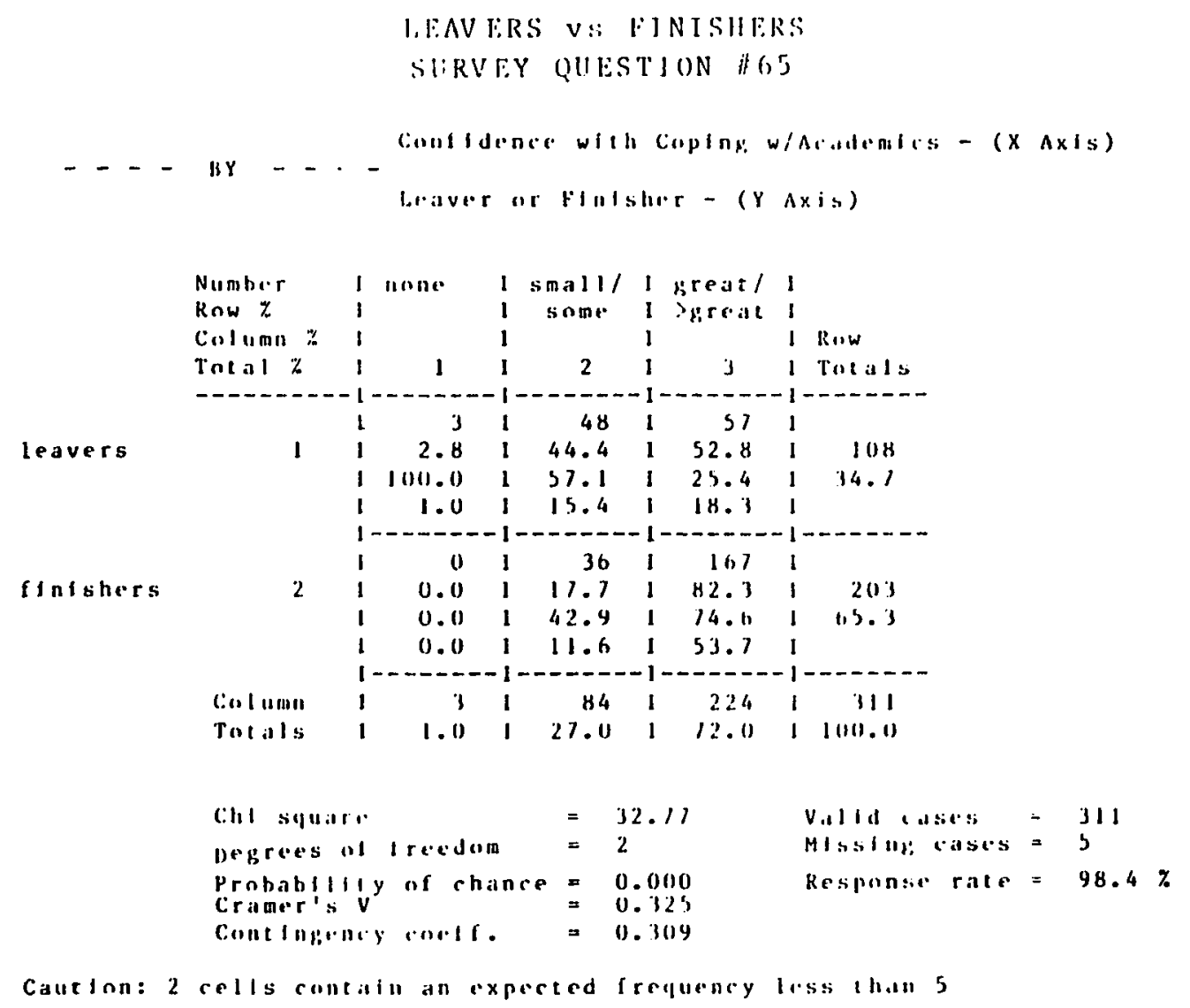




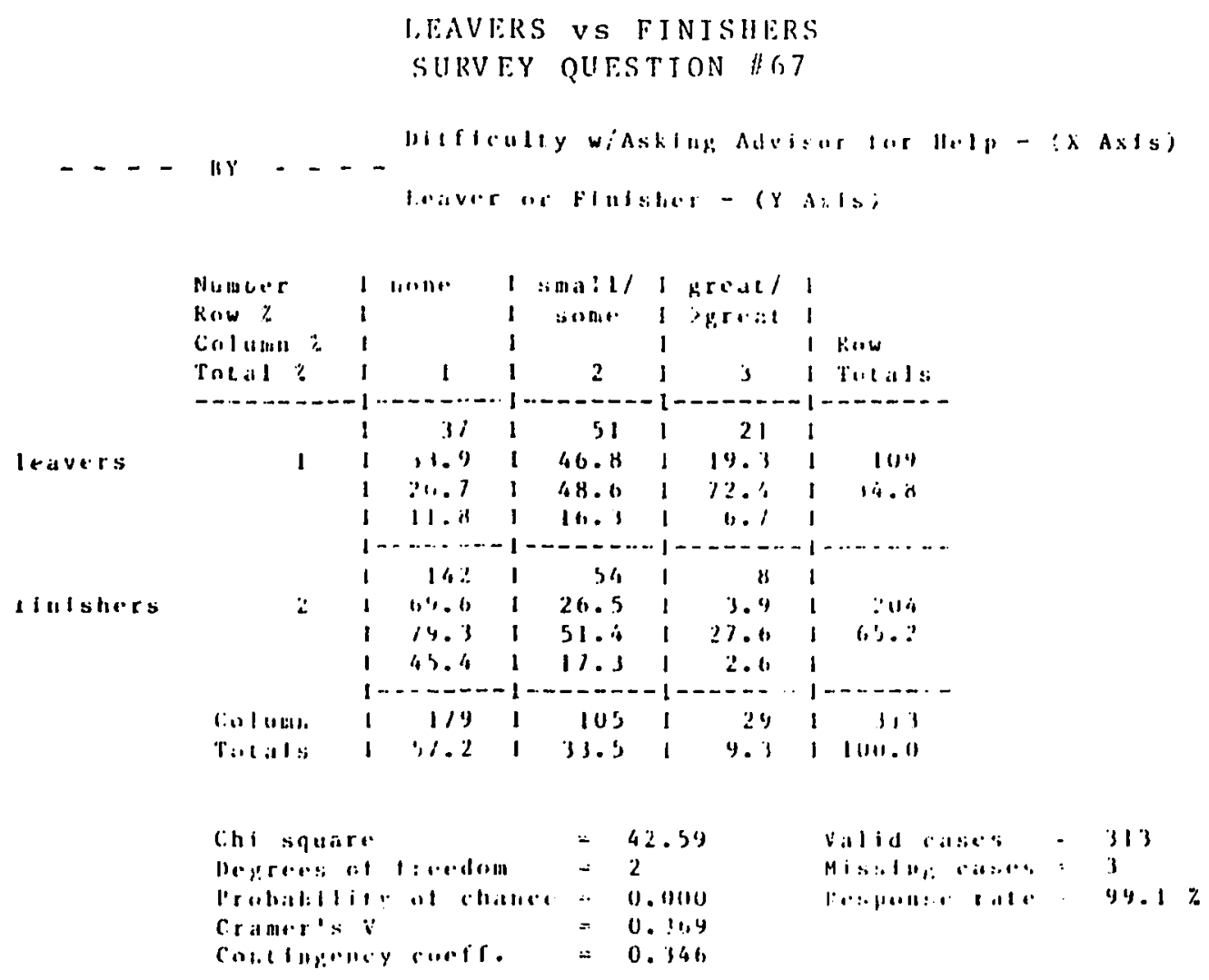




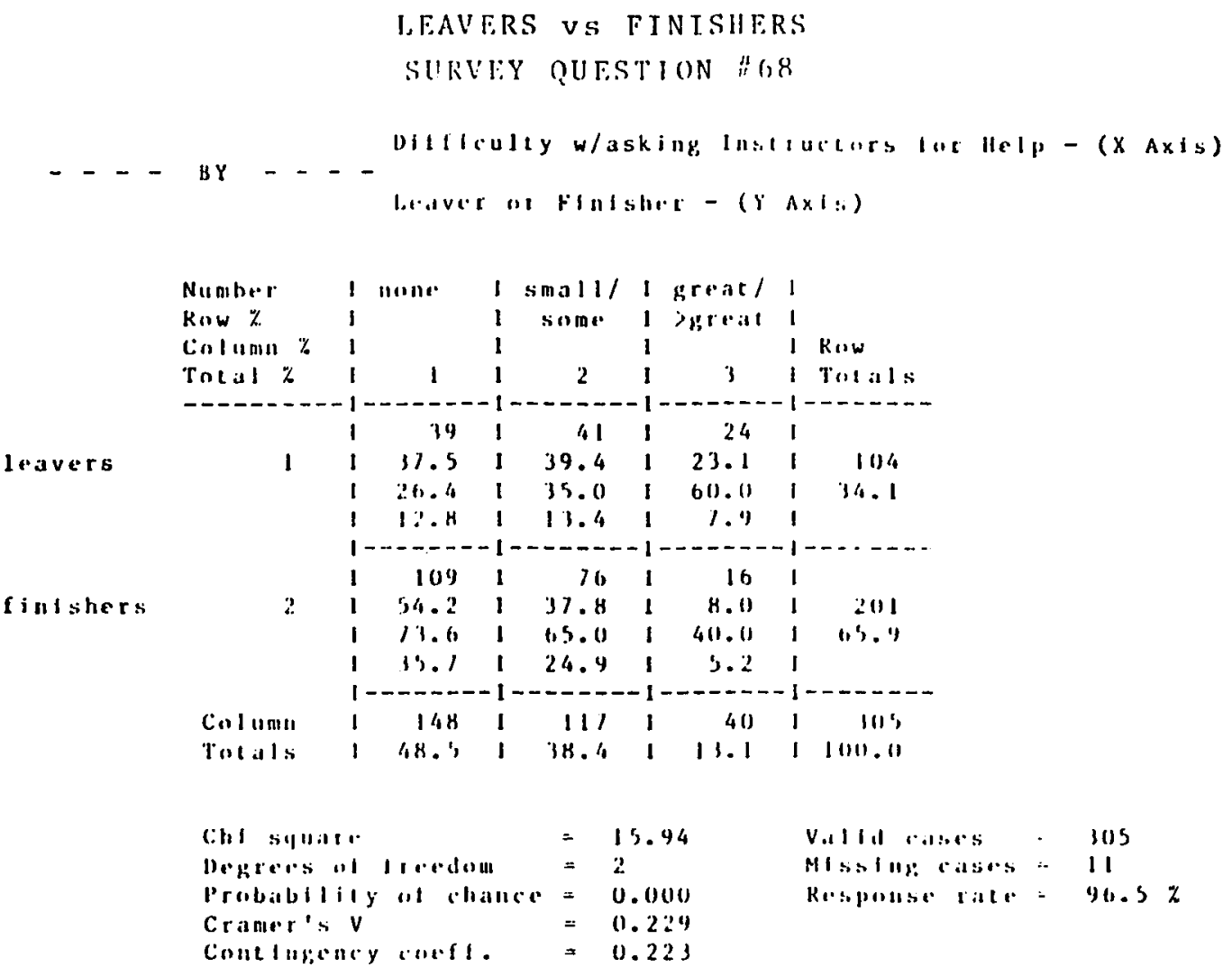




\section{ANVERS VS FINISHERS}

SURVEY QULSTION \#69

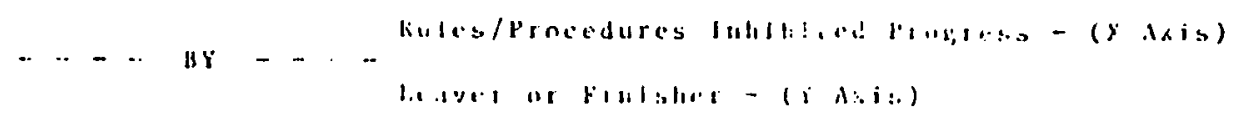

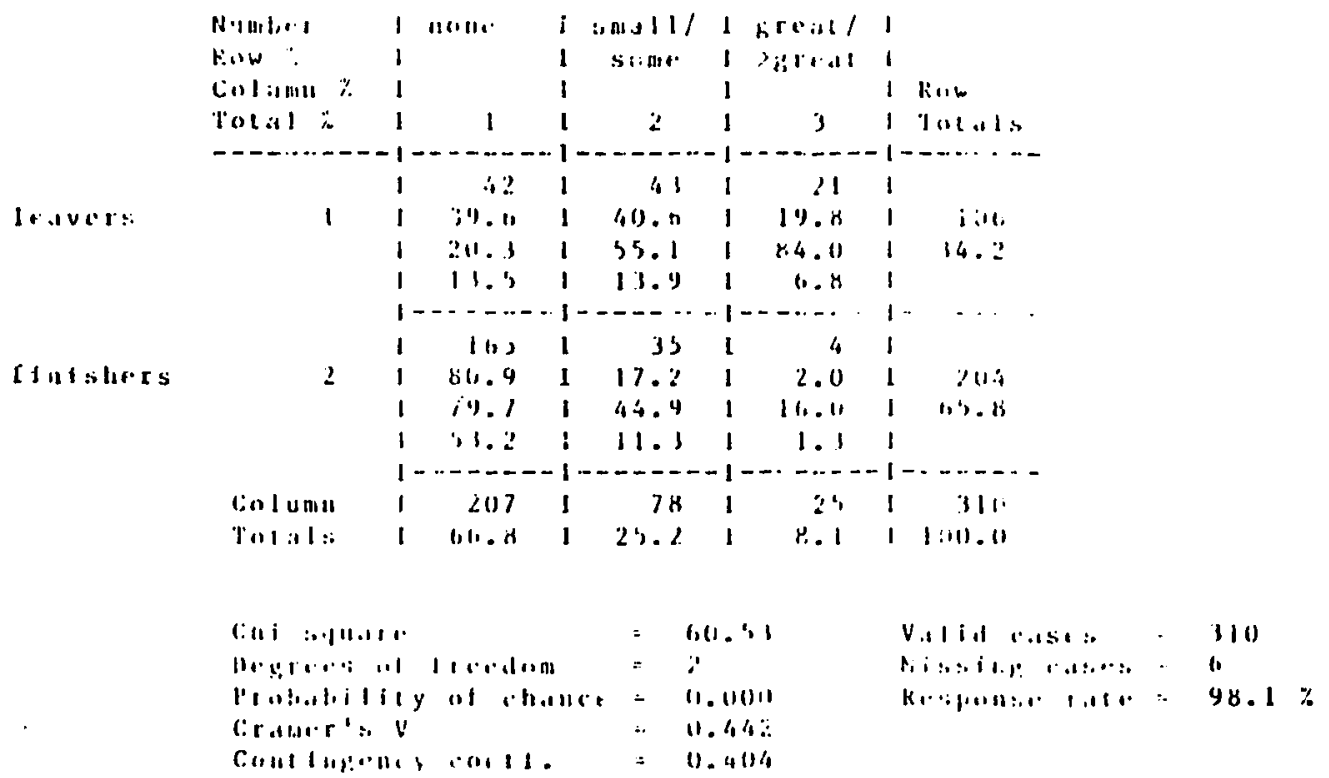




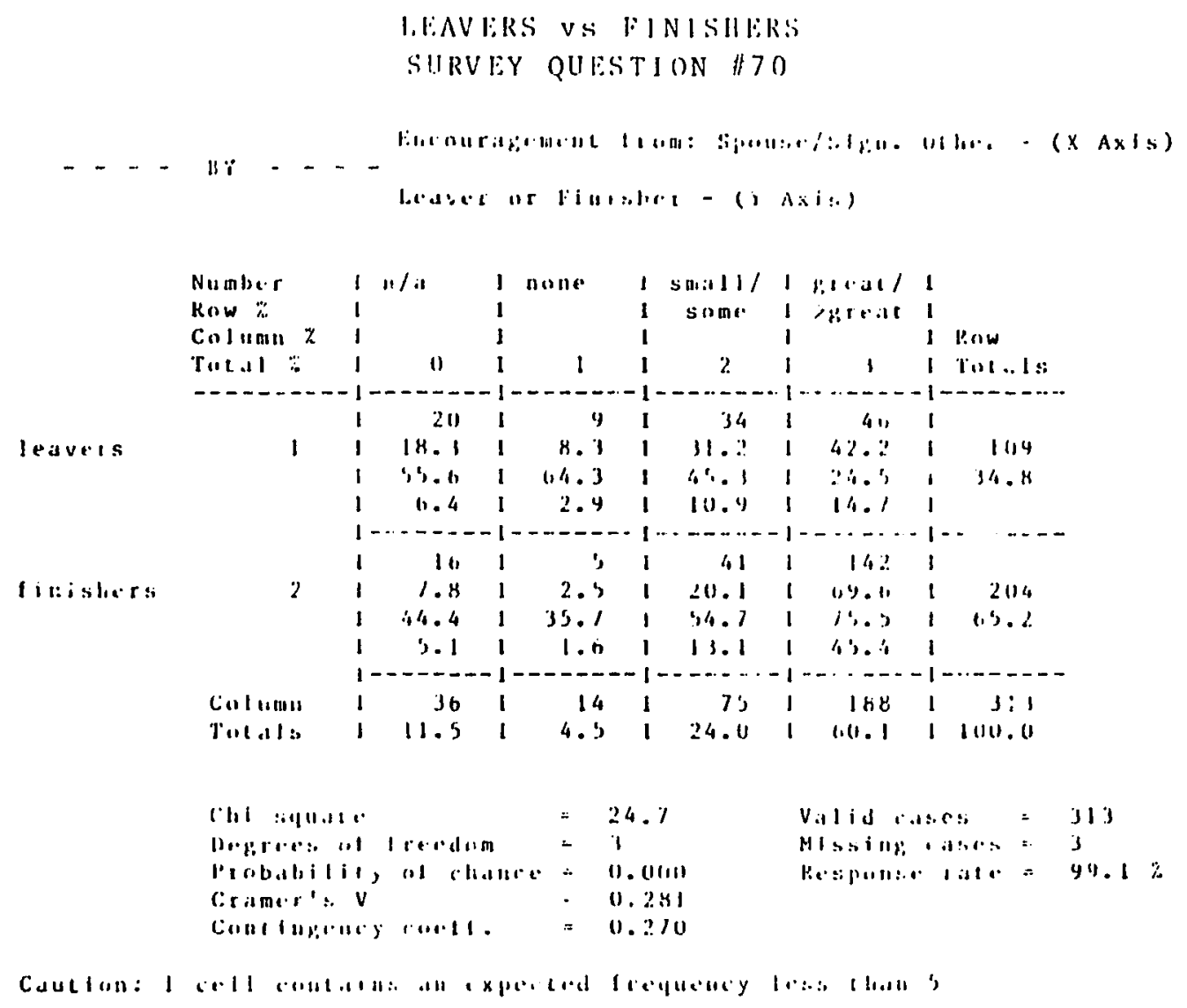




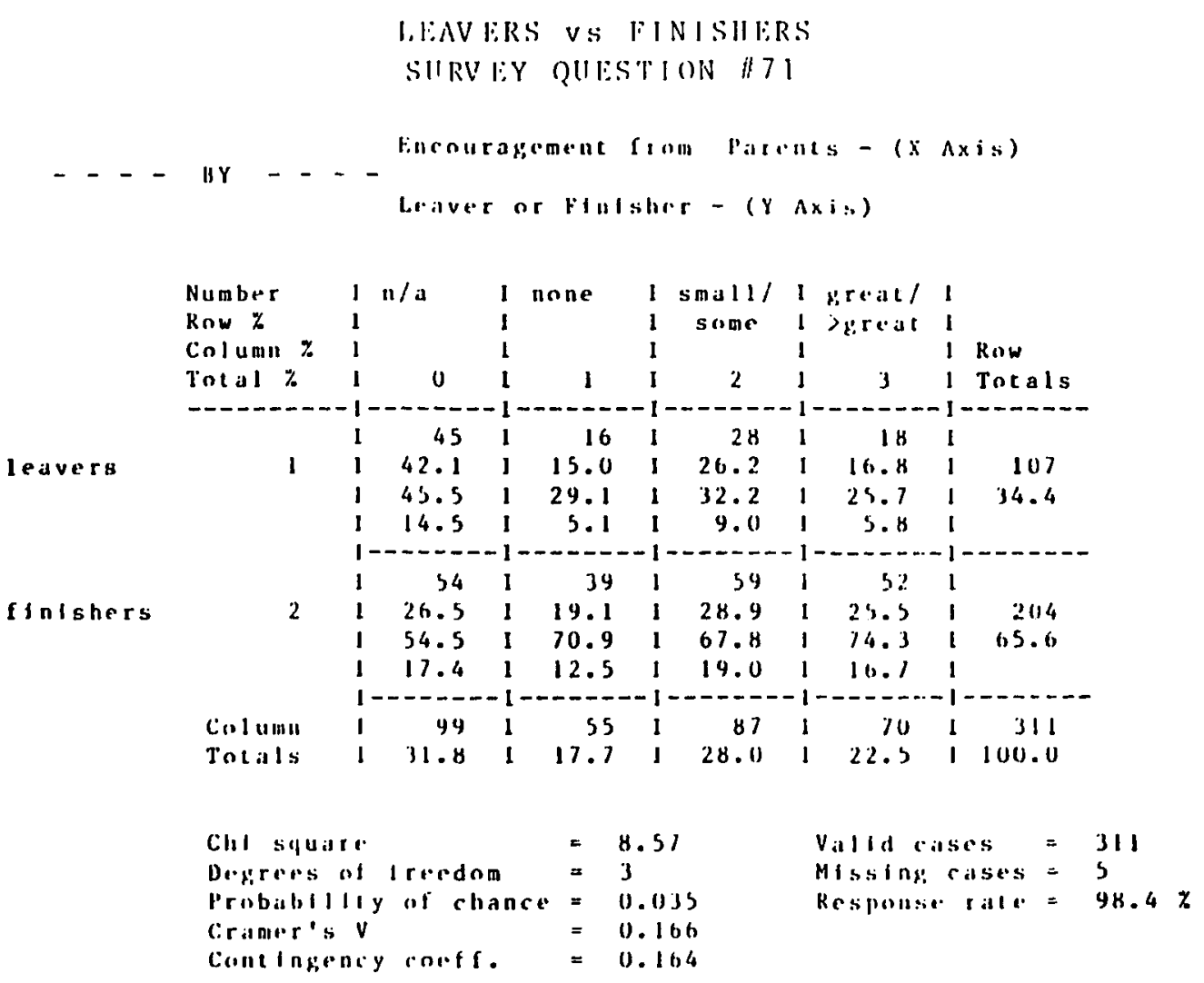




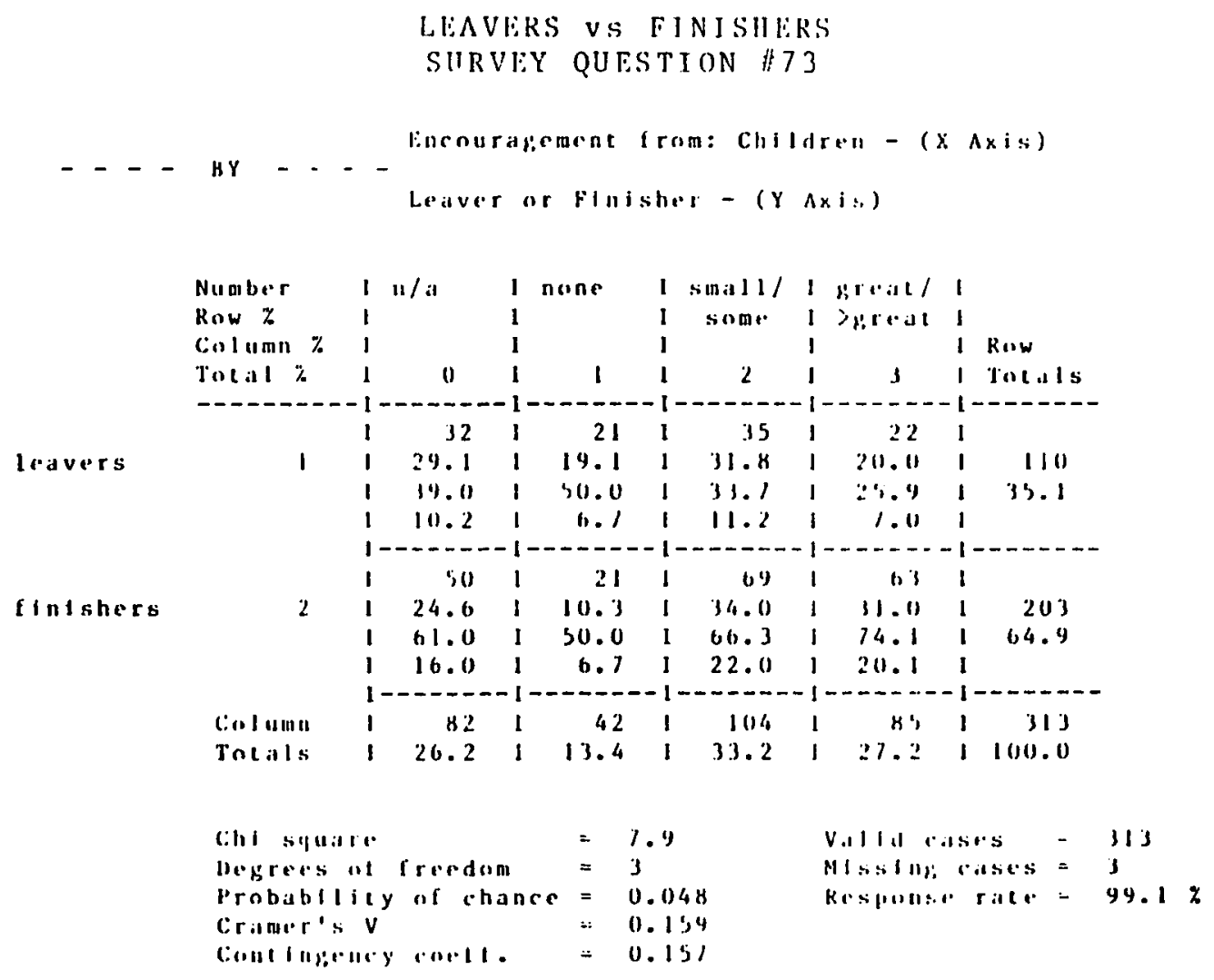




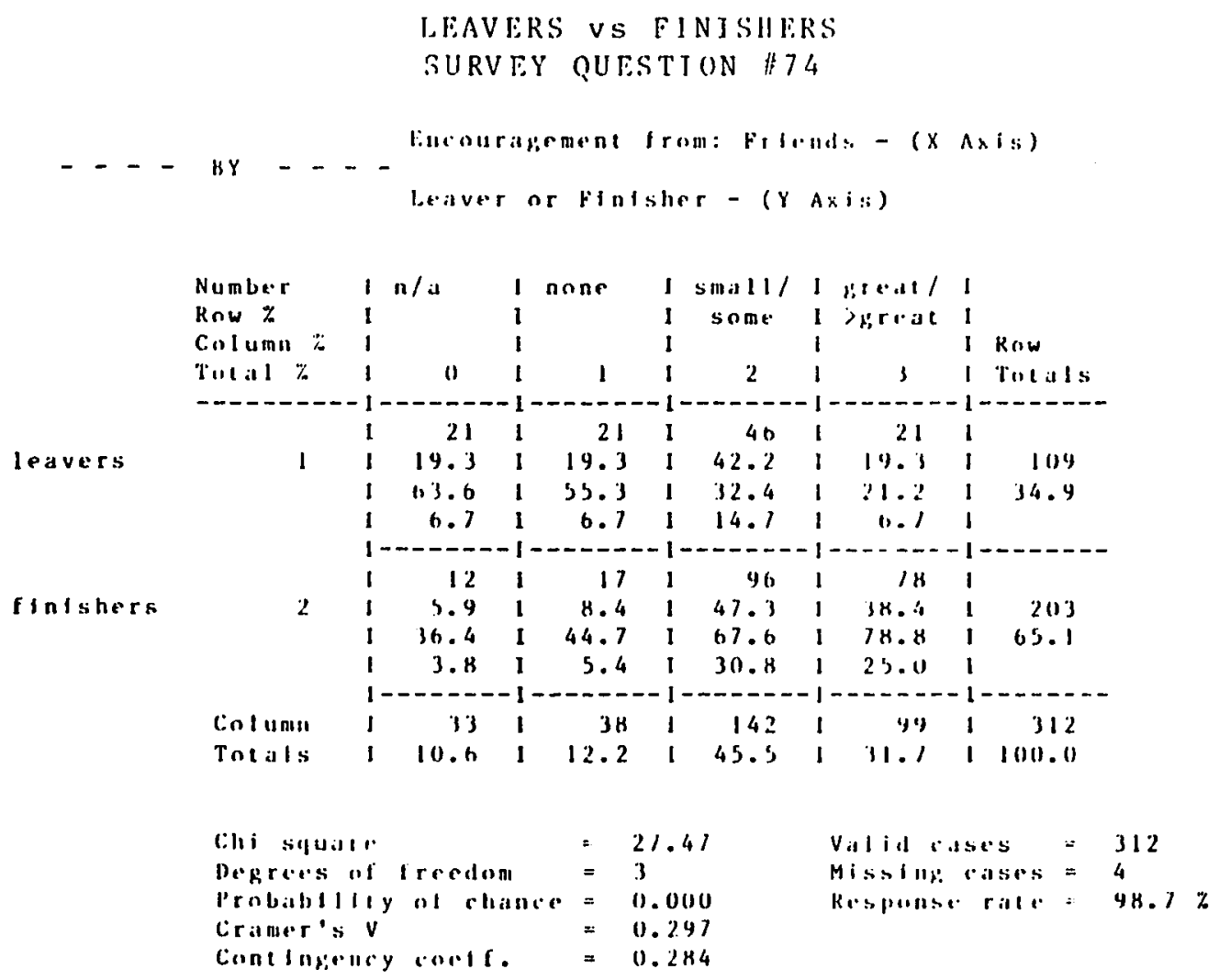




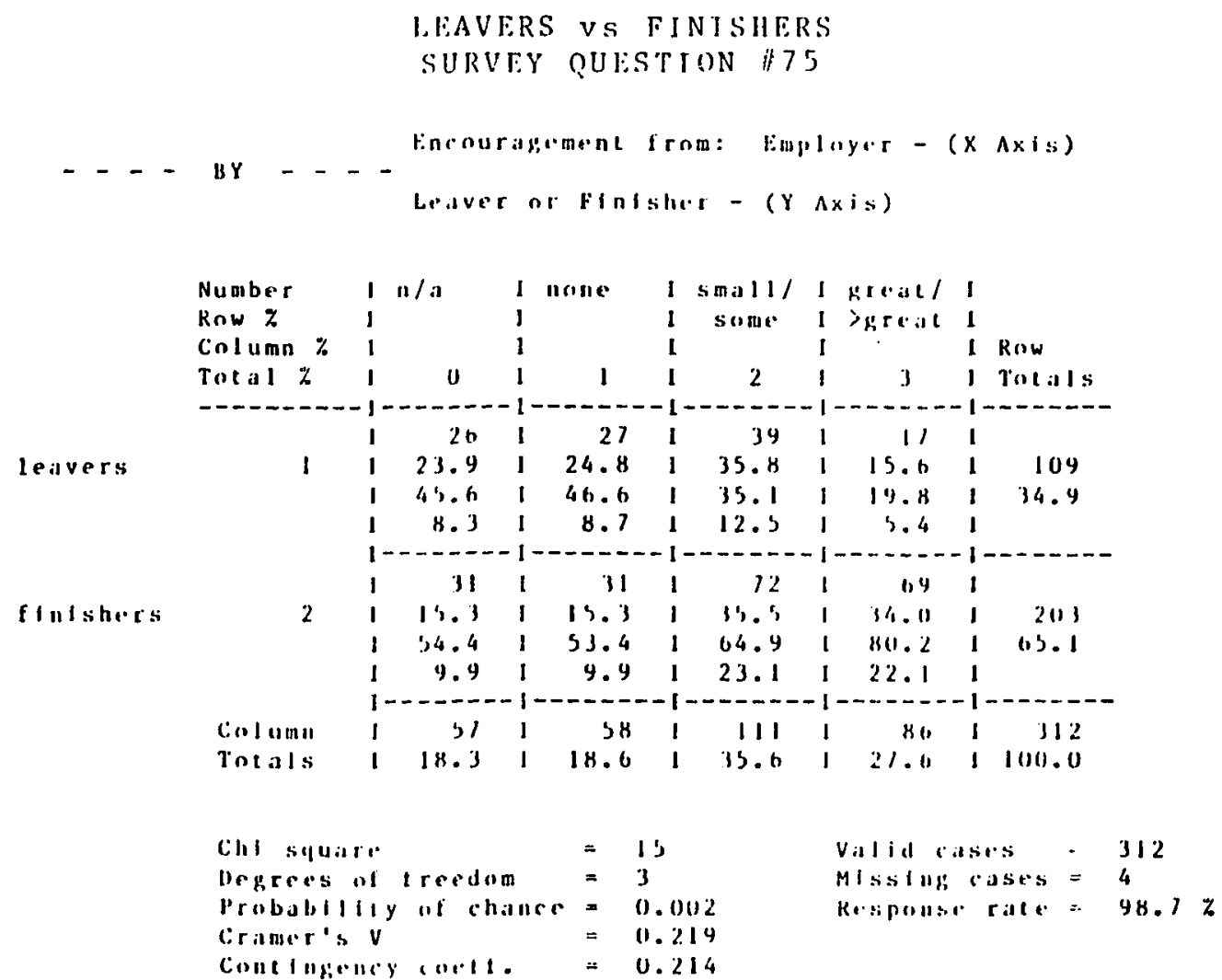




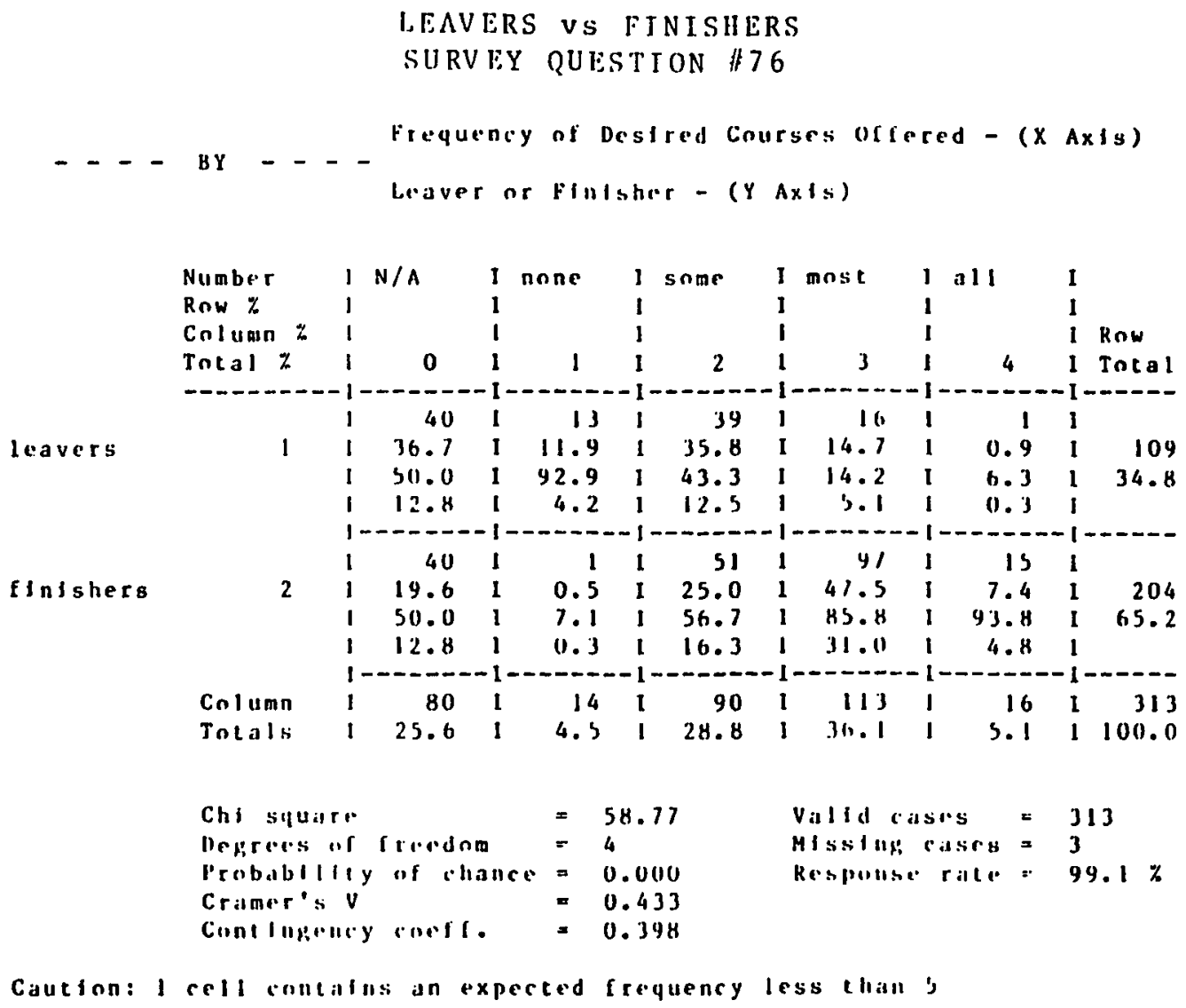




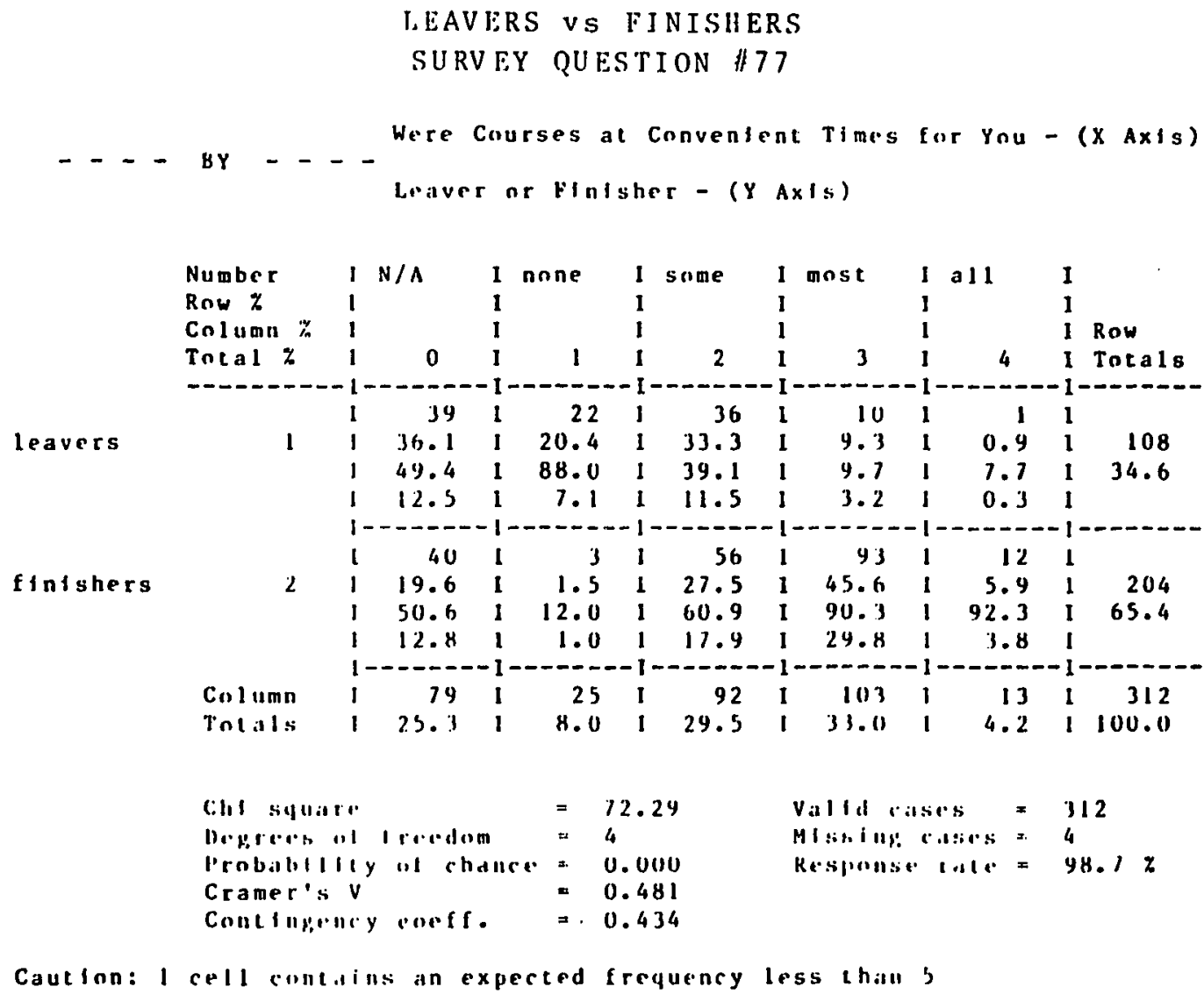




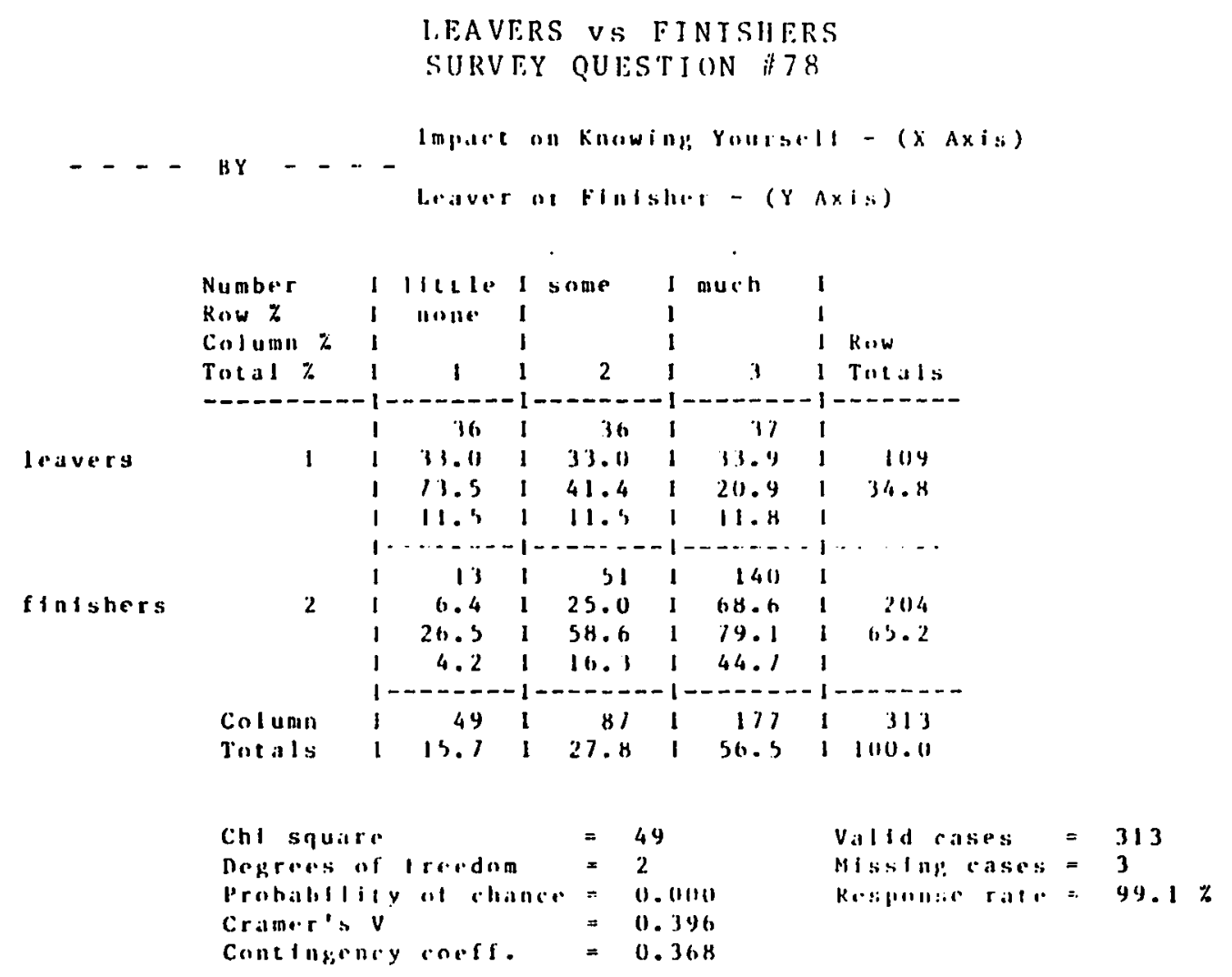




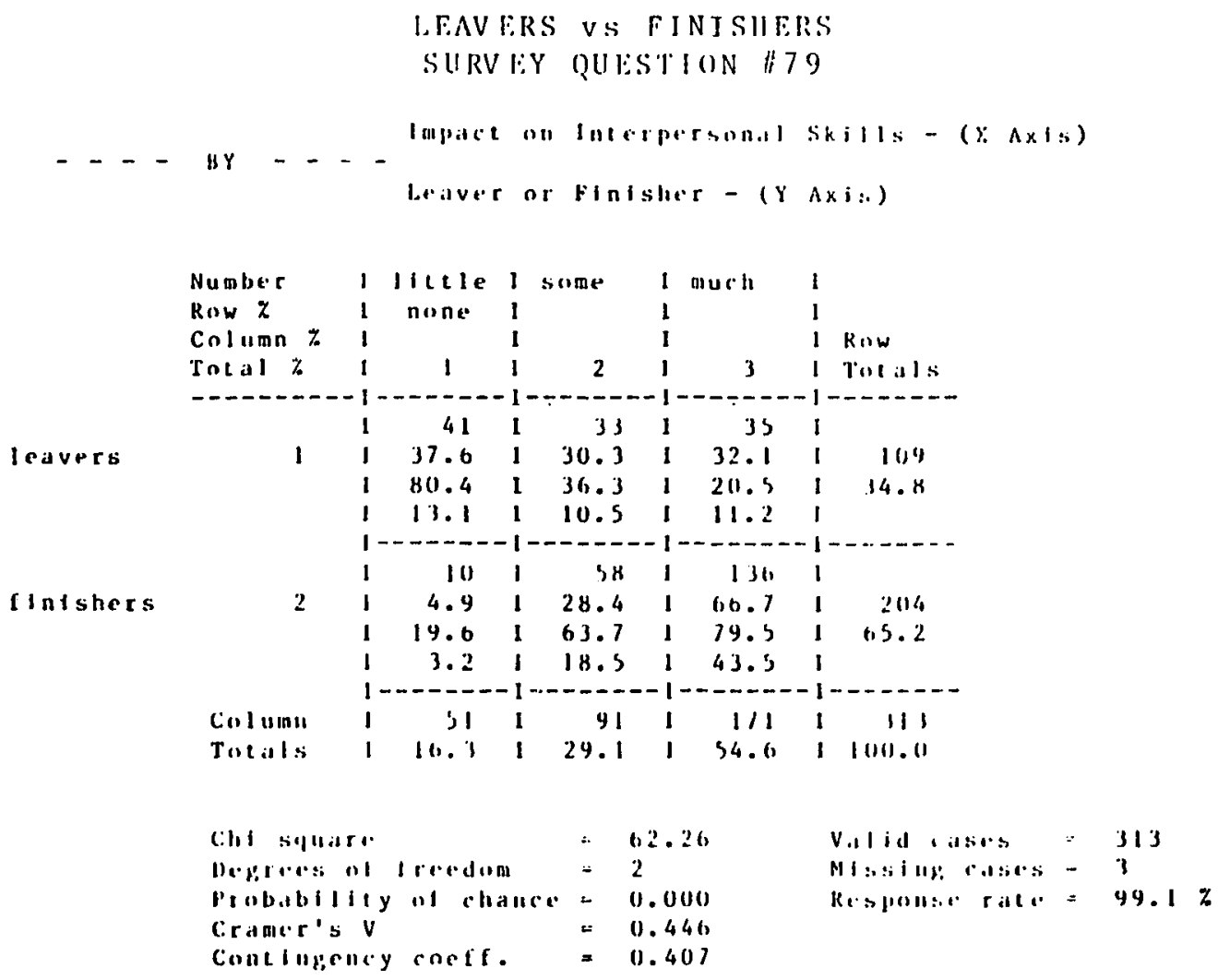




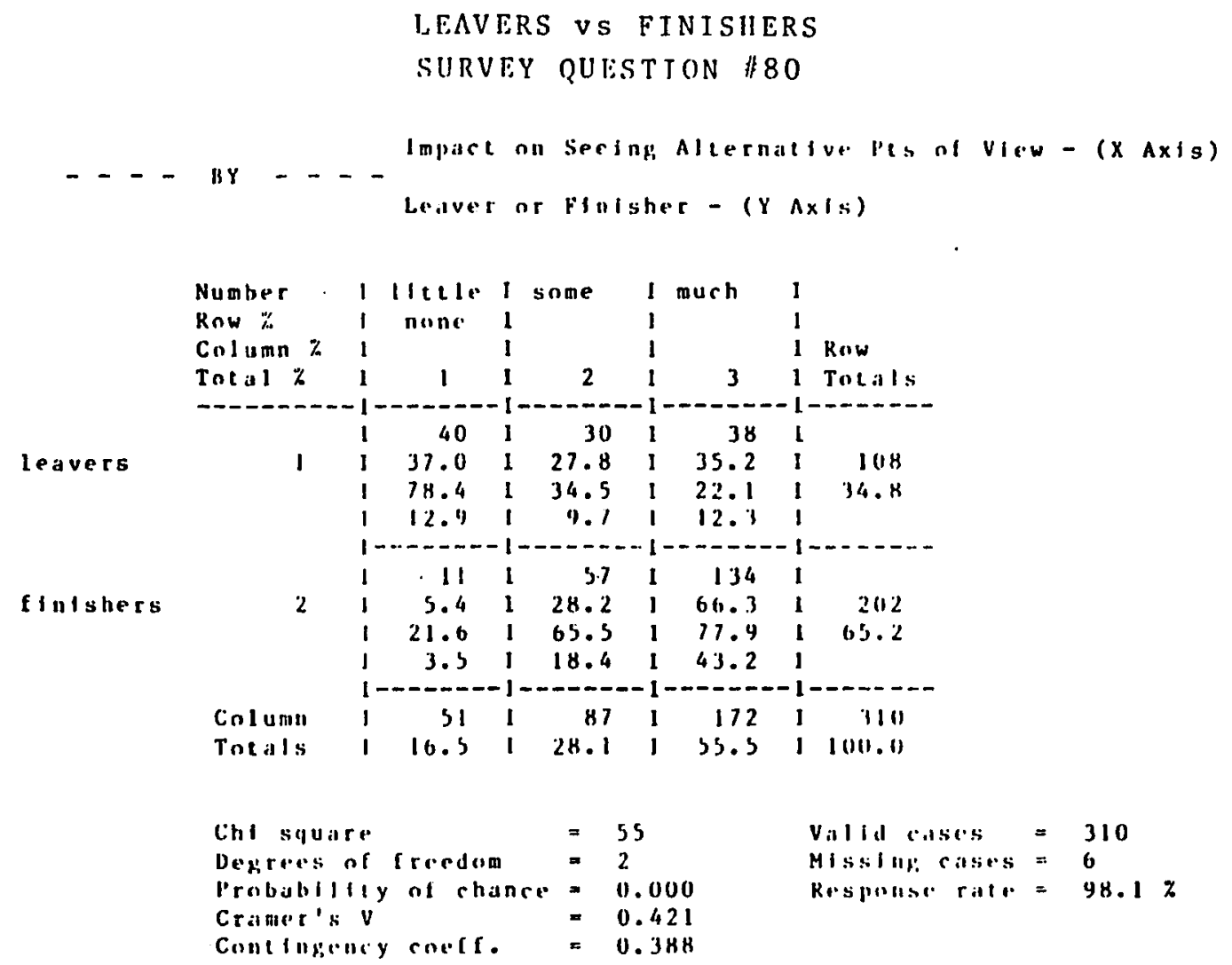


A COMPARISON OP LEAVERS AND FINISHERS ON

STUDIENT DATA BASE INFURMATION: GPA

Vulable used to proup casis - Leaver or Flutiher

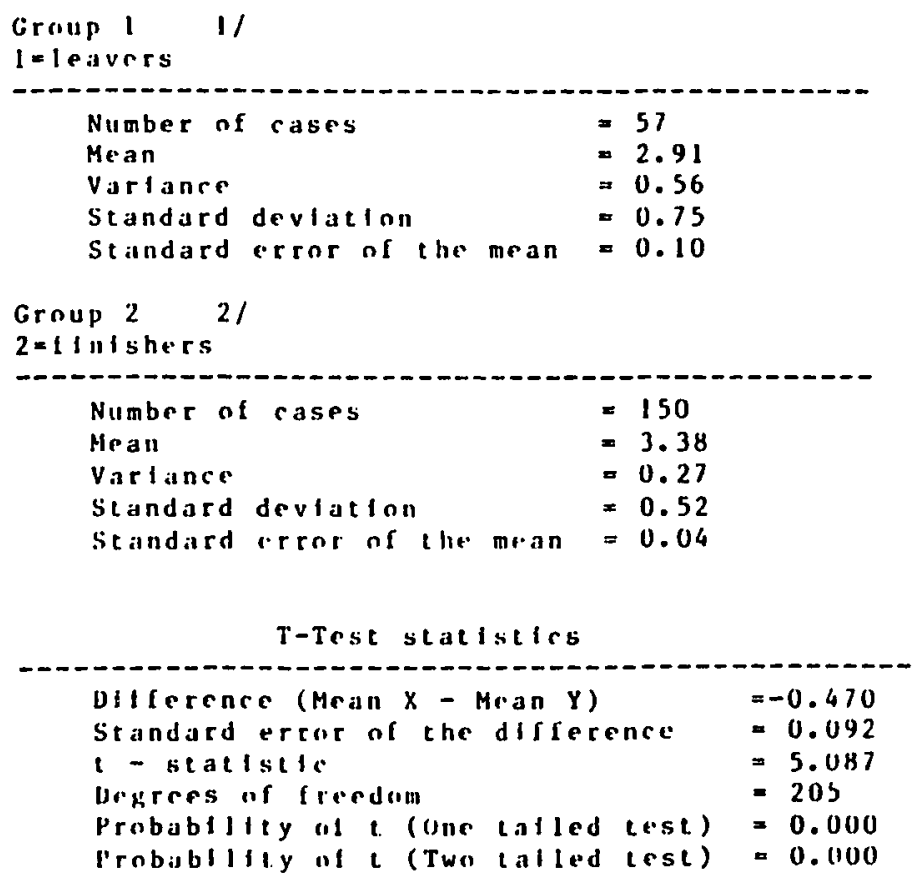

ANALYSIS OF VARIANCE ON LEAVER/FINISHER GPA DIFFERENCES

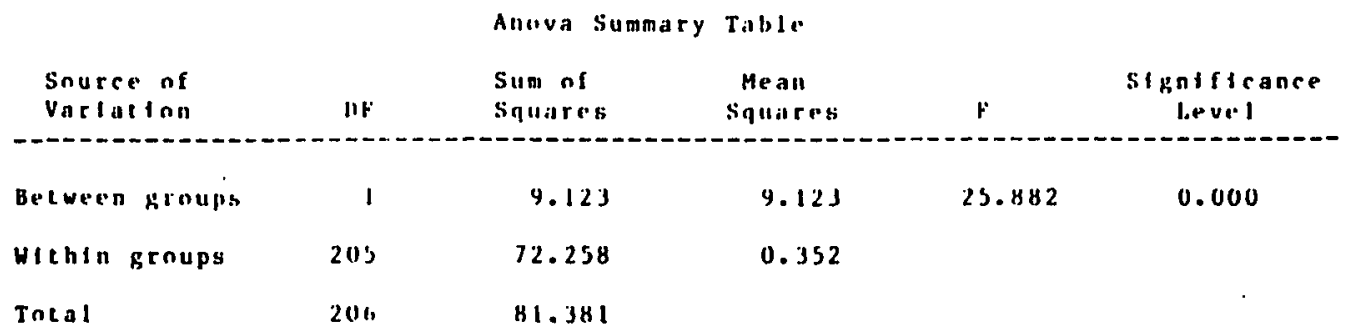

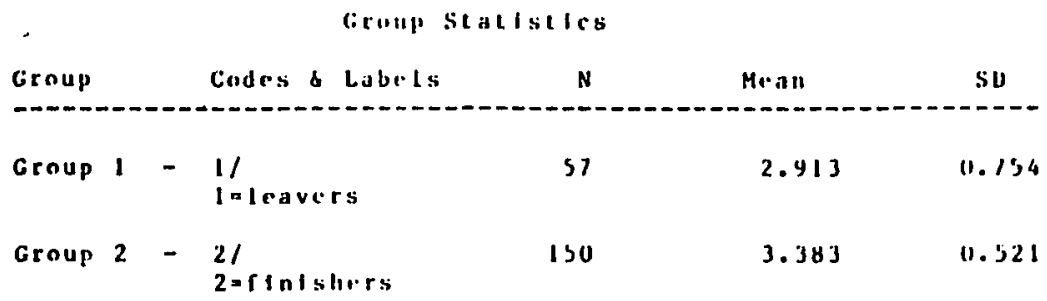

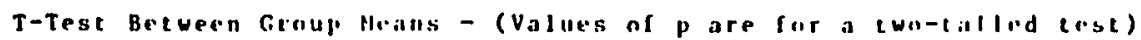

Note: Statistics nto only princed lf p ls less than or inlil to. OSO

Nore

$\begin{array}{ll}l=5.087 & \text { Girul } 1 \\ p=.000 & \text { croul } 2\end{array}$ 


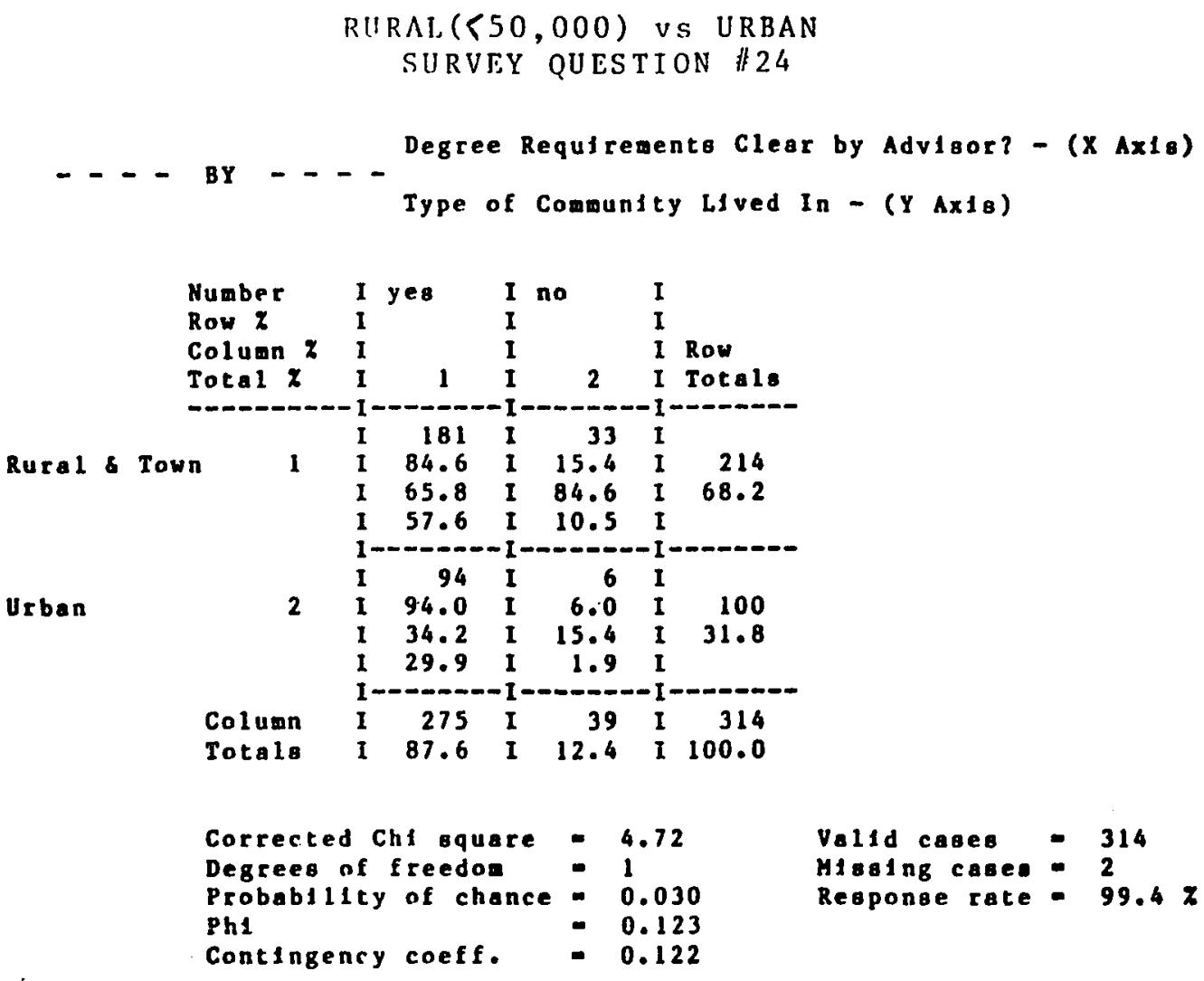


E I:MAILE FINISIIERS VS MAIE FINTSHERS REVTSED SURVEY QUESTION \#48

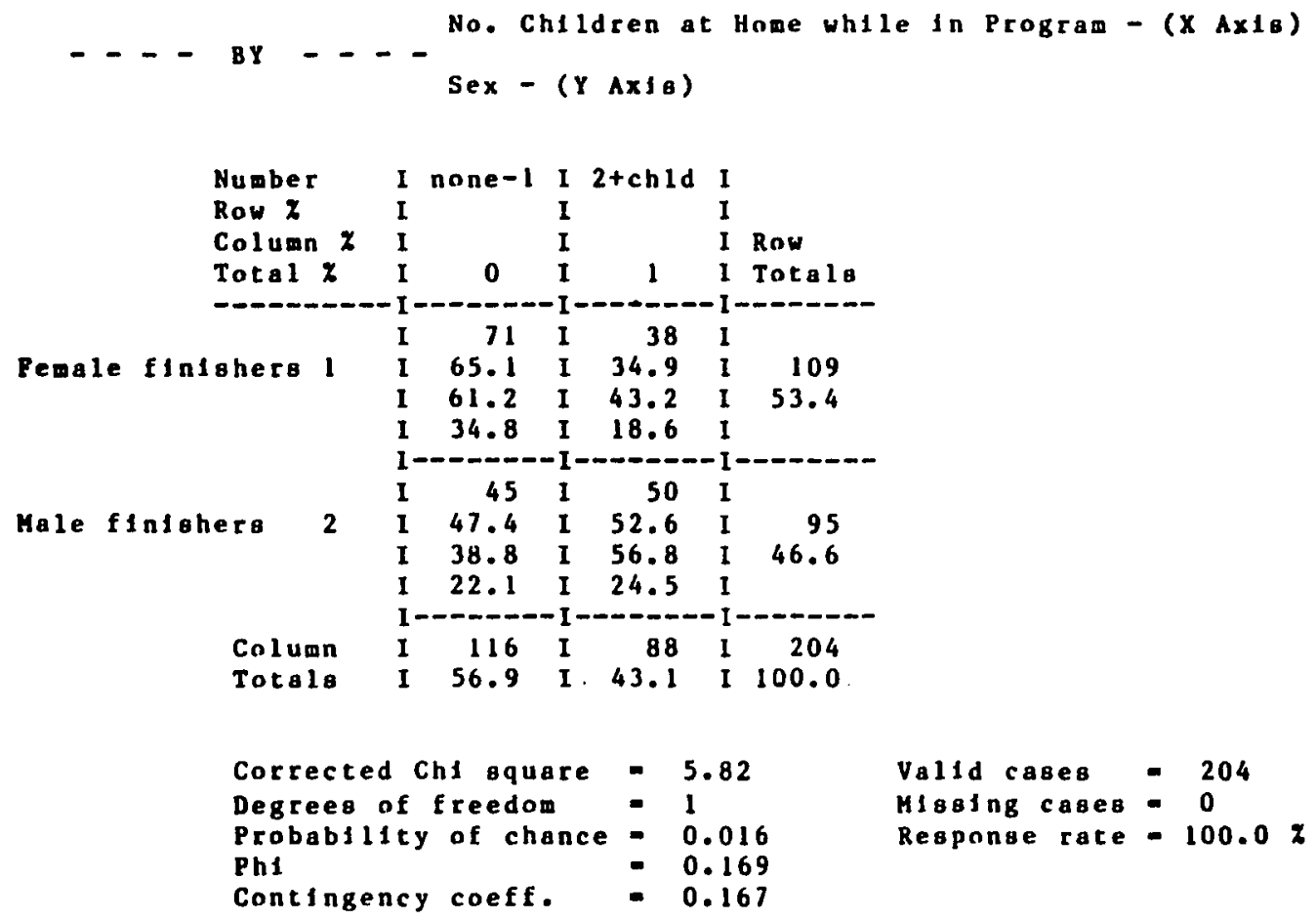


FEMALE JLEAVERS VS MALE I.FAVIERS

REVISED SURVEY OUISTTON \#G

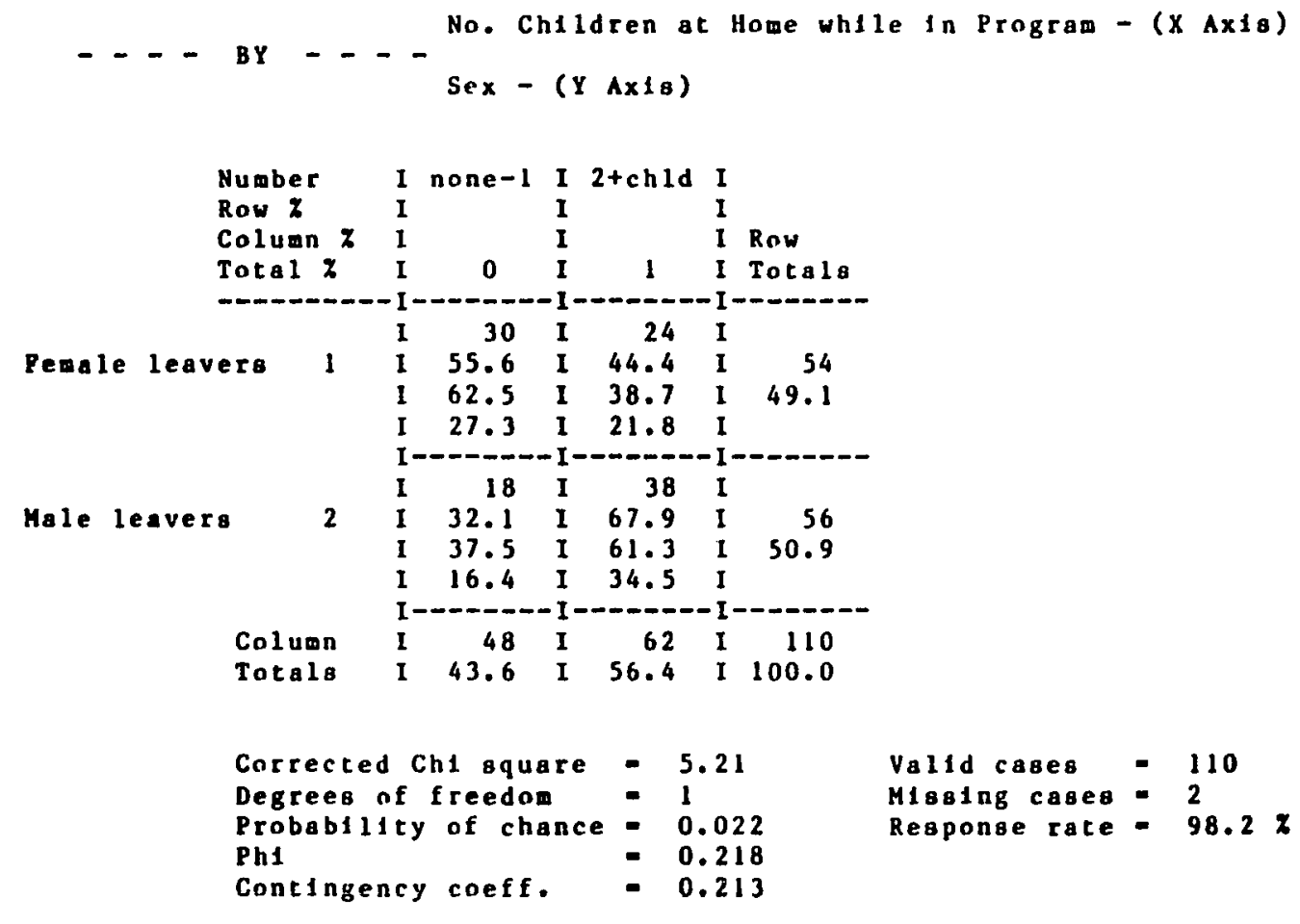


FEMALE, I, BAV ERS VS FEMAIEF FTNTSHLRS SURVIEY QUESTION $\# 49$

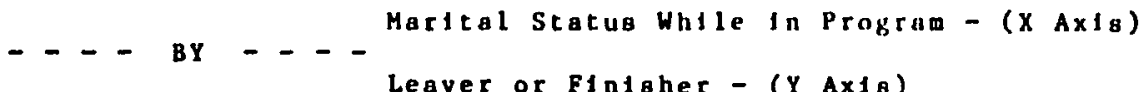

\begin{tabular}{|c|c|c|c|c|c|c|c|c|}
\hline & $\begin{array}{l}\text { Numbe } \\
\text { Row } 7 \\
\text { Colum } \\
\text { Total }\end{array}$ & $x^{x}$ & $\begin{array}{l}I \\
I \\
I \\
I\end{array}$ & olngle & $\begin{array}{l}\text { I } \\
\text { I } \\
\text { I } \\
\text { I }\end{array}$ & $\max { }^{\prime} d$ & $\begin{array}{l}I \\
I \\
I \\
I\end{array}$ & $\begin{array}{l}\text { Row } \\
\text { Total } 8\end{array}$ \\
\hline male & leavers & 1 & $\begin{array}{l}\text { I } \\
\text { I } \\
\text { I } \\
\text { I }\end{array}$ & $\begin{array}{r}24 \\
44.4 \\
50.0 \\
14.7\end{array}$ & $\begin{array}{l}\text { I } \\
\text { I } \\
\text { I } \\
\text { I }\end{array}$ & $\begin{array}{r}30 \\
55.6 \\
26.1 \\
18.4\end{array}$ & $\begin{array}{l}I \\
I \\
1 \\
I\end{array}$ & $\begin{array}{r}54 \\
33.1\end{array}$ \\
\hline ale & findohers & 2 & $\begin{array}{l}1- \\
1 \\
1 \\
1 \\
1\end{array}$ & $\begin{array}{r}24 \\
22.0 \\
50.0 \\
14.7\end{array}$ & $\begin{array}{l}\text { I } \\
\text { I } \\
\text { I } \\
\text { I }\end{array}$ & $\begin{array}{r}85 \\
78.0 \\
73.9 \\
52.1\end{array}$ & $\begin{array}{l}I \\
I \\
I \\
I\end{array}$ & $\begin{array}{r}109 \\
66.9\end{array}$ \\
\hline & $\begin{array}{l}\text { Col } \\
\text { Tot }\end{array}$ & & 1 & $\begin{array}{r}48 \\
29.4\end{array}$ & I & $\begin{array}{r}115 \\
70.6\end{array}$ & $\begin{array}{l}I \\
I\end{array}$ & $\begin{array}{r}163 \\
100.0\end{array}$ \\
\hline
\end{tabular}

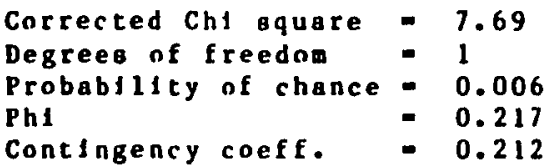

Validcases=163

MLsing cares-1

Responge rate - $99.4 \%$ 
FEMAIA FINISUIERS VS MAI,E FINISIIERS SIIRVIEY OQIIESTION \#49

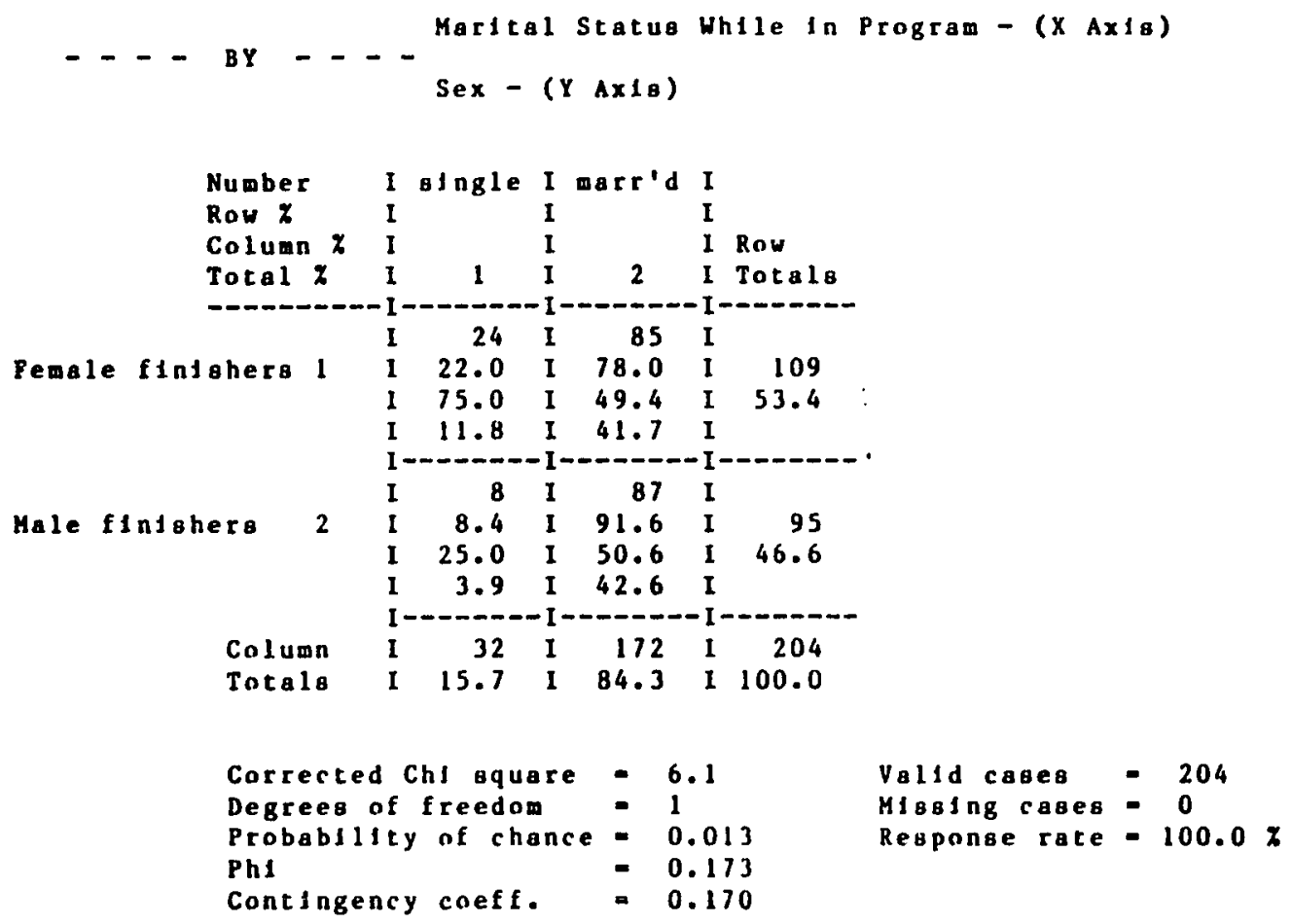




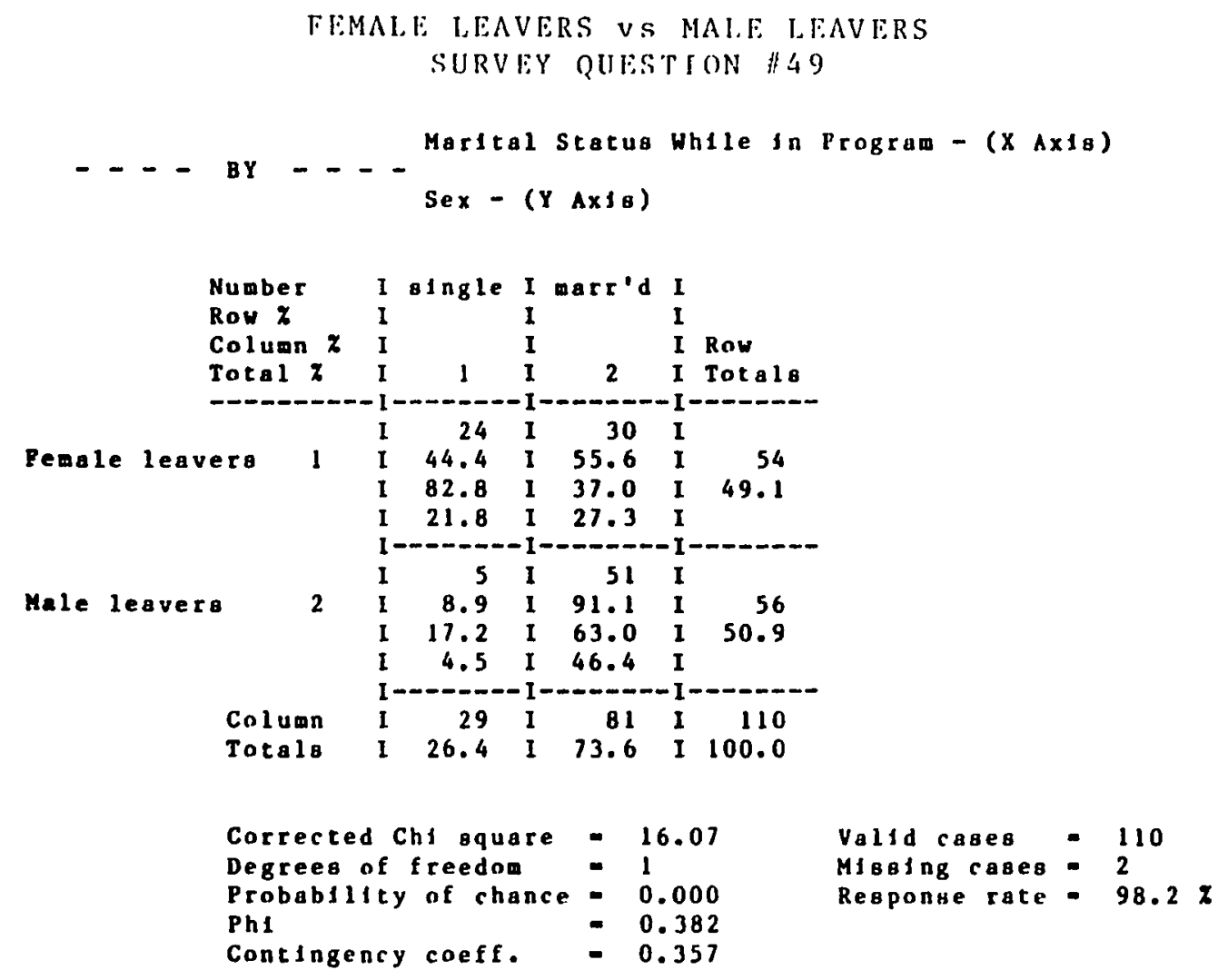




\section{APPENDIX C}

OFFICIAL STATISTICAL TABLES OF ALL NON-SIGNIFICANTLY

DIFFERENT COMPARISONS

The first section of this appendix includes tables of comparisons between respondents and non-respondents. The second section, comparisons between leavers and finishers. The third section includes comparisons between rural and urban respondents; and the fourth, comparisons between male and female respondents. 
ALL RESPONDENTS VS ALL NON-RESPONDENTS STUDEN'I' DATA BASE INFORMATJON: SFX

\begin{tabular}{|c|c|c|c|c|c|c|c|}
\hline $\begin{array}{l}\text { Numb } \\
\text { Row } \\
\text { Colu } \\
\text { Tota }\end{array}$ & ${ }^{n} x^{x}$ & $\begin{array}{lc}\text { I } & \text { Female } \\
\text { I } & \\
1 & \\
1 & 1\end{array}$ & $\begin{array}{ll}\text { I } & \text { M } \\
\text { I } & \\
\text { I } & \\
\text { I } & \end{array}$ & $\begin{array}{r}\text { Male } \\
2\end{array}$ & $\begin{array}{ll}\text { I } & \\
\text { I } & \\
\text { I } & \text { Row } \\
\text { I } & \text { Tota } 18\end{array}$ & & \\
\hline reapondents & 1 & $\begin{array}{rr}\text { I } & 164 \\
1 & 51.9 \\
\text { I } & 82.8 \\
1 & 42.7\end{array}$ & $\begin{array}{l}\text { I } \\
\text { I } \\
\text { I } \\
\text { I }\end{array}$ & $\begin{array}{l}152 \\
48.1 \\
81.7 \\
39.6\end{array}$ & $\begin{array}{rr}1 & \\
1 & 316 \\
1 & 82.3 \\
1 & \end{array}$ & & \\
\hline \multirow[t]{3}{*}{ nonrespondent } & 3 & $\begin{array}{rr}1 & 34 \\
1 & 50.0 \\
1 & 17.2 \\
1 & 8.9\end{array}$ & $\begin{array}{l}\text { I } \\
\text { I } \\
\text { I } \\
I\end{array}$ & $\begin{array}{r}34 \\
50.0 \\
18.3 \\
8.9\end{array}$ & $\begin{array}{rr}1 & \\
I & 68 \\
1 & 17.7 \\
I & \end{array}$ & & \\
\hline & & $\begin{array}{r}198 \\
1 \quad 51.6\end{array}$ & I & $\begin{array}{r}186 \\
48.4\end{array}$ & $\begin{array}{rr}\text { I } & 384 \\
I & 100.0\end{array}$ & & \\
\hline & $\begin{array}{l}\text { ect } \\
\text { ees } \\
\text { abi } \\
\text { Ing }\end{array}$ & $\begin{array}{l}\text { d Chi squ } \\
\text { of freedo } \\
\text { tity of ch } \\
\text { ncy coeff }\end{array}$ & & $\begin{array}{l}\dot{-} \\
\dot{=} \\
\dot{-}\end{array}$ & $\begin{array}{l}02 \\
.880 \\
.007 \\
.007\end{array}$ & $\begin{array}{l}\text { Valid cases } \\
\text { Mising cases } \\
\text { Response rate }\end{array}$ & $\begin{array}{l}=384 \\
=\quad 0 \\
=100.0\end{array}$ \\
\hline
\end{tabular}




\section{RIESPONIING VS NON-RESPONDING FINISHERS STIIDFNT DATA BASE. TNFORMAIION: SEX}

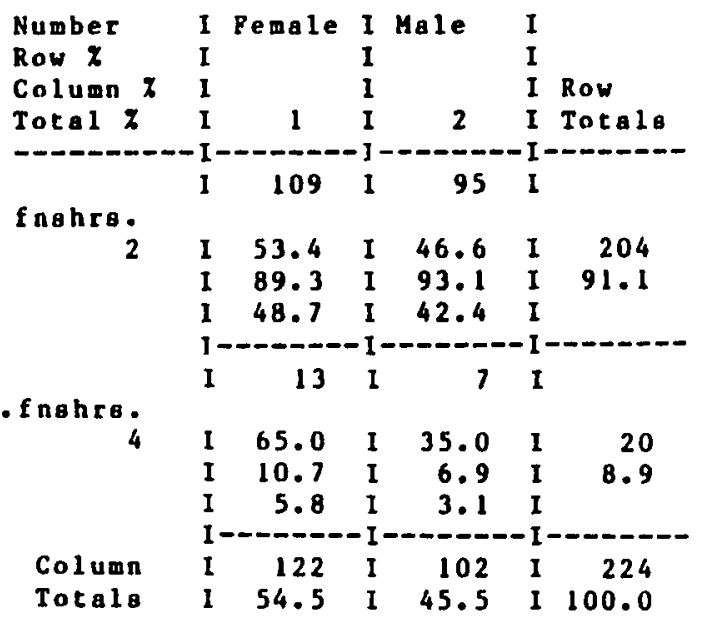

\begin{tabular}{|c|c|}
\hline $\begin{array}{l}\text { cted Chl } \\
\text { es of free } \\
\text { bility of }\end{array}$ & $\begin{array}{l}=1 \\
=0 \\
=0\end{array}$ \\
\hline
\end{tabular}

Valdd cases -224

Mising cases $=0$

Regponse rate $=100.0 x$ 


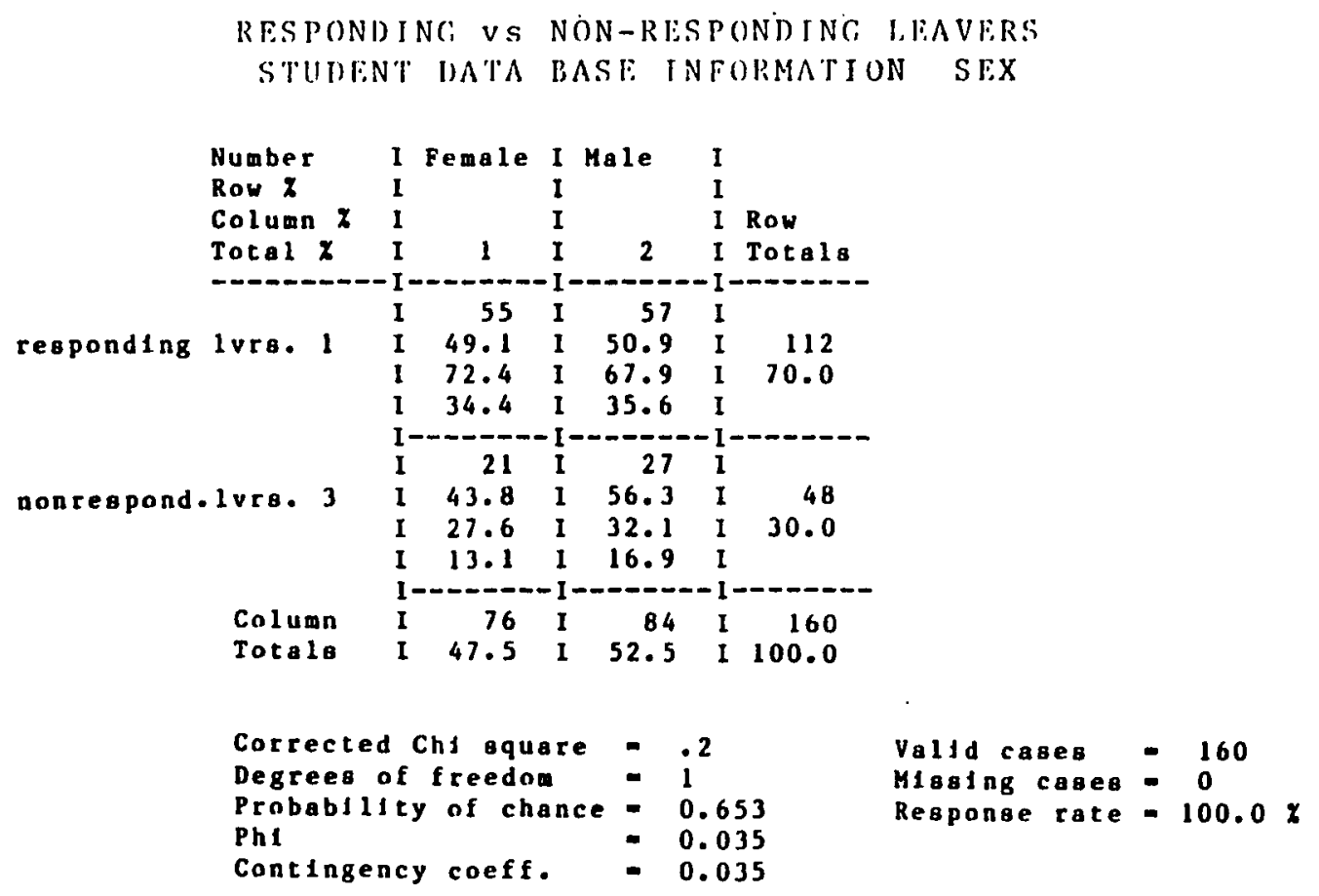


ALL RESPONDENTS VS ALL NON-RESPONDENTS

STUDENT DATA BASE JNFORMATION: RACE

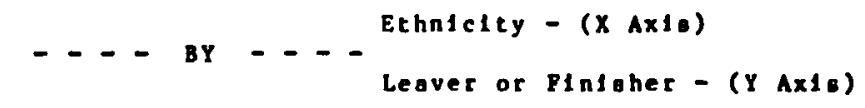

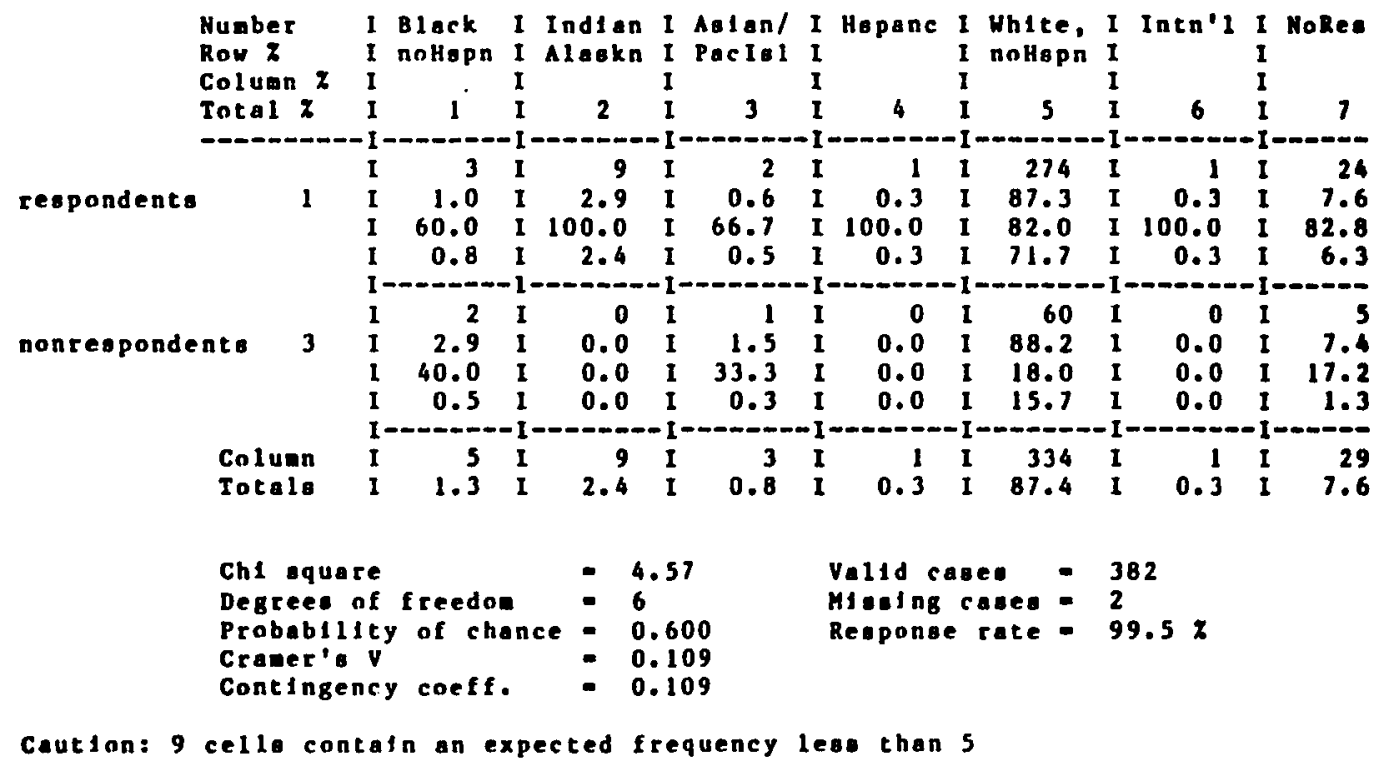




\section{RESPONIING VS NON-RESPONDING FINISHERS \\ STUDENT DATA BASE INFORMATION: RACE}
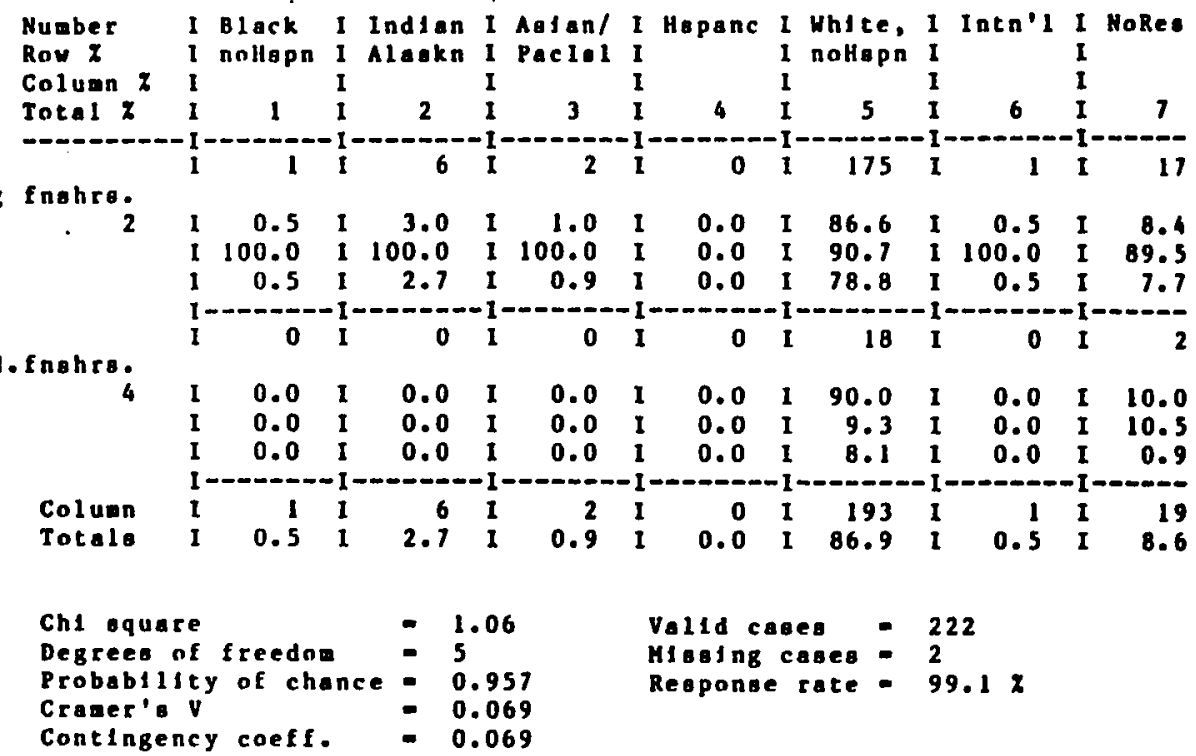

Val1d cases -222

nonrespond. fnohrs:

Hising cases - 2

Probability of chance $=0.957$
Craner' $v$

Response rate - $99.1 \%$

Caution: 8 cello contain an expected frequency lese than 5 
RTSPONDING VS NON-RESPONDING LEAVERS

STUDENT DATA BASE INEORMATION: RACE,

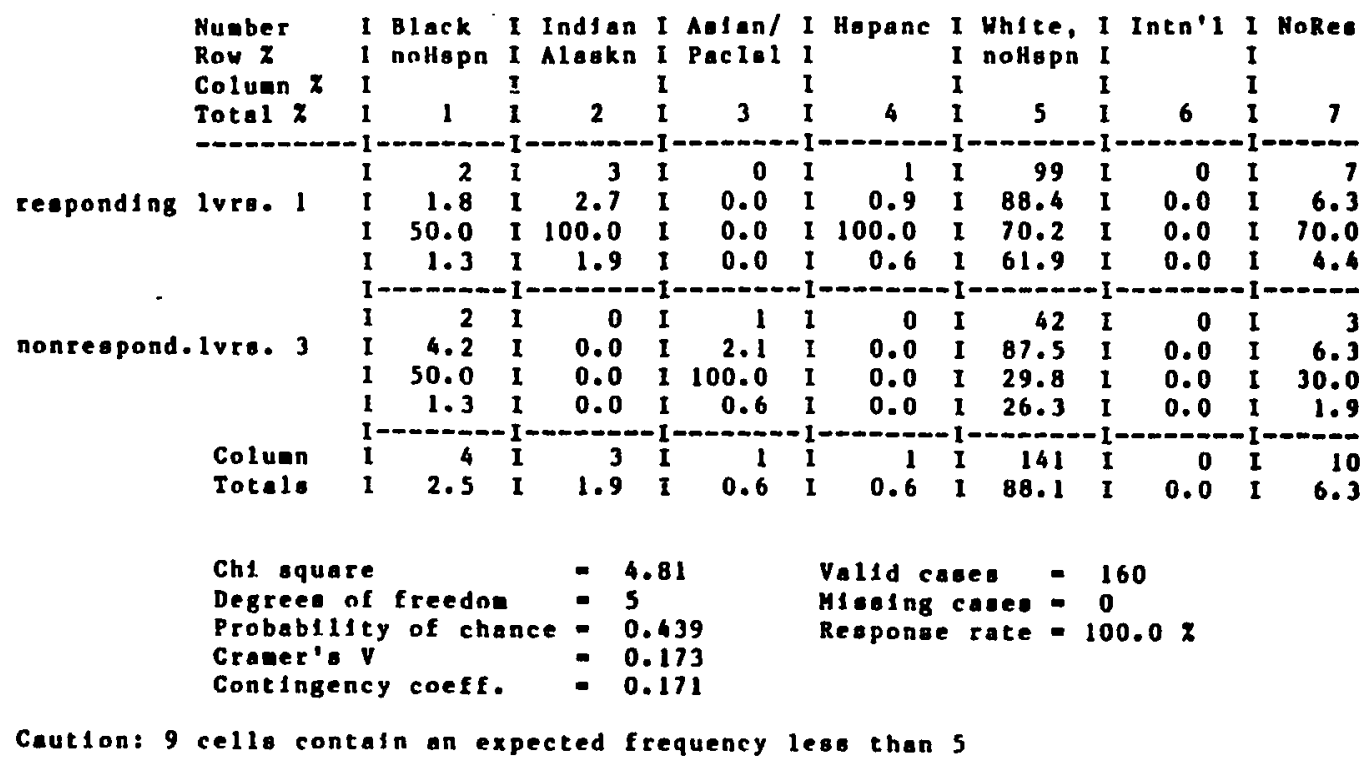


ALL RESPONDENTS VS ALL NON-RESPONDENTS STUDIENT DATA BASE, INFORMATION: GPA

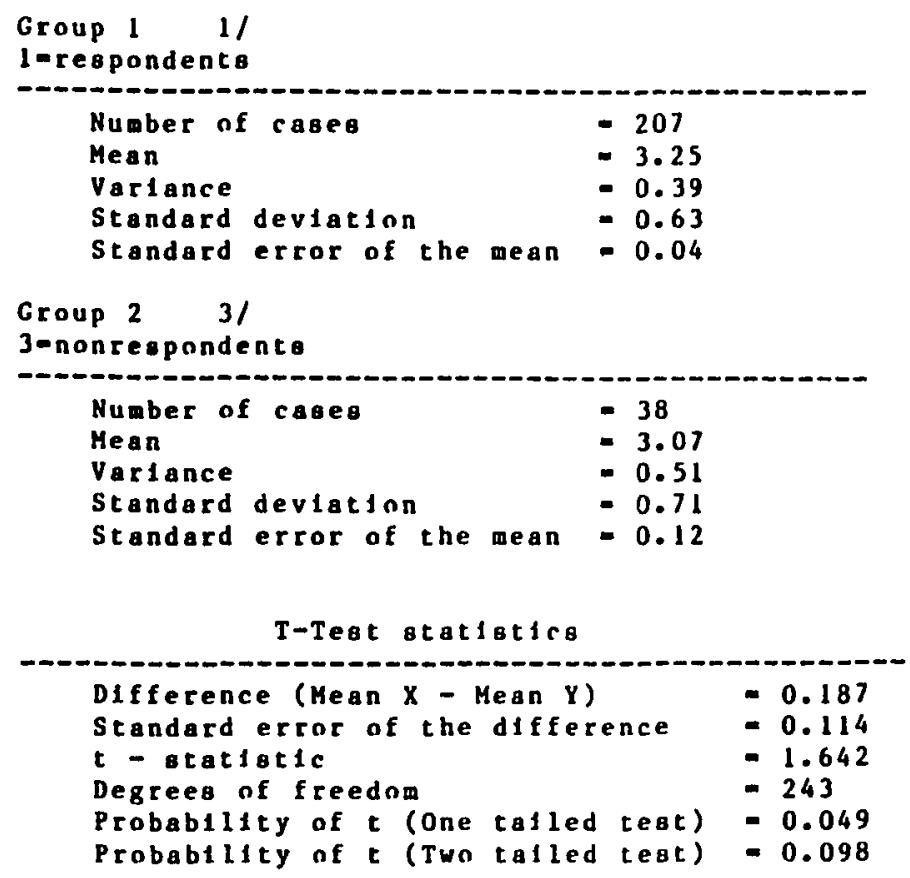


RESPONDING VS NON-RESPONIDING FINISIIERS STII)IENT DATA BASLE INFORMATJON: (;PA

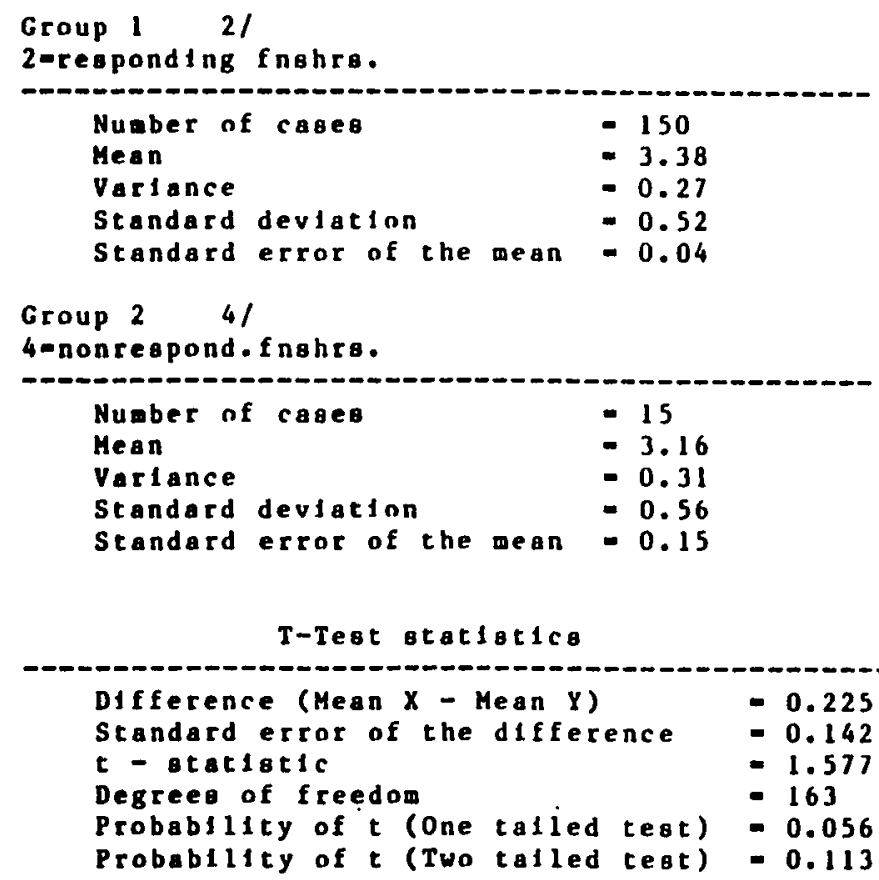

RLSPONDING VS NON-RESPONDING LEAVIERS STIIIINT IATA BASIE TNFORMATION: CIPA

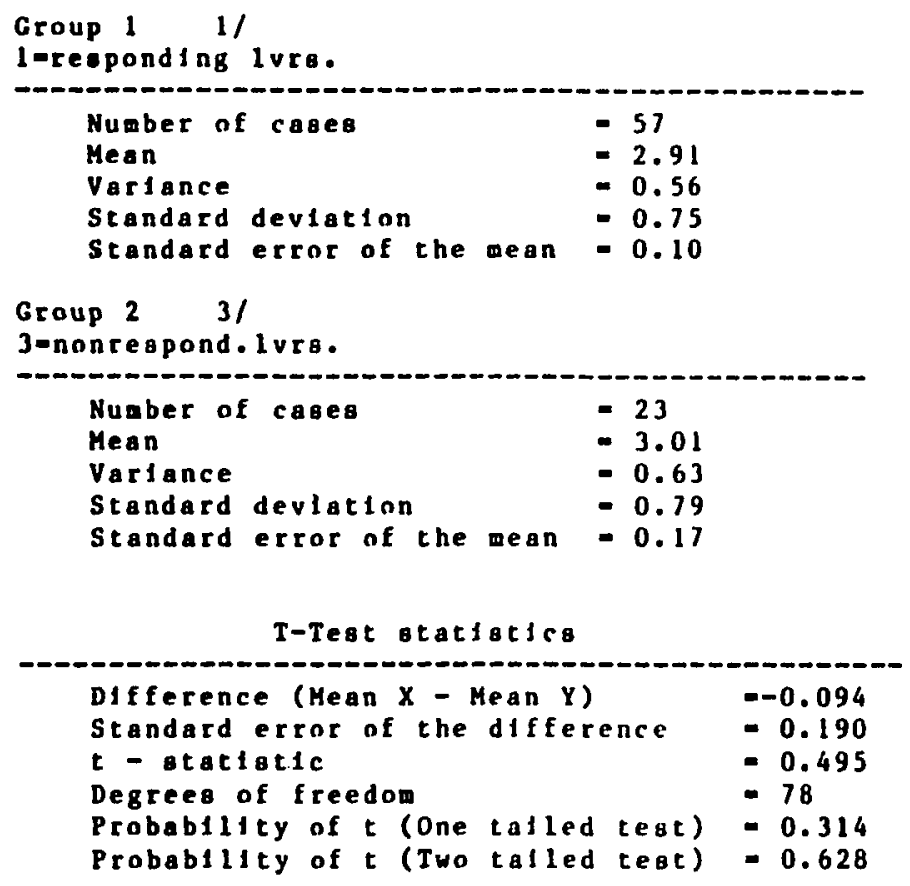


ALL RESPONIENTS VS ALL NON-RESPONDLNTS STUDENT DATA BASE INFORMATION: NGE

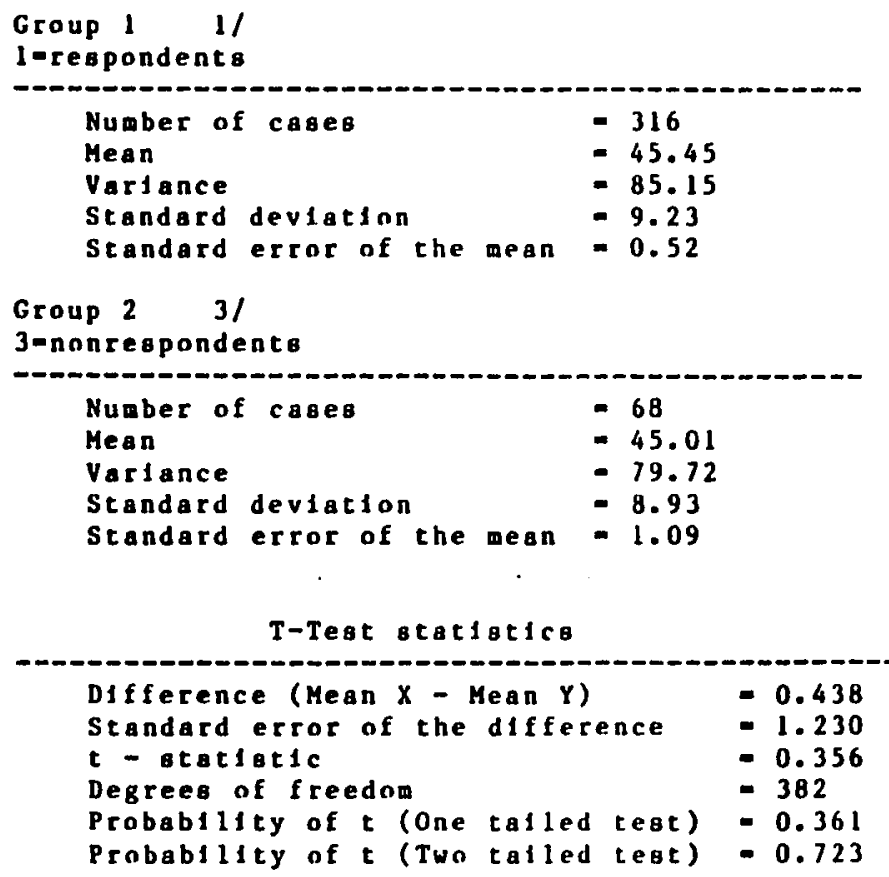


RLSPONITNG VS NON-RESPONDING FINISHERS STUIDIT INTA BASE TNFORMATTON: ACE

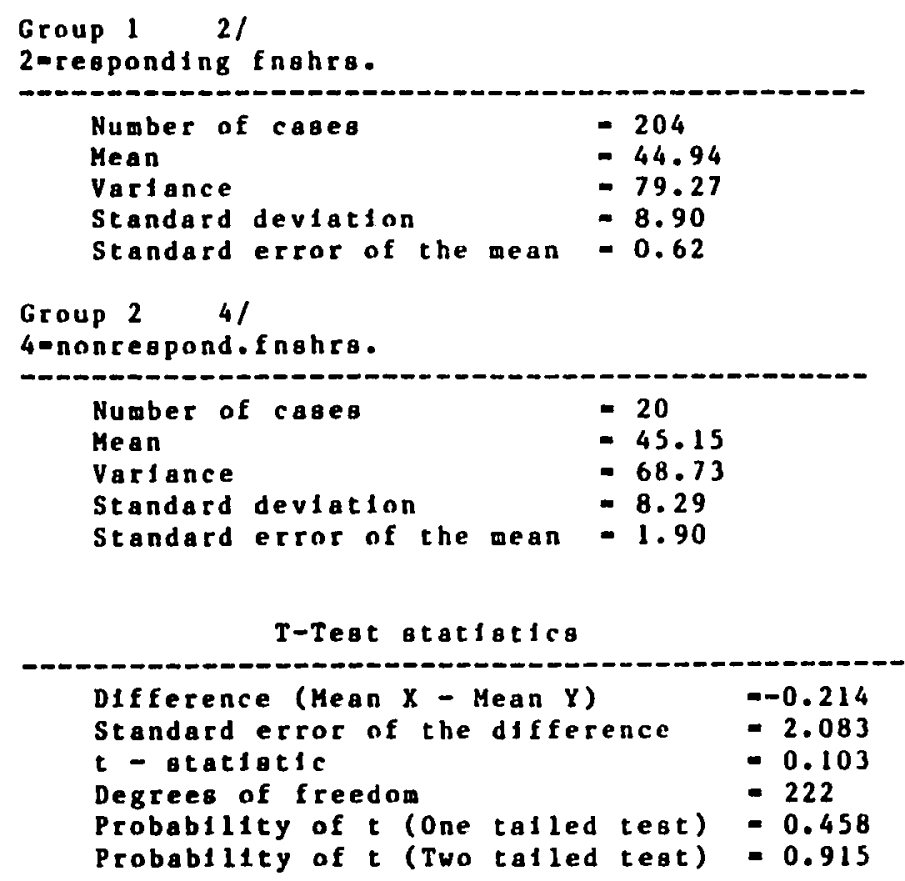

RESPONDING; VS NON-RESPONDING ILIEAVES

STUDENT DATA BASE INFORMATTON: AGE

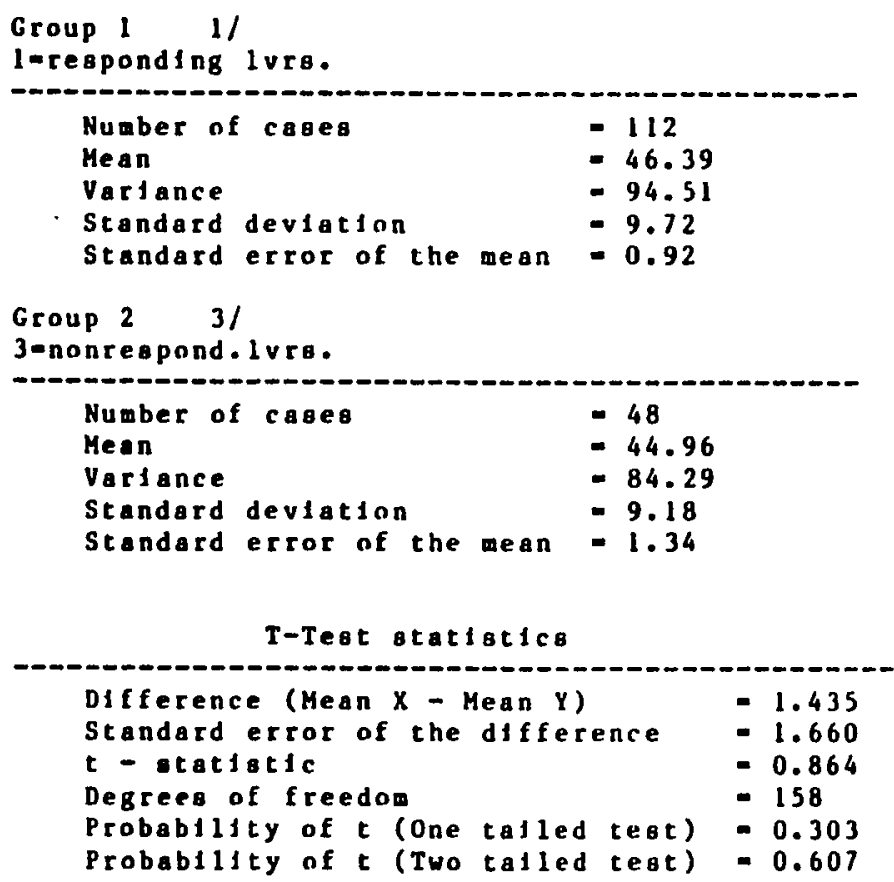

1.660 


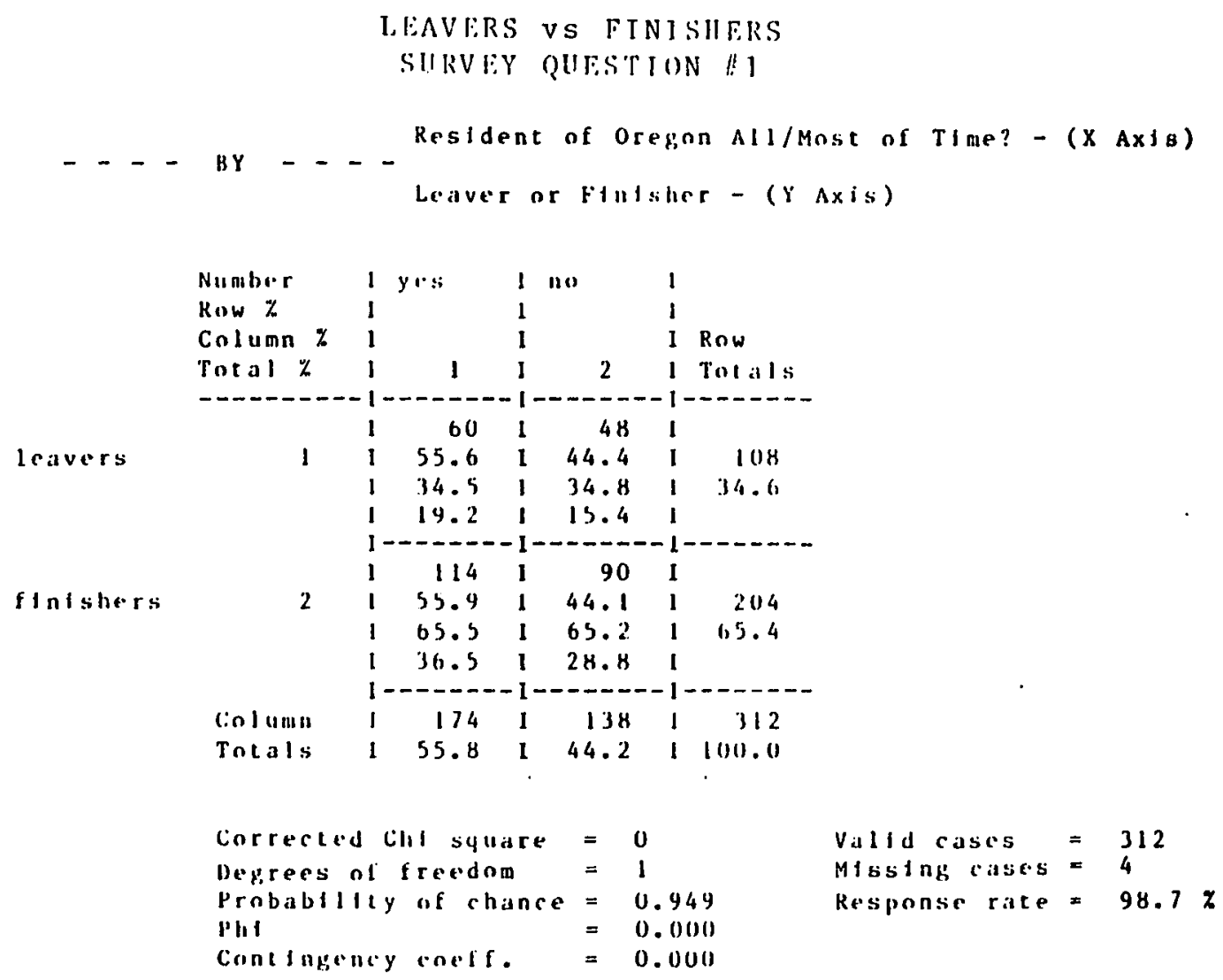




\section{I.EAVERS VS FINISHERS SURV EY QUESTION \#2}

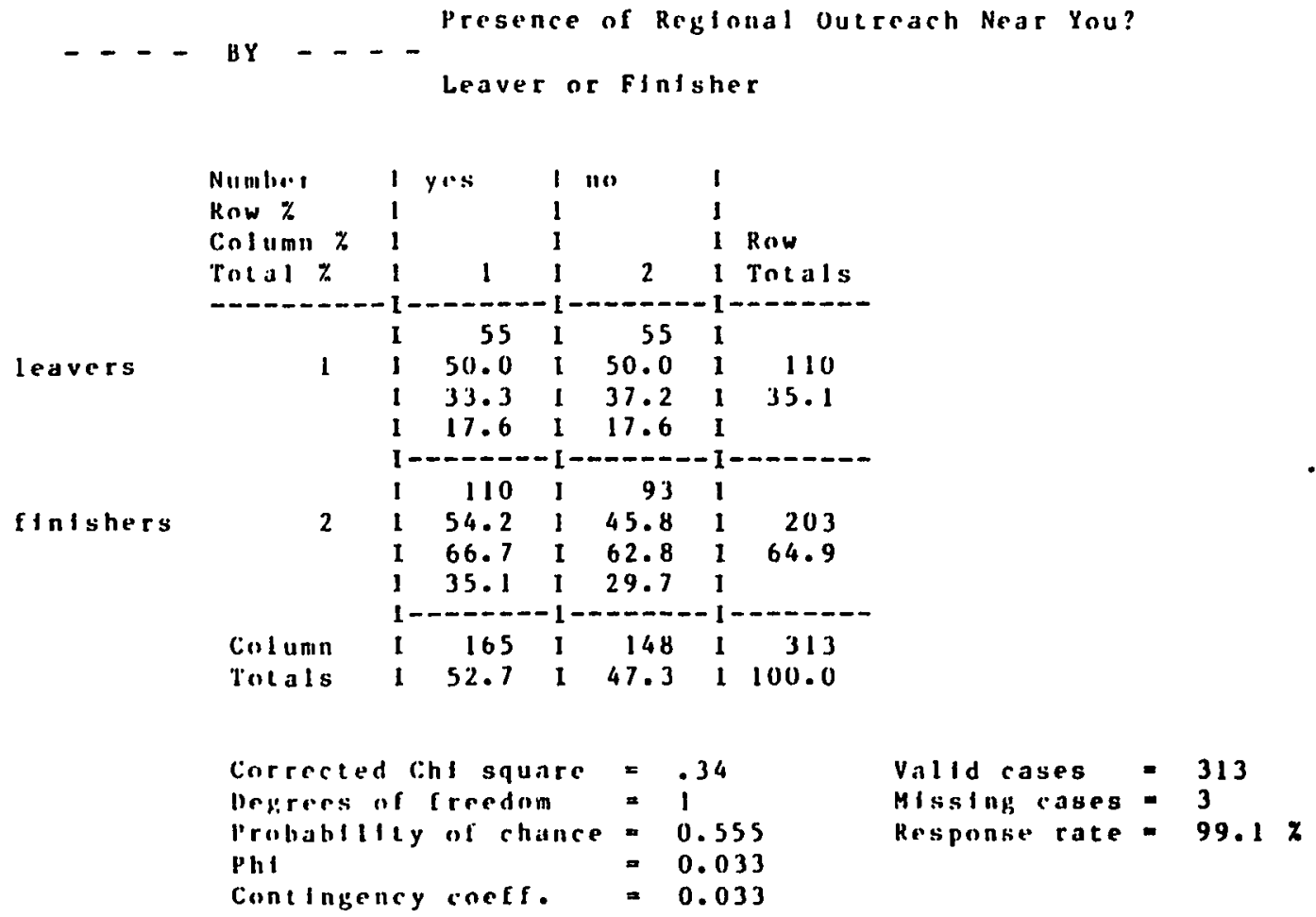

Valid cases $=313$

Missing cases - 3

Rosponse rate $=99.1 \mathrm{Z}$ 


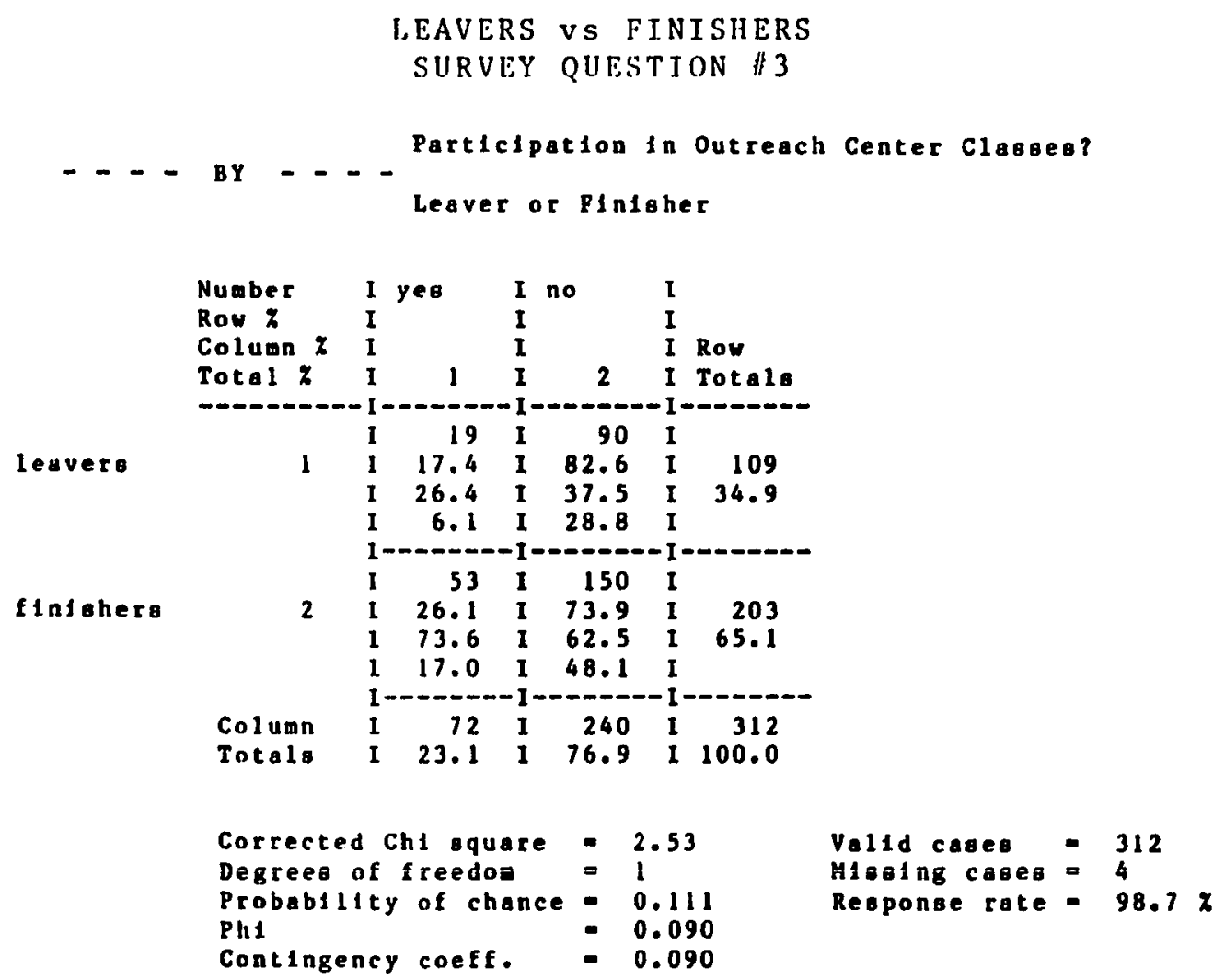




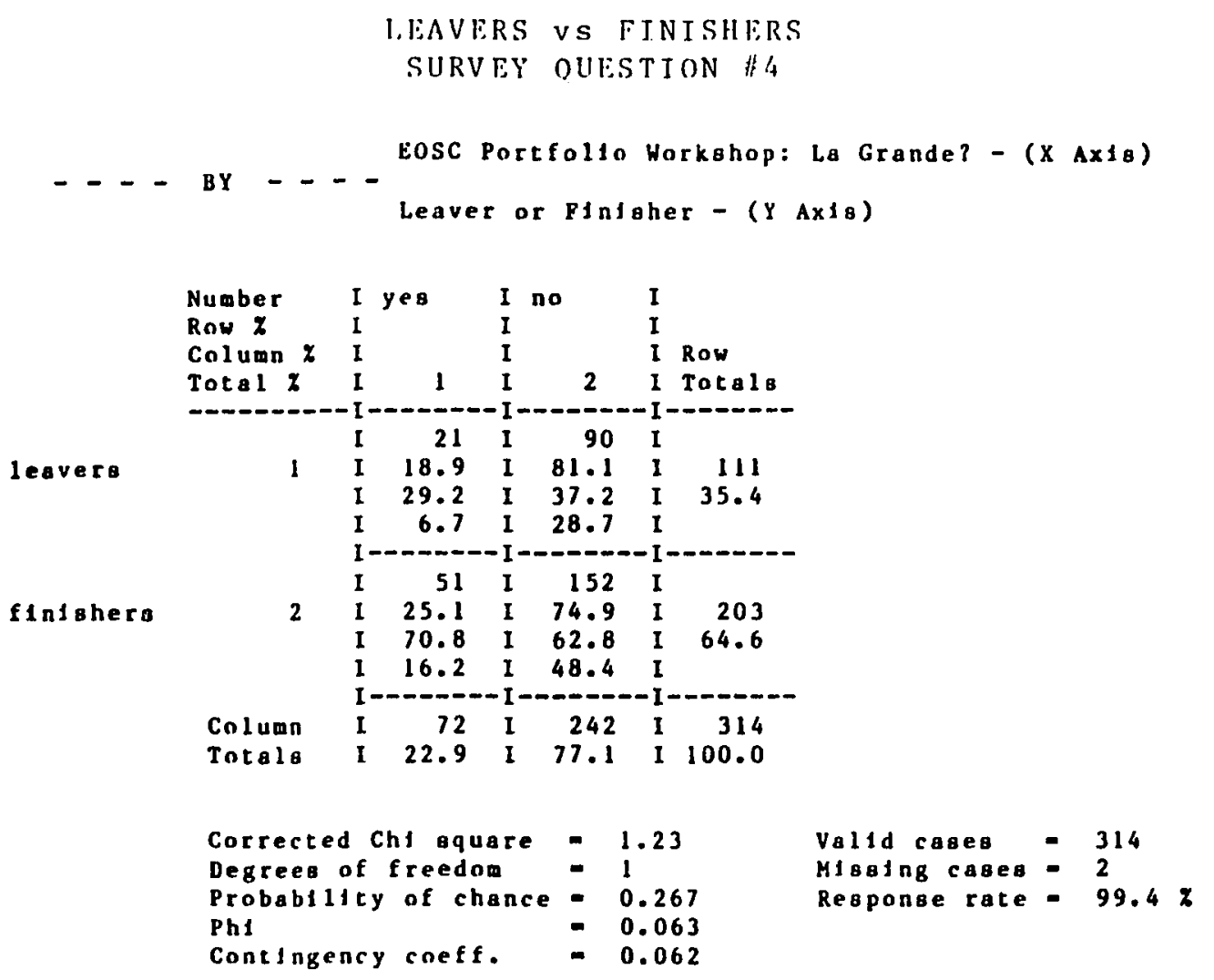




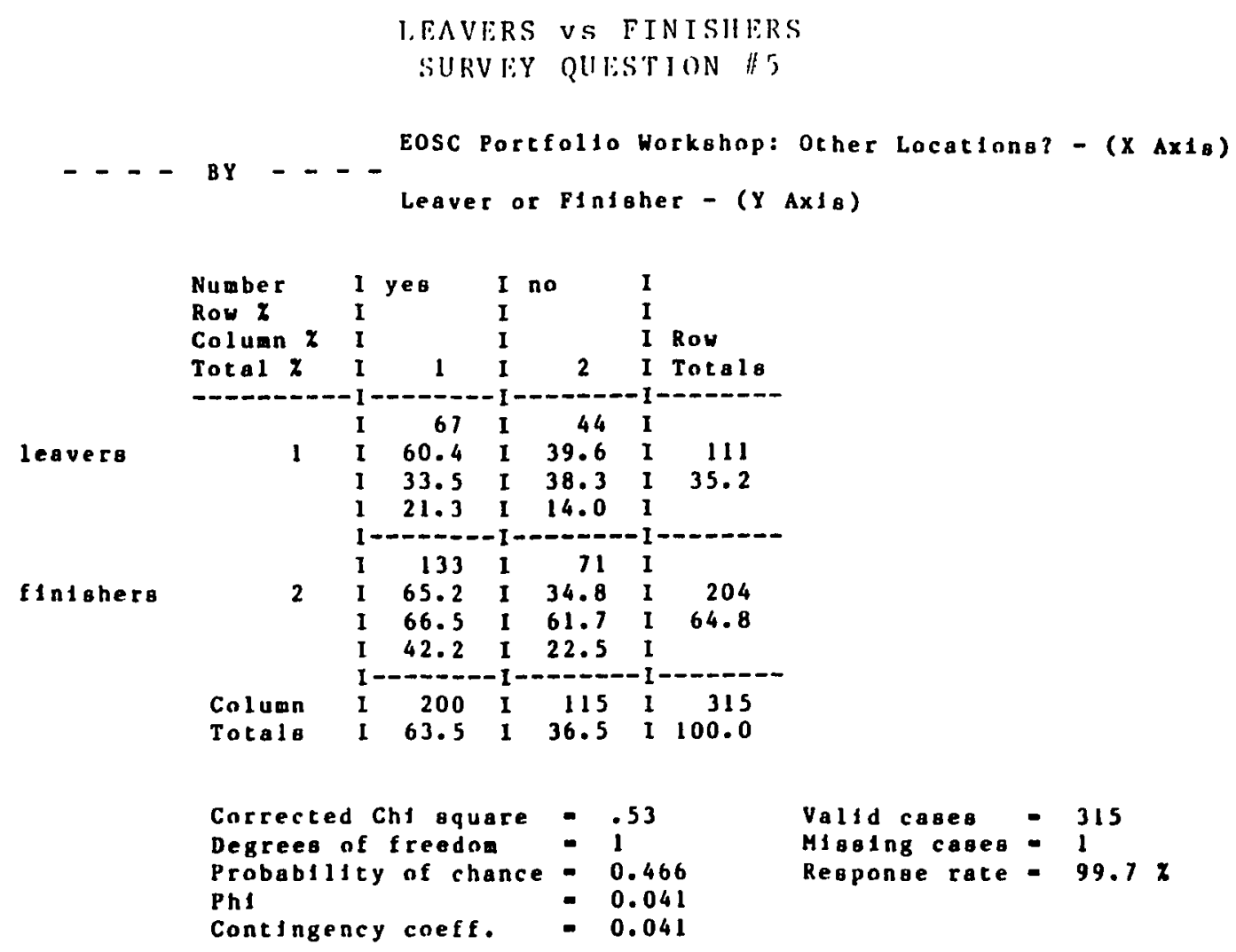




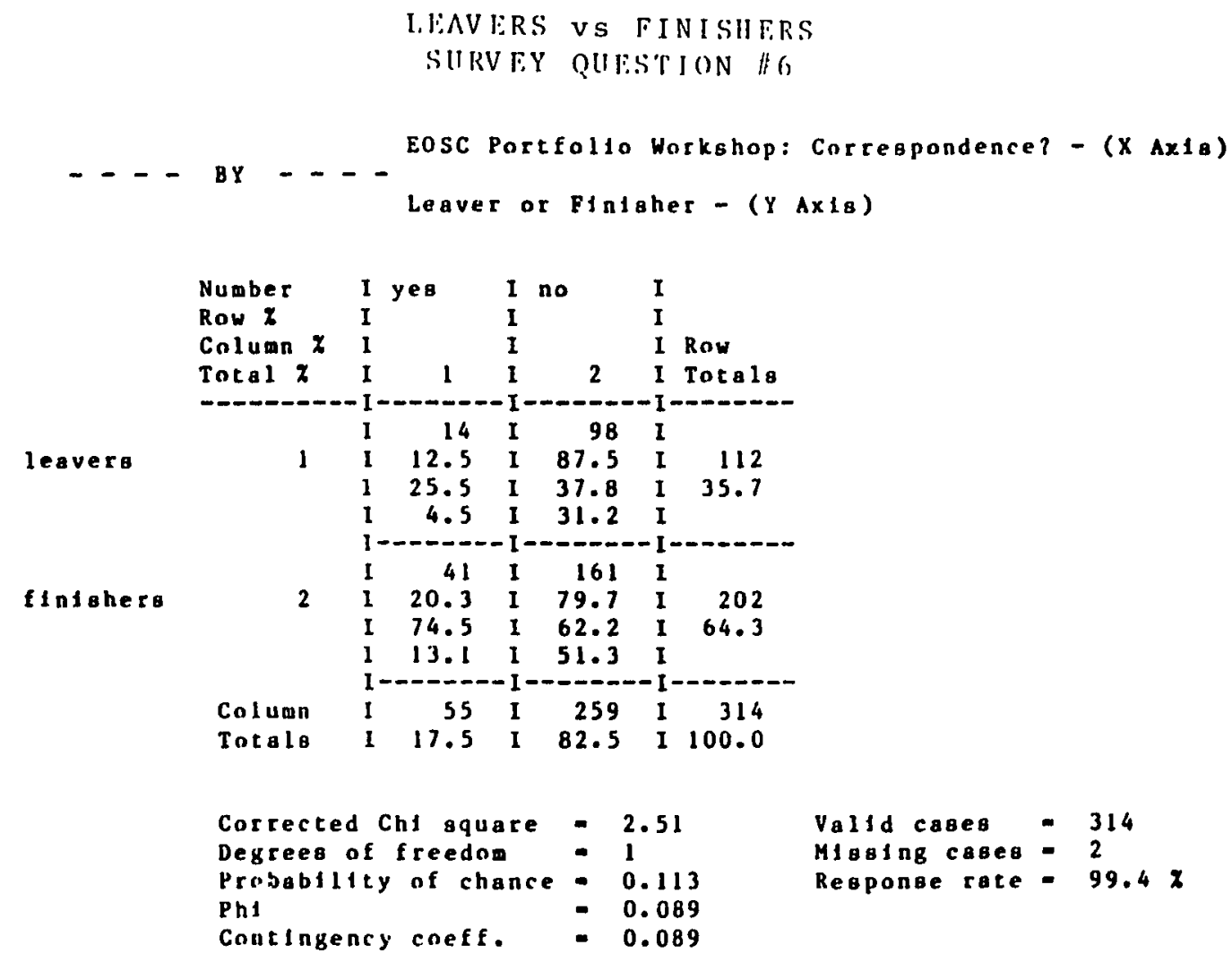




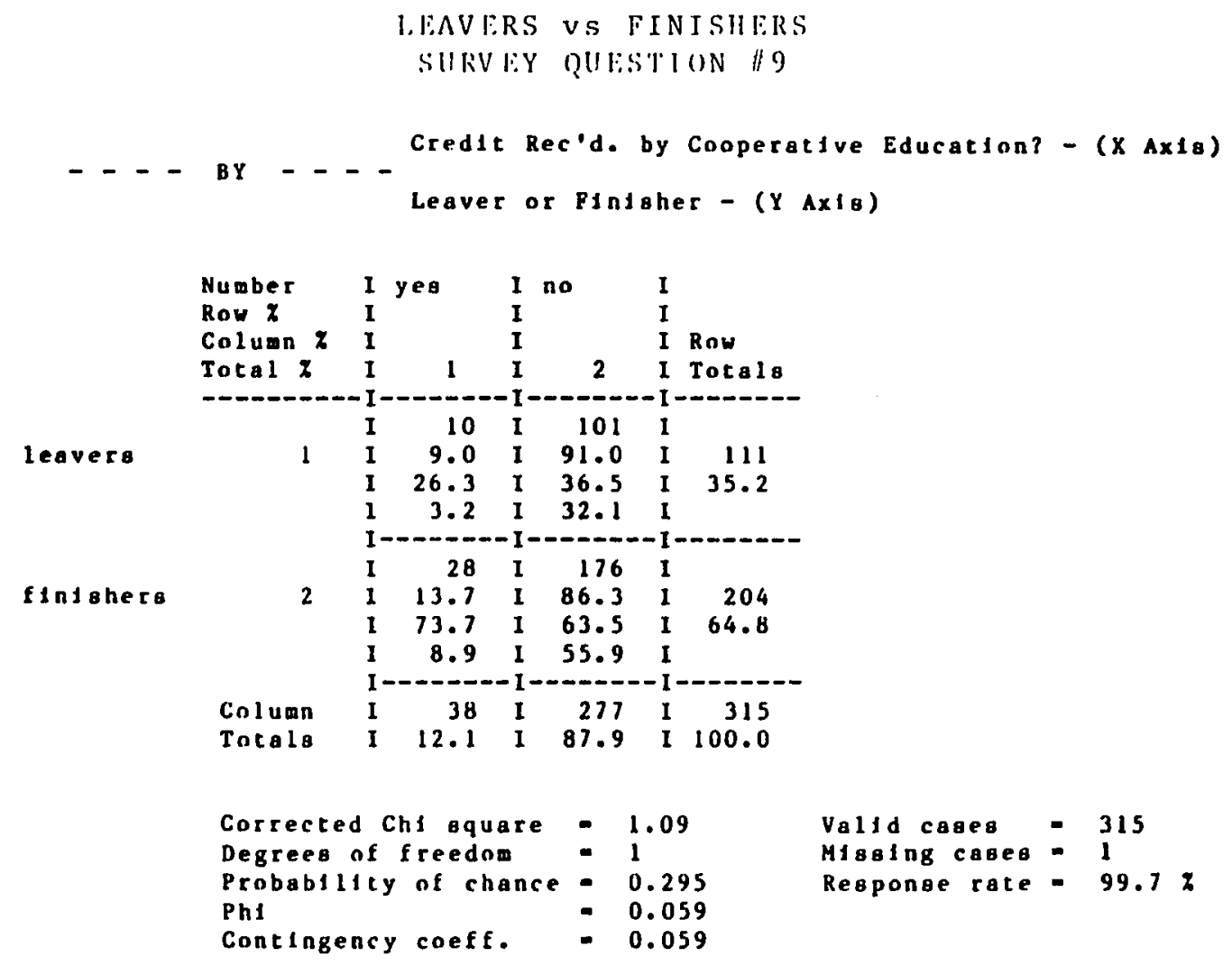




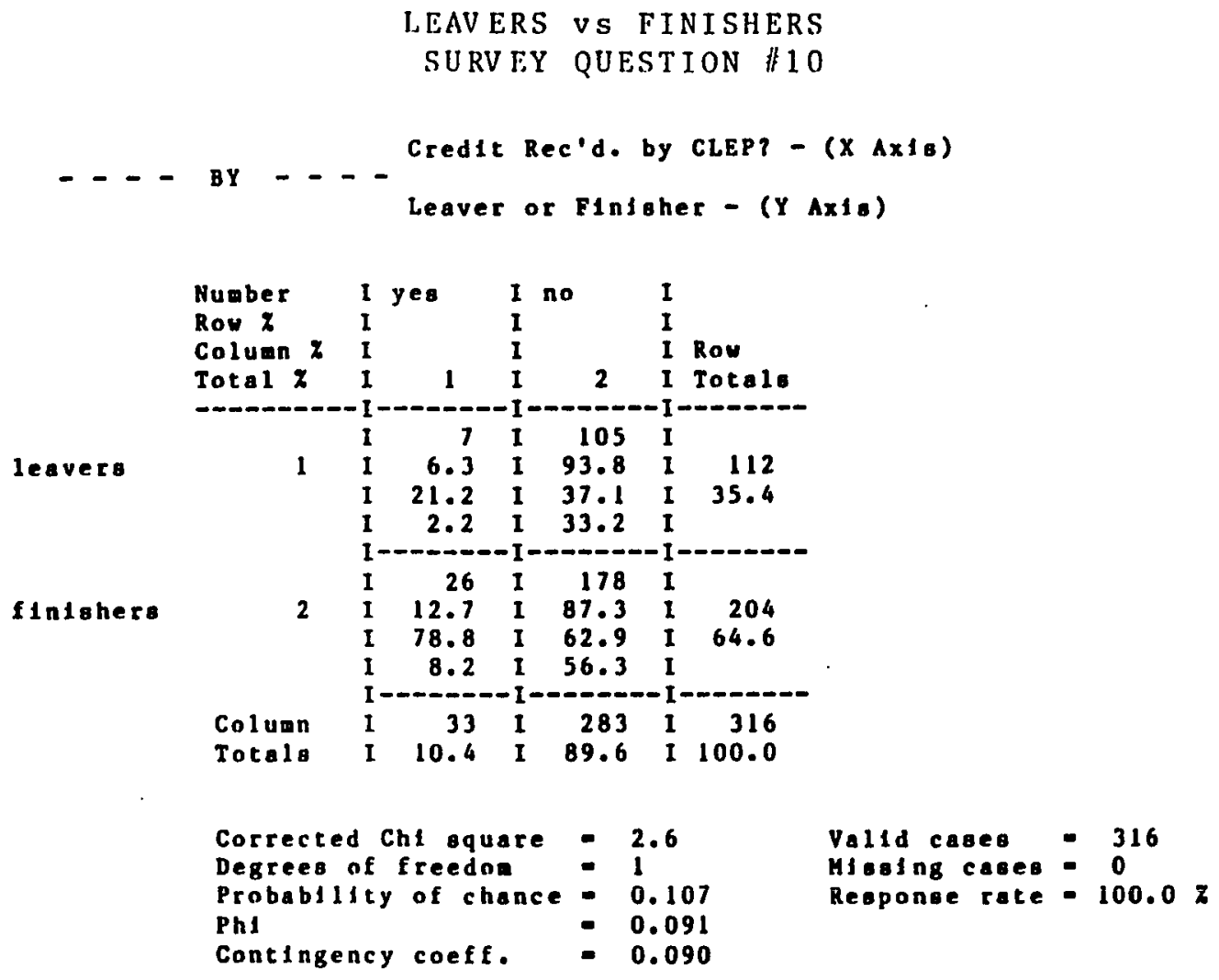




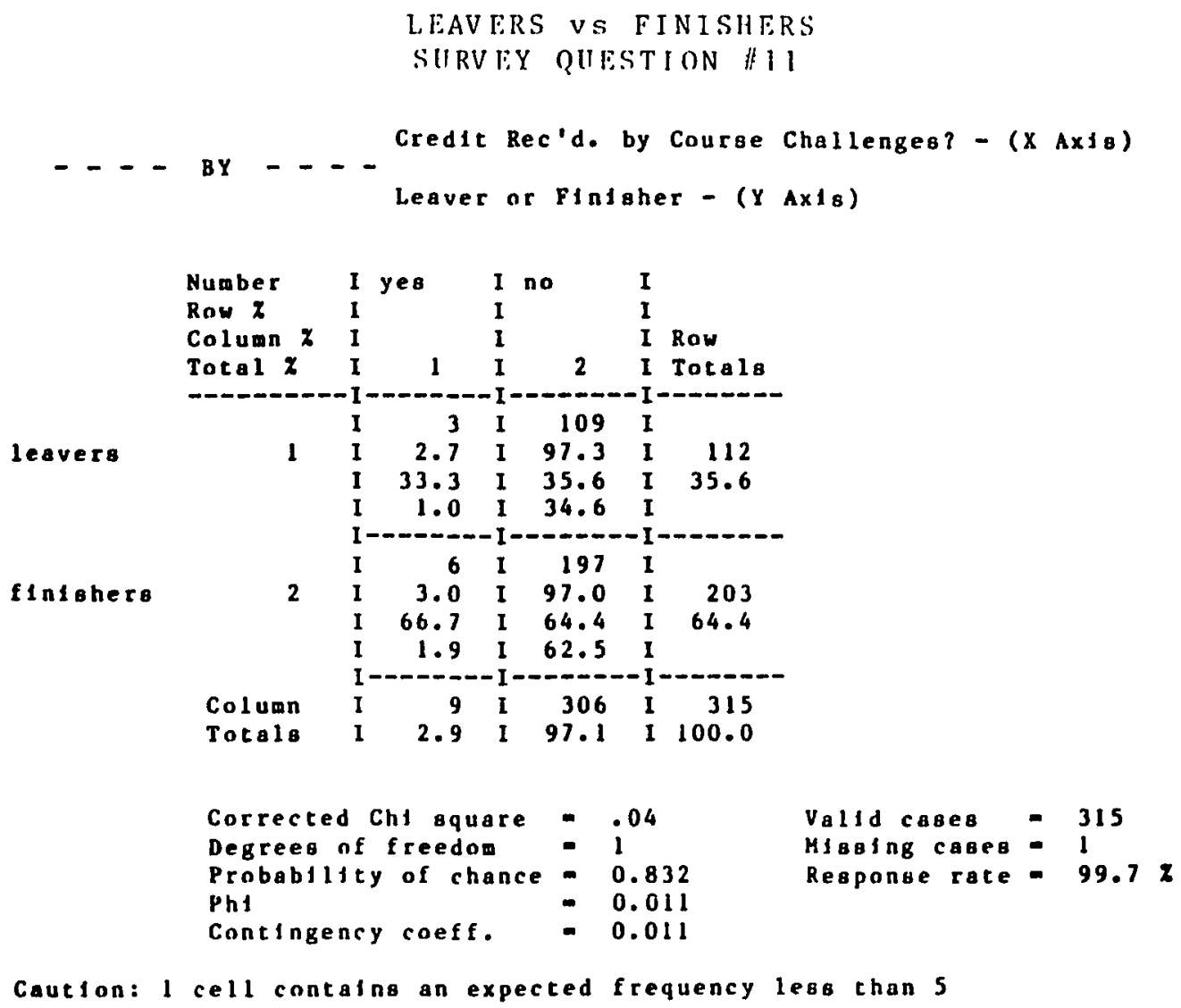



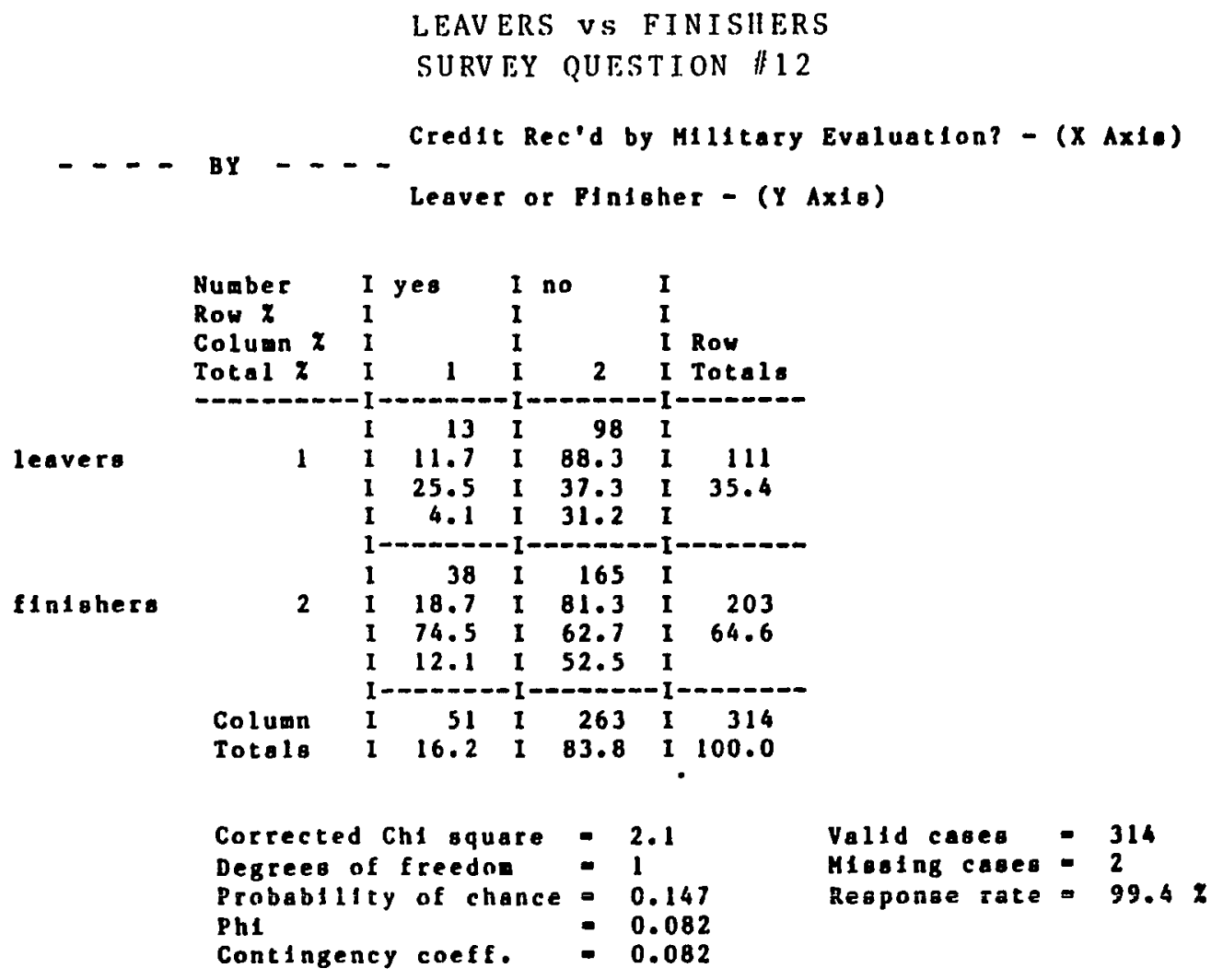


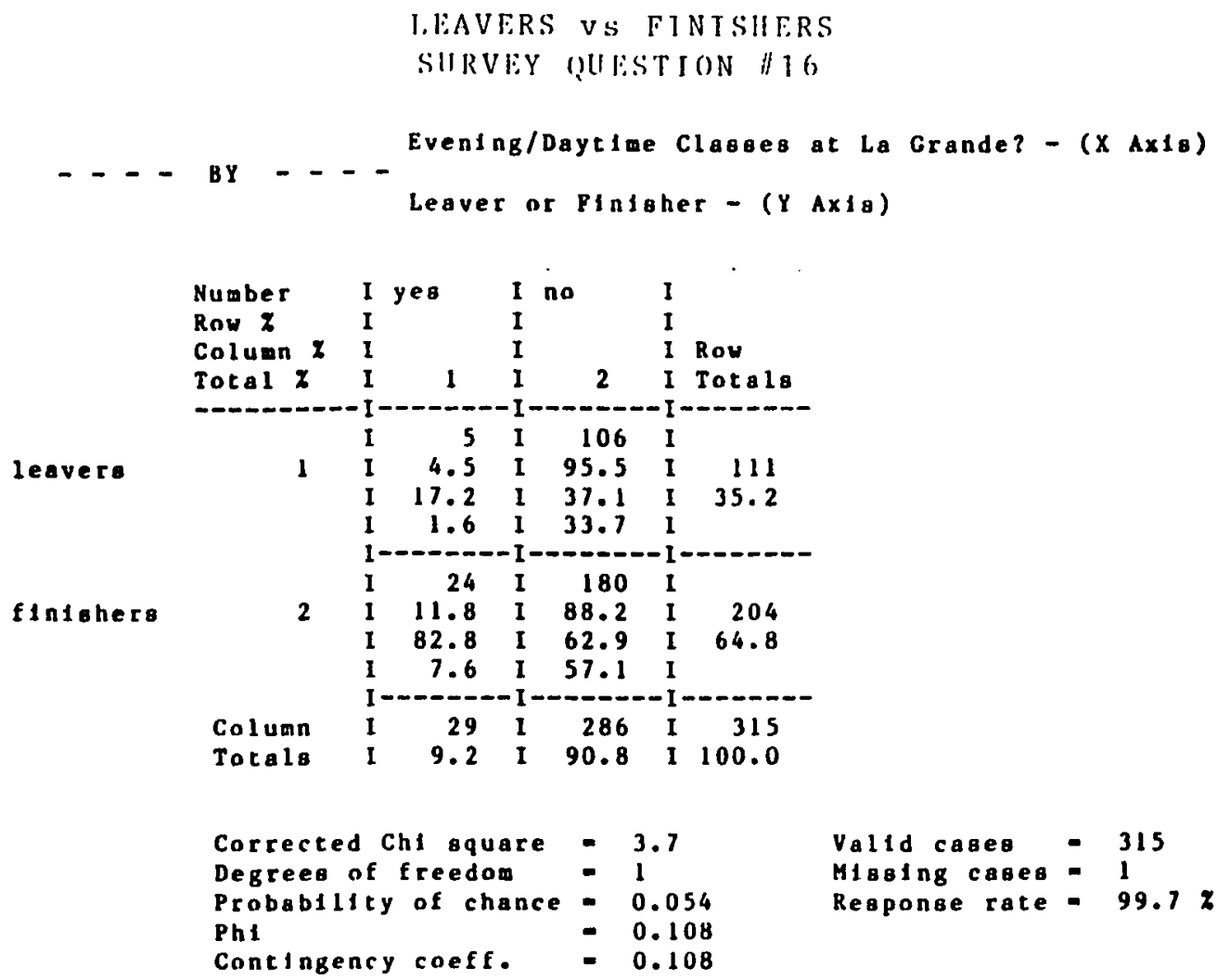




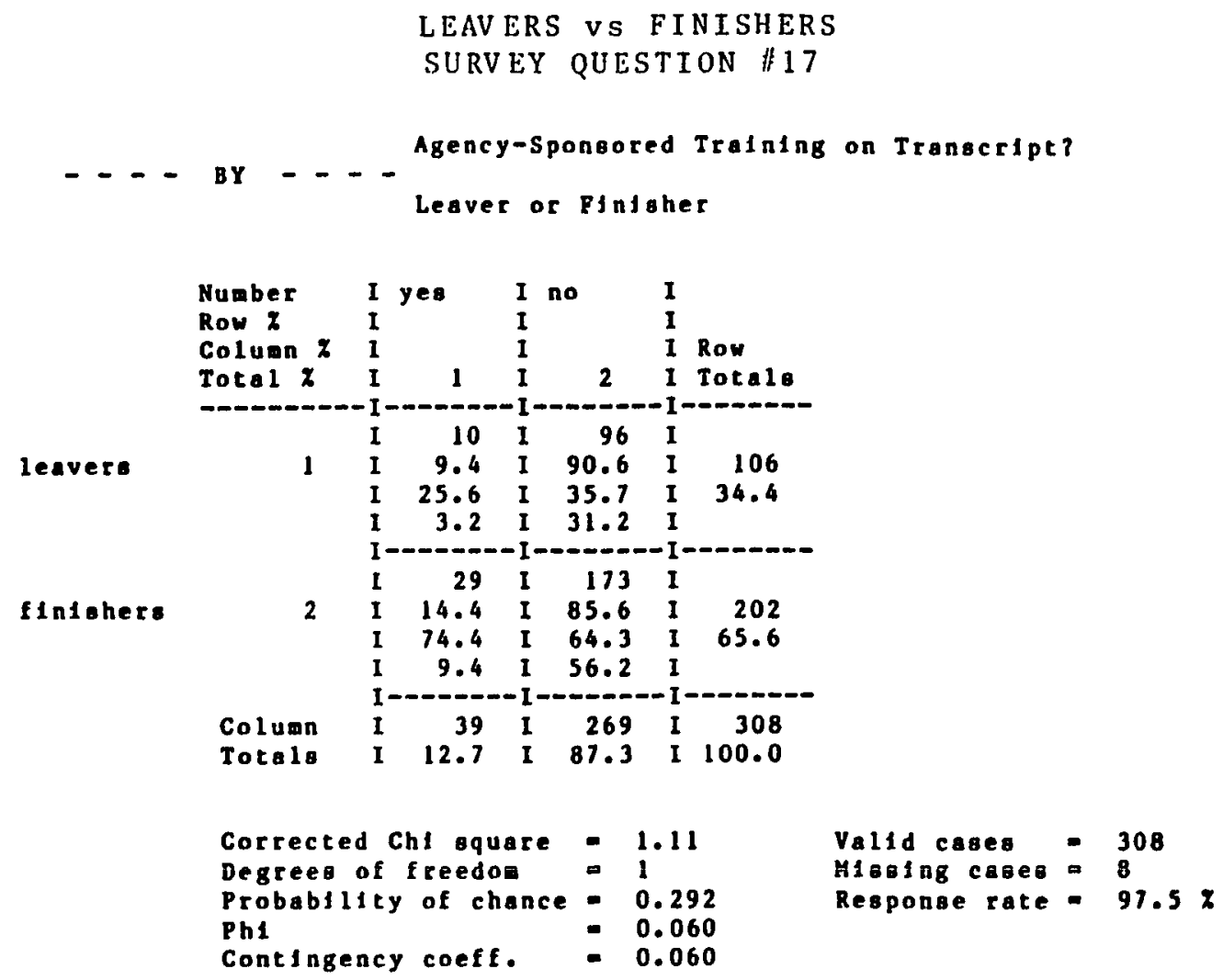




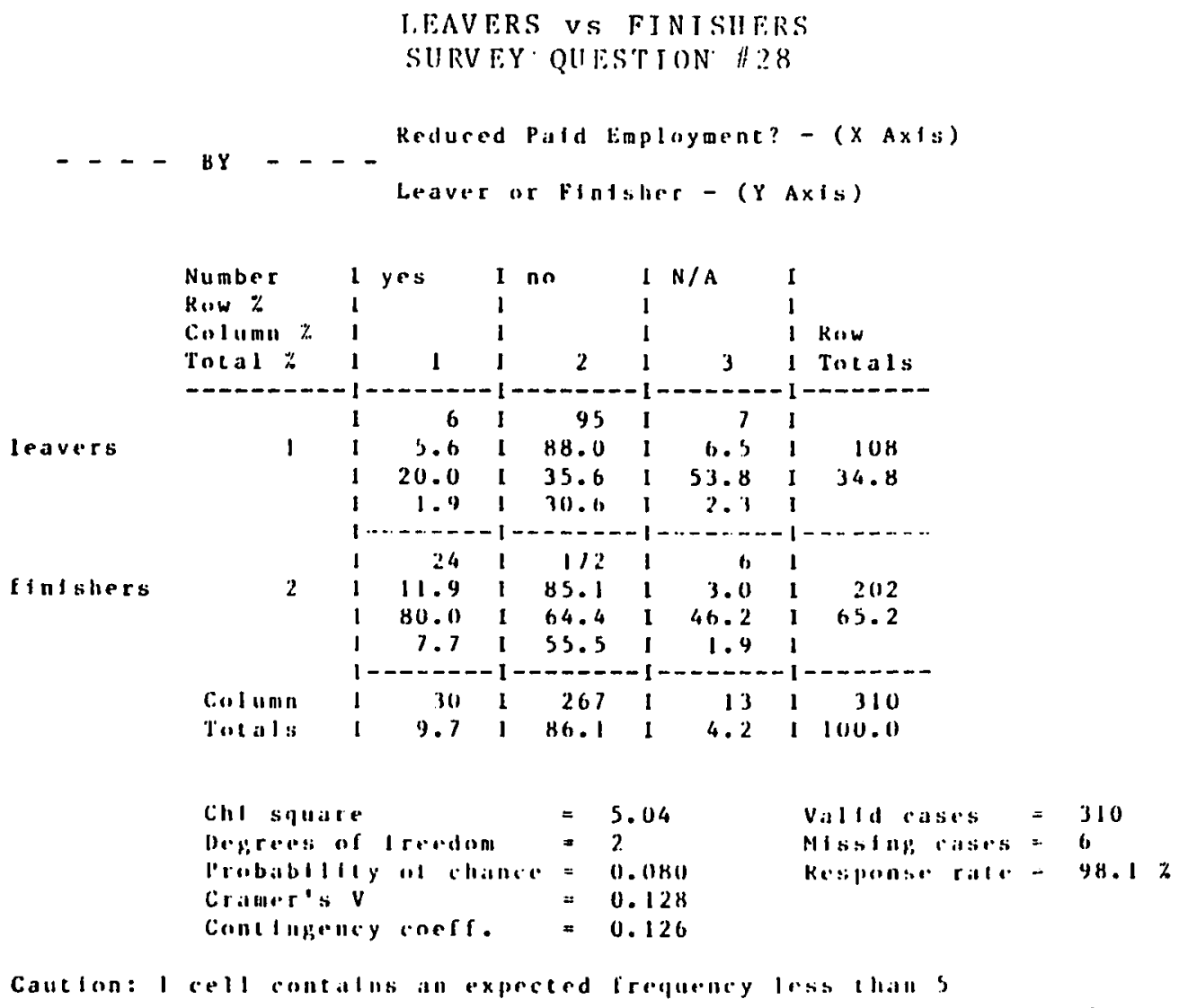

Caution: I cell contalus an expected frequelucy lass thalls 


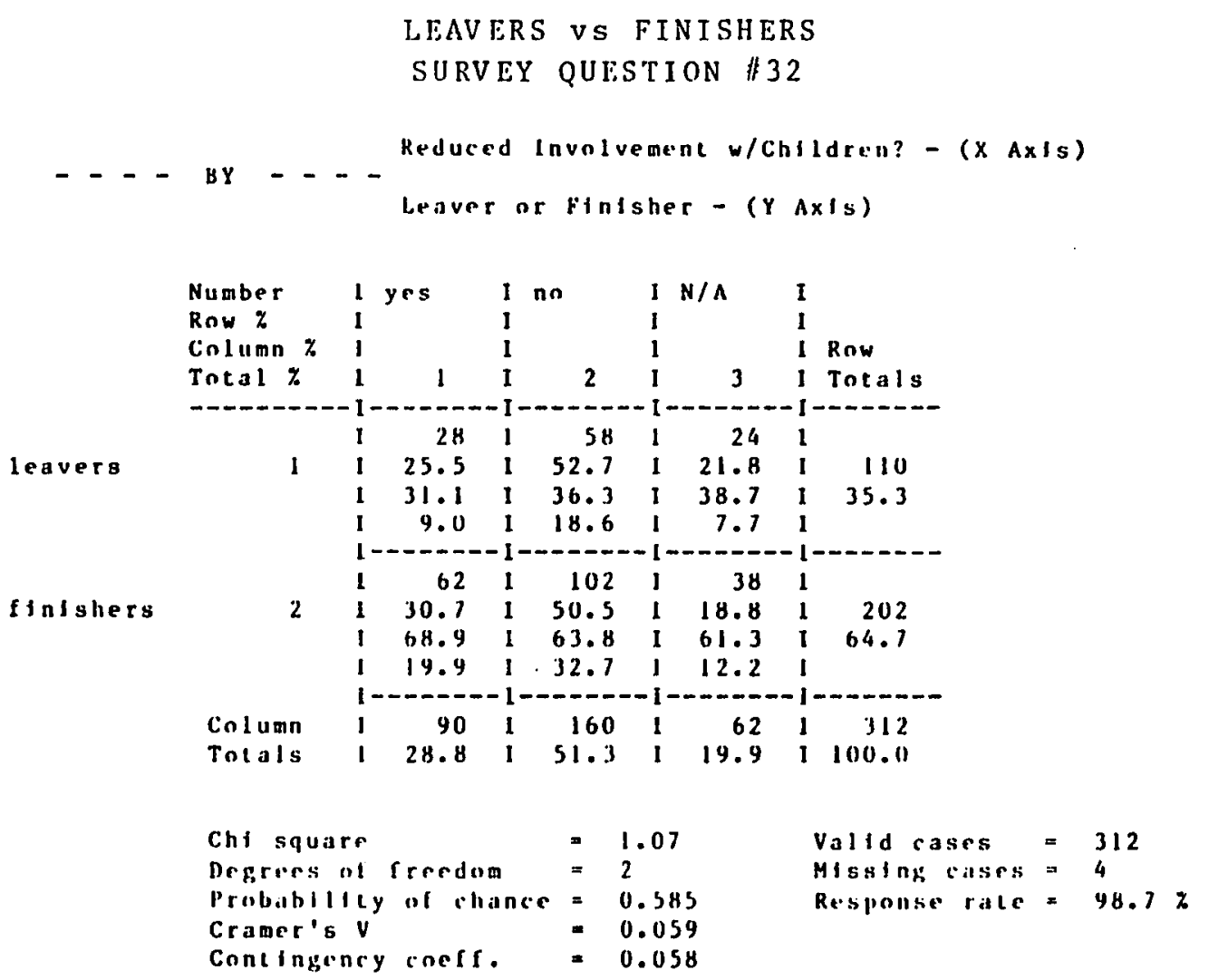




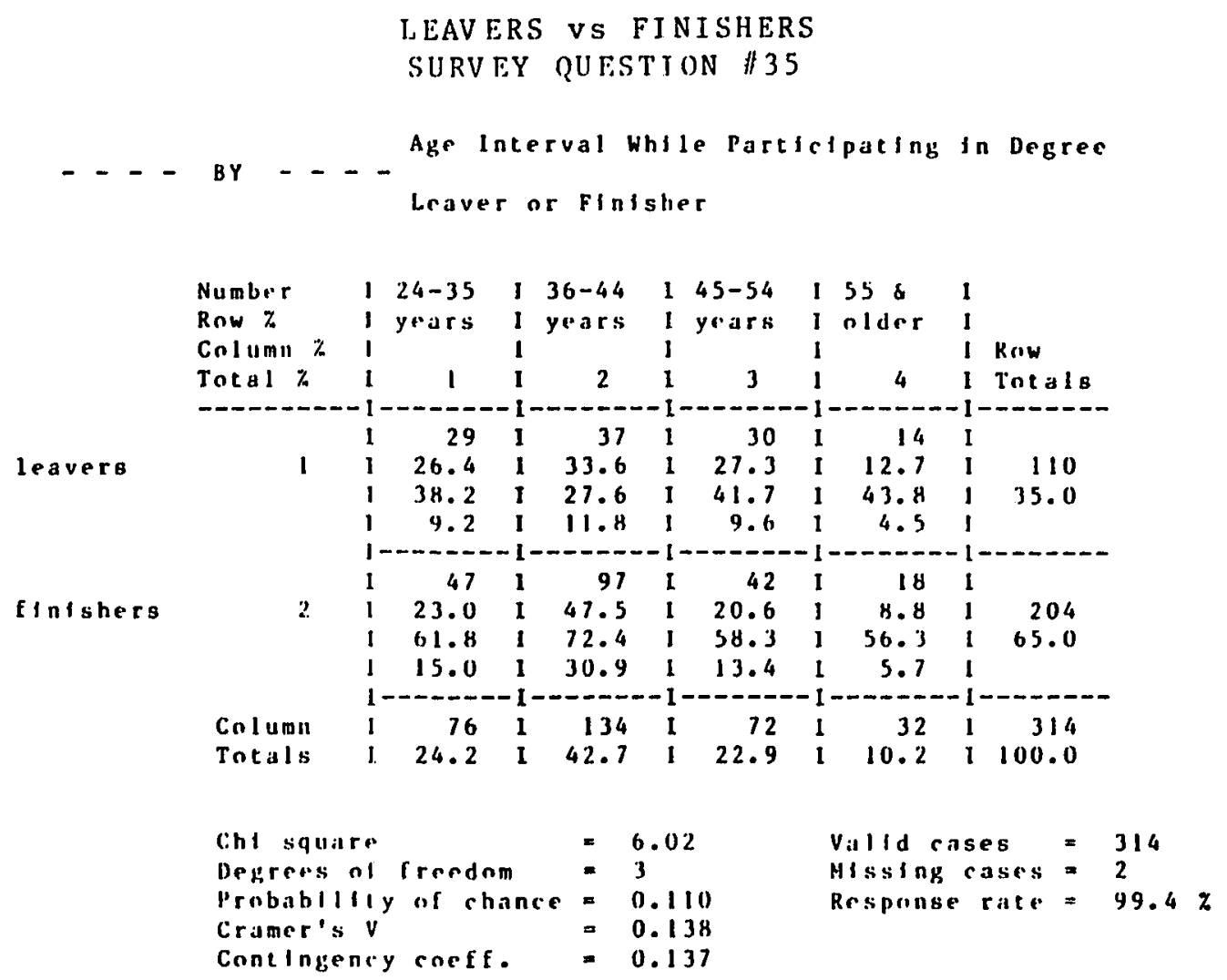




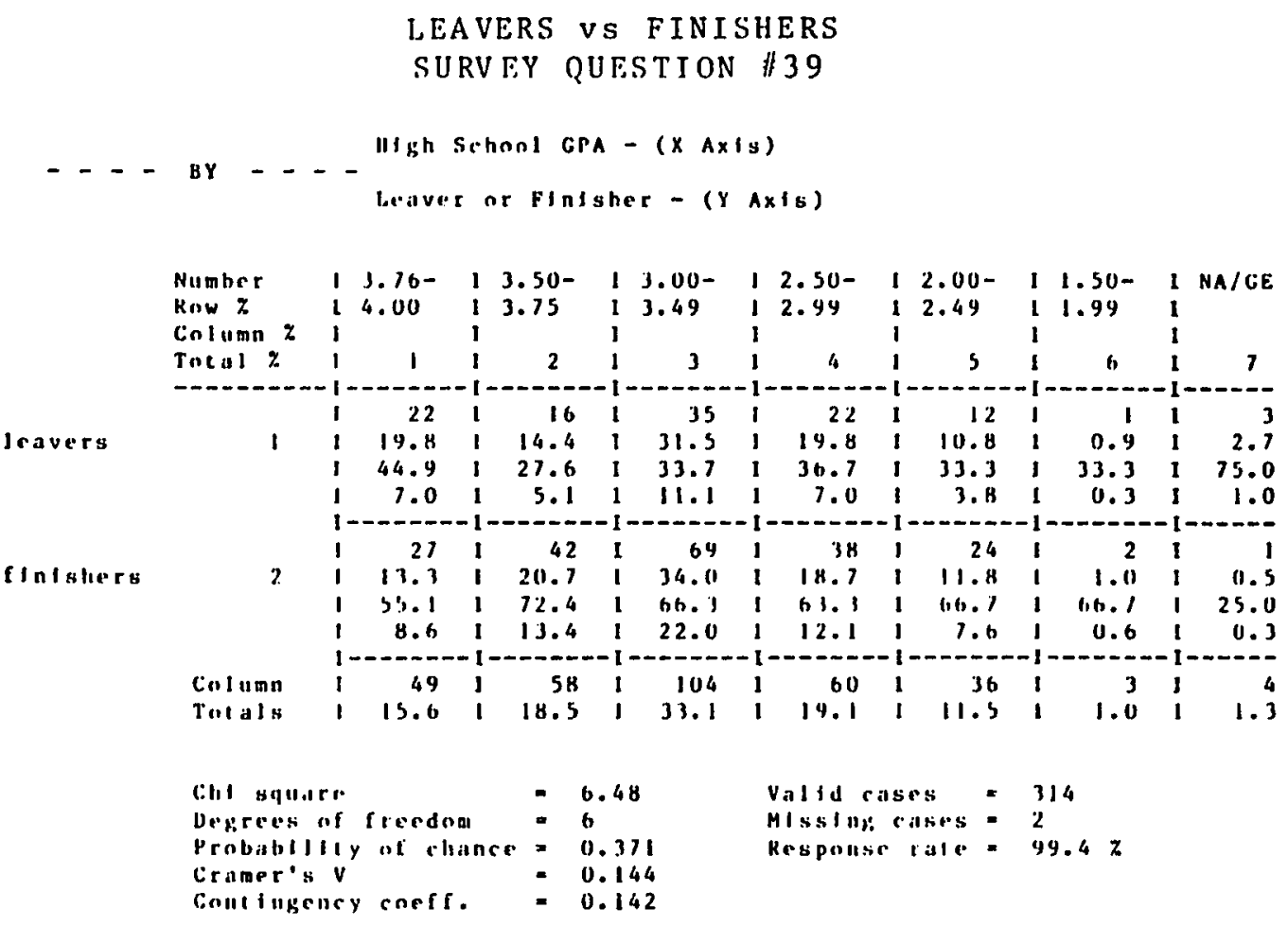

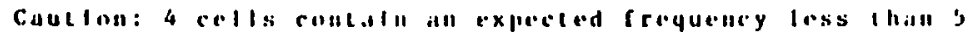




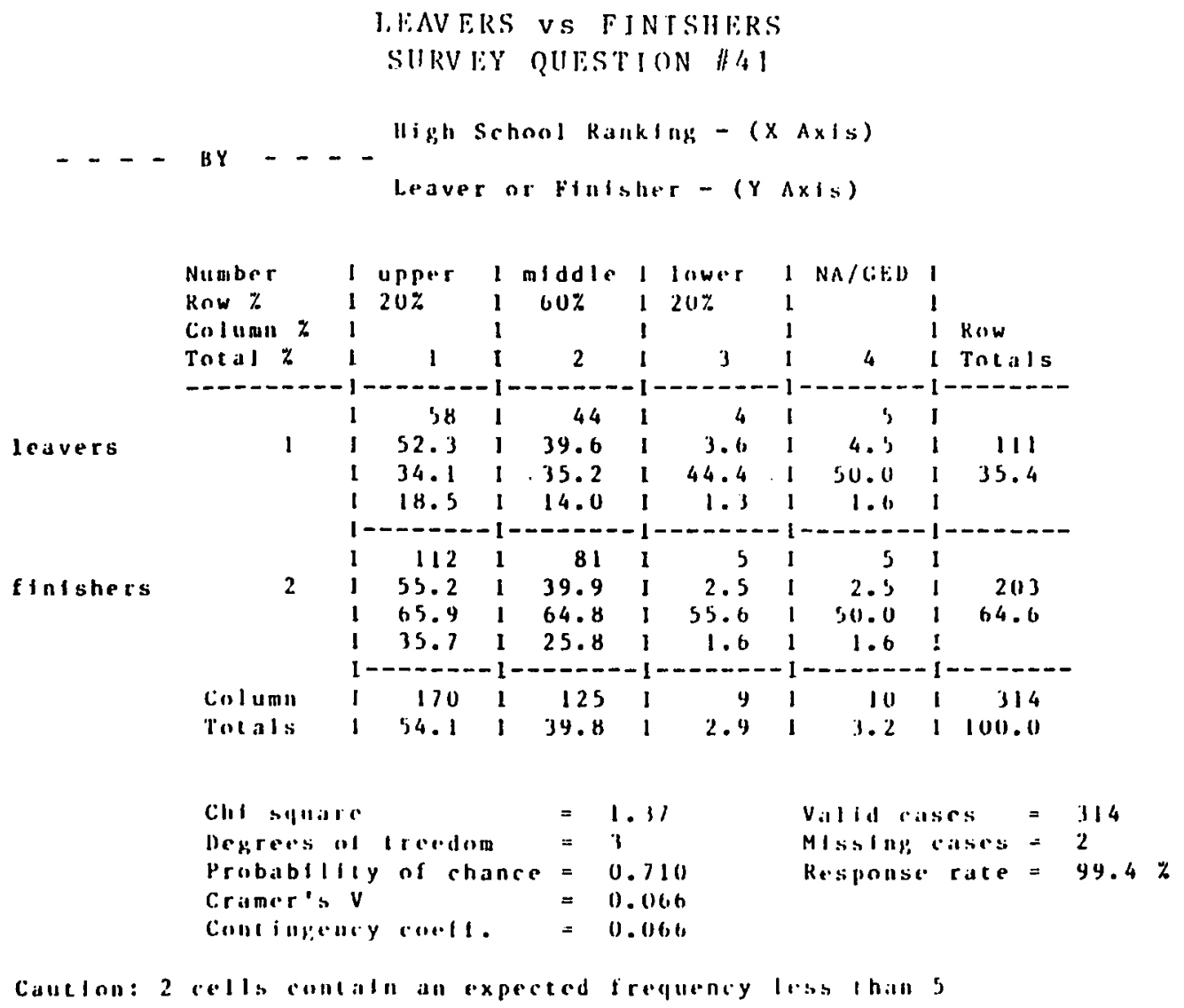

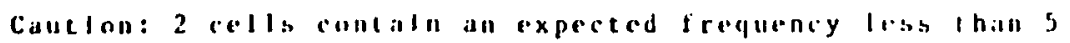




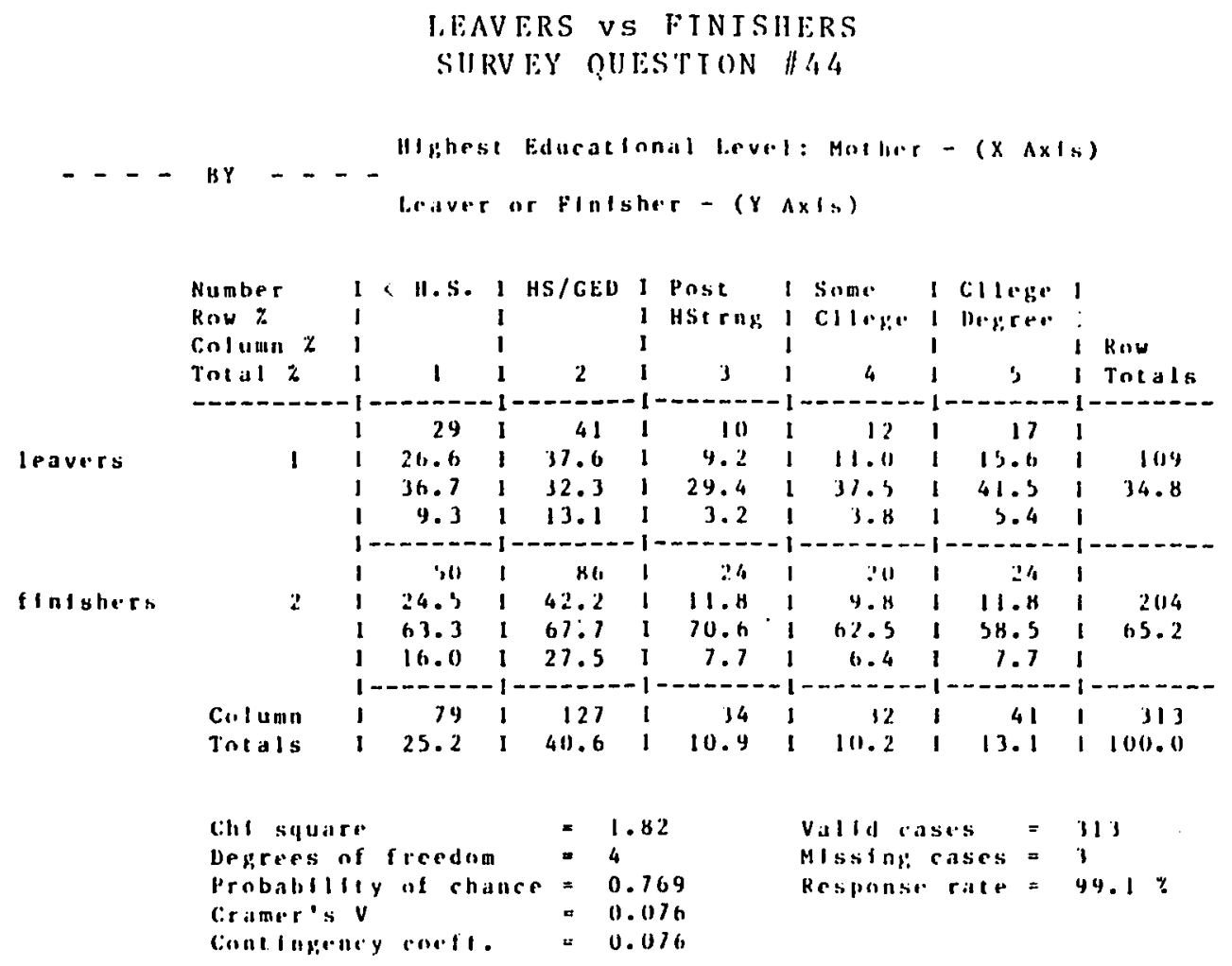




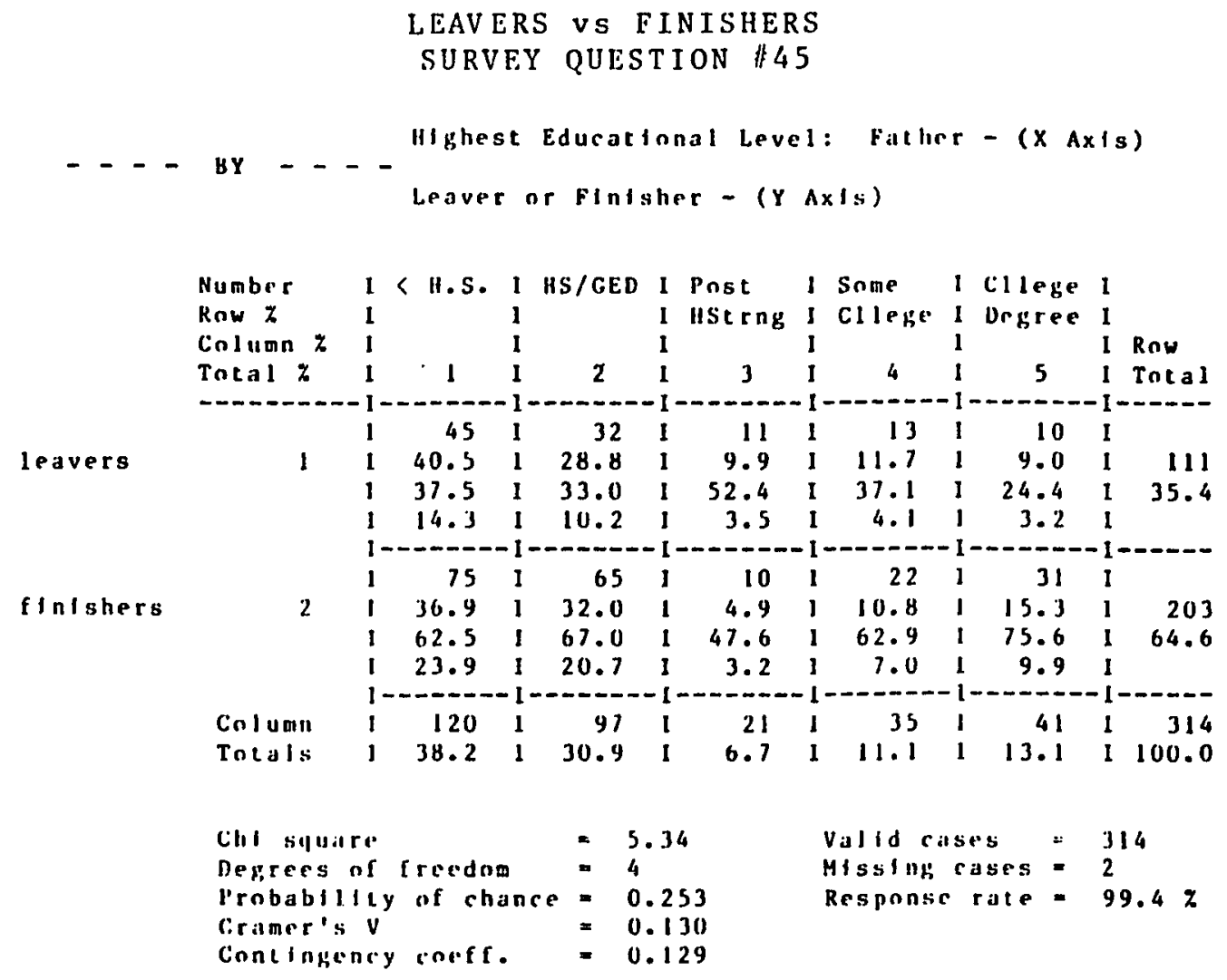




\section{EAVERS VS FINISHERS} SURVEY QUESTION \#46

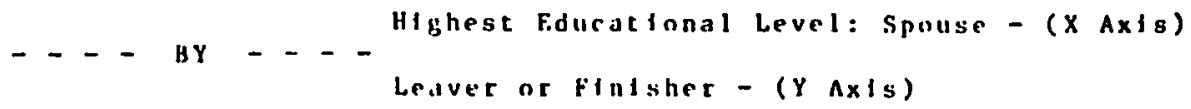

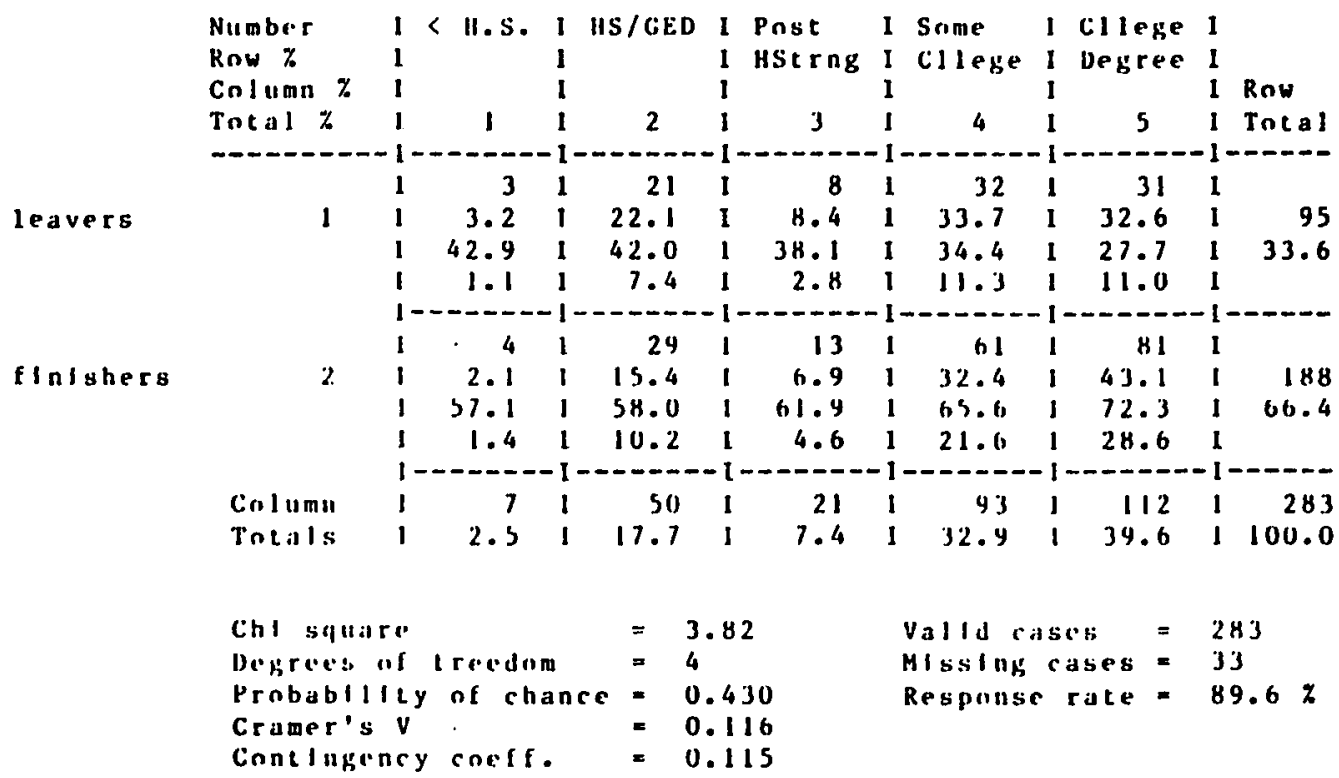

Caution: 2 cells contain an expected frequency less than 5 


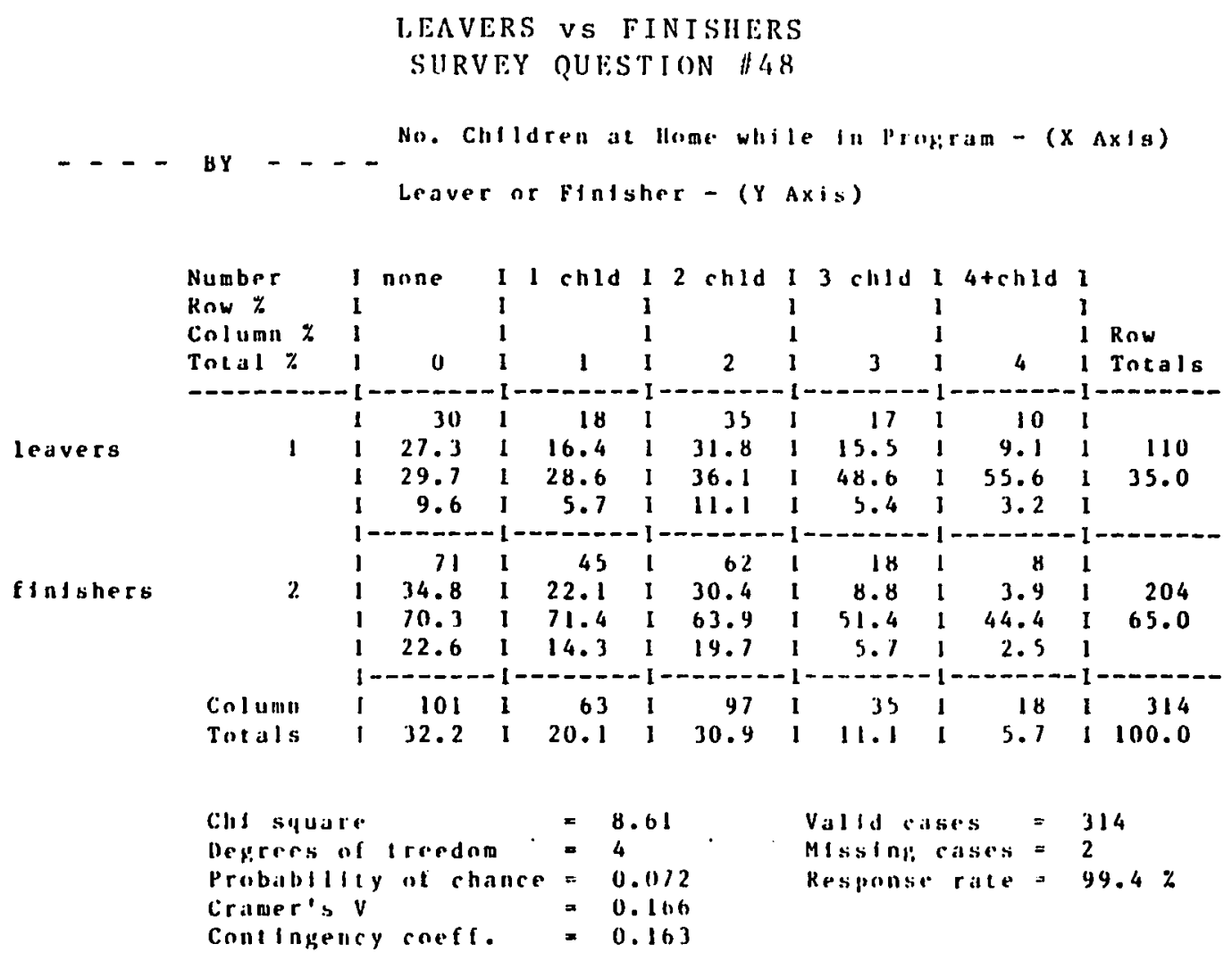




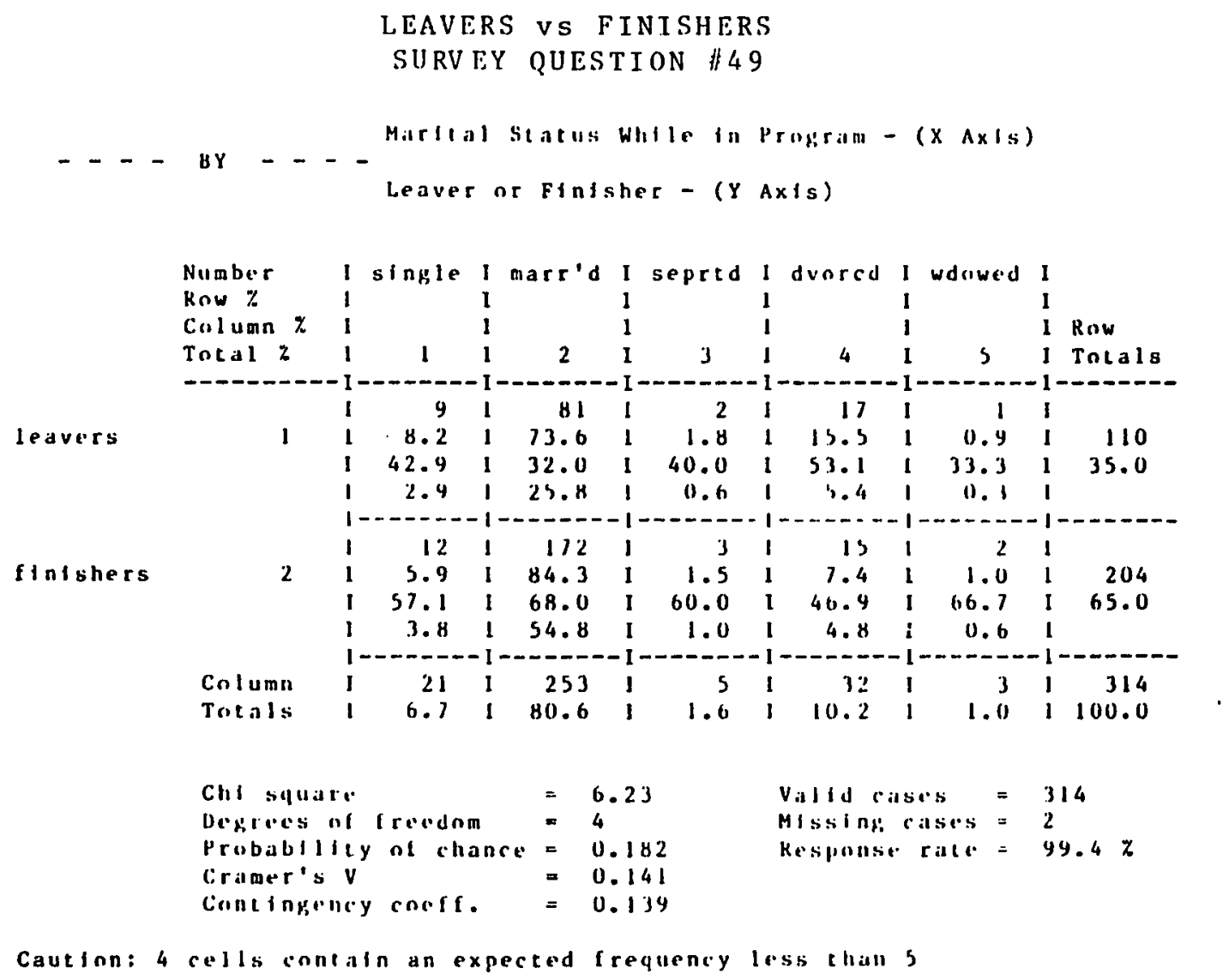




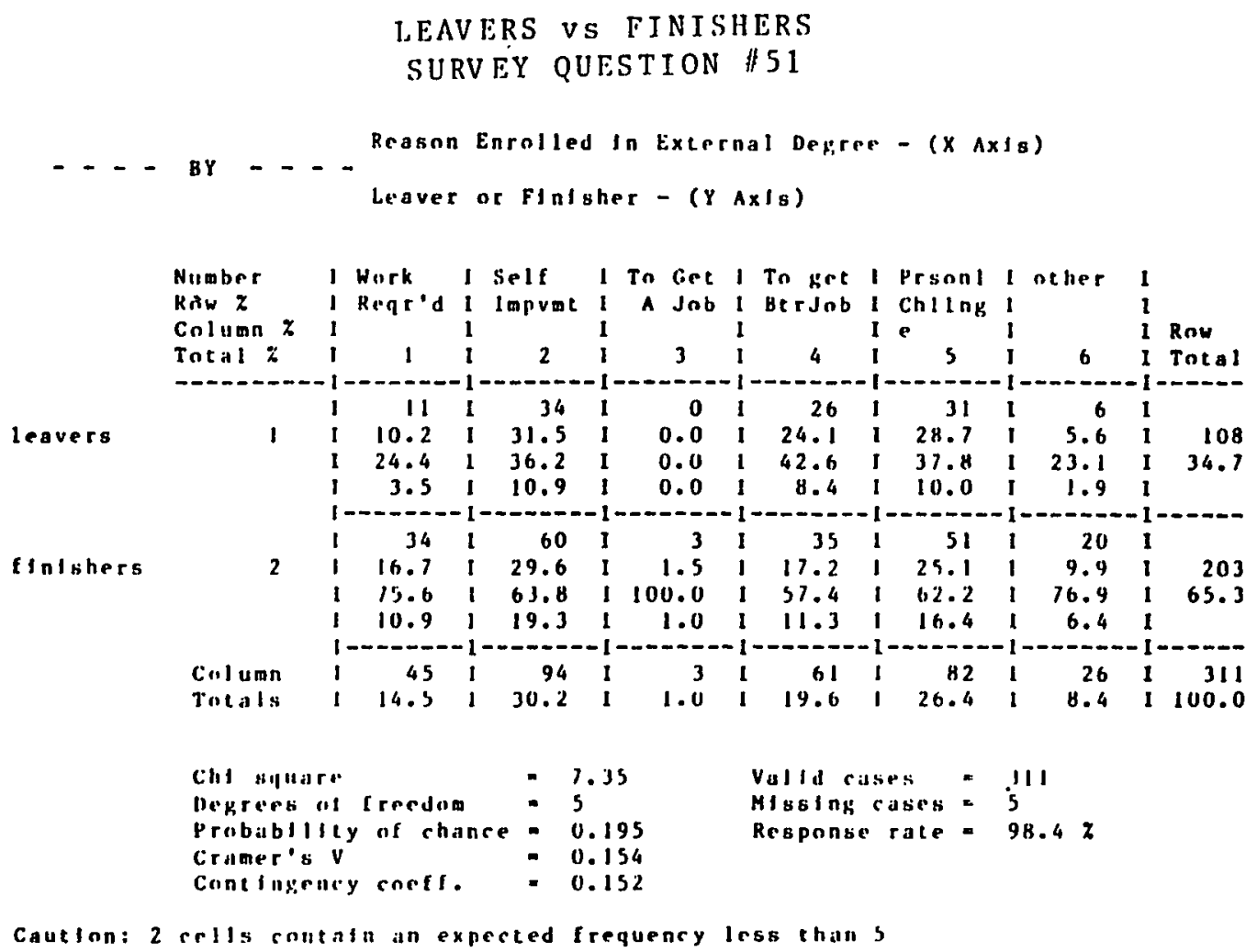

Caution: 2 crils contatin an expected frequency less thall $b$ 


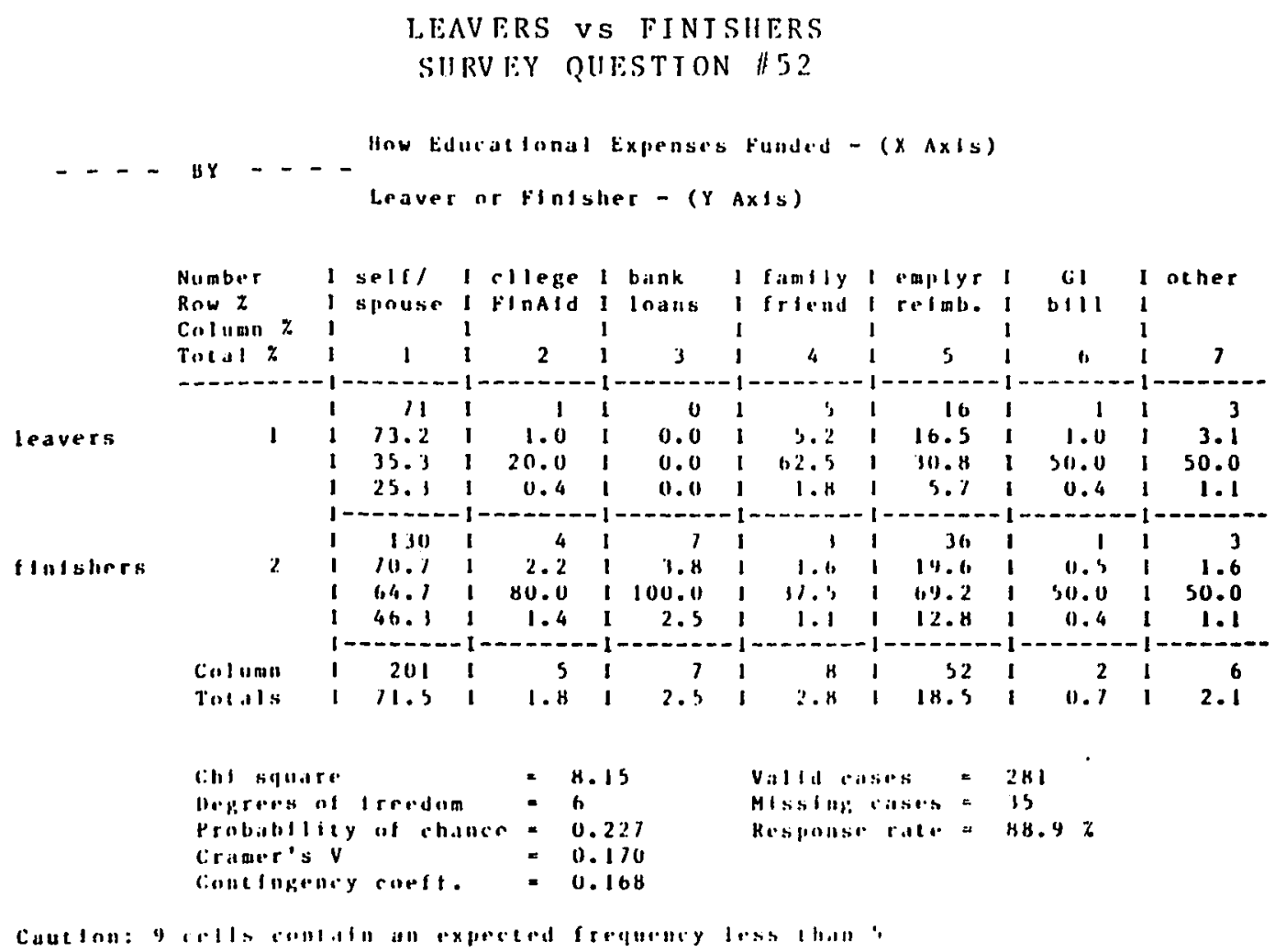




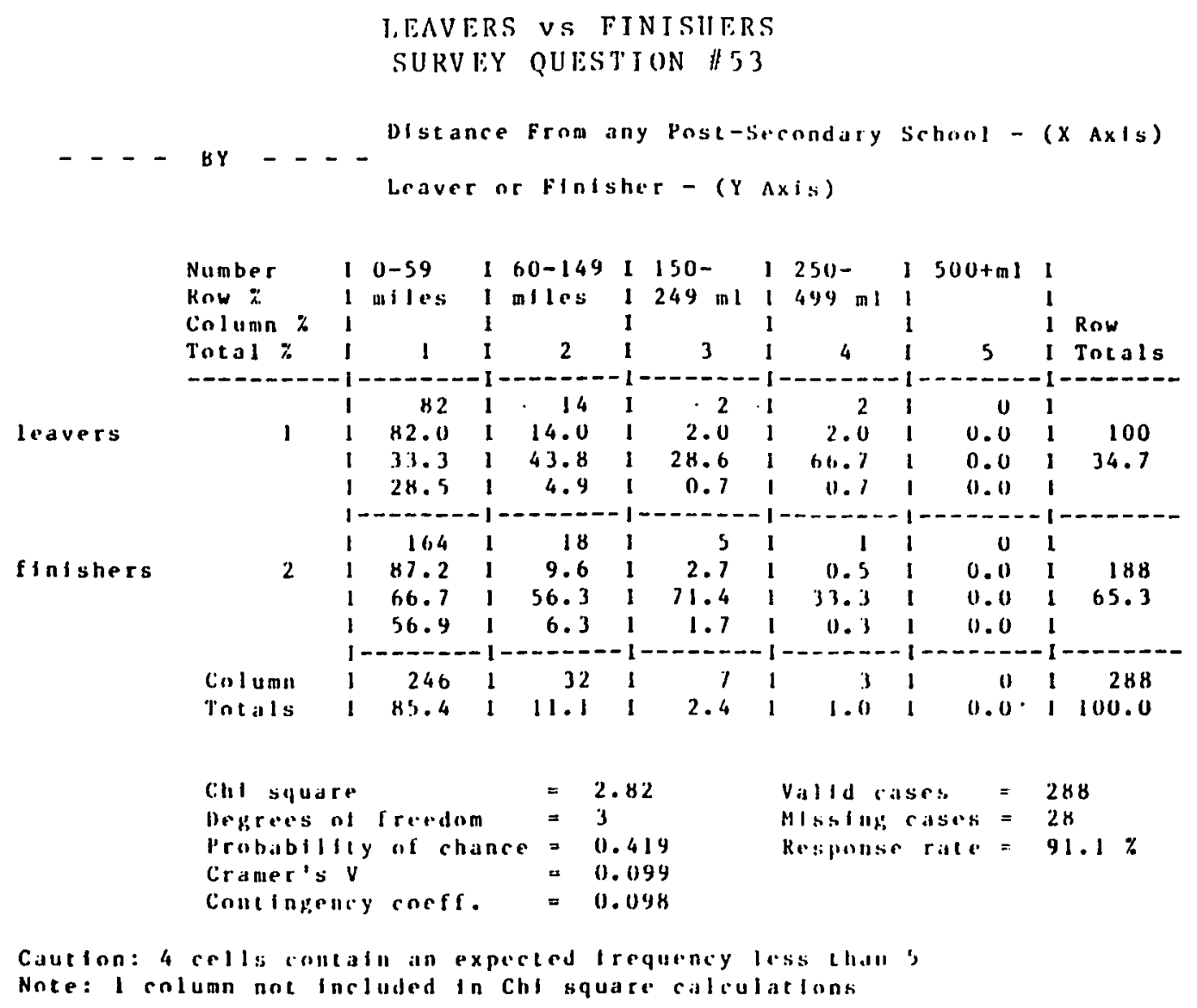




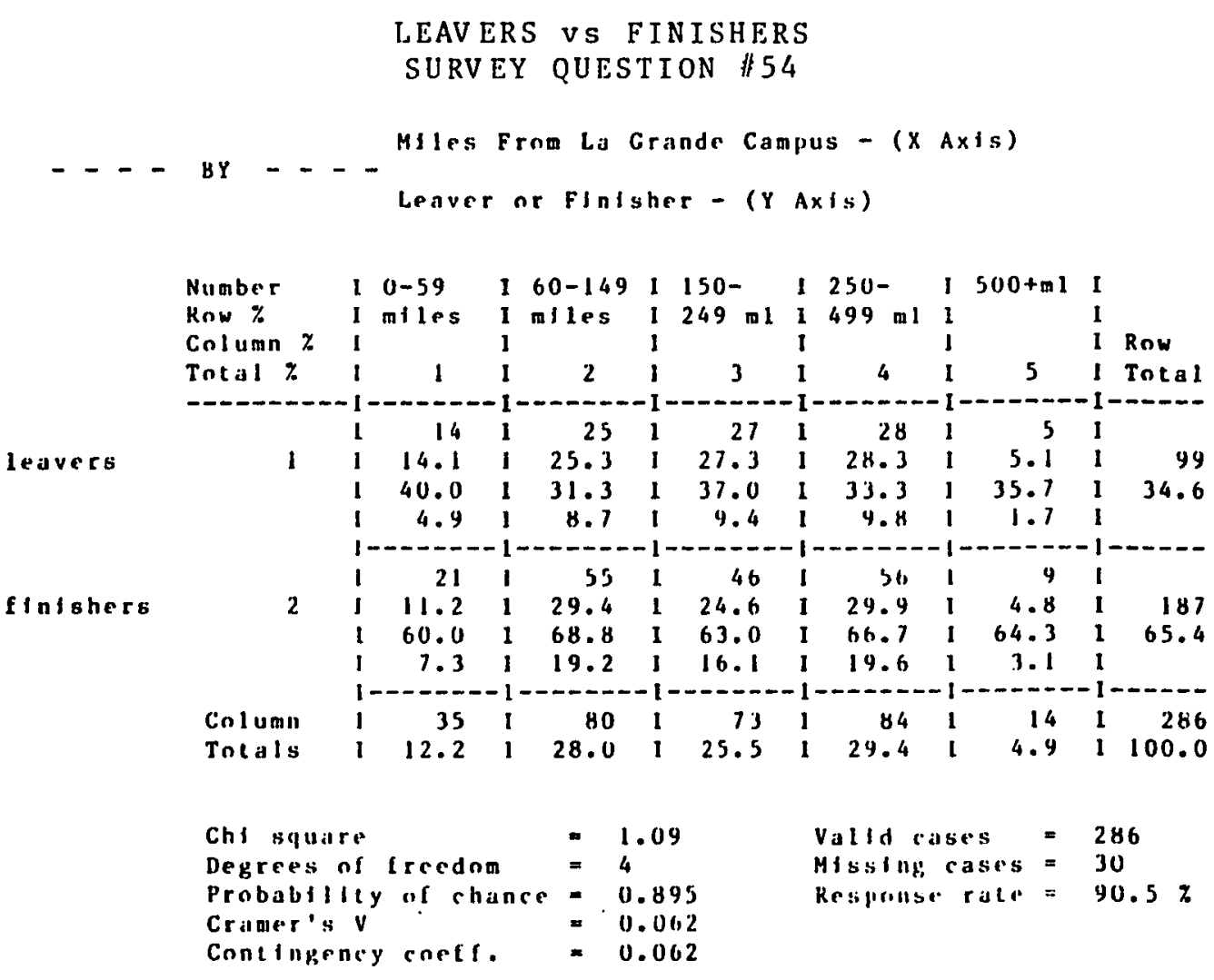

Cautinn: 1 cell contalns an expected frequency less thall 5 


\section{LEAVERS VS FINISHERS \\ SURVEY QUESTION \#55}

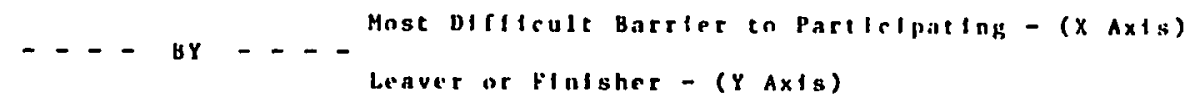

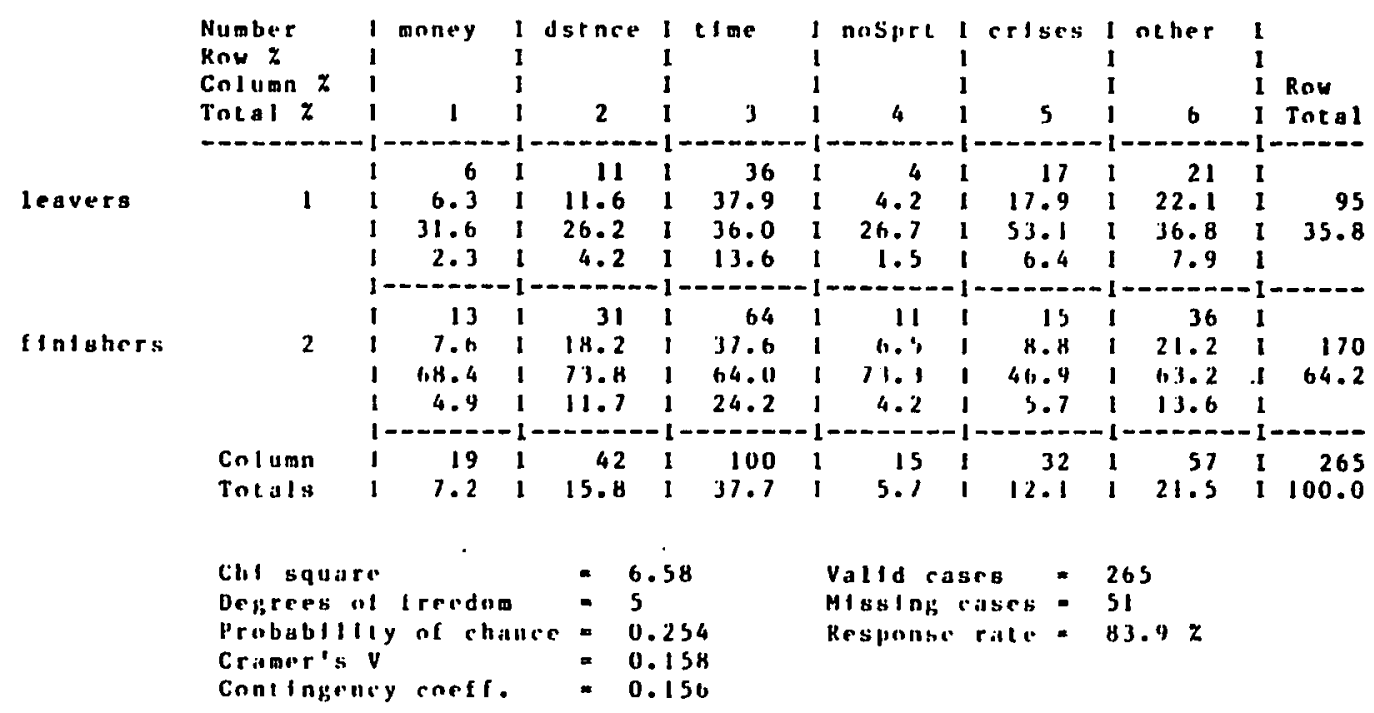




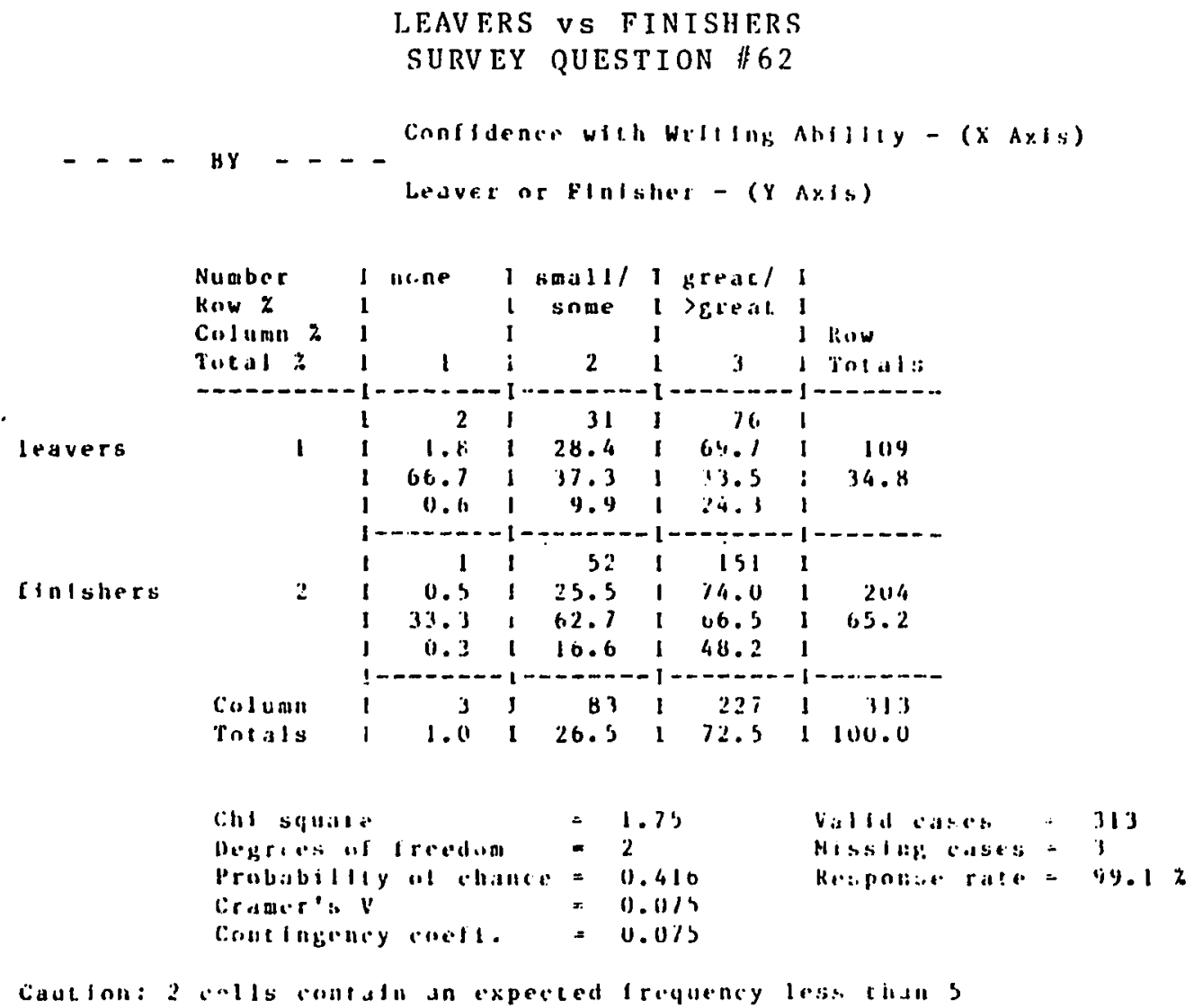




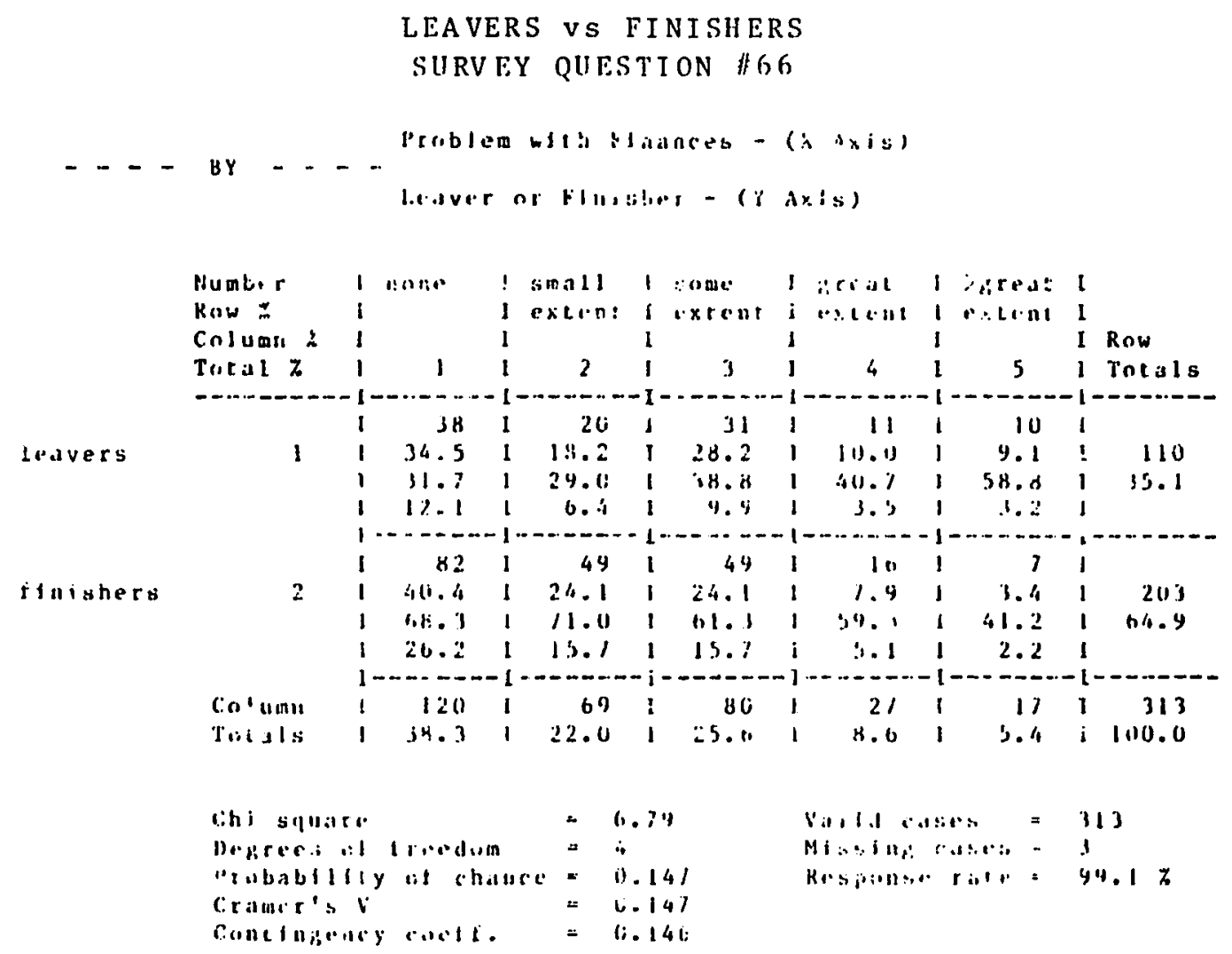




\section{LEAVERS VS FINISHERS}

SURVEY QUESTION $\# 72$

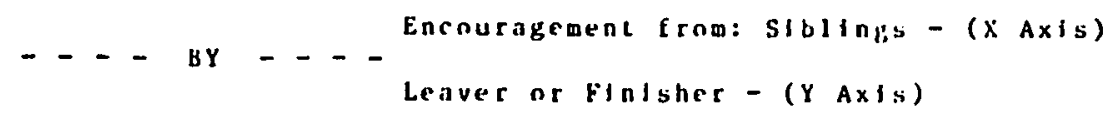

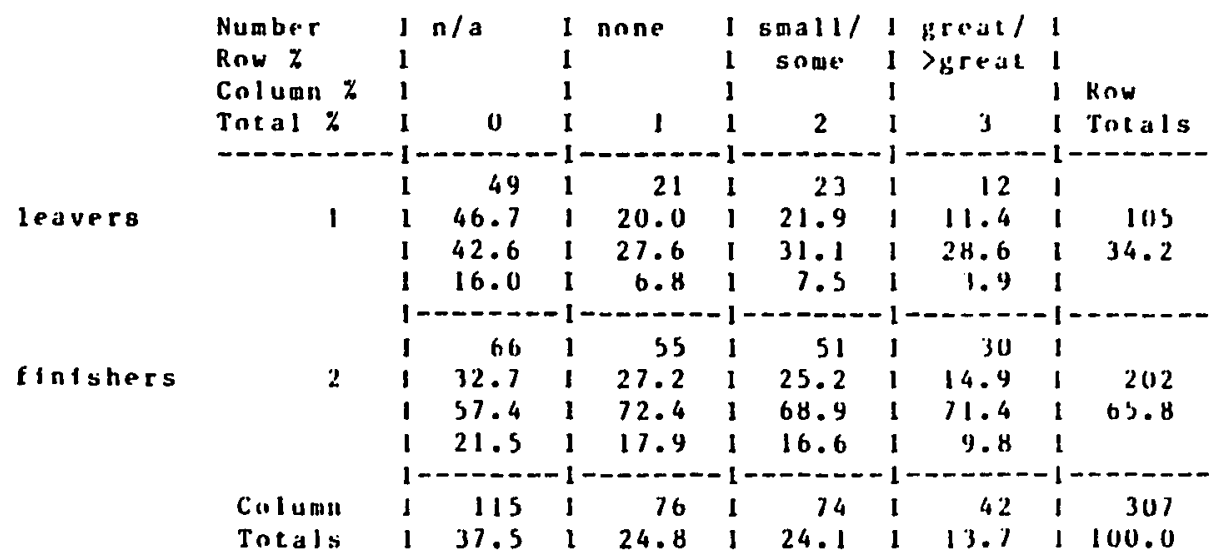

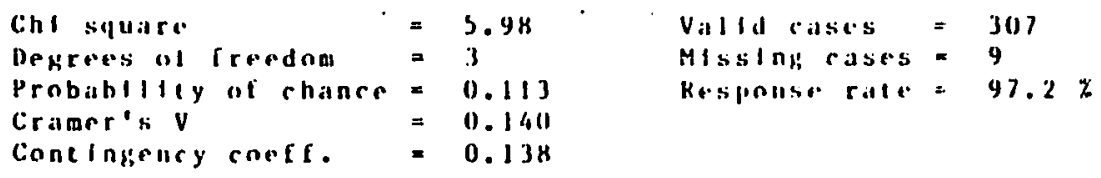


A COMPARISON BETWEEN LEAVERS AND FINISHERS ON STUDENT DATA P.ASE INTEORMATION: SEX

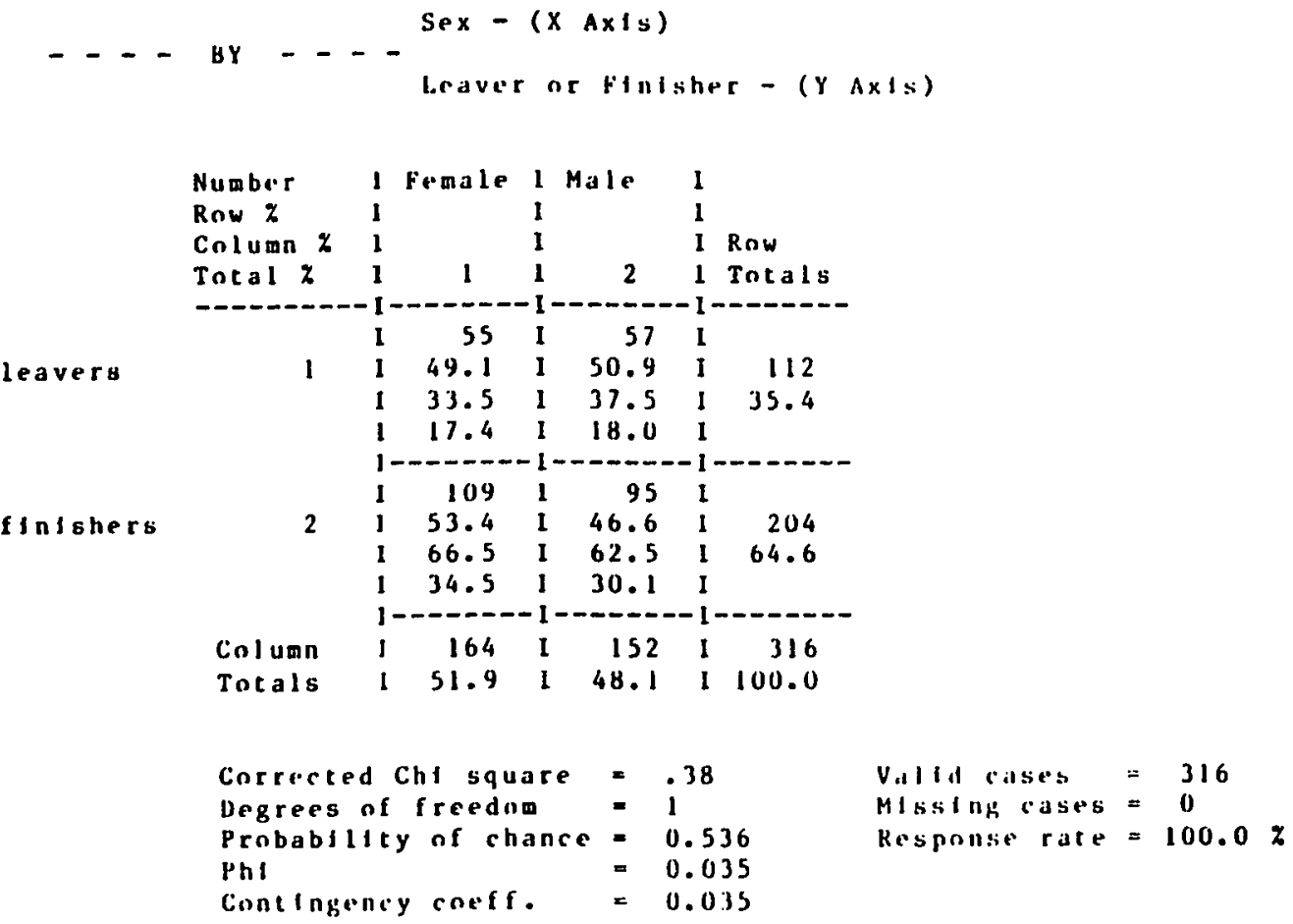




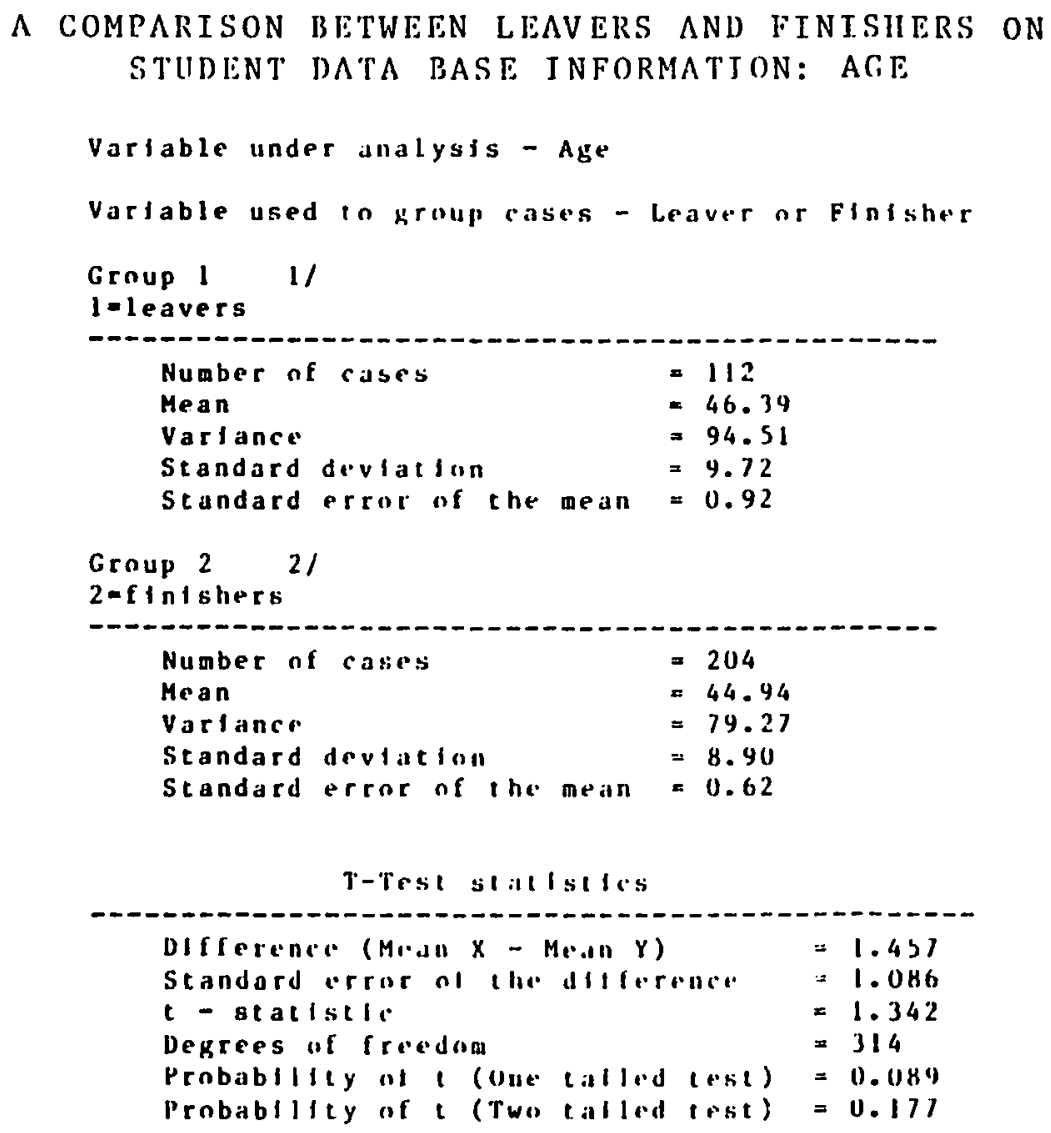




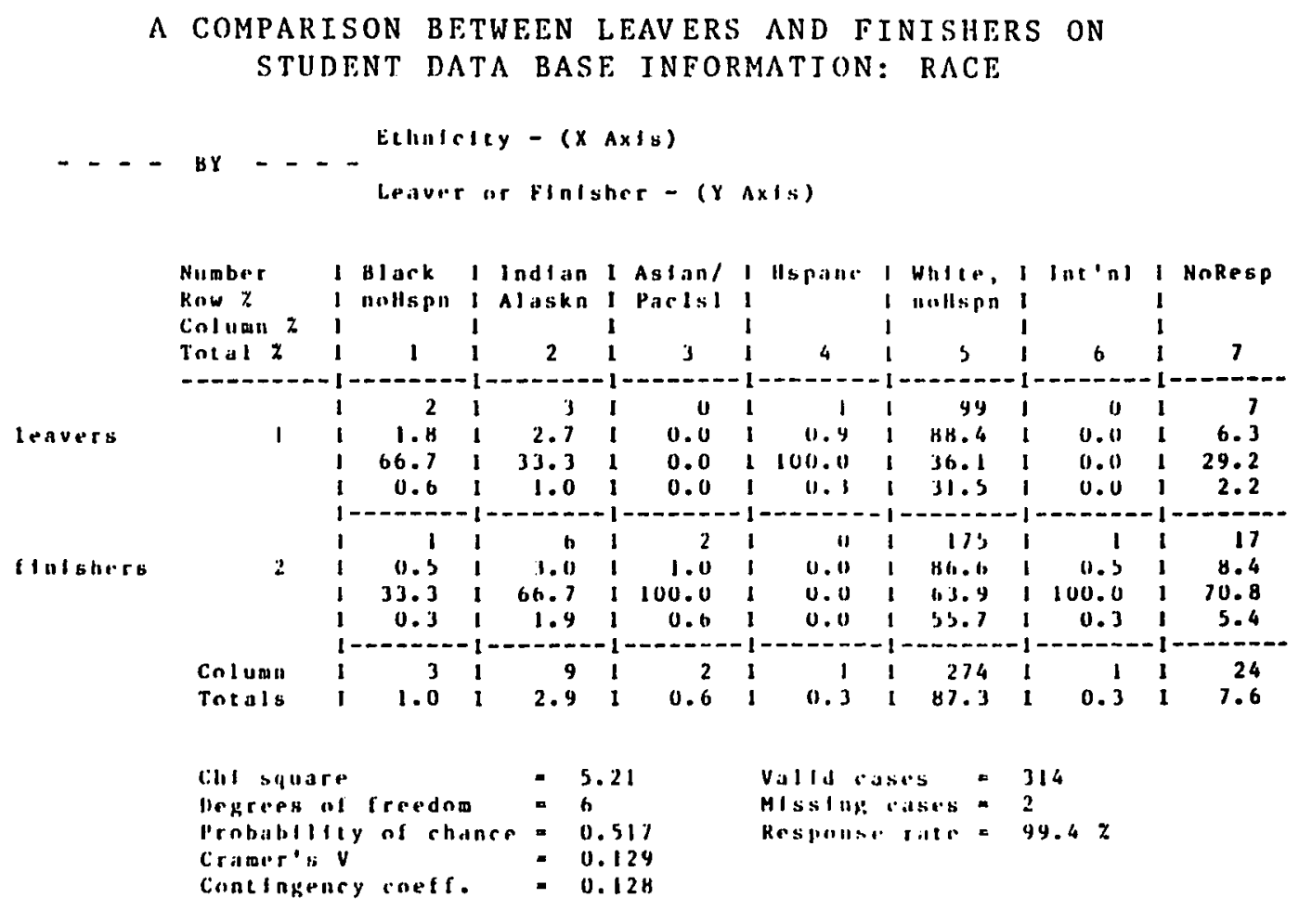

Caution: y cells contain an pxpected frequency loss thins 


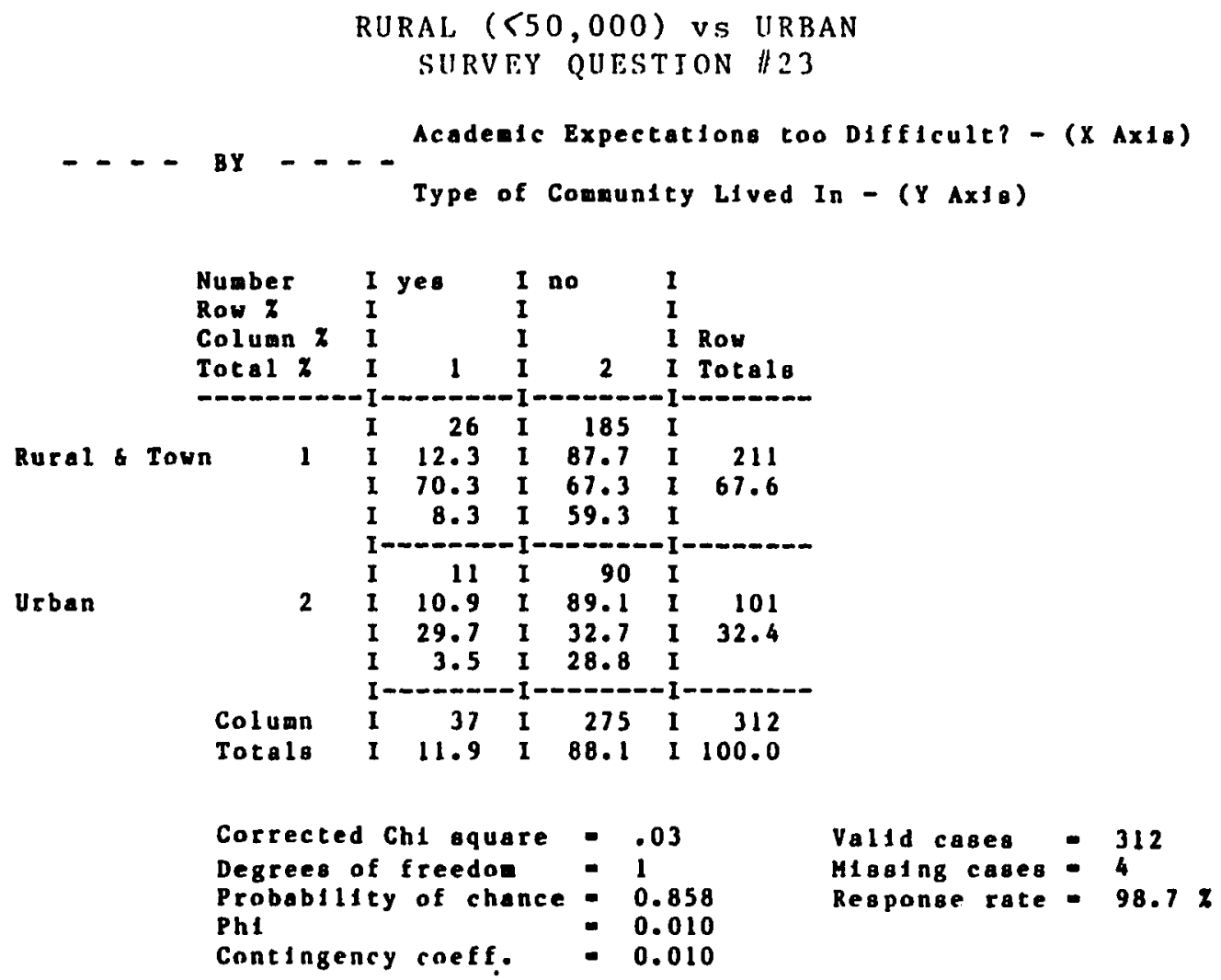




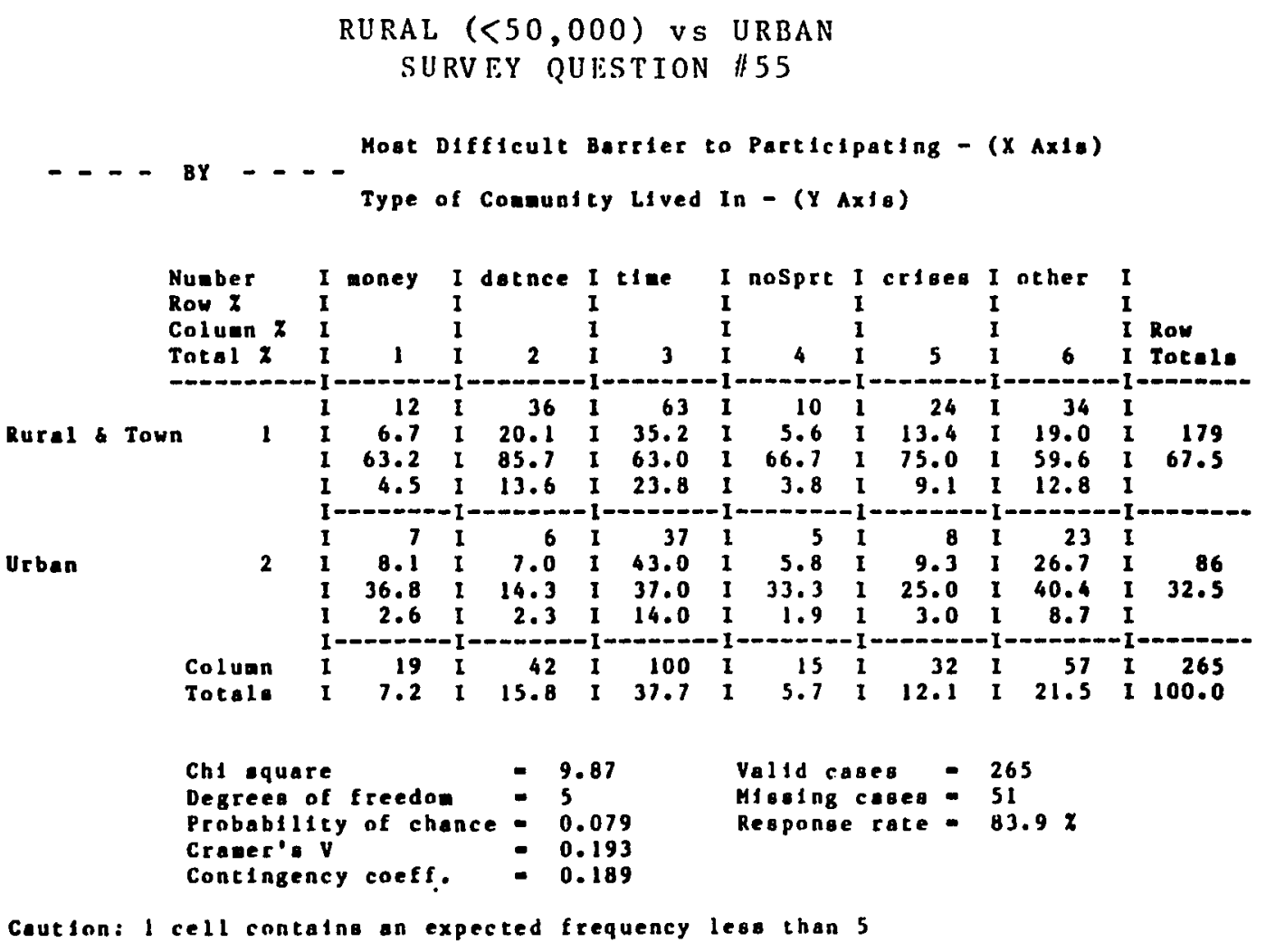




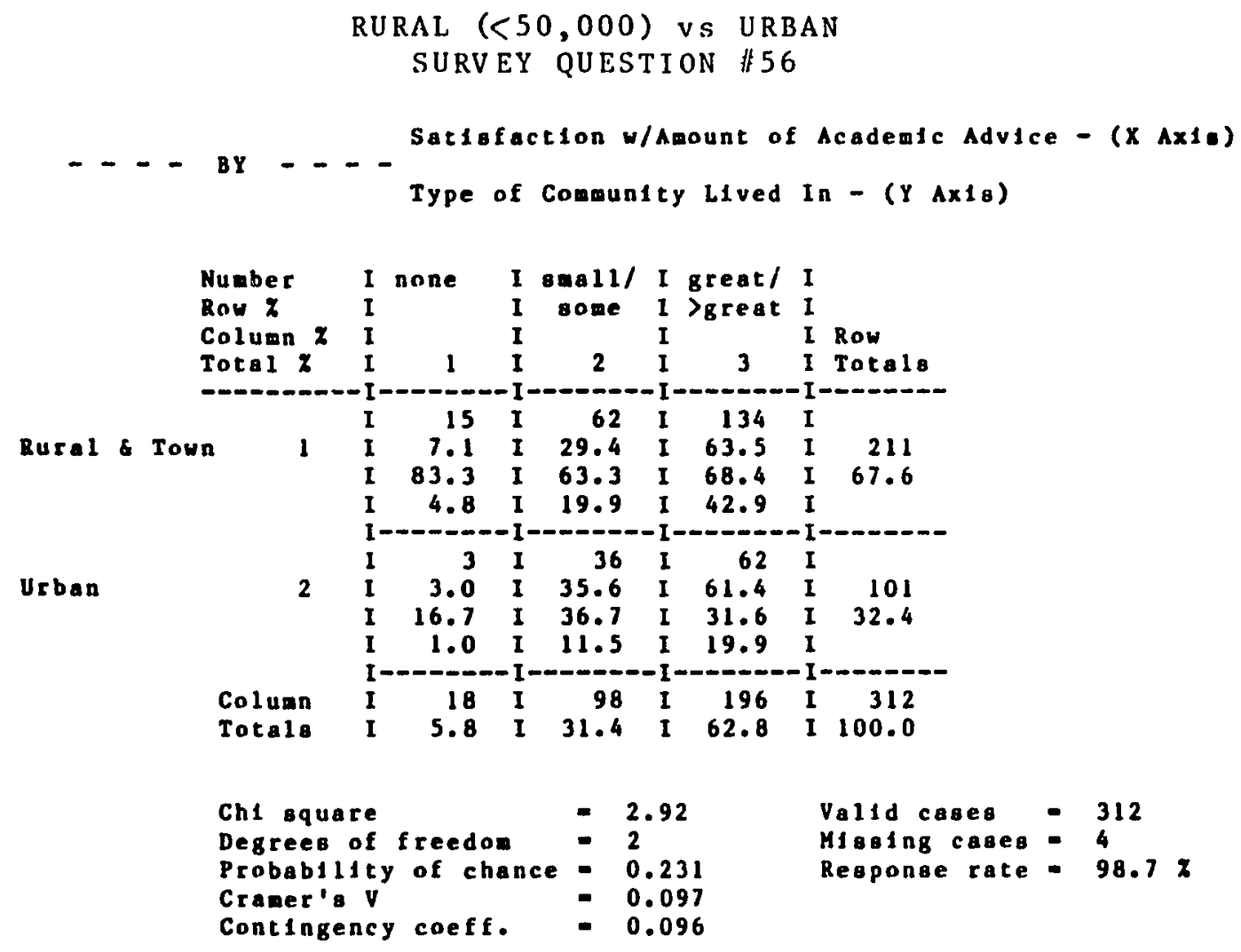




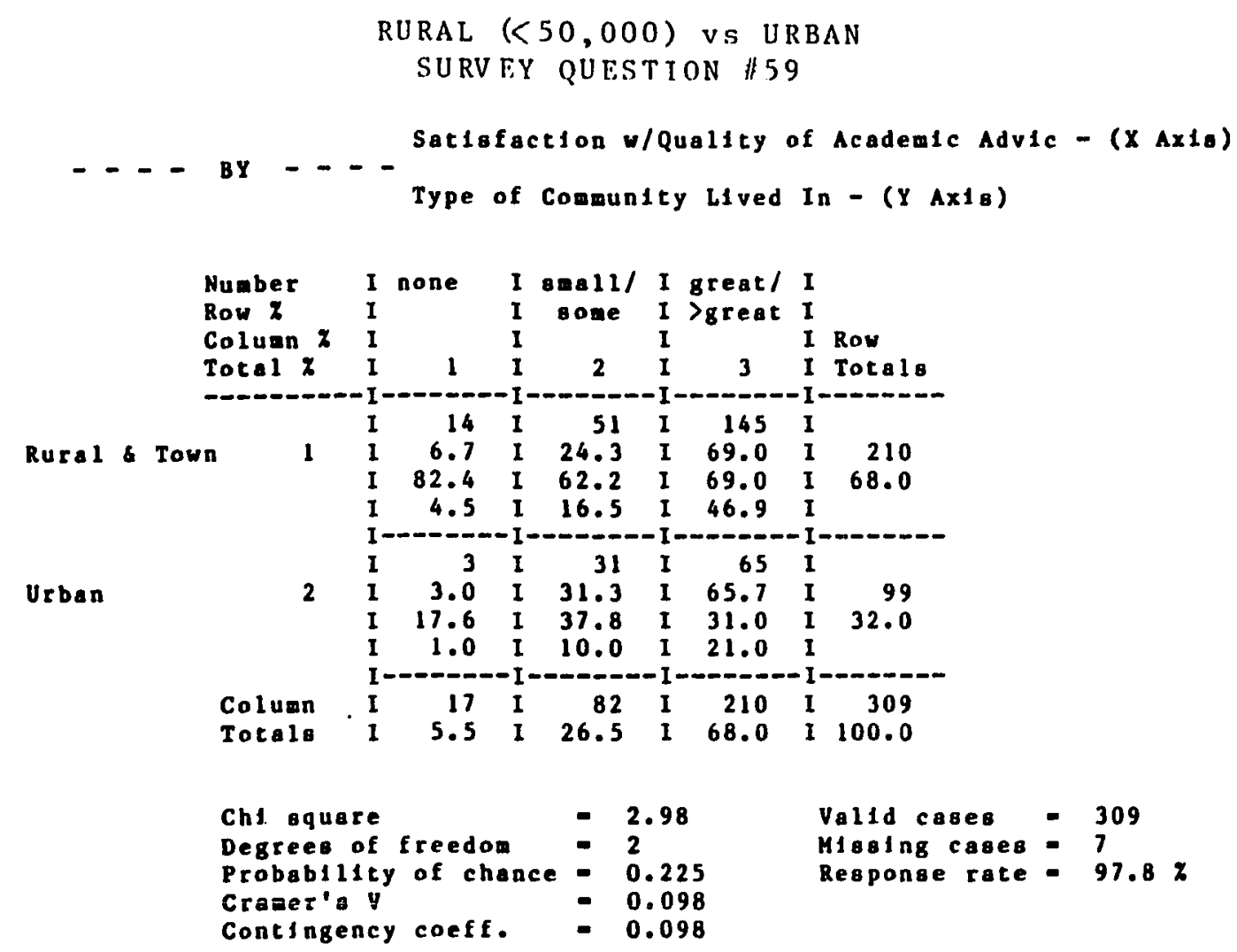


RURAL $(<50,000)$ vs URBAN SURVEY .QUESTION . \#66

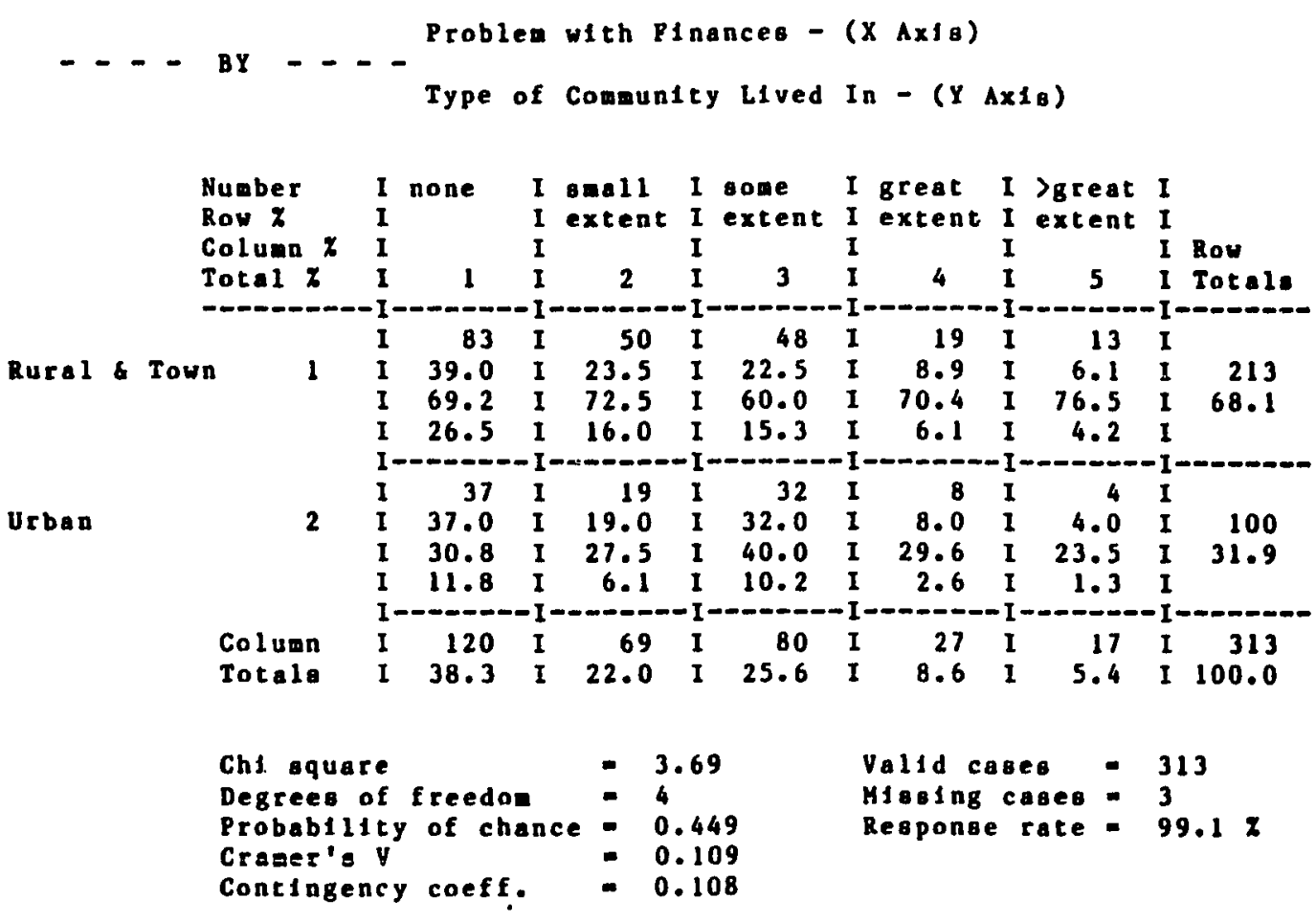




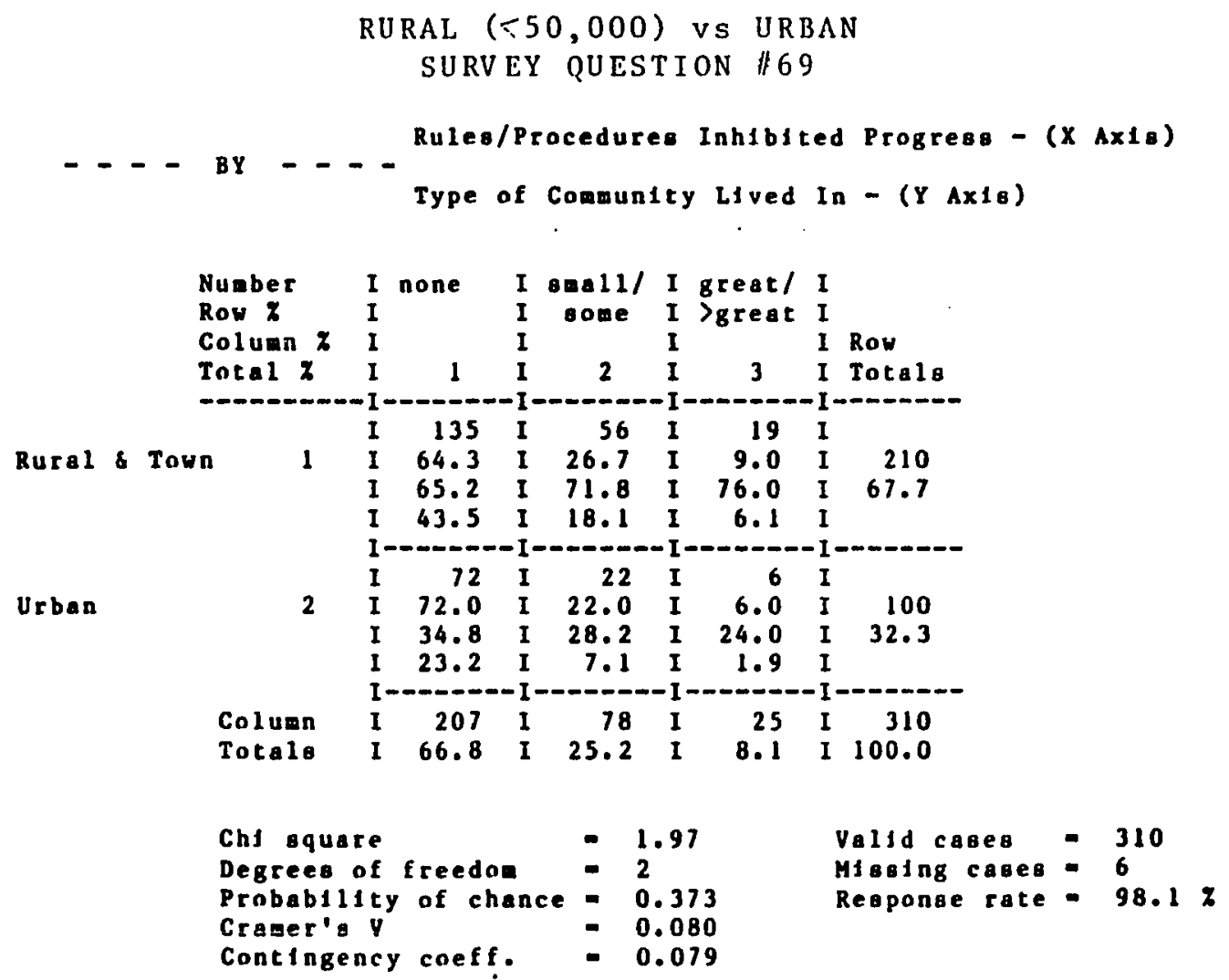


RURAL FARM VS TOWN/URBAN SURVEY QUESTION \#23

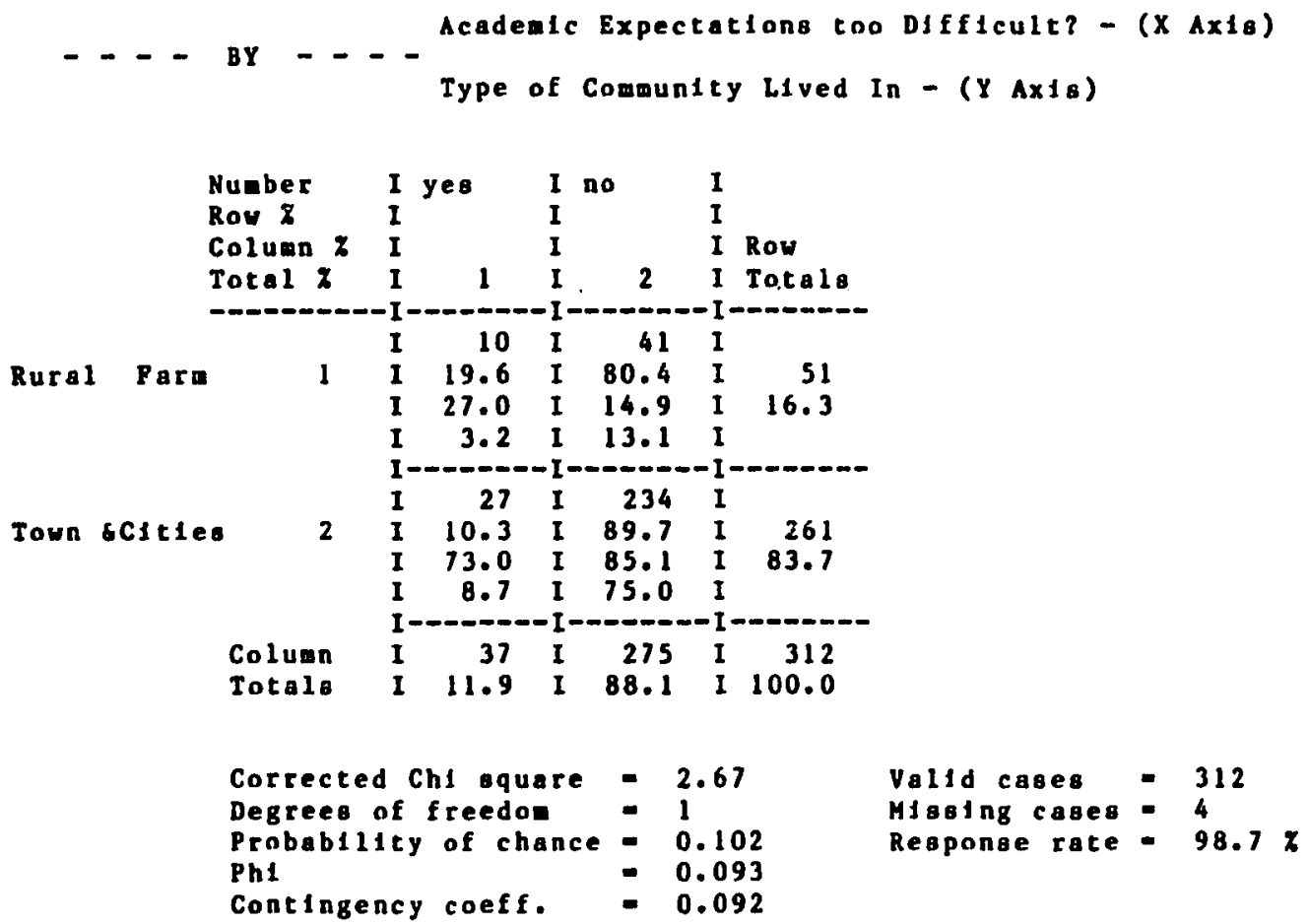


RURAL FARM VS TOWN/URBAN SURVEY QUESTION \#24

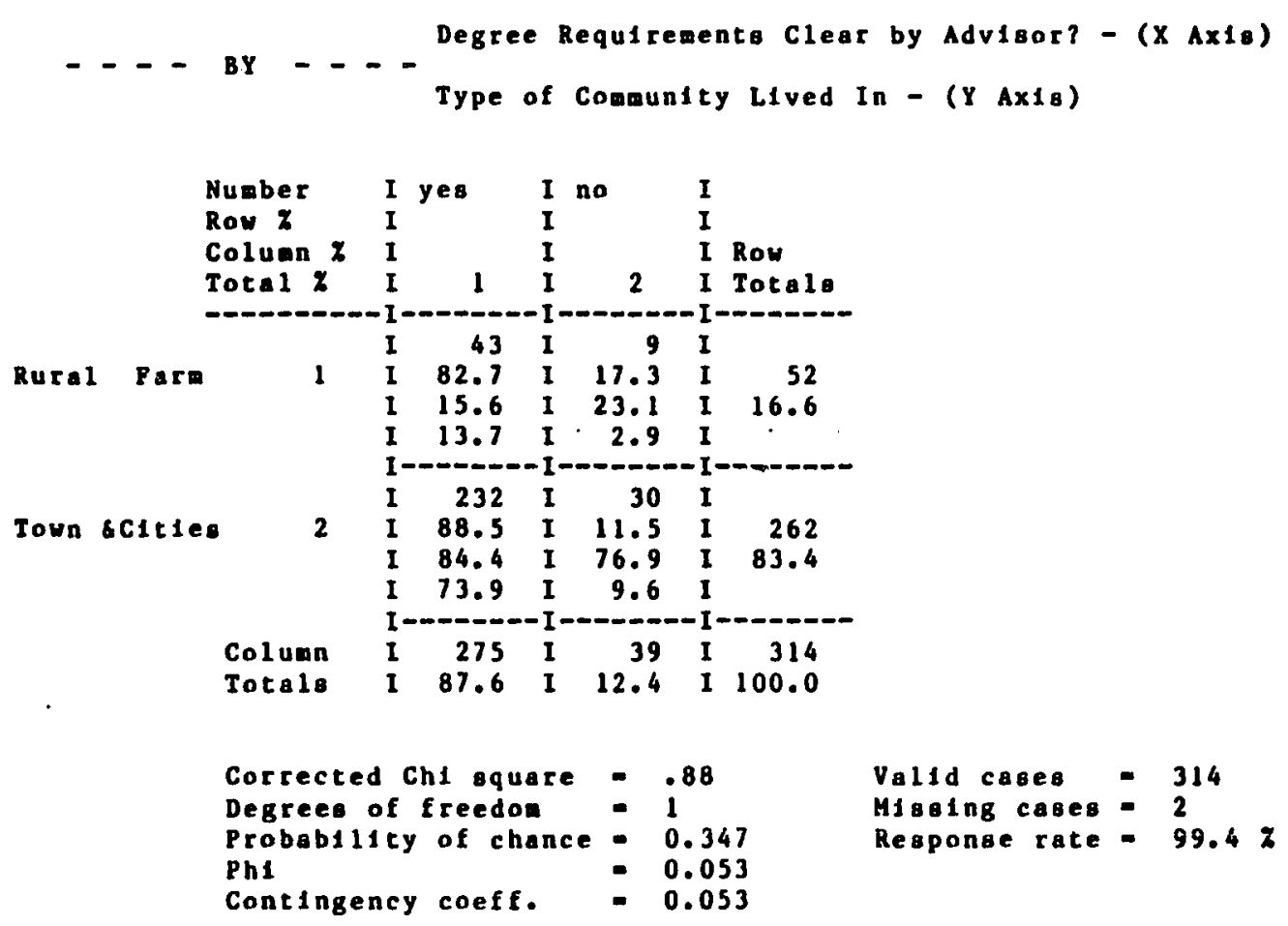


RURAL FARM VS TOWN/URBAN SURVEY QUESTION \#55

- - - BY - - - Hot Difficult Bartier to Participating $-(X A \times 10)$

Type of Comenity Lived In - ( $X \times 1=)$

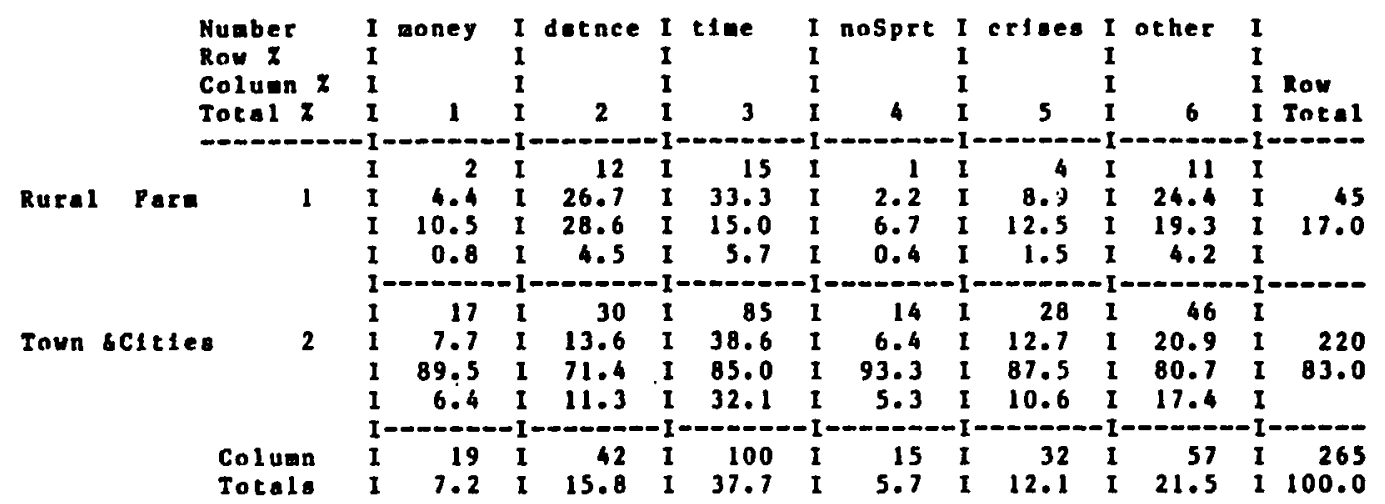

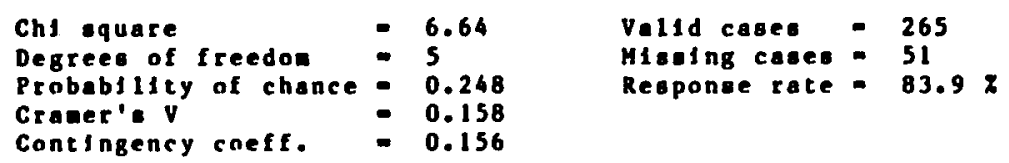

Caution: 2 celle contain an expected frequency lese than 5 


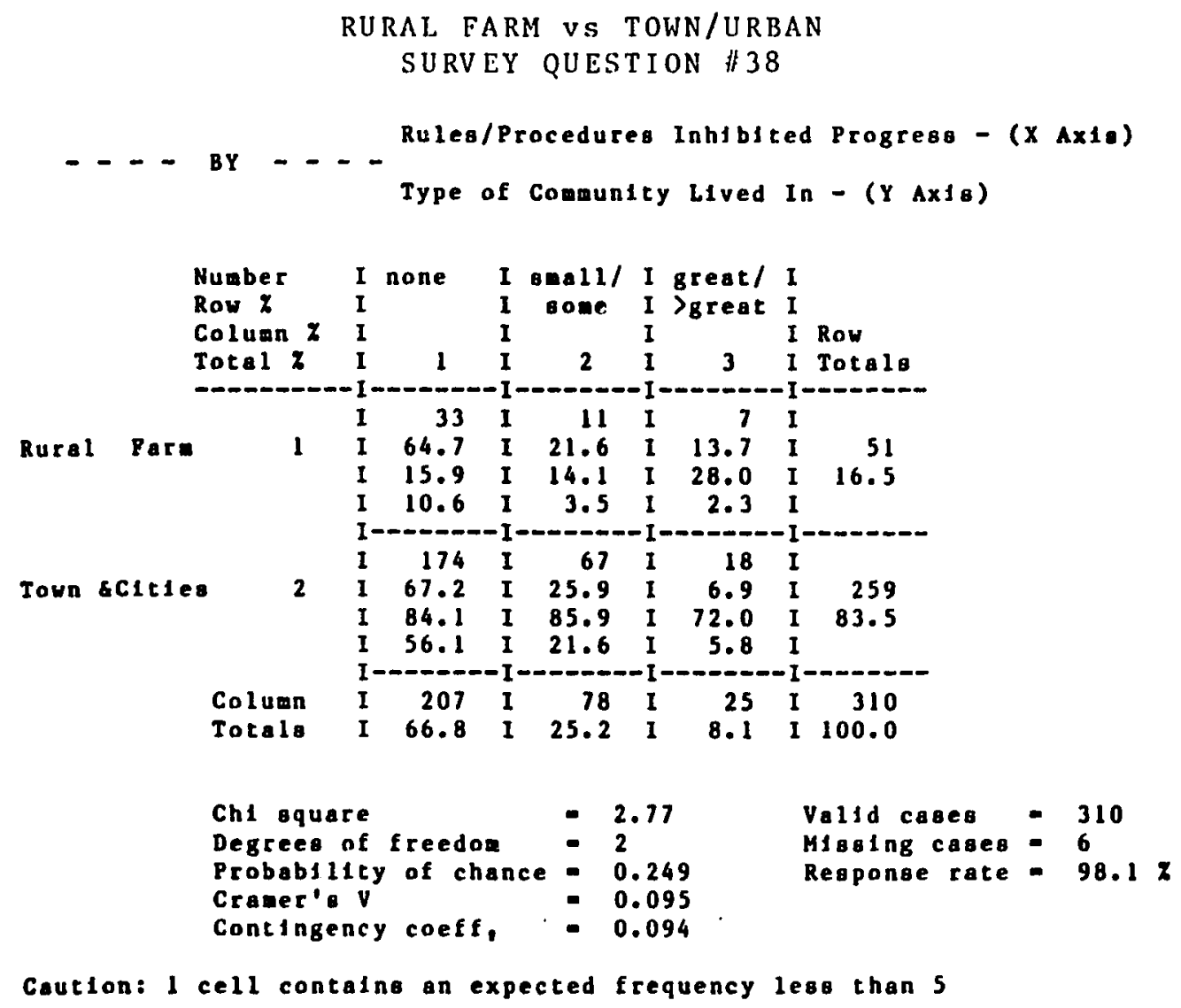


RURAL FARM VS TOWN/URBAN SURV EY QUESTION \#56

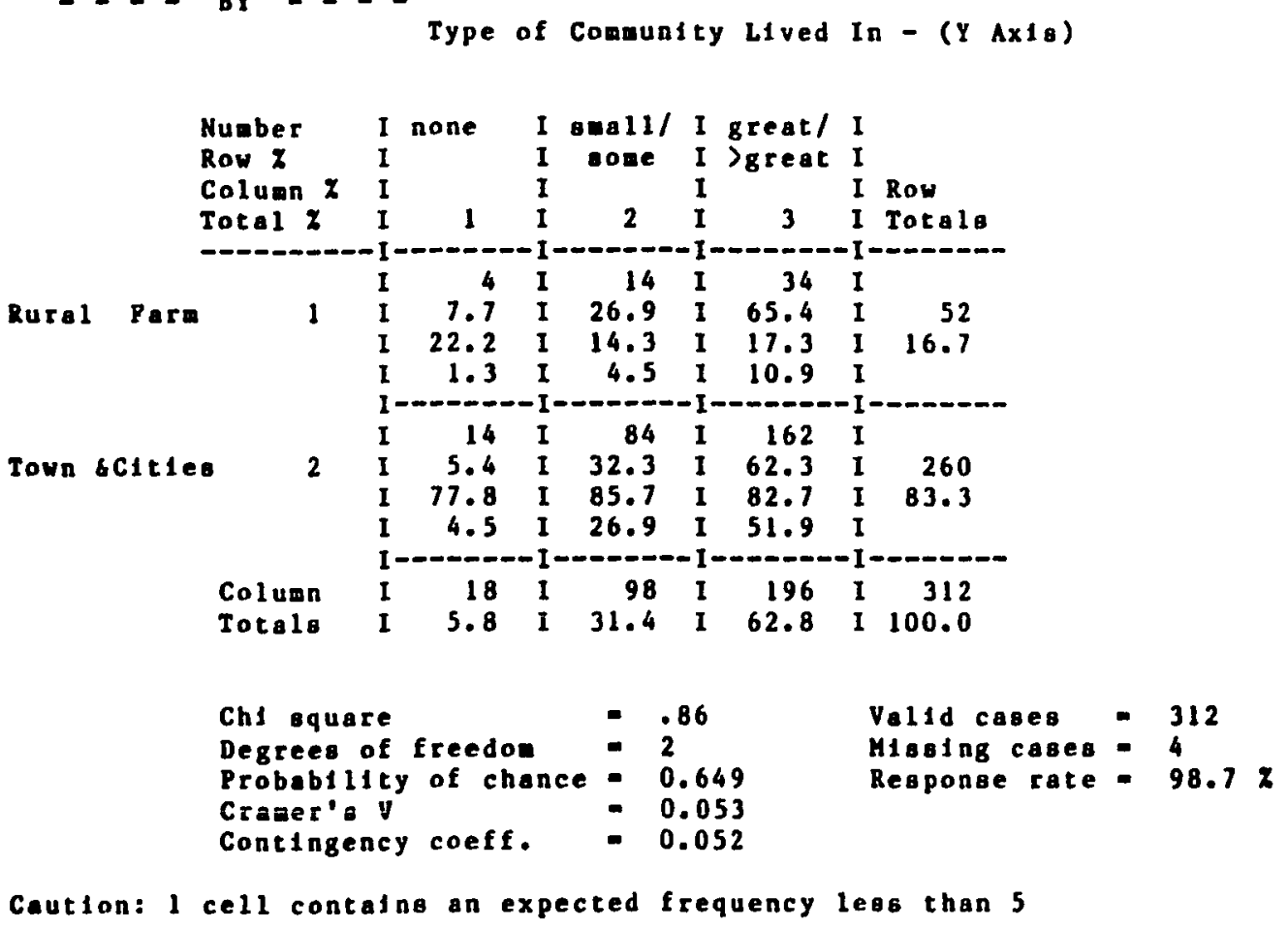

Caution: 1 cell containg an expected frequency leos than 5 


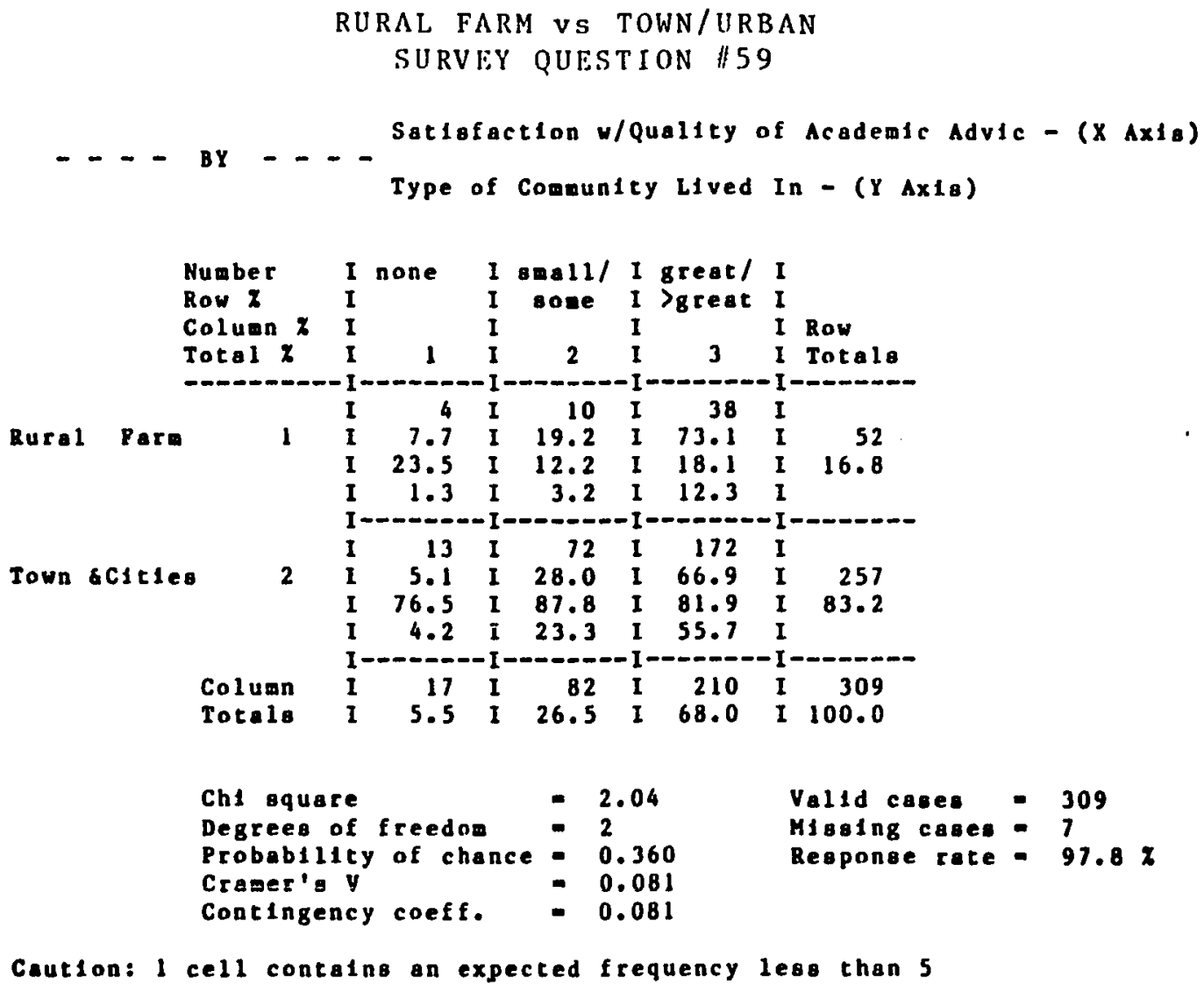

Caution: I cell contains an expected frequency lese than 5 
RURAL FARM VS TOWN/URBAN SURVEY QUESTION \#66

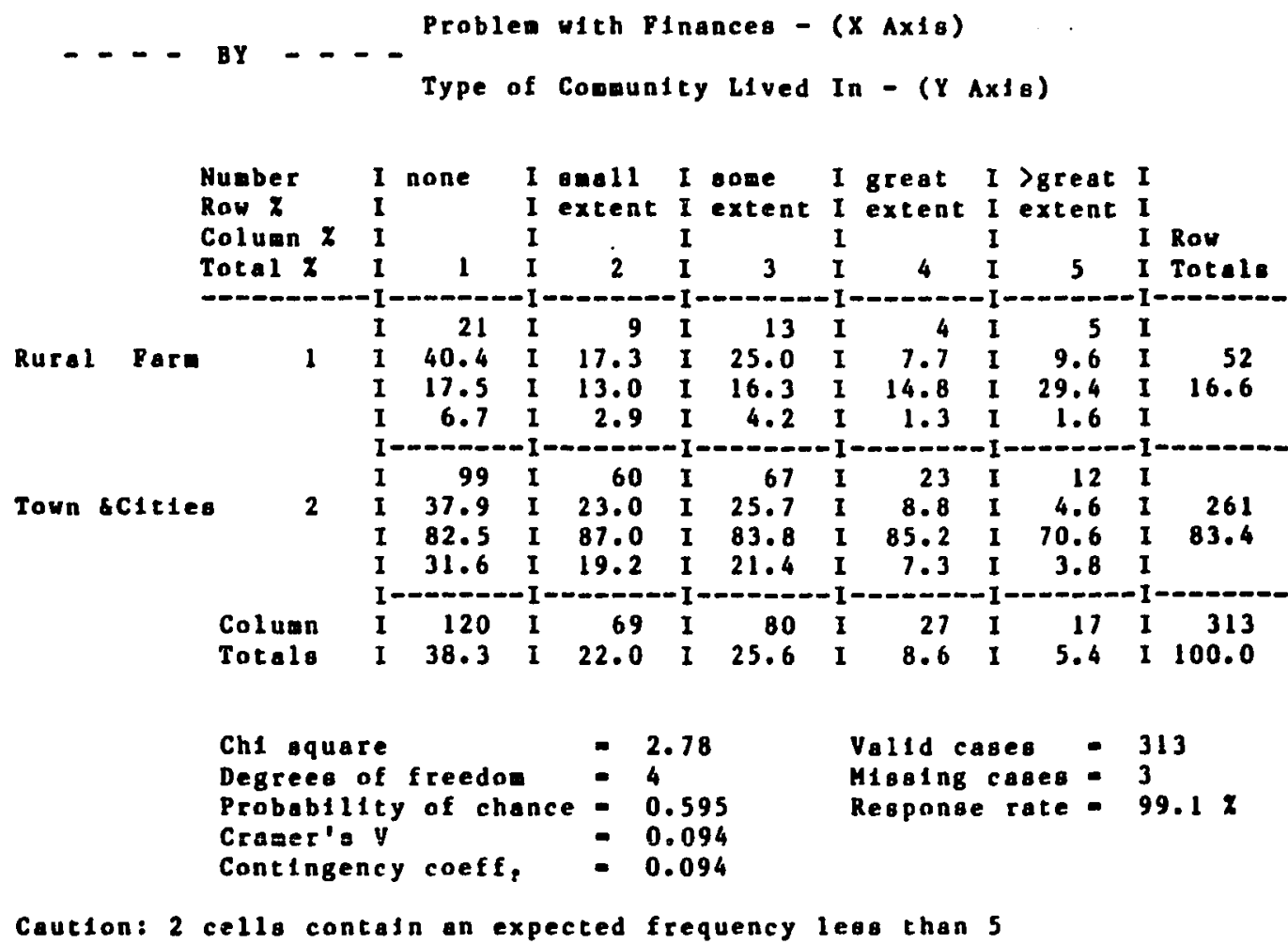

Caution: 2 cella contaln an expected frequency legs than 5 


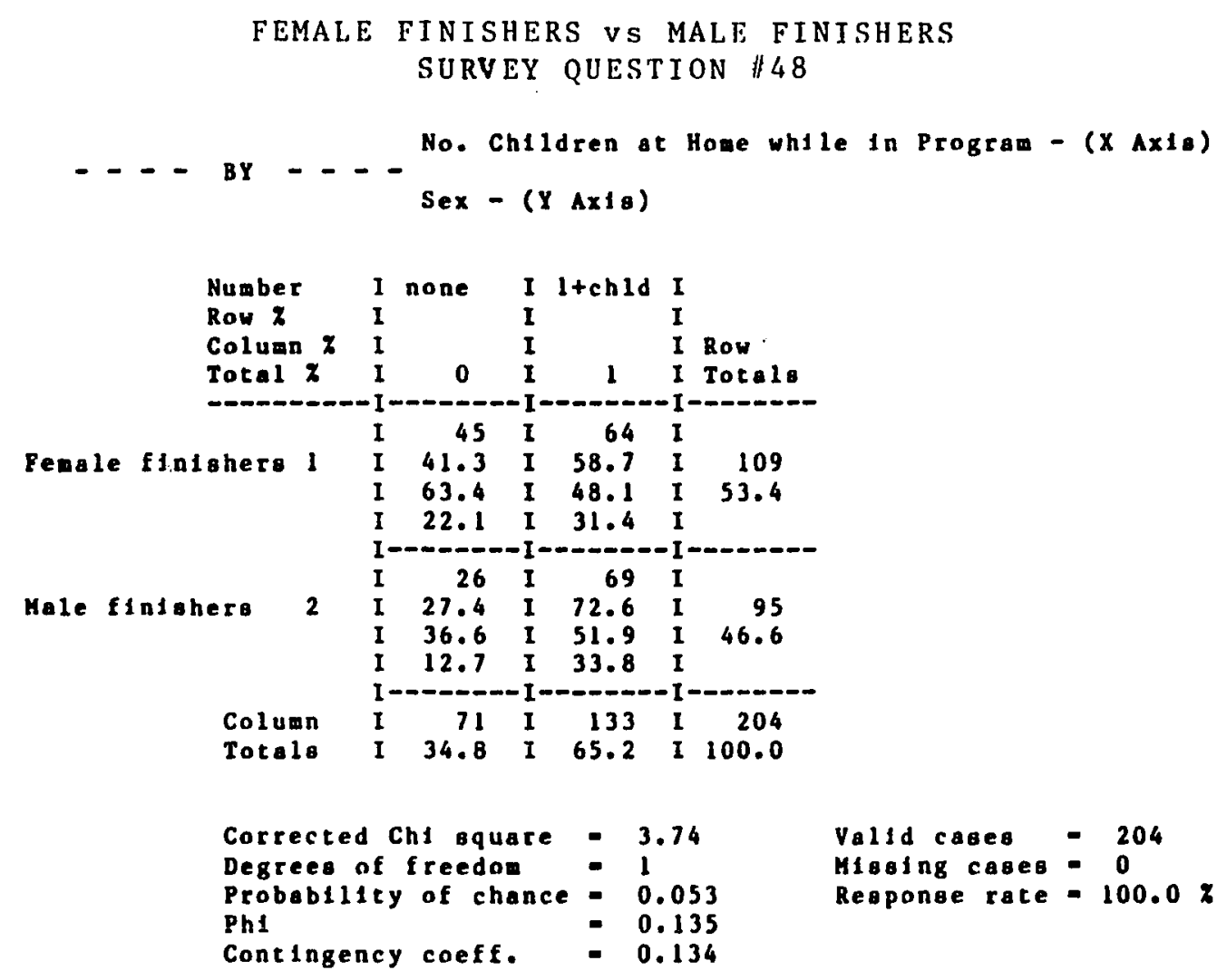




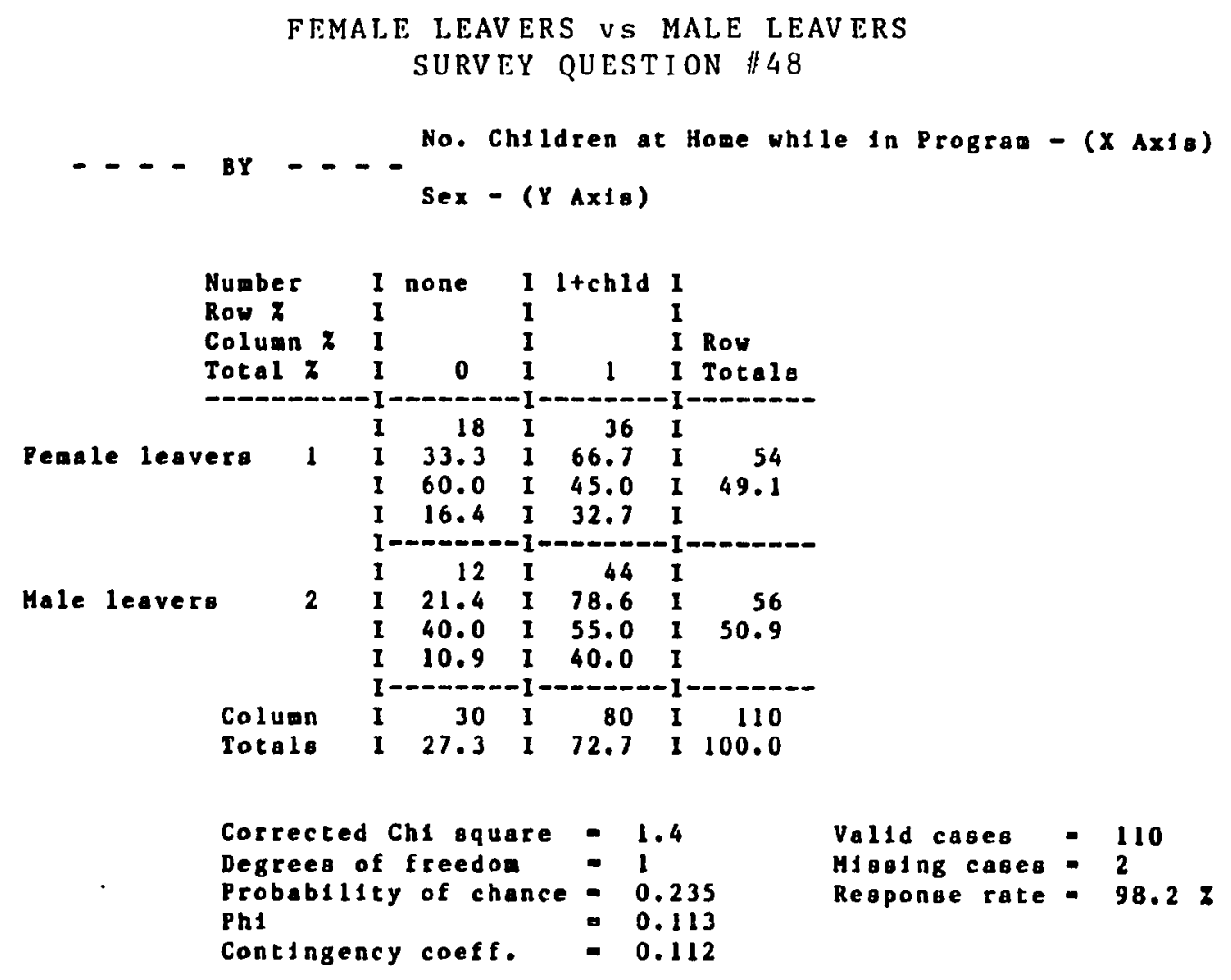


MALE LEAVERS VS MALE FINISHERS REVISED SURVEY QUESTION \#48

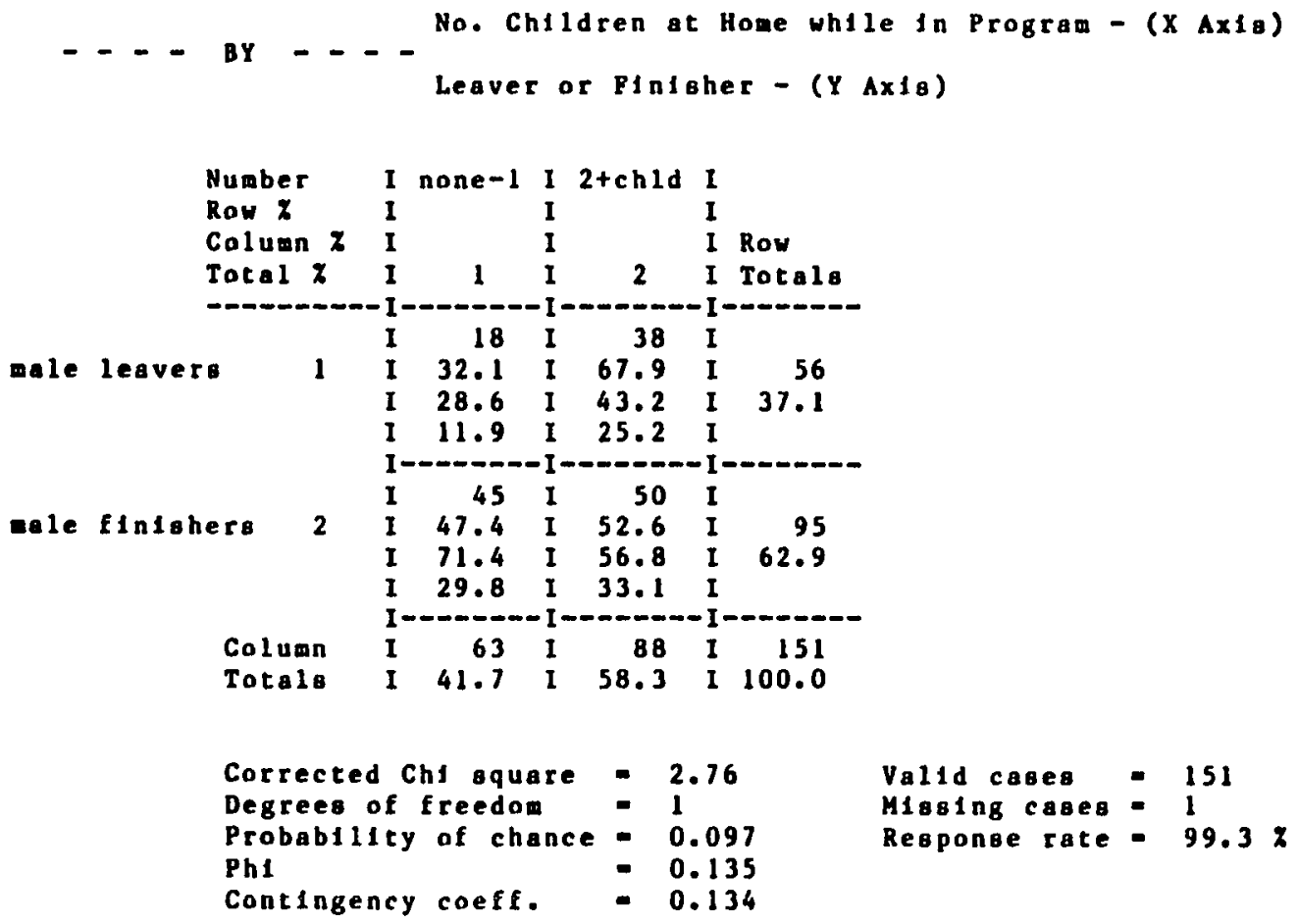


FEMALE LEAVERS VS FEMALE FINISHERS

REV ISED SURVEY QUESTTON \#48
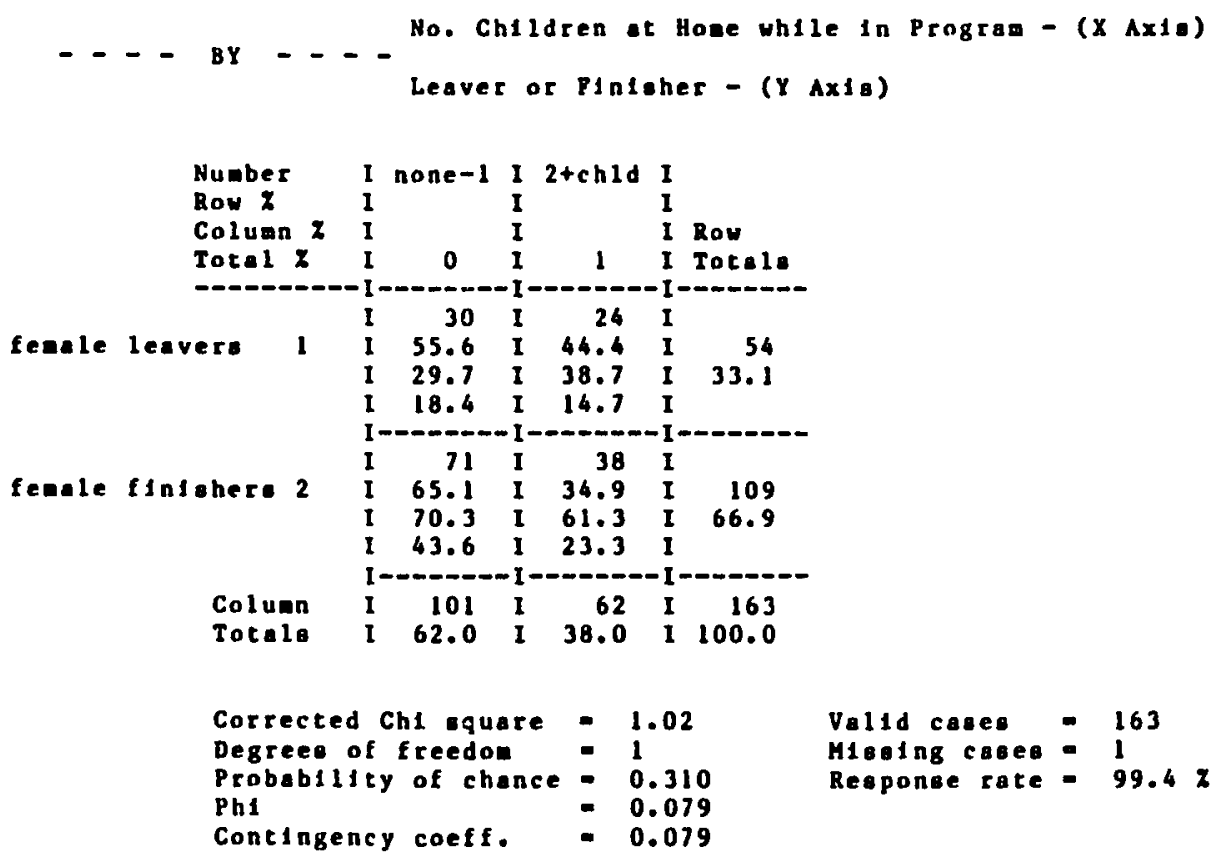
MALE LEAVERS VS MALE FINISHERS SURVEY QUESTION \#48

No. Children at Home while In Program-(X Axis) $---B Y---$

Leaver or FInioher - (Y Axis)

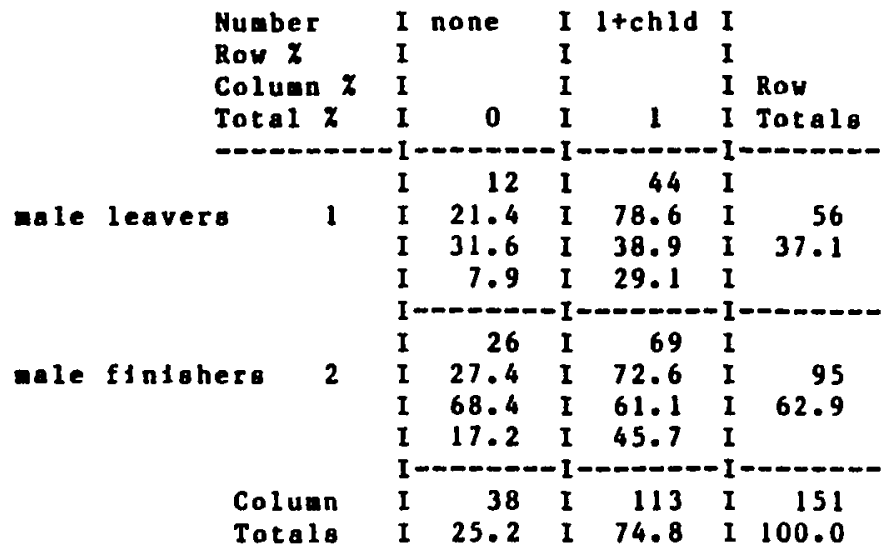

\begin{tabular}{|c|c|}
\hline $\begin{array}{l}\text { rected Chi squ } \\
\text { reeg of freedo } \\
\text { babllity of ch } \\
\text { cingency coeff }\end{array}$ & $\ddot{-}$. \\
\hline
\end{tabular}

Val1d caser -151

Misejng coser - 1

Response rate - $99.3 x$ 


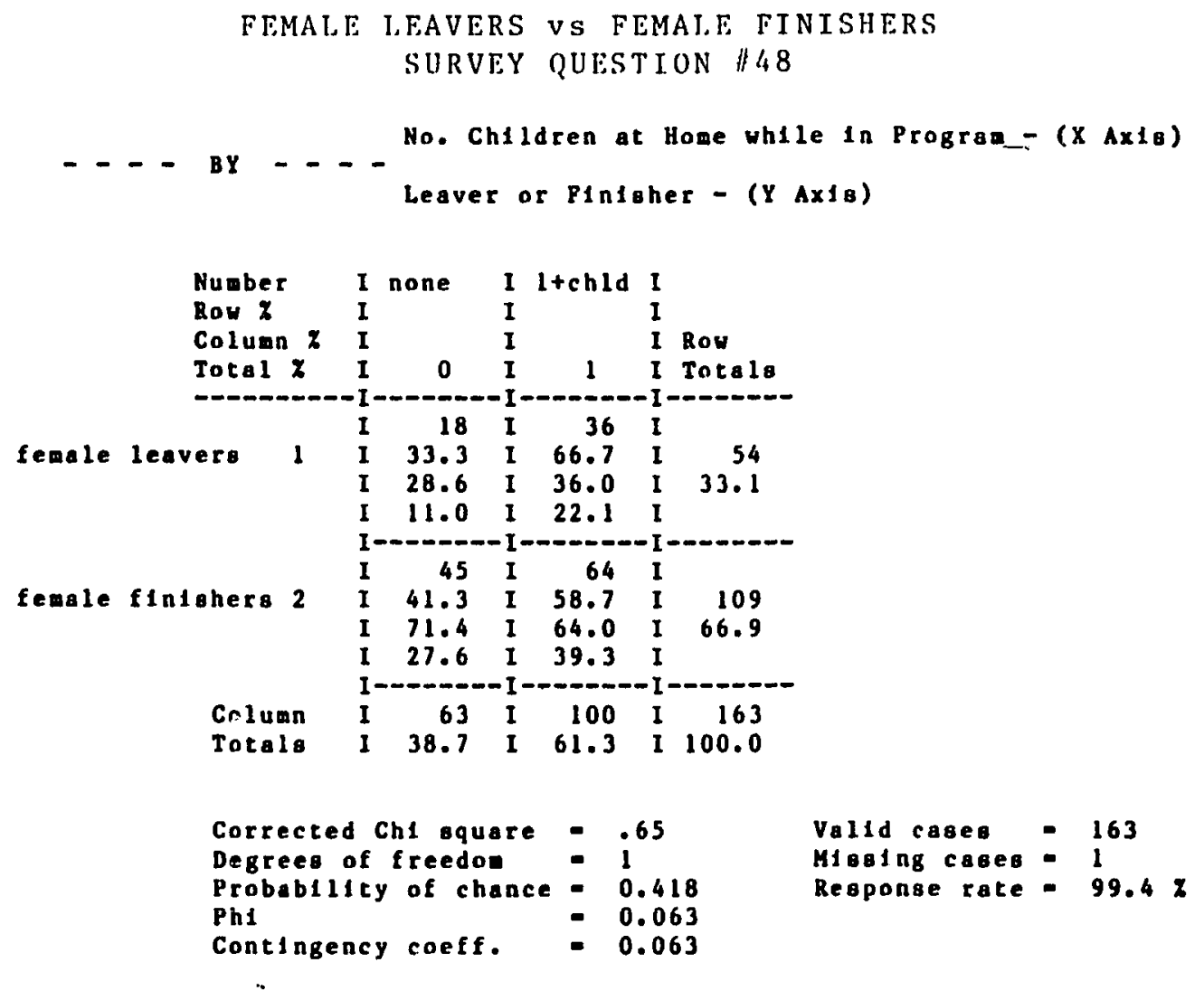




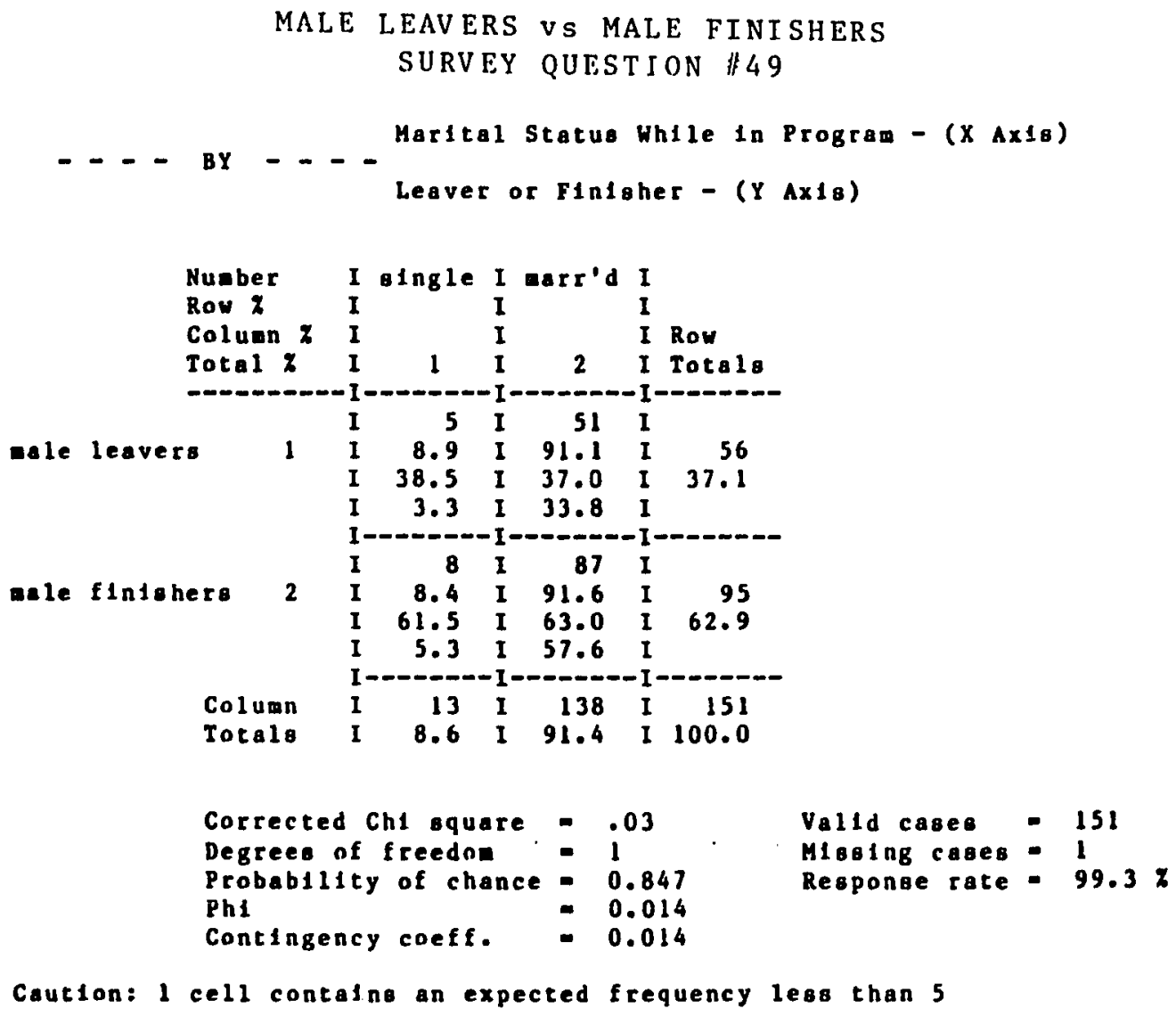


APPENDIX D

STEPWISE MULTIPLE REGRESSION

The table in the following section shows the results of regressing responses from the External Degree Survey to five questions that were deemed less dependent on the length of time the participants had spent in the Program:

Question 19: Awareness of other External Degrees

Question 27: Linkage of Degree with Career Requirement

Question 36: Grade Level upon Admission to Program

Question 37: Highest Degree Aspirations

Question 50: Amount of Time to Commit to Program 


\section{PRINTOUT OF MULTIPLE STEPWISE REGRESSION PROCEDURE}

1

MTB > stop c6 c10 c12 c13 c15-c17 c19-c21 c23-c261

HTB > fremove 0

MTB > fentor 1.

8TEPWIBE REgREsSION OF Cb ON 13 PREDICTORS, HITH N $=297$

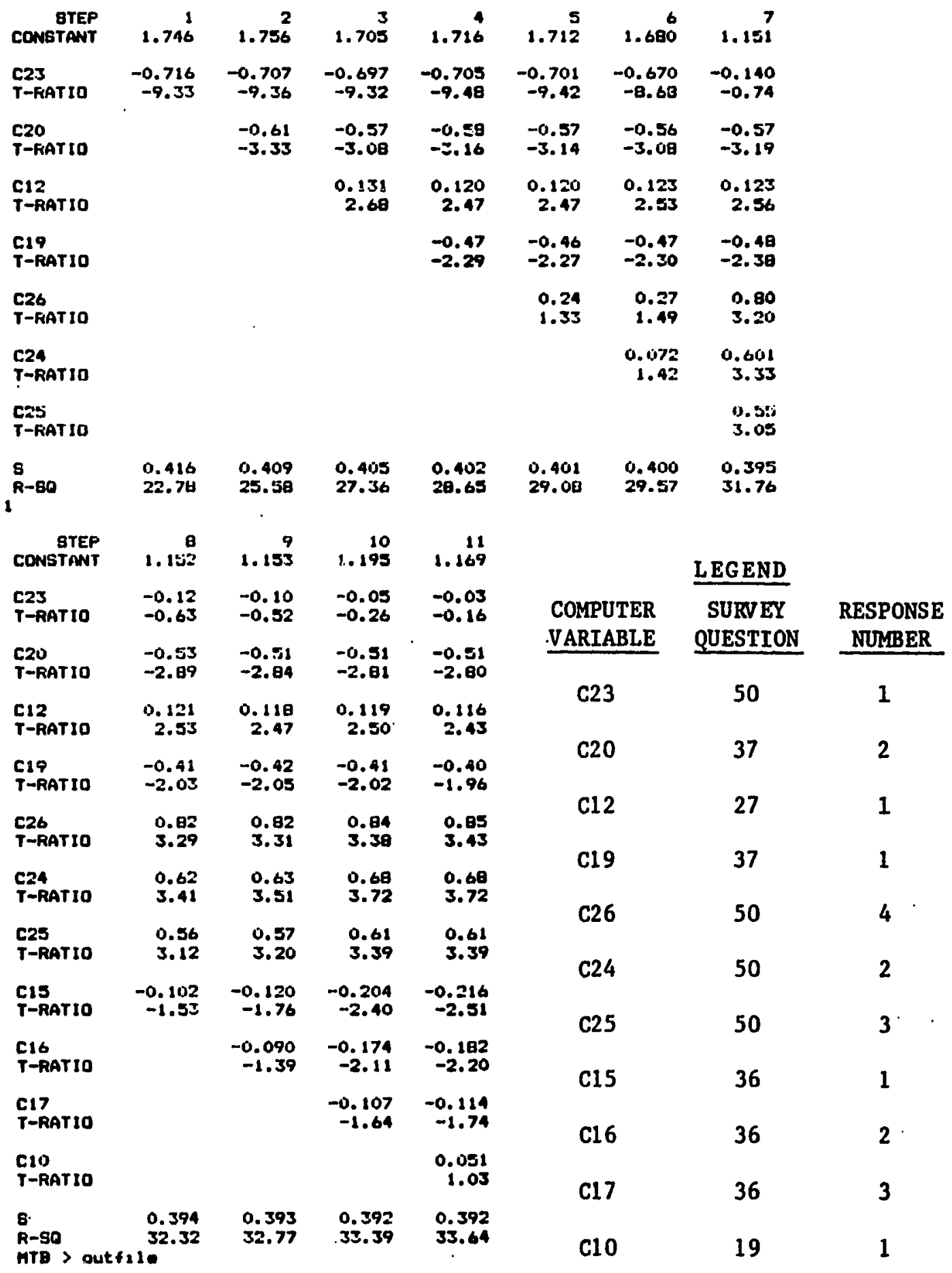

